\title{
Unravelling the elicitin
}

perception pathway against Phytophthora in potato 


\section{Propositions}

1. The identification of immune receptors can be accelerated by using proteomics.

(this thesis)

2. Binding of an effector to a receptor does not necessarily mean downstream response activation.

(this thesis)

3. Genome editing will be a requirement for reverse genetic studies in the future.

4. Results from human nutrition studies are only reliable when the test population is large enough.

5. A course "designing experiments" should be an integral part of MSc and $\mathrm{PhD}$ training programs.

6. Innovation is driven by either real problems or plain laziness.

7. To achieve real sustainability, every crop should be planted in areas where minimal input is required.

Propositions belonging to the thesis entitled "Unravelling the elicitin perception pathway against Phytophthora in potato" Emmanouil Domazakis Wageningen, 1 June 2018 


\section{Unravelling the elicitin perception pathway against Phytophthora in potato}

Emmanouil Domazakis 


\section{Thesis Committee}

\section{Promotor}

Prof. Dr Richard G. F. Visser

Professor of Plant Breeding

Wageningen University \& Research

\section{Co-promotor}

Dr Vivianne G. A. A. Vleeshouwers

Assistant professor, Plant Breeding

Wageningen University \& Research

\section{Other members}

Prof. Dr Dolf Weijers, Wageningen University \& Research

Dr Geert Smant, Wageningen University \& Research

Dr Suzan H. E. J. Gabriëls, Wageningen University \& Research

Dr Stan Oome, Averis seeds B.V., Valthermond

This research was conducted under the auspices of the Graduate School EPS (Experimental Plant Sciences). 


\section{Unravelling the elicitin perception pathway against Phytophthora in potato}

Emmanouil Domazakis

Thesis

submitted in fulfilment of the requirements for the degree of doctor at Wageningen University

by the authority of the Rector Magnificus,

Prof. Dr A. P. J. Mol,

in the presence of the

Thesis Committee appointed by the Academic Board to be defended in public

on Friday 1 June 2018

at 4 p.m. in the Aula. 
Emmanouil Domazakis

Unravelling the elicitin perception pathway against Phytophthora in potato, 168 pages.

PhD thesis, Wageningen University, Wageningen, the Netherlands (2018) With references, with summaries in English and Dutch.

ISBN: 978-94-6343-286-3

DOI: $10.18174 / 449015$ 


\section{Table of Contents}

$\begin{array}{lll}\text { Chapter } 1 & \text { General introduction } & 7\end{array}$

Chapter 2 Effectoromics-based identification of cell surface receptors in potato

Chapter 3 The ELR-SOBIR1 complex functions as a two-component RLK to mount defense against Phytophthora infestans

Chapter 4 ELR binds elicitins from Phytophthora species to trigger SOBIR1/SERK3-mediated cell death

Chapter 5 Targeted mutagenesis of ELR in wild Solanum species using CRISPR/Cas9

Chapter 6 General discussion

Summary

Samenvatting

Acknowledgements

About the author

List of publications

Education statement 



\section{Chapter 1}

General introduction 


\section{A never-ending war between plants and pathogens}

Plants have to cope with harsh biotic and abiotic stresses in their environment in order to thrive. To do so, they employ physical barriers (trichomes, cuticle, epidermis and cell wall) and induced immunity triggered by innate immune receptors (Agrios, 2005; Freeman, 2008; Dodds and Rathjen, 2010; Wirthmueller et al., 2013). Induced plant immunity is based on two factors; the capacity of individual cells to recognize invading organisms and the rapid activation of defense mechanisms. It is important to note that in natural systems, disease is the exception rather than the rule and most plants are able to resist infection from potential pathogens, while at the same time, they can establish symbiotic interactions with other organisms. Unfortunately, this is not the case for most agricultural systems; that is, due to the limited genetic variation in the plant material used and intensive agricultural practices, pathogens may cause serious crop losses with immense effects for the farmers and the society in general (Dangl et al., 2013). Therefore it is of major importance to continuously breed for disease resistant crops by exploiting all genetic variation available or even precisely engineer plant genomes to outcompete the co-evolving pathogens.

\section{Plant immunity: conceptual models and a contemporary overview}

A first explanation of plant immunity came from Flor (1942) who, by studying the flax-flax rust interaction, proposed that inheritance of plant immunity to pathogens as well as the ability of the latter to cause disease is controlled by corresponding gene pairs. In this 'gene for gene' model, for a specific plant-pathogen interaction, the plant has a resistance $(R)$ gene that matches with the corresponding avirulence $(A v r)$ gene of the pathogen strain. Upon recognition of the corresponding gene products, defense responses are mounted, which can lead to resistance (Flor, 1942; Keen, 1990). However, later studies showed that some R proteins monitor (guard) the state of host components that are targeted by pathogen molecules, leading to the formulation of the guard hypothesis (van Der Biezen and Jones, 1998). From this time, it became evident that certain pathogen molecules are promoting pathogen virulence by modulating host components (virulence targets). But in turn, this manipulation can be sensed by the R proteins, and subsequently lead to resistance. A later view on plant immune system is described in the zig-zag model, proposed by Jones and Dangl (2006). This model describes that plants sense invading pathogens through pattern recognition receptors (PRRs) that recognize pathogen-associated molecular patterns (PAMPs), which are typically well-conserved molecules that pathogens need for survival. Recognition of PAMPs 
can activate host defense responses leading to PAMP-triggered immunity (PTI) (Jones and Dangl, 2006). Since PAMPs can be found in non-pathogenic microbes as well, the terms microbe-associated molecular patterns (MAMPs) and MAMPtriggered immunity (MTI) became more relevant. In addition, plants recognize the self-damage caused by biotic or abiotic factors through damage-associated molecular patterns (DAMPs) (Dangl et al., 2013) (Fig. 1).

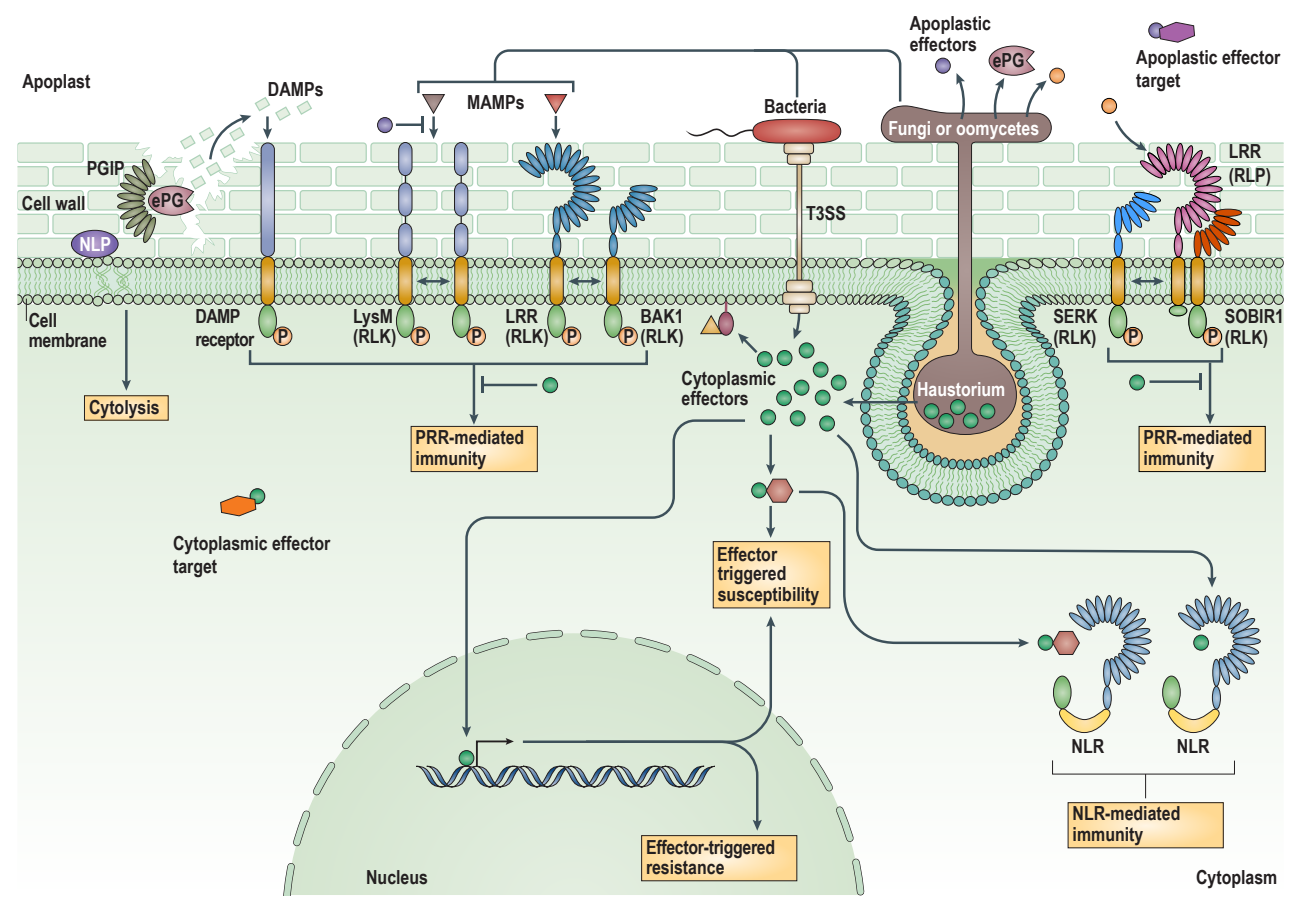

FIGURE 1 | A simplified view of the molecular players in induced plant immunity (adapted from Wirthmueller et al. (2013)). Plants are continuously threatened by several enemies such as fungi, oomycetes and bacteria. Pathogens secrete a wide range of apoplastic and cytoplasmic effectors during infection. For example, they secrete enzymes (e.g. endo-polygalacturonases-ePGs), toxins (e.g. ethylene-induced Nep1-like proteins-NLPs), nutrient uptake proteins (e.g. oomycete elicitins) or effectors that target specific host components (apoplastic/cytoplasmic effector targets) for the benefit of the pathogen. To defend themselves, plants evolved protease inhibitors (e.g. PG-inhibiting proteinsPGIPs), cell surface pattern recognition receptors (PRRs) and cytoplasmic receptors (nucleotidebinding leucine-rich repeat proteins-NLRs). Via these proteins, the plants either block effector activity or trigger defense responses by binding microbe-associated molecular patterns (MAMPs) or effectors, thereby sensing the pathogen. Indirectly, plants may sense self-derived components called damageassociated molecular patterns (DAMPs) (e.g. cell wall fragments) or the manipulation of host proteins. PRRs are often functioning in complex with co-regulatory RLKs of the somatic-embryogenesis receptor kinase (SERK) family (e.g. BRI1-associated kinase-BAK1) or the suppressor of BIR1-1 (SOBIR1) while other PRRs function as homodimers (e.g. lysin motif-LysM receptors). Other abbreviations: phosphate $(P)$, leucine-rich repeat (LRR), lysin motif (LysM), type III secretion system (T3SS). 
During evolution, plant pathogens have developed effector proteins to circumvent MTI and establish disease, a phenomenon called effector triggered susceptibility (ETS). According to Hogenhout et al. (2009) and Win et al. (2012), effectors are "microbial and pest secreted molecules that alter host-cell processes or structures generally promoting the microbe lifestyle. Effector functions are as diverse as suppressing immune responses or enhancing access to nutrients". These molecules are important components in the interaction between microbes and host plants, as they form the molecular keys to establish a parasitic or symbiotic interaction. Initially it was considered that only bacteria and filamentous pathogens secrete effectors, but increasing evidence supports the widespread use of such molecules from a plethora of organisms including nematodes, insects or even parasitic plants (Spallek et al., 2017). In turn, plants have evolved cytoplasmic resistance proteins that are able to recognize cytoplasmic pathogen effectors and activate defense responses leading to effector triggered immunity (ETI) (Jones and Dangl, 2006).

Following the zig-zag model, immunity against pathogens is quantitative with the strongest responses leading to hypersensitive response (HR) and weakest responses being ineffective for defense. As more knowledge was obtained during the past decade, it became clear that pathogen molecules that were initially considered as avirulence factors, are in fact virulence factors, and also the distinction between MAMPs and effectors cannot be strictly maintained (van Der Biezen and Jones, 1998; Thomma et al., 2011). In some cases, conserved socalled 'core effectors' could be considered as MAMPs, since they are conserved among strains of the pathogen or even among distant kingdoms of life (Bohm et al., 2014; Oome et al., 2014). An example of effectors with virulence contribution and MAMP features is the Nep1-like protein (NLP) (Gijzen and Nürnberger, 2006; Bohm et al., 2014). From this protein, a small 20-amino acid epitope (nlp20) is recognized by some plants (Albert et al., 2015). Recently, an alternative model called the invasion model has been proposed to deal with this dilemma, (Cook et al., 2015). This model highlights that cell surface PRRs are also co-evolving with their corresponding ligands, similar to cytoplasmic R-genes, and may target less conserved patterns or effectors. Overall, the plant immune system is highly dynamic and complex and needs to be tightly regulated (Couto and Zipfel, 2016; Huang et al.; Wu et al., 2017). 


\section{The first layer of defense; recognition of MAMPs and apoplastic effectors by plant PRRs}

The MAMP definition entails molecules that are innate components found widespread in whole classes of microbes and are important for the fitness of the invading organism (Newman et al., 2013). MAMPs act as signature for recognition by the host and they are found exposed in the plant apoplast where they can interact with the host. Some well-known MAMPs include elongation factor thermo unstable (EF-Tu) (elf18/26), flagellin (flg22, 28), chitin, lipopolysaccharides, activator of XA21 (Ax21) and ethylene-inducing xylanase (EIX) (Newman et al., 2013). MTI in plants has been most extensively studied using the peptides elf1 8 and flg22 derived from EF-Tu and flagellin, respectively (Felix et al., 1999; Zipfel et al., 2006).

PRRs are germline-encoded sensors, typically localizing at the cell surface (the plasma membrane). They act as the first line of recognition of self- or nonselfderived molecules found in the apoplast. This recognition triggers a defense response that in many cases results in quantitative resistance against pathogens (Jones and Dangl, 2006). In contrast to animal genomes, plants encode a vast number of PRRs and in the past 20 years, several of them have been cloned and characterized (Fig. 2). PRRs consist of an apoplastic, ligand binding domain, a single pass transmembrane domain and a cytoplasmic domain. The apoplastic ligand binding (Boutrot and Zipfel, 2017) domain varies depending on the ligand; LRR type PRRs typically recognize proteinaceous MAMPs or effectors, LysM type PRRs recognize chitin oligosaccharides, EGF-like and lectin type PRRs recognize DAMPs, proteins or other carbohydrates (Zipfel, 2014; Boutrot and Zipfel, 2017). All cloned PRRs are divided in two classes, receptor-like kinases (RLKs) and receptor-like proteins (RLPs). The main difference between those two classes is that RLKs contain a cytoplasmic kinase domain, while RLPs have only a short cytosolic tail without any obvious signaling domain (Newman et al., 2013; Couto and Zipfel, 2016). Among the most well studied PRRs are the ones recognizing EF-Tu, flagellin, chitin and nlp-20, namely EFR, FLS2 and CEBiP/CERK1/LYK4,5 and RLP23, respectively (Fig. 2) (Gómez-Gómez and Boller; Zipfel et al., 2006; Miya et al., 2007; Wan et al., 2008; Cao et al., 2014; Albert et al., 2015). However, the function and ligands of the majority of RLPs and RLKs remains unknown.

It is becoming increasingly evident that RLPs and RLKs require additional proteins for triggering downstream signaling. Members of the somatic-embryogenesis receptor kinase (SERK) family of RLKs have been found to associate with PRRs. Examples include the RLKs FLS2, EFR and RLPs such as RLP23 associate with SERK3 upon MAMP perception (Zipfel, 2014; Couto and Zipfel, 2016). So, it became evident 
that SERK proteins, especially SERK3 (BAK1 in Arabidopsis) act as a general coregulatory RLK from RLKs acting as PRRs. However in the case of RLPs, which lack a downstream signaling domain, another co-regulatory RLK, SOBIR1 has been found to be required for function, often in addition to SERK3 (Liebrand et al., 2014). For example, Cf-4- and Cf-9-mediated resistance to Cladosprorium fulvum was found to require SOBIR1 and SERK3 (Liebrand et al., 2013; Postma et al., 2016). Several other RLPs involved in immunity, such as RLP23, RBPG1, Ve1 require the same coregulatory RLKs (Bi et al., 2014; Gust and Felix, 2014; Liebrand et al., 2014b; Albert et al., 2015; Bi et al., 2016; Postma et al., 2016). Since both SOBIR1 and SERK3 are required for PRR functioning in immunity, it is anticipated that they are involved in resistance to pathogens. Experimental evidence supports this as either SOBIR1- or SERK3-silenced or mutant plants were found to be more susceptible in a wide array of pathogens (examples include Phytophthora parasitica, Sclerotinia sclerotiorum, Botrytis cinerea, Verticillium dahliae, C. fulvum, Magnaporthe oryzae in tomato and Arabidopsis) (Chaparro-Garcia et al., 2011; Liebrand et al., 2013; Zhang et al., 2013; Liebrand et al., 2014; Zhang et al., 2014; Takahashi et al., 2016). Therefore, co-regulatory RLKs, also known as co-receptors, are necessary components for the induction of defense responses and resistance to pathogens conferred by PRRs (Chinchilla et al., 2009; Liebrand et al., 2014) (Figs. 1, 2).

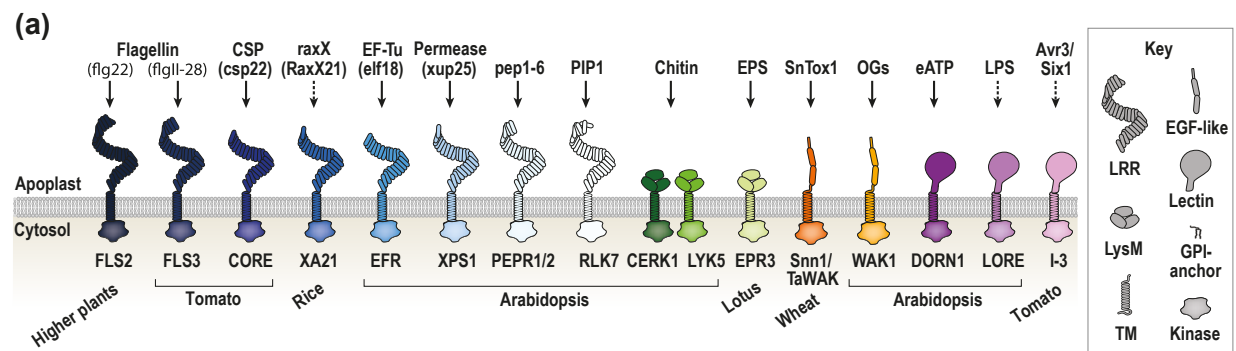

(b)

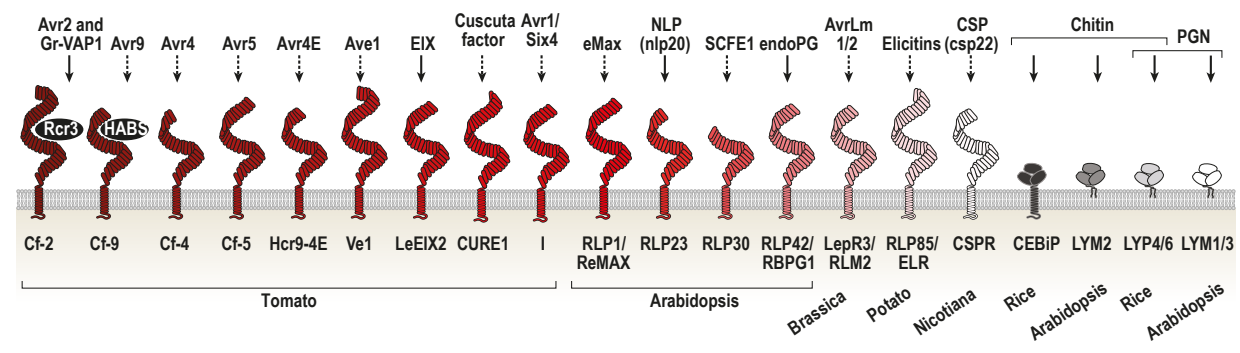

FIGURE 2 | An overview of PRR receptors cloned and characterized to date and their (potential) ligands (adapted from Boutrot and Zipfel (2017)). (a) Receptor-like kinases (RLKs) and (b) receptorlike proteins (RLPs) have been cloned from several plant species. Normal arrows indicate biochemical evidence of binding while dashed arrows indicate that the PRR-ligand interaction has not been biochemically confirmed. 


\section{The second layer of defense; recognition of cytoplasmic effectors by NLRs}

Cytoplasmic effectors are secreted by multiple pathogens and aim into manipulating the host cells by serving structural roles in the formation of infection structures, promoting nutrient leakage or suppressing defense responses (Jones and Dangl, 2006). When those effectors are introduced into the plant cells, a second layer of plant immunity may be triggered (ETI), leading to a robust HR cell death. ETI is triggered by cytoplasmic NLR receptors, often called products of R-genes (Fig. 1). Most resistance proteins cloned to date are NLRs (Zhu et al., 2012). Those modular proteins, typically comprise of a $N^{\prime}$ domain which is either Toll-Interleukin receptor 1 (TIR) or coiled coil (CC) domain, a nucleotide-binding site (NB) and an LRR domain. The NB (NB-ARC in Pfam) domain is conserved and is responsible for binding and hydrolyzing ATP (Tameling et al., 2002), while the LRR domain is believed to mediate the protein-protein interaction with cytoplasmic effectors. However, there are also reports of NLRs that lack LRRs, yet these are still are able to recognize effectors (Duxbury et al., 2016; Sarris et al., 2016). In more recent studies, NLRs are described to be among the most rapidly evolving proteins in plants (Mondragón-Palomino et al., 2002; Ballvora et al., 2007). Several NLR proteins are recognizing cytoplasmic effectors through direct binding with the LRR domain or through interaction with an integrated decoy domain. The list of NLRs which directly bind cytoplasmic effectors has been growing over the last years. NLRs can also recognize pathogen effectors indirectly, by guarding another NLR carrying a decoy domain (Kroj et al., 2016). In this case, the actual NLR receptor is monitoring the state of another NLR, which is called 'guardee' if it is involved in signaling, or 'decoy' if it is just mimicking the actual effector host target (Sarris et al., 2016). Any modification of the integrated guardee/decoy NLRs is sensed by the NLR receptors leading to immunity. Recently, NLRs were found that originate from the fusion of NLRs with additional proteins. Such domains are serving as 'baits' as they are targeted by pathogen effectors, with three examples identified so far, carrying WRKY or HMA integrated domains (Sarris et al., 2016).

\section{The potato crop: importance and challenges}

The potato (Solanum tuberosum L.) is among the most nutritious crops in the world and a basic component for the diet of billions of people (King and Slavin, 2013). Potato is ranked fourth among the most consumed crops, following rice, wheat and maize (Haverkort et al., 2009; Haverkort et al., 2016). Besides growing potatoes for food, potatoes are used for industrial and dietary production of fibers 
(potato skin), starch and protein (mainly patatin) (Burlingame et al., 2009; Zaheer and Akhtar, 2016). The largest areas of potato cultivation are found in Europe and Asia, together accounting for $80 \%$ of the world's production. Total production of potato tubers exceeded 381 Megatons in 2014 (FAO http://www.fao.org/faostat/ en/\#data/OC).

The cultivated potato originates from the central Andes mountain region and was imported in Europe by the conquistadors in the $16^{\text {th }}$ century (Hawkes, 1990; Gavrilenko et al., 2013). Wild tuber bearing Solanum spp. belong to section Petota ( $~ 200$ species) and are ranging from diploid $(2 n=2 x=24)$ to hexaploid $(2 n=6 x$ $=72$ ) species and are distributed over a large geographical area ranging from the south-western United States to central Argentina (Spooner and Hijmans, 2001).

Most diploid potato species are self-incompatible while the tetra- and hexaploid species are mostly self-compatible allopolyploids (Hawkes, 1990). Cultivated potato suffers from severe inbreeding depression and most cultivated species are allotetraploid. This makes breeding new cultivars carrying new traits a difficult and long process. With the sequencing of the potato genome in 2011, insights were obtained into the high heterozygosity, inbreeding depression, the evolution of tuberization and repertoire of disease resistance genes (PGSC, 2011).

Potato is susceptible to several diseases, such as stem canker and black scurf caused by Rhizoctonia solani, early blight caused by Alternaria solani and late blight caused by Phytophthora infestans. From the sequenced potato genome, a plethora of putative resistance genes were identified (PGSC, 2011). However, to obtain resistance against these pathogens, the wild potato relatives form a major resource (Vleeshouwers et al., 2011a; Machida-Hirano, 2015).

\section{Phytophthora infestans, the potato late blight pathogen}

Potato plants are susceptible to several pests and pathogens; however the most devastating disease in most countries is late blight (Fry et al., 2015; Kamoun et al., 2015). Late blight is caused by the oomycete Phytophthora infestans Mont. de Bary, which is considered the most notorious oomycete pathogen (Kamoun et al., 2015). The name of the genus Phytophthora comes from the Greek words phyto ( $\varphi$ utóv-phyto $=$ plant) and phthora ( $\varphi$ Өopá-phthora $=$ damage). Late blight alone is accounted for more than $16 \%$ of the total potato yield losses globally (Haverkort et al., 2009; Haverkort et al., 2016). Typically farmers in the Netherlands spray at least 10 times during the growing season in order to control this disease. This accounts for $50 \%$ of the total fungicides used in the country (Haverkort et al., 2016). 
From a historic perspective, heavy late blight infection of potato fields in Ireland is renowned for triggering the Irish potato famine. Due to this devastation in the main food crop of Irish people, around 1 million people died and another million migrated outside of the island in the mid-19th century (Yoshida et al., 2013). To date, whenever left uncontrolled, P. infestans can destroy a potato field in a matter of days. Oomycetes in general, contain some highly adaptable species in terms of overcoming introduced plant resistances or even chemical pesticides. P. infestans is renowned for its ability to overcome any introduced singular resistance gene and has developed resistance to some of the chemicals used for its control (Fry, 2008; Vleeshouwers et al., 2011; Cooke et al., 2012; Randall et al., 2014).

$P$. infestans is able to infect all parts of the plants causing whole plant collapse or post-harvest damage on the tubers (Fig. 3). Its life cycle begins from a sporangium landing on a leaf. Then depending on the temperature and humidity, these spores of $P$. infestans can germinate directly (at $>18^{\circ} \mathrm{C}$ ) or form zoospores (at $<18^{\circ} \mathrm{C}$ ), motile spores that encyst on the host surface. In both cases, sporangia and cysts form a germination hypha, an appressorium and a penetration peg with which they invade the host (Fig. 3). Initially P. infestans behaves as a biotroph and does not kill the infected cells (Judelson and Blanco, 2005). Hypha grow around the mesophyll cells where later on, haustoria are formed. These are structures involved in effector secretion into the host and presumably nutrient uptake. In the final stage, the pathogen starts to form sporangiophores and sporangia which are protruding from the host stomata. At this stage and depending on the host susceptibility, the plant cells are killed by the pathogen as it enters the necrotrophic stage. In contrast to other Phytophthora spp., P. infestans is a heterothalic oomycete, with two known mating types, A1 and A2 (Fig. 3) (Judelson and Blanco, 2005; Schoina and Govers, 2015). When both mating types co-occur, specialized hyphal structures called oogonium and antheridium, are formed. Those fuse together to create an oospore. Oospores are reinforced sexual spores which can rest in the soil debris and cause infection. This mode of reproduction is assumed to contribute to the high evolutionary potential of the pathogen. 
(a)

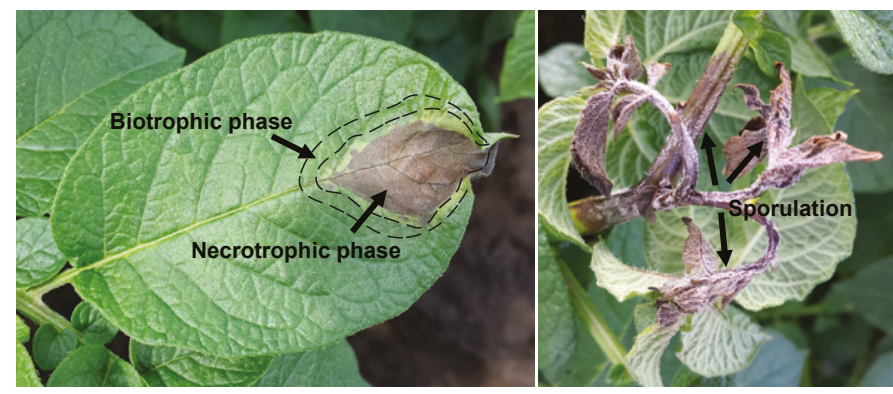

(b)

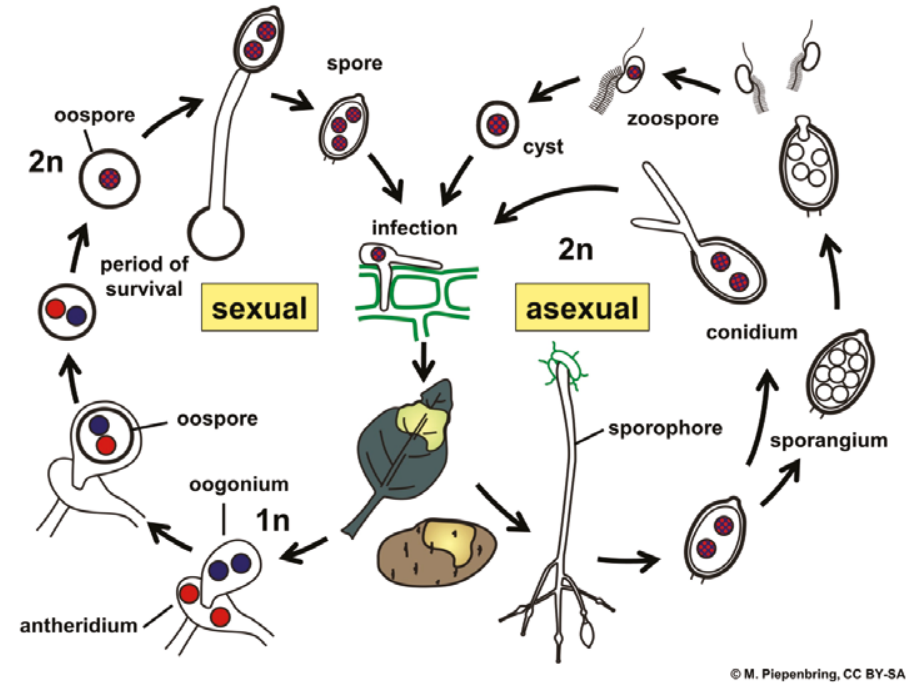

FIGURE 3 | Late blight symptoms in potato caused by Phytophthora infestans infection and the pathogen life cycle. (a) As a hemi-biotroph, P. infestans initially infects cells without causing cell death (biotrophic phase) while at a later point it switches to necrotrophy where tissue collapses (necrotrophic phase). Following colonization of potato, sporulation may occur under humid conditions. (a) Life cycle of $P$. infestans (adapted from M. Piepenbring (https://creativecommons.org/licenses/by-sa/3.0), via Wikimedia Commons).

\section{Phytophthora infestans effectors: structures and functions}

Oomycete plant pathogen genomes are known to encode for hundreds of apoplastic and cytoplasmic effectors (Kamoun, 2006; Morgan and Kamoun, 2007; Raffaele et al., 2010a). Both kinds of effectors are modular (Schornack et al., 2009). Apoplastic effectors typically consist of a signal peptide and a cysteine-rich mature protein part which serves their biological function. Apoplastic effectors often include proteases, protease inhibitors, proteins involved in nutrient uptake or in necrosis induction. Cytoplasmic effectors consist of a signal peptide, a host 
translocation motif (RXLR or LXLFLAK) and a C-terminal domain which possesses the biochemical activity of the protein (Whisson et al., 2007; Schornack et al., 2009).

Phytophthora pathogens secrete a wide array of cysteine-rich effectors in the apoplast. Among those effectors, elicitins were identified as major secreted proteins in culture filtrates. Elicitins were among the first oomycete genes to ever be cloned (Ricci et al., 1989; Panabieres et al., 1995; Fawke et al., 2015).

Elicitins form a diverse family of secreted proteins, specific to Phytophthora and Pythium. They are found in complex multigene families and form diverse subclasses (Jiang et al., 2006). Elicitins sharing a highly conserved 98-amino acid domain with six cysteine residues spaced in a typical pattern are classified as ELIs while all other elicitins, with variable lengths of elicitin domains are named elicitin-likes (ELLs). So far, four ELI and 13 ELL clades have been identified (Jiang et al., 2006). Within each clade, elicitins show similar expression patterns and are under purifying selection. The crystal structure of elicitin $\beta$-CRY (aka CRY-B, class ELI-1) revealed a highly conserved region, the $\omega$-loop, critical for sterol binding (Boissy et al.). B-CRY and INF1 (class ELI-1) elicitins are among the most well studied (Derevnina et al., 2016). Clades besides ELI-1 possess C-terminal extensions of a variable length which are believed to serve as anchors to the cell wall (Jiang et al., 2006). Elicitins carry many MAMP attributes; they are structurally conserved, show difference to plant proteins, and fulfill an important biological function for the pathogen by taking up nutrients (Derevnina et al., 2016). Namely, elicitins bind sterols and other lipids with varying affinities (Mikes et al., 1998; Osman et al., 2001). Sterols are important for oomycete growth and sporulation (Stong et al., 2013). Phytophthora and Pythium are sterol auxotrophs and as such, elicitins are required for scavenging sterols from the host (Stong et al., 2013; Derevnina et al., 2016).

Protease inhibitors represent another class of well-characterized $P$. infestans effectors. Those effectors are known to block plant secreted serine (EPI1 and EPI10) and cysteine (EPIC1 and EPIC2B) proteases. EPI1 and EPI10 effectors contain two or three Kazal-like protein domains, respectively, and were found to interact with and inhibit the pathogenesis-related, subtilisin-like serine protease P69B of tomato (Tian et al., 2004; Tian et al., 2005). EPIC1 and EPIC2B are directly interacting and blocking the potato and tomato papain cysteine protease C14, which leads to increased pathogen fitness on potato (Kaschani et al., 2010). Both EPIC1 and EPIC2B target the tomato protease PIP1 and RCR3, but with lower affinity than C14 and only at apoplastic pH (Kaschani et al., 2010). Therefore, those effectors have similar function as Avr2 from the tomato fungal pathogen C. fulvum (van Esse et al., 2008), indicating that such protease inhibitor activity is 
necessary for successful colonization of plants by filamentous fungi and oomycete pathogens. This hypothesis is further supported by the fact that PIP1, RCR3 and C14 are under diversifying selection in Solanum, probably due to being in an arms race with pathogens that manipulate them in order to colonize the host (Kaschani et al., 2010).

Nep1-like proteins (NLPs) and other small cysteine-rich (SCR) proteins form another class of apoplastic effectors of $P$. infestans. Necrosis-inducing NLPs PiNPP1.1, PiNPP1.2 and PiNPP1.3 of P. infestans are known to be secreted at later stages of infection, some of which are acting as toxins, promoting cell death (Kanneganti et al., 2006; Zuluaga et al., 2016). Several SCR effector proteins have been found, which show similarity to the PcF effector from a strain of Phytophthora cactorum thas was isolated from infected strawberry (Orsomando et al., 2003; Nicastro et al., 2009; Orsomando et al., 2011). Those effectors in P. infestans are named with the acronym SCR followed by the number of amino acid residues and include SCR74 and SCR91, among others (Bos et al., 2003; Liu et al., 2005). SCR74 is highly upregulated during early stages of tomato and potato colonization. It belongs to a highly polymorphic family with at least 21 members identified (Liu et al., 2005). All $P$. infestans strains tested so far, contain at least two and up to six SCR74 variants, while no strain has been identified without this effector. The polymorphism found in SCR74 is due to gene duplication and recombination and is likely the result of diversifying selection forces between wild Solanum and $P$. infestans (Liu et al., 2005; Kamoun, 2006). A study of Orsomando et al. (2011) showed that SCR74 and SCR91 are inducing apical withering when applied at high $(10-18 \mu \mathrm{M})$ concentrations in tomato seedlings, suggesting a function similar to PcF. However, SCR74 was less potent in inducing those symptoms compared to PcF and SCR91 (Orsomando et al., 2011). The function of these fast evolving effectors in $P$. infestans remains to be elucidated.

During infection, P. infestans secretes a plethora of cytoplasmic effectors into the host cells. Such proteins are believed to be secreted via specialized hyphal structures called haustoria that are common infection structures found in biotrophic and hemi-biotrophic pathogens. Haustoria are enveloped in a modified plant plasma membrane and are not completely disrupting it. Two major cytoplasmic effector classes are found in P. infestans, RXLR effectors and crinkling and necrosis (CRN) inducing effectors (Kamoun, 2006; Schornack et al., 2009). RXLR effectors contain the homonymous arginine-X-leucine-arginine motif (Xstands for any amino acid) in the sequence following the secretion signal peptide. Effector prediction pipelines identified hundreds ( $>500$ ) of candidate RXLR effectors in the P. infestans genome and several have been studied using high throughput in planta screens and biochemical studies (Bos et al., 2003; Torto et al., 2003; Haas et al., 2009; 
Vleeshouwers et al., 2011). RXLR effectors were found to target a variety of host proteins and processes. AVR3a was shown to target and stabilize the ubiquitin ligase protein CYS, MET, PRO, and GLY PROTEIN 1 (CMPG1), thereby suppressing immunity (Bos et al., 2010; Gilroy et al., 2011). Another function for AVR3a was found to be suppression of receptor endocytosis by associating with the dynaminrelated protein 2(DRP2) (Chaparro-Garcia et al., 2015). AVR2 was found to target the phosphatase BSL1 to suppress immunity (Saunders et al., 2012b). Another effector, PexRD54, was found to dampen host defenses by binding ATG8 and antagonizing a host autophagy cargo receptor Joka2 (Dagdas et al., 2016). AVRblb2 was shown to suppress C14 protease secretion, an enzyme which is also targeted with the apoplastic effectors EPIC1 and EPIC2B mentioned above (Bozkurt et al., 2011). CRN are present in all sequenced oomycete species sequenced so far (Stam et al., 2013). With only some exceptions in Hyaloperonospora arabidopsidis (Baxter et al., 2010), CRN effectors do not have an RXLR motif, but carry a LXLFLAK motif for translocation. In $P$. infestans, CRNs form a complex family of effectors, among which CRN1 and CRN2 were identified as necrosis-inducing proteins in Nicotiana and Solanum sp. (Torto et al., 2003). In general, there are a plethora of studies on cytoplasmic effectors providing insights on a diversity of functions.

\section{Identified resistances against potato late blight}

As mentioned above, the $P$. infestans genome contains a plethora of effectors, some of which are translocated into the host cells and some are effectors confined in the apoplast. In the center of origin of $P$. infestans, wild Solanum plants are a source for resistance genes as the pathogen co-evolves with the host (Vleeshouwers et al., 2011). To enable effector functional tests as well as identification of resistance genes, scientists have employed high throughput in planta expression of effectors in a wide late blight-resistant Solanum germplasm (Vleeshouwers et al., 2008; Oh et al., 2009; Vleeshouwers et al., 2011). This combination of effector prediction and wide germplasm screening was termed 'effectoromics'. The same strategy also yielded the first PRR against oomycetes which specifically recognizes elicitins (Du et al., 2015).

\section{Response to elicitins in Solanum is mediated by ELR}

Elicitin signaling has been found important for the basal resistance of $N$. benthamiana to $P$. infestans, as pathogen strains deficient in INF1 elicitin production showed enhanced virulence (Kamoun et al., 1998). The first cell-surface receptor RLP that specifically responds to elicitins has been recently cloned from a wild 
potato species, Solanum microdontum (Du et al., 2015). The elicitin-response receptor (ELR) is a RLP lacking a cytoplasmic kinase domain that recognizes several elicitins ranging from 45-65\% amino acid similarity (Du et al., 2015). This recognition spectrum includes Phytophthora elicitins belonging to class ELI-1, ELI2 and ELI-4 elicitins (Jiang et al., 2006; Du et al., 2015). Elicitins that are recognized by ELR do not seem to share a conserved stretch of amino acids, as it is found in bacterial flagellin, EF-Tu or NLPs (Felix et al., 1999; Kunze et al., 2004; Bohm et al., 2014). Rather, the responsiveness of ELR to several elicitins likely depends on the structural similarity of this class of effectors (Derevnina et al., 2016).

\section{Genome-editing technologies to advance plant breeding}

With the advancement of plant breeding, it is always desirable to introduce novel variation in cultivars without introducing too much unwanted traits. Around the year 2000, the dominant tool for genome editing was zinc finger nucleases (ZFNs) (Kim et al., 1996; Carroll, 2011). This was later followed with the discovery of transcription activator-like effector nucleases (TALENs) (Christian et al., 2010). Both ZFNs and TALENs are artificial fusion proteins comprised of a DNA-binding domain and a Fokl restriction endonuclease and have been used successfully in many organisms including plants (Bortesi and Fischer, 2015). They both function as dimers, which requires the design of a pair of nucleases in order to achieve the intended mutation. Despite their success, these methods required difficult design of reagents and did not find wide applicability. Recently, the discovery of clustered regularly interspaced short palindromic repeats (CRISPR), which is part of an adaptive bacterial immune system, has emerged as an alternative genome editing technology (Jinek et al., 2012). CRISPR/CRISPR-associated 9 (Cas9) is utilizing single guide RNA (sgRNA) to target the complementary sequence in the genome in conjunction with the unspecific Cas9 endonuclease. CRISPR/Cas9-mediated genome editing is easier to design as it requires only the design and cloning of a short sgRNA sequence and is functional in a plethora of organisms. This made it the most widely used system for genome editing in plants (Belhaj et al., 2013).

Some cultivated potato genotypes have a relatively high transformation efficiency and thus, genome editing assays are applicable. Indeed, several recent studies have described the use of CRISPR/Cas9 for studying gene function in potato (Butler et al., 2015; Wang et al., 2015; Andersson et al., 2017). Therefore, assuming that several wild potato relatives are also amenable to transformation, CRISPR/ Cas 9 could revolutionize targeted genetic improvement for this crop and facilitate reverse genetic studies. 


\section{Objectives of the thesis}

Potato late blight is the most threatening disease of potato cultivation worldwide. So far, plant breeding for late blight resistance was focused on the introduction of mostly singular NLR resistance genes (R-genes). However, despite their effectiveness, those introduced resistances have been defeated by the pathogen rather quickly. In my thesis, I studied how surface-triggered immunity functions against $P$. infestans in potato. I investigate how the perception of elicitins is activated by a potato PRR. Moreover, I studied how biochemical and genome editing approaches could accelerate novel immune receptor identification and gene functional analysis in this important crop.

Identifying surface receptors in crops like potato is a difficult task and effectoromics have proved a major tool for doing this (Vleeshouwers et al., 2011; Vleeshouwers and Oliver, 2014). In the case of potato late blight, effectors are predicted and screened in a wide collection of wild potato germplasm using different assays such as agroinfiltration, PVX agroinfection or protein infiltration. In Chapter 2, we describe the latter three methods in high detail as step by step protocols. We emphasize on the production of effector proteins in yeast with details for small scale, efficient protein production of six P. infestans apoplastic effectors.

PRRs are predominantly found to function in receptor complexes. Increasing experimental evidence supports the association of LRR type RLPs with coregulatory RLKs. In Chapter 3, we study whether ELR requires such partner proteins for its functioning using a multidisciplinary approach combining gene silencing, genetic complementation and biochemistry. PRRs are expected to physically associate with their respective ligands in order to activate defense signaling. For ELR, such information was missing since its identification. In Chapter 4, we investigate whether ELR is a true PRR by physically binding elicitins and study the mechanistics of elicitin perception in Solanaceae.

Reverse genetics is commonly used to characterize gene function. In wild potato species, such assays were not possible, causing researchers to shift to model species. However, recent advances in technologies such as CRISPR/Cas9mediated mutagenesis have provided opportunities for genome editing in crop plants like potato. Previously, the effect of ELR on disease resistance was studied by overexpression in cv. Désireé, but not in its own native genetic background. In Chapter 5, we attempt to perform functional characterization of ELR homologs in several wild Solanum species using CRISPR/Cas9 genome editing. We report on the efficacy of the method for genome editing by generating ELR mutants and discuss on its potential application for characterizing newly discovered PRRs. 
In Chapter 6, the outcomes of this thesis research are summarized and placed in the broader research context regarding cell surface-mediated immunity. By looking at ELR as a model we gained a lot of information which is useful for the identification of novel PRRs. Being able to apply this knowledge on wild potato species has the potential to provide us with genetic tools to combat the most devastating potato pathogen; P. infestans. 


\section{References}

Agrios, G.N. 2005. Chapter five - how pathogens attack plants. Pages 175-205 in: Plant Pathology (Fifth Edition), Academic Press, San Diego.

Albert, I., Bohm, H., Albert, M., Feiler, C.E., Imkampe, J., Wallmeroth, N., Brancato, C., Raaymakers, T.M., Oome, S., Zhang, H., Krol, E., Grefen, C., Gust, A.A., Chai, J., Hedrich, R., van den Ackerveken, G., and Nurnberger, T. 2015. An RLP23-SOBIR1-BAK1 complex mediates NLP-triggered immunity. Nat Plants 1:15140.

Andersson, M., Turesson, H., Nicolia, A., Falt, A.S., Samuelsson, M., and Hofvander, P. 2017. Efficient targeted multiallelic mutagenesis in tetraploid potato (Solanum tuberosum) by transient CRISPRCas9 expression in protoplasts. Plant Cell Rep 36:117-128.

Ballvora, A., Jocker, A., Viehover, P., Ishihara, H., Paal, J., Meksem, K., Bruggmann, R., Schoof, H., Weisshaar, B., and Gebhardt, C. 2007. Comparative sequence analysis of Solanum and Arabidopsis in a hot spot for pathogen resistance on potato chromosome $\mathrm{V}$ reveals a patchwork of conserved and rapidly evolving genome segments. BMC genomics 8:112.

Baxter, L., Tripathy, S., Ishaque, N., Boot, N., Cabral, A., Kemen, E., Thines, M., Ah-Fong, A., Anderson, R., Badejoko, W., Bittner-Eddy, P., Boore, J.L., Chibucos, M.C., Coates, M., Dehal, P., Delehaunty, K., Dong, S., Downton, P., Dumas, B., Fabro, G., Fronick, C., Fuerstenberg, S.I., Fulton, L., Gaulin, E., Govers, F., Hughes, L., Humphray, S., Jiang, R.H.Y., Judelson, H., Kamoun, S., Kyung, K., Meijer, H., Minx, P., Morris, P., Nelson, J., Phuntumart, V., Qutob, D., Rehmany, A., Rougon-Cardoso, A., Ryden, P., Torto-Alalibo, T., Studholme, D., Wang, Y., Win, J., Wood, J., Clifton, S.W., Rogers, J., van den Ackerveken, G., Jones, J.D.G., McDowell, J.M., Beynon, J., and Tyler, B.M. 2010. Signatures of adaptation to obligate biotrophy in the Hyaloperonospora arabidopsidis genome. Science 330:1549-1551.

Belhaj, K., Chaparro-Garcia, A., Kamoun, S., and Nekrasov, V. 2013. Plant genome editing made easy: targeted mutagenesis in model and crop plants using the CRISPR/Cas system. Plant Methods 9:39.

Bi, G., Liebrand, T.W., Cordewener, J.H., America, A.H., Xu, X., and Joosten, M.H. 2014. Arabidopsis thaliana receptor-like protein AtRLP23 associates with the receptor-like kinase AtSOBIR1. Plant Signal Behav 9:e27937.

Bi, G., Liebrand, T.W., Bye, R.R., Postma, J., van der Burgh, A.M., Robatzek, S., Xu, X., and Joosten, M.H. 2016. SOBIR1 requires the GxxxG dimerization motif in its transmembrane domain to form constitutive complexes with receptor-like proteins. Mol Plant Pathol 17:96-107.

Bohm, H., Albert, I., Oome, S., Raaymakers, T.M., van den Ackerveken, G., and Nurnberger, T. 2014. A conserved peptide pattern from a widespread microbial virulence factor triggers patterninduced immunity in Arabidopsis. PLoS Pathog 10:e1004491.

Boissy, G., de La Fortelle, E., Kahn, R., Huet, J.C., Bricogne, G., Pernollet, J.C., and Brunie, S. 1996. Crystal structure of a fungal elicitor secreted by Phytophthora cryptogea, a member of a novel class of plant necrotic proteins. Structure 4:1429-1439.

Bortesi, L., and Fischer, R. 2015. The CRISPR/Cas9 system for plant genome editing and beyond. Biotechnol Adv 33:41-52.

Bos, J.I.B., Armstrong, M.R., Gilroy, E.M., Boevink, P.C., Hein, I., Taylor, R.M., Zhendong, T., Engelhardt, S., Vetukuri, R.R., Harrower, B., Dixelius, C., Bryan, G., Sadanandom, A., Whisson, S.C., Kamoun, S., and Birch, P.R. 2010. Phytophthora infestans effector AVR3a is essential for virulence and manipulates plant immunity by stabilizing host E3 ligase CMPG1. Proc Natl Acad Sci USA 107:9909-9914.

Bos, J.I.B., Armstrong, M.R., Whisson, S.C., Torto, T.A., Ochwo, M., Birch, P.R.J., and Kamoun, S. 2003. Intraspecific comparative genomics to identify avirulence genes from Phytophthora. New Phytol 159:63-72.

Boutrot, F., and Zipfel, C. 2017. Function, discovery, and exploitation of plant pattern recognition receptors for broad-spectrum disease resistance. Annu Rev Phytopathol 55:257-286.

Bozkurt, T.O., Schornack, S., Win, J., Shindo, T., Ilyas, M., Oliva, R., Cano, L.M., Jones, A.M., Huitema, E., van der Hoorn, R.A., and Kamoun, S. 2011. Phytophthora infestans effector AVRblb2 prevents secretion of a plant immune protease at the haustorial interface. Proc Natl Acad Sci USA 108:20832-20837. 
Burlingame, B., Mouillé, B., and Charrondière, R. 2009. Nutrients, bioactive non-nutrients and antinutrients in potatoes. J Food Compos Anal 22:494-502.

Butler, N.M., Atkins, P.A., Voytas, D.F., and Douches, D.S. 2015. Generation and inheritance of targeted mutations in potato (Solanum tuberosum L.) using the CRISPR/Cas System. PLoS One 10:e0144591.

Cao, Y., Liang, Y., Tanaka, K., Nguyen, C.T., Jedrzejczak, R.P., Joachimiak, A., and Stacey, G. 2014. The kinase LYK5 is a major chitin receptor in Arabidopsis and forms a chitin-induced complex with related kinase CERK1. eLife 3:e03766.

Carroll, D. 2011. Genome engineering with zinc-finger nucleases. Genetics 188:773-782.

Chaparro-Garcia, A., Wilkinson, R.C., Gimenez-lbanez, S., Findlay, K., Coffey, M.D., Zipfel, C., Rathjen, J.P., Kamoun, S., and Schornack, S. 2011. The receptor-like kinase SERK3/BAK1 is required for basal resistance against the late blight pathogen Phytophthora infestans in Nicotiana benthamiana. PLoS One 6:e16608.

Chaparro-Garcia, A., Schwizer, S., Sklenar, J., Yoshida, K., Petre, B., Bos, J.I., Schornack, S., Jones, A.M., Bozkurt, T.O., and Kamoun, S. 2015. Phytophthora infestans RXLR-WY effector AVR3a associates with dynamin-related protein 2 required for endocytosis of the plant pattern recognition receptor FLS2. PLoS One 10:e0137071.

Chinchilla, D., Shan, L., He, P., de Vries, S., and Kemmerling, B. 2009. One for all: the receptor-associated kinase BAK1. Trends Plant Sci 14:535-541.

Christian, M., Cermak, T., Doyle, E.L., Schmidt, C., Zhang, F., Hummel, A., Bogdanove, A.J., and Voytas, D.F. 2010. Targeting DNA double-strand breaks with TAL effector nucleases. Genetics 186:757761.

Cook, D.E., Mesarich, C.H., and Thomma, B.P. 2015. Understanding plant immunity as a surveillance system to detect invasion. Annu Rev Phytopathol 53:541-563.

Cooke, D.E., Cano, L.M., Raffaele, S., Bain, R.A., Cooke, L.R., Etherington, G.J., Deahl, K.L., Farrer, R.A., Gilroy, E.M., Goss, E.M., Grunwald, N.J., Hein, I., MacLean, D., McNicol, J.W., Randall, E., Oliva, R.F., Pel, M.A., Shaw, D.S., Squires, J.N., Taylor, M.C., Vleeshouwers, V.G.A.A., Birch, P.R., Lees, A.K., and Kamoun, S. 2012. Genome analyses of an aggressive and invasive lineage of the Irish potato famine pathogen. PLoS Pathog 8:e1002940.

Couto, D., and Zipfel, C. 2016. Regulation of pattern recognition receptor signalling in plants. Nat Rev Immunol 16:537-552.

Dagdas, Y.F., Belhaj, K., Maqbool, A., Chaparro-Garcia, A., Pandey, P., Petre, B., Tabassum, N., CruzMireles, N., Hughes, R.K., Sklenar, J., Win, J., Menke, F., Findlay, K., Banfield, M.J., Kamoun, S., and Bozkurt, T.O. 2016. An effector of the Irish potato famine pathogen antagonizes a host autophagy cargo receptor. eLife 5:e10856.

Dangl, J.L., Horvath, D.M., and Staskawicz, B.J. 2013. Pivoting the plant immune system from dissection to deployment. Science 341:746-751.

Derevnina, L., Dagdas, Y.F., De la Concepcion, J.C., Bialas, A., Kellner, R., Petre, B., Domazakis, E., Du, J., Wu, C.H., Lin, X., Aguilera-Galvez, C., Cruz-Mireles, N., Vleeshouwers, V.G.A.A., and Kamoun, S. 2016. Nine things to know about elicitins. New Phytol 212:888-895.

Dodds, P.N., and Rathjen, J.P. 2010. Plant immunity: towards an integrated view of plant-pathogen interactions. Nat Rev Genet 11:539-548.

Du, J., Verzaux, E., Chaparro-Garcia, A., Bijsterbosch, G., Keizer, L.C., Zhou, J., Liebrand, T.W., Xie, C., Govers, F., Robatzek, S., van der Vossen, E.A., Jacobsen, E., Visser, R.G., Kamoun, S., and Vleeshouwers, V.G.A.A. 2015. Elicitin recognition confers enhanced resistance to Phytophthora infestans in potato. Nat Plants 1:15034.

Duxbury, Z., Ma, Y., Furzer, O.J., Huh, S.U., Cevik, V., Jones, J.D., and Sarris, P.F. 2016. Pathogen perception by NLRs in plants and animals: Parallel worlds. Bioessays 38:769-781.

Fawke, S., Doumane, M., and Schornack, S. 2015. Oomycete interactions with plants: infection strategies and resistance principles. Microbiol Mol Biol Rev 79:263-280.

Felix, G., Duran, J.D., Volko, S., and Boller, T. 1999. Plants have a sensitive perception system for the most conserved domain of bacterial flagellin. Plant J 18:265-276.

Flor, H.H. 1942. Inheritance of pathogenicity in Melampsora lini. Phytopathology:653-669.

Freeman, B.C.B., Gwyn A. 2008. An overview of plant defenses against pathogens and herbivores. The Plant Health Instructor 94. 
Fry, W. 2008. Phytophthora infestans: the plant (and R gene) destroyer. Mol Plant Pathol 9:385-402.

Fry, W.E., Birch, P.R., Judelson, H.S., Grunwald, N.J., Danies, G., Everts, K.L., Gevens, A.J., Gugino, B.K., Johnson, D.A., Johnson, S.B., McGrath, M.T., Myers, K.L., Ristaino, J.B., Roberts, P.D., Secor, G., and Smart, C.D. 2015. Five reasons to consider Phytophthora infestans a reemerging pathogen. Phytopathology 105:966-981.

Gavrilenko, T., Antonova, O., Shuvalova, A., Krylova, E., Alpatyeva, N., Spooner, D.M., and Novikova, L. 2013. Genetic diversity and origin of cultivated potatoes based on plastid microsatellite polymorphism. Genet Resour Crop Evol 60:1997-2015.

Gijzen, M., and Nurnberger, T. 2006. Nep1-like proteins from plant pathogens: recruitment and diversification of the NPP1 domain across taxa. Phytochemistry 67:1800-1807.

Gilroy, E.M., Taylor, R.M., Hein, I., Boevink, P., Sadanandom, A., and Birch, P.R. 2011. CMPG1-dependent cell death follows perception of diverse pathogen elicitors at the host plasma membrane and is suppressed by Phytophthora infestans RXLR effector AVR3a. New Phytol 190:653-666.

Gómez-Gómez, L., and Boller, T. 2000. FLS2: an LRR receptor-like kinase Involved in the perception of the bacterial elicitor flagellin in Arabidopsis. Mol Cell 5:1003-1011.

Gust, A.A., and Felix, G. 2014. Receptor like proteins associate with SOBIR1-type of adaptors to form bimolecular receptor kinases. Curr Opin Plant Biol 21:104-111.

Haas, B.J., Kamoun, S., Zody, M.C., Jiang, R.H., Handsaker, R.E., Cano, L.M., Grabherr, M., Kodira, C.D., Raffaele, S., Torto-Alalibo, T., Bozkurt, T.O., Ah-Fong, A.M., Alvarado, L., Anderson, V.L., Armstrong, M.R., Avrova, A., Baxter, L., Beynon, J., Boevink, P.C., Bollmann, S.R., Bos, J.I., Bulone, V., Cai, G., Cakir, C., Carrington, J.C., Chawner, M., Conti, L., Costanzo, S., Ewan, R., Fahlgren, N., Fischbach, M.A., Fugelstad, J., Gilroy, E.M., Gnerre, S., Green, P.J., Grenville-Briggs, L.J., Griffith, J., Grunwald, N.J., Horn, K., Horner, N.R., Hu, C.H., Huitema, E., Jeong, D.H., Jones, A.M., Jones, J.D., Jones, R.W., Karlsson, E.K., Kunjeti, S.G., Lamour, K., Liu, Z., Ma, L., Maclean, D., Chibucos, M.C., McDonald, H., McWalters, J., Meijer, H.J., Morgan, W., Morris, P.F., Munro, C.A., O'Neill, K., Ospina-Giraldo, M., Pinzon, A., Pritchard, L., Ramsahoye, B., Ren, Q., Restrepo, S., Roy, S., Sadanandom, A., Savidor, A., Schornack, S., Schwartz, D.C., Schumann, U.D., Schwessinger, B., Seyer, L., Sharpe, T., Silvar, C., Song, J., Studholme, D.J., Sykes, S., Thines, M., van de Vondervoort, P.J., Phuntumart, V., Wawra, S., Weide, R., Win, J., Young, C., Zhou, S., Fry, W., Meyers, B.C., van West, P., Ristaino, J., Govers, F., Birch, P.R., Whisson, S.C., Judelson, H.S., and Nusbaum, C. 2009. Genome sequence and analysis of the Irish potato famine pathogen Phytophthora infestans. Nature 461:393-398.

Haverkort, A.J., Struik, P.C., Visser, R.G.F., and Jacobsen, E. 2009. Applied biotechnology to combat the late blight in potato caused by Phytophthora infestans. Potato Research 52:249-264.

Haverkort, A.J., Boonekamp, P.M., Hutten, R., Jacobsen, E., Lotz, L.A.P., Kessel, G.J.T., Vossen, J.H., and Visser, R.G.F. 2016. Durable late blight resistance in potato through dynamic varieties obtained by cisgenesis: scientific and societal advances in the DuRPh Project. Potato Research 59:35-66.

Hogenhout, S.A., van der Hoorn, R.A., Terauchi, R., and Kamoun, S. 2009. Emerging concepts in effector biology of plant-associated organisms. Mol Plant Microbe Interact 22:115-122.

Huang, S., Chen, X., Zhong, X., Li, M., Ao, K., Huang, J., and Li, X. 2016. Plant TRAF proteins regulate NLR immune receptor turnover. Cell Host Microbe 19:204-215.

Jiang, R.H., Tyler, B.M., Whisson, S.C., Hardham, A.R., and Govers, F. 2006. Ancient origin of elicitin gene clusters in Phytophthora genomes. Mol Biol Evol 23:338-351.

Jinek, M., Chylinski, K., Fonfara, I., Hauer, M., Doudna, J.A., and Charpentier, E. 2012. A programmable dual-RNA-guided DNA endonuclease in adaptive bacterial immunity. Science 337:816-821.

Jones, J.D., and Dangl, J.L. 2006. The plant immune system. Nature 444:323-329.

Judelson, H.S., and Blanco, F.A. 2005. The spores of Phytophthora: weapons of the plant destroyer. Nat Rev Microbiol 3:47-58.

Kamoun, S. 2006. A catalogue of the effector secretome of plant pathogenic oomycetes. Annu Rev Phytopathol 44:41-60.

Kamoun, S., van West, P., Vleeshouwers, V.G.A.A., de Groot, K.E., and Govers, F. 1998. Resistance of Nicotiana benthamiana to Phytophthora infestans is mediated by the recognition of the elicitor protein INF1. Plant Cell 10:1413-1426. 
Kamoun, S., Furzer, O., Jones, J.D., Judelson, H.S., Ali, G.S., Dalio, R.J., Roy, S.G., Schena, L., Zambounis, A., Panabieres, F., Cahill, D., Ruocco, M., Figueiredo, A., Chen, X.R., Hulvey, J., Stam, R., Lamour, K., Gijzen, M., Tyler, B.M., Grunwald, N.J., Mukhtar, M.S., Tome, D.F., Tor, M., van Den Ackerveken, G., McDowell, J., Daayf, F., Fry, W.E., Lindqvist-Kreuze, H., Meijer, H.J., Petre, B., Ristaino, J., Yoshida, K., Birch, P.R., and Govers, F. 2015. The Top 10 oomycete pathogens in molecular plant pathology. Mol Plant Pathol 16:413-434.

Kanneganti, T.D., Huitema, E., Cakir, C., and Kamoun, S. 2006. Synergistic interactions of the plant cell death pathways induced by Phytophthora infestans Nepl-like protein PiNPP1.1 and INF1 elicitin. Mol Plant Microbe Interact 19:854-863.

Kaschani, F., Shabab, M., Bozkurt, T., Shindo, T., Schornack, S., Gu, C., Ilyas, M., Win, J., Kamoun, S., and van der Hoorn, R.A. 2010. An effector-targeted protease contributes to defense against Phytophthora infestans and is under diversifying selection in natural hosts. Plant Physiol 154:17941804.

Keen, N.T. 1990. Gene-for-gene complementarity in plant-pathogen interactions. Annu Rev Genet 24:447-463.

Kim, Y.G., Cha, J., and Chandrasegaran, S. 1996. Hybrid restriction enzymes: zinc finger fusions to Fok I cleavage domain. Proc Natl Acad Sci USA 93:1156-1160.

King, J.C., and Slavin, J.L. 2013. White potatoes, human health, and dietary guidance. Adv Nutr 4:393S-401S.

Kroj, T., Chanclud, E., Michel-Romiti, C., Grand, X., and Morel, J.B. 2016. Integration of decoy domains derived from protein targets of pathogen effectors into plant immune receptors is widespread. New Phytol 210:618-626.

Kunze, G., Zipfel, C., Robatzek, S., Niehaus, K., Boller, T., and Felix, G. 2004. The N terminus of bacterial elongation factor Tu elicits innate immunity in Arabidopsis plants. Plant Cell 16:3496-3507.

Liebrand, T.W., van den Burg, H.A., and Joosten, M.H. 2014. Two for all: receptor-associated kinases SOBIR1 and BAK1. Trends Plant Sci 19:123-132.

Liebrand, T.W., van den Berg, G.C., Zhang, Z., Smit, P., Cordewener, J.H., America, A.H., Sklenar, J., Jones, A.M., Tameling, W.I., Robatzek, S., Thomma, B.P., and Joosten, M.H. 2013. Receptor-like kinase SOBIR1/EVR interacts with receptor-like proteins in plant immunity against fungal infection. Proc Natl Acad Sci USA 110:10010-10015.

Liu, Z., Bos, J.I.B., Armstrong, M.R., Whisson, S.C., da Cunha, L., Torto-Alalibo, T., Win, J., Avrova, A.O., Wright, F., Birch, P.R., and Kamoun, S. 2005. Patterns of diversifying selection in the phytotoxin-like scr74 gene family of Phytophthora infestans. Mol Biol Evol 22:659-672.

Machida-Hirano, R. 2015. Diversity of potato genetic resources. Breed Sci 65:26-40.

Mikes, V., Milat, M.L., Ponchet, M., Panabieres, F., Ricci, P., and Blein, J.P. 1998. Elicitins, proteinaceous elicitors of plant defense, are a new class of sterol carrier proteins. Biochem Biophys Res Commun 245:133-139.

Miya, A., Albert, P., Shinya, T., Desaki, Y., Ichimura, K., Shirasu, K., Narusaka, Y., Kawakami, N., Kaku, H., and Shibuya, N. 2007. CERK1, a LysM receptor kinase, is essential for chitin elicitor signaling in Arabidopsis. Proc Natl Acad Sci USA 104:19613-19618.

Mondragon-Palomino, M., Meyers, B.C., Michelmore, R.W., and Gaut, B.S. 2002. Patterns of positive selection in the complete NBS-LRR gene family of Arabidopsis thaliana. Genome Res 12:13051315.

Morgan, W., and Kamoun, S. 2007. RXLR effectors of plant pathogenic oomycetes. Curr Opin Microbiol 10:332-338.

Newman, M.A., Sundelin, T., Nielsen, J.T., and Erbs, G. 2013. MAMP (microbe-associated molecular pattern) triggered immunity in plants. Front Plant Sci 4:139.

Nicastro, G., Orsomando, G., Ferrari, E., Manconi, L., Desario, F., Amici, A., Naso, A., Carpaneto, A., Pertinhez, T.A., Ruggieri, S., and Spisni, A. 2009. Solution structure of the phytotoxic protein PcF: the first characterized member of the Phytophthora PcF toxin family. Protein Sci 18:1786-1791.

Oh, S.K., Young, C., Lee, M., Oliva, R., Bozkurt, T.O., Cano, L.M., Win, J., Bos, J.I., Liu, H.Y., van Damme, M., Morgan, W., Choi, D., van der Vossen, E.A., Vleeshouwers, V.G.A.A., and Kamoun, S. 2009. In planta expression screens of Phytophthora infestans RXLR effectors reveal diverse phenotypes, including activation of the Solanum bulbocastanum disease resistance protein Rpi-blb2. Plant Cell 21:2928-2947. 
Oome, S., Raaymakers, T.M., Cabral, A., Samwel, S., Bohm, H., Albert, I., Nurnberger, T., and van den Ackerveken, G. 2014. Nep1-like proteins from three kingdoms of life act as a microbe-associated molecular pattern in Arabidopsis. Proc Natl Acad Sci USA 111:16955-16960.

Orsomando, G., Brunetti, L., Pucci, K., Ruggeri, B., and Ruggieri, S. 2011. Comparative structural and functional characterization of putative protein effectors belonging to the PcF toxin family from Phytophthora spp. Protein Sci 20:2047-2059.

Orsomando, G., Lorenzi, M., Ferrari, E., de Chiara, C., Spisni, A., and Ruggieri, S. 2003. PcF protein from Phytophthora cactorum and its recombinant homologue elicit phenylalanine ammonia lyase activation in tomato. Cell Mol Life Sci 60:1470-1476.

Osman, H., Vauthrin, S., Mikes, V., Milat, M.-L., Panabières, F., Marais, A., Brunie, S., Maume, B., Ponchet, M., Blein, J.-P., and Meyerowitz, E. 2001. Mediation of elicitin activity on tobacco is assumed by elicitin-sterol complexes. Mol Biol Cell 12:2825-2834.

Panabieres, F., Marais, A., Le Berre, J.Y., Penot, I., Fournier, D., and Ricci, P. 1995. Characterization of a gene cluster of Phytophthora cryptogea which codes for elicitins, proteins inducing a hypersensitive-like response in tobacco. Mol Plant Microbe Interact 8:996-1003.

PGSC. 2011. Genome sequence and analysis of the tuber crop potato. Nature 475:189-195.

Postma, J., Liebrand, T.W., Bi, G., Evrard, A., Bye, R.R., Mbengue, M., Kuhn, H., Joosten, M.H., and Robatzek, S. 2016. Avr4 promotes Cf-4 receptor-like protein association with the BAK1/SERK3 receptor-like kinase to initiate receptor endocytosis and plant immunity. New Phytol 210:627642.

Raffaele, S., Win, J., Cano, L.M., and Kamoun, S. 2010. Analyses of genome architecture and gene expression reveal novel candidate virulence factors in the secretome of Phytophthora infestans. BMC genomics 11:637.

Randall, E., Young, V., Sierotzki, H., Scalliet, G., Birch, P.R., Cooke, D.E., Csukai, M., and Whisson, S.C. 2014. Sequence diversity in the large subunit of RNA polymerase I contributes to mefenoxam insensitivity in Phytophthora infestans. Mol Plant Pathol 15:664-676.

Ricci, P., Bonnet, P., Huet, J.C., Sallantin, M., Beauvais-Cante, F., Bruneteau, M., Billard, V., Michel, G., and Pernollet, J.C. 1989. Structure and activity of proteins from pathogenic fungi Phytophthora eliciting necrosis and acquired resistance in tobacco. Eur J Biochem 183:555-563.

Sarris, P.F., Cevik, V., Dagdas, G., Jones, J.D., and Krasileva, K.V. 2016. Comparative analysis of plant immune receptor architectures uncovers host proteins likely targeted by pathogens. BMC Biol 14:8.

Saunders, D.G., Breen, S., Win, J., Schornack, S., Hein, I., Bozkurt, T.O., Champouret, N., Vleeshouwers, V.G.A.A., Birch, P.R., Gilroy, E.M., and Kamoun, S. 2012. Host protein BSL1 associates with Phytophthora infestans RXLR effector AVR2 and the Solanum demissum immune receptor R2 to mediate disease resistance. Plant Cell 24:3420-3434.

Schoina, C., and Govers, F. 2015. The oomycete Phytophthora infestans, the Irish potato famine pathogen. Pages 371-378 in: Principles of Plant-Microbe Interactions: Microbes for Sustainable Agriculture, B. Lugtenberg, ed. Springer International Publishing, Cham.

Schornack, S., Huitema, E., Cano, L.M., Bozkurt, T.O., Oliva, R., van Damme, M., Schwizer, S., Raffaele, S., Chaparro-Garcia, A., Farrer, R., Segretin, M.E., Bos, J., Haas, B.J., Zody, M.C., Nusbaum, C., Win, J., Thines, M., and Kamoun, S. 2009. Ten things to know about oomycete effectors. Mol Plant Pathol 10:795-803.

Spallek, T., Melnyk, C.W., Wakatake, T., Zhang, J., Sakamoto, Y., Kiba, T., Yoshida, S., Matsunaga, S., Sakakibara, H., and Shirasu, K. 2017. Interspecies hormonal control of host root morphology by parasitic plants. Proc Natl Acad Sci USA 114:5283-5288.

Spooner, D.M. 1990. The potato: evolution, biodiversity and genetic resources. Am. J. Pot Res 67:733735.

Spooner, D.M., and Hijmans, R.J. 2001. Potato systematics and germplasm collecting, 1989-2000. Am. J. Pot Res 78:237-268.

Stam, R., Jupe, J., Howden, A.J.M., Morris, J.A., Boevink, P.C., Hedley, P.E., and Huitema, E. 2013. Identification and characterisation CRN Effectors in Phytophthora capsici shows modularity and functional diversity. PLoS One 8:e59517.

Stong, R.A., Kolodny, E., Kelsey, R.G., Gonzalez-Hernandez, M.P., Vivanco, J.M., and Manter, D.K. 2013. Effect of plant sterols and tannins on Phytophthora ramorum growth and sporulation. J Chem Ecol 39:733-743. 
Takahashi, T., Shibuya, H., and Ishikawa, A. 2016. SOBIR1 contributes to non-host resistance to Magnaporthe oryzae in Arabidopsis. Biosci Biotechnol Biochem 80:1577-1579.

Tameling, W.I.L., Elzinga, S.D.J., Darmin, P.S., Vossen, J.H., Takken, F.L.W., Haring, M.A., and Cornelissen, B.J.C. 2002. The tomato R gene products $\mathrm{I}-2$ and $\mathrm{Mi}-1$ are functional ATP binding proteins with ATPase activity. Plant Cell 14:2929-2939.

Thomma, B.P., Nurnberger, T., and Joosten, M.H. 2011. Of PAMPs and effectors: the blurred PTI-ETI dichotomy. Plant Cell 23:4-15.

Tian, M., Benedetti, B., and Kamoun, S. 2005. A second Kazal-like protease inhibitor from Phytophthora infestans inhibits and interacts with the apoplastic pathogenesis-related protease P69B of tomato. Plant Physiol 138:1785-1793.

Tian, M., Huitema, E., Da Cunha, L., Torto-Alalibo, T., and Kamoun, S. 2004. A Kazal-like extracellular serine protease inhibitor from Phytophthora infestans targets the tomato pathogenesis-related protease P69B. J Biol Chem 279:26370-26377.

Torto, T.A., Li, S., Styer, A., Huitema, E., Testa, A., Gow, N.A., van West, P., and Kamoun, S. 2003. EST mining and functional expression assays identify extracellular effector proteins from the plant pathogen Phytophthora. Genome Res 13:1675-1685.

van der Biezen, E.A., and Jones, J.D. 1998. Plant disease-resistance proteins and the gene-for-gene concept. Trends Biochem Sci 23:454-456.

van Esse, H.P., van't Klooster, J.W., Bolton, M.D., Yadeta, K.A., van Baarlen, P., Boeren, S., Vervoort, J., de Wit, P.J., and Thomma, B.P. 2008. The Cladosporium fulvum virulence protein Avr2 inhibits host proteases required for basal defense. Plant Cell 20:1948-1963.

Vleeshouwers, V.G.A.A., and Oliver, R.P. 2014. Effectors as tools in disease resistance breeding against biotrophic, hemibiotrophic, and necrotrophic plant pathogens. Mol Plant Microbe Interact 27:196-206.

Vleeshouwers, V.G.A.A., Raffaele, S., Vossen, J.H., Champouret, N., Oliva, R., Segretin, M.E., Rietman, H., Cano, L.M., Lokossou, A., Kessel, G., Pel, M.A., and Kamoun, S. 2011. Understanding and exploiting late blight resistance in the age of effectors. Annu Rev Phytopathol 49:507-531.

Vleeshouwers, V.G.A.A., Rietman, H., Krenek, P., Champouret, N., Young, C., Oh, S.K., Wang, M., Bouwmeester, K., Vosman, B., Visser, R.G., Jacobsen, E., Govers, F., Kamoun, S., and van der Vossen, E.A. 2008. Effector genomics accelerates discovery and functional profiling of potato disease resistance and Phytophthora infestans avirulence genes. PLoS One 3:e2875.

Wan, J., Zhang, X.C., Neece, D., Ramonell, K.M., Clough, S., Kim, S.Y., Stacey, M.G., and Stacey, G. 2008. A LysM receptor-like kinase plays a critical role in chitin signaling and fungal resistance in Arabidopsis. Plant Cell 20:471-481.

Wang, S., Zhang, S., Wang, W., Xiong, X., Meng, F., and Cui, X. 2015. Efficient targeted mutagenesis in potato by the CRISPR/Cas9 system. Plant Cell Rep 34:1473-1476.

Whisson, S.C., Boevink, P.C., Moleleki, L., Avrova, A.O., Morales, J.G., Gilroy, E.M., Armstrong, M.R., Grouffaud, S., van West, P., Chapman, S., Hein, I., Toth, I.K., Pritchard, L., and Birch, P.R. 2007. A translocation signal for delivery of oomycete effector proteins into host plant cells. Nature 450:115-118.

Win, J., Chaparro-Garcia, A., Belhaj, K., Saunders, D.G., Yoshida, K., Dong, S., Schornack, S., Zipfel, C., Robatzek, S., Hogenhout, S.A., and Kamoun, S. 2012. Effector biology of plant-associated organisms: concepts and perspectives. Cold Spring Harb Symp Quant Biol 77:235-247.

Wirthmueller, L., Maqbool, A., and Banfield, M.J. 2013. On the front line: structural insights into plantpathogen interactions. Nat Rev Microbiol 11:761-776.

Wu, Z., Huang, S., Zhang, X., Wu, D., Xia, S., and Li, X. 2017. Regulation of plant immune receptor accumulation through translational repression by a glycine-tyrosine-phenylalanine (GYF) domain protein. eLife 6:e23684.

Yoshida, K., Schuenemann, V.J., Cano, L.M., Pais, M., Mishra, B., Sharma, R., Lanz, C., Martin, F.N., Kamoun, S., Krause, J., Thines, M., Weigel, D., and Burbano, H.A. 2013. The rise and fall of the Phytophthora infestans lineage that triggered the Irish potato famine. eLife 2:e00731.

Zaheer, K., and Akhtar, M.H. 2016. Potato production, usage, and nutrition-a review. Crit Rev Food Sci Nutr 56:711-721. 
Zhang, L., Kars, I., Essenstam, B., Liebrand, T.W., Wagemakers, L., Elberse, J., Tagkalaki, P., Tjoitang, D., van den Ackerveken, G., and van Kan, J.A. 2014. Fungal endopolygalacturonases are recognized as microbe-associated molecular patterns by the Arabidopsis receptor-like protein RESPONSIVENESS TO BOTRYTIS POLYGALACTURONASES1. Plant Physiol 164:352-364.

Zhang, W., Fraiture, M., Kolb, D., Loffelhardt, B., Desaki, Y., Boutrot, F.F., Tor, M., Zipfel, C., Gust, A.A., and Brunner, F. 2013. Arabidopsis receptor-like protein30 and receptor-like kinase suppressor of BIR1-1/EVERSHED mediate innate immunity to necrotrophic fungi. Plant Cell 25:4227-4241.

Zhu, S., Li, Y., Vossen, J.H., Visser, R.G., and Jacobsen, E. 2012. Functional stacking of three resistance genes against Phytophthora infestans in potato. Transgenic Res 21:89-99.

Zipfel, C. 2014. Plant pattern-recognition receptors. Trends Immunol 35:345-351.

Zipfel, C., Kunze, G., Chinchilla, D., Caniard, A., Jones, J.D., Boller, T., and Felix, G. 2006. Perception of the bacterial PAMP EF-Tu by the receptor EFR restricts Agrobacterium-mediated transformation. Cell 125:749-760.

Zuluaga, A.P., Vega-Arreguin, J.C., Fei, Z., Ponnala, L., Lee, S.J., Matas, A.J., Patev, S., Fry, W.E., and Rose, J.K. 2016. Transcriptional dynamics of Phytophthora infestans during sequential stages of hemibiotrophic infection of tomato. Mol Plant Pathol 17:29-41. 



\section{Chapter 2}

\section{Effectoromics-based identification of cell surface receptors in potato}

Emmanouil Domazakis

Xiao Lin

Carolina Aguilera-Galvez

Doret Wouters

Gerard Bijsterbosch

Pieter J. Wolters

Vivianne G.A.A. Vleeshouwers 
In modern resistance breeding, effectors have emerged as tools for accelerating and improving the identification of immune receptors. Effector-assisted breeding was pioneered for identifying resistance genes ( $R$ genes) against Phytophthora infestans in potato (Solanum tuberosum). Here we show that effectoromics approaches are also well suitable for identifying pathogen recognition receptors (PRR) that recognize apoplastic effectors. To detect genotypes that recognize apoplastic proteins of $P$. infestans, routine agroinfiltration and potato virus $X(P V X)$ agroinfection methods can be applied. In addition, protein infiltrations are feasible for assessing responses to apoplastic effectors and aid in confirming results obtained from the aforementioned methods. Protocols for the effectoromics pipeline are provided, starting from phenotyping for effector responses, up to genotyping and PRR gene identification.

Keywords: Pattern recognition receptors (PRR), apoplastic effector, genetic mapping, agroinfiltration, PVX agroinfection, protein infiltration, effectoromics, yeast protein production, Solanum. 


\section{Introduction}

Breeding for broad-spectrum and durable disease resistance is one of the most important prerequisites for achieving a stable food production. Potato (Solanum tuberosum L.) is the third staple crop world-wide, and suffers from dramatic yield losses due to the devastating late blight pathogen Phytophthora infestans Mont. de Bary. To understand and improve resistance to late blight in potato, effectors of $P$. infestans have been successfully exploited in breeding (Vleeshouwers et al., 2008; Vleeshouwers et al., 2011). In this 'effectoromics' strategy, effectors are functionally tested for responses in potato germplasm. After detecting responding genotypes, the receptors are being genetically mapped on progeny populations derived from crosses between responding $(R)$ and non-responding (NR) genotypes, in which phenotyping is done by high throughput effector assays (Takken et al., 2000; Vleeshouwers et al., 2006).

Effectoromics was originally focused on detecting resistance $(R)$ genes of the NBSLRR class by assaying cytoplasmic effectors, and protocols were established for a.o. Solanum and Nicotiana species (Kapila et al., 1997; Kanneganti et al., 2007; Du and Vleeshouwers, 2014). Recently, the strategy was expanded to identifying pattern recognition receptors (PRR), or surface receptors, by functionally screening for responses to apoplastic effectors in potato (Du et al., 2015).

With the ever increasing amount of pathogen genome data, effectoromics is now being implemented for various other crops and pathosystems. Not only biotrophic pathogens, but also pathogens with other life styles can be the target of effectoromics, and e.g. toxins can be identified for necrotrophic pathogens (Oliver et al., 2012; Vleeshouwers and Oliver, 2014). The main requirements for effectoromics, is availability of 1 ) resistant plant material for sourcing the immune receptors, 2) candidate effectors predicted from pathogen genomes (Box 1), and 3) reliable and efficient functional assays (Box 2/Fig. 1). Agrobacteriumbased expression systems, such as for agroinfiltration and potato virus X (PVX)agroinfection, are well established in Solanaceae (Takken et al., 2000; Torto et al., 2003; Du et al., 2014) but are less applicable in e.g. monocots. An advantage of targeting apoplastic effectors is that these are typically more stable than cytoplasmic effectors and can be assayed by protein infiltrations (Vleeshouwers et al., 2006). Protein infiltration may provide a reliable way to assay responses obtained by other systems (Vleeshouwers et al., 2006), since it is not dependent on transformation efficiency and cannot be hindered by extreme resistance responses. 


\section{Box 1: Prediction of candidate apoplastic effectors}

Effector candidates can be identified by applying selection criteria on a database of proteins from the pathogen of interest. Such data might already be available, or could be generated by a genome sequencing and/or RNAseq experiment.

A number of criteria used in various publications (Tan et al., 2010; Liu et al., 2012; Saunders et al., 2012a; Mirzadi Gohari et al., 2015) are generally established for the selection of apoplastic effectors:

1. Presence of a secretion signal. In order for effectors to be secreted in the apoplast, they need to contain a signal peptide for secretion. Signal peptides can be predicted with software such as SignalP (Petersen et al., 2011).

2. Size. Effectors are often small proteins (e.g. $<30$ kDa).

3. Cysteine content. Apoplastic effectors are typically cysteine rich proteins; the formation of disulphide bonds is believed to help stabilize the proteins in the apoplastic environment

4. Expression profile. If such data are available. Functional effectors need to be expressed during the infection process.

Depending on the pathogen, additional criteria may be useful to further prioritize the list of effector candidates, for example: location in the genome (in Phytophthora spp., most effectors reside in repeat-rich regions (Haas et al., 2009) and in Fusarium spp. effectors are found close to transposable elements on so-called 'pathogenicity' chromosomes (Ma et al., 2010; Schmidt et al., 2013), presence or absence of certain domains and motifs (for example including proteins with a predicted LysM domain to find effectors that bind chitin (Vleeshouwers et al., 2006; Bolton et al., 2008), but excluding proteins with motifs like RxLR, which are required for cell entry (Vleeshouwers et al., 2006; Whisson et al., 2007; Manning et al., 2008), to filter out cytoplasmic effectors), similarity to known effectors, or information about presence/ absence of homologs in virulent or avirulent strains of the pathogen.

Being able to produce high quality apoplastic effector proteins using heterologous systems is of great importance. Pichia pastoris has emerged as an appropriate host for secreted protein production (Ahmad et al., 2014). As an eukaryote, it is able to post-translationally modify target effector proteins and secrete them into the growth medium (Brondyk et al., 2009). This is in a way similar to eukaryotic pathogens secreting effectors in the host apoplast. In addition, compared to Escherichia coli-based expression systems, it is able to produce higher quality protein with appropriate folding and does not form aggregates (Brondyk et al., 2009). 
Recent advances have enabled integration of novel methods, such as proteomics approaches for detecting protein activity and resistance gene enrichment sequencing (RenSeq) for accelerated genetic mapping (Jupe et al., 2013). In this chapter, we provide protocols for an effectoromics pipeline in potato (Box 2/Fig. 1). These include routine Agrobacterium-based methods that are applicable for all types of immune receptors known so far, and with emphasis on apoplastic effector screening methods that are useful for identifying new surface receptors.

\section{Box 2: Effectoromics workflow to identify novel surface receptors}

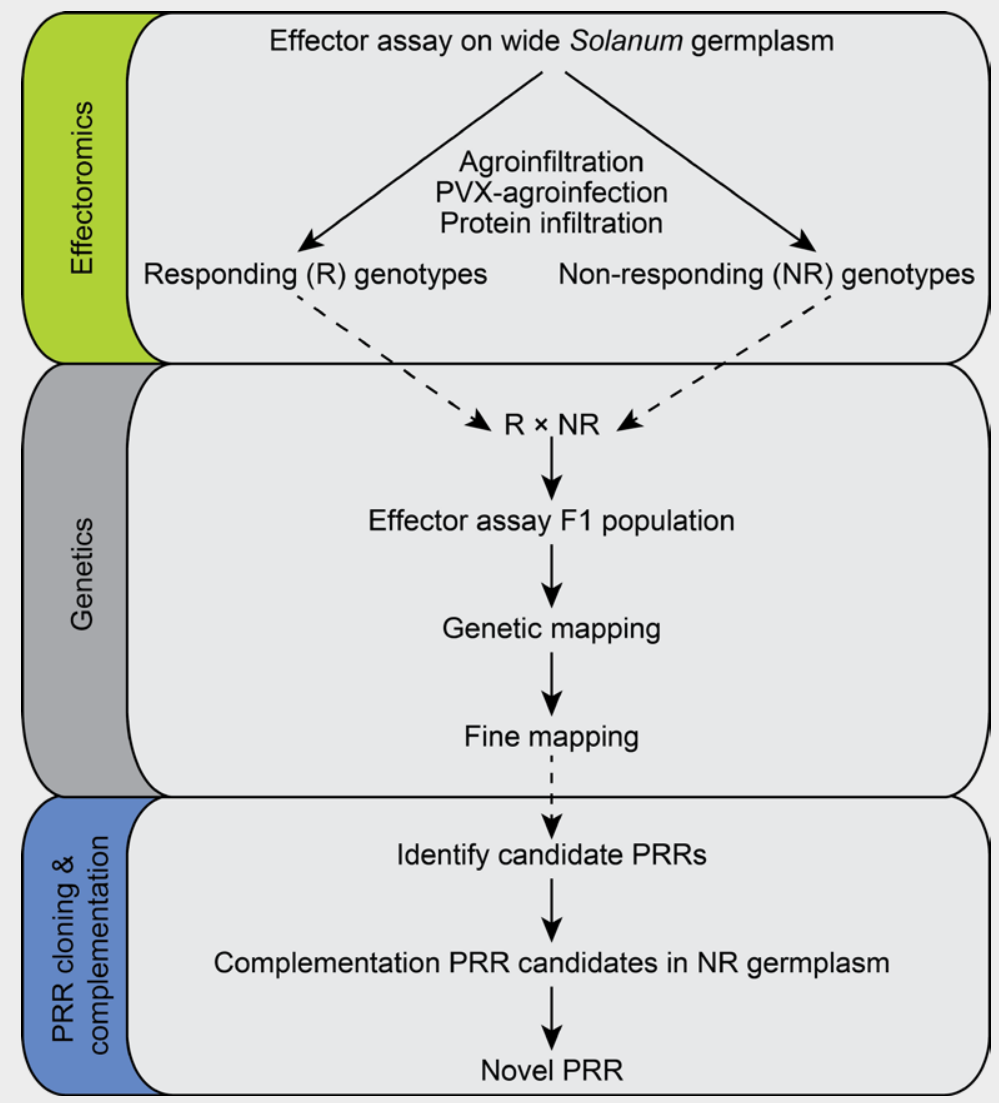




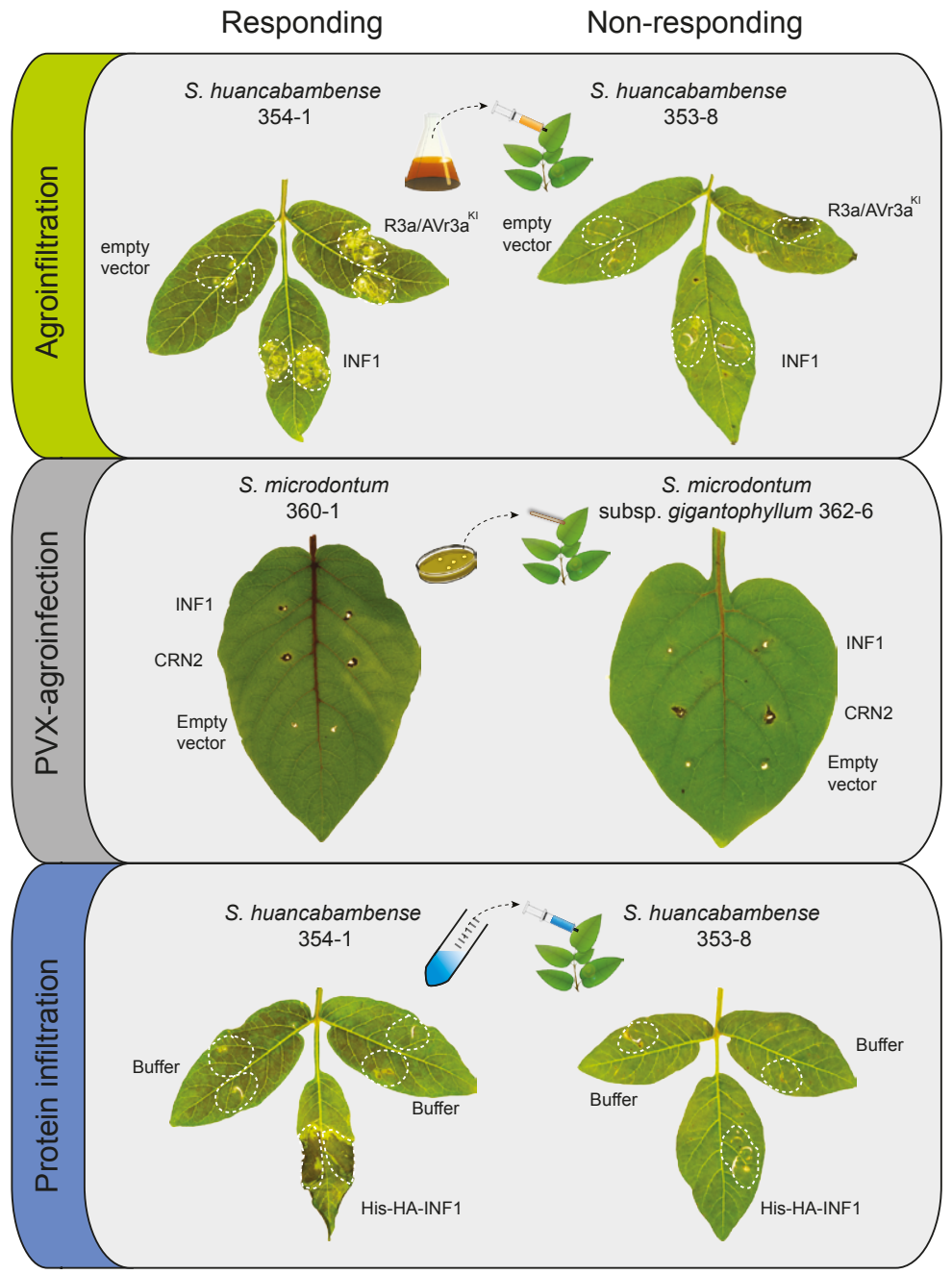

FIGURE 1 | Effectoromics screening for responses to apoplastic effectors in Solanum species using agroinfiltration, PVX-agroinfection or protein infiltration. Leaves of responding $(R)$ and nonresponding (NR) Solanum genotypes are agroinfiltrated, $\mathrm{PVX}$-agroinfected or protein-infiltrated with INF1 effector expressing constructs or with His-HA-INF1 protein purified from P. pastoris. As negative control, in the case of agroinfiltration and PVX agroinfection, empty vector carrying Agrobacterium strains are used. In the case of protein infiltration, buffer infiltration is used. In case of agroinfiltration and PVX-agroinfection, a positive control is included (R3a/AVr3a ${ }^{\mathrm{Kl}}$ (Armstrong et al., 2005; Huang et al., 2005) or CRN2 (Torto et al., 2003), respectively). No cell death is observed for the negative controls and INF1 is only causing cell death in the responding genotypes as confirmed by three methods (Vleeshouwers et al., 2006). 


\section{Materials}

\section{Potato in vitro propagation and maintenance}

MS20 medium (per I: $4.4 \mathrm{~g}$ Murashige and Skoog basal salt mixture without vitamins, $20 \mathrm{~g}$ sucrose in $700 \mathrm{ml}$ of demineralized water $\left(\mathrm{ddH}_{2} \mathrm{O}\right)$. Adjust $\mathrm{pH}$ to 5.8 with $\mathrm{NaOH}$ and $\mathrm{HCl}$ and bring to a final volume of $1 \mathrm{l}$. Add $8 \mathrm{~g}$ of micro agar and autoclave) (Du et al., 2014).

\section{Agroinfiltration and PVX agroinfection}

1. Agrobacterium tumefaciens strains AGL1 (Lazo et al., 1991) or GV3101 (Koncz and Schell, 1986)

2. LB (lysogeny broth) medium/LBA (LB + agar) (per l: $10 \mathrm{~g}$ tryptone, $5 \mathrm{~g}$ yeast extract and $10 \mathrm{~g} \mathrm{NaCl}$. For LBA add $10 \mathrm{~g} / \mathrm{l}$ bacteriological agar. Autoclave the media).

3. (Agroinfiltration only) $200 \mathrm{mM}$ acetosyringone (4-Hydroxy-3,5dimethoxyacetophenone) stock (39,3 mg of acetosyringone in $1 \mathrm{ml}$ of DMSO).

4. (Agroinfiltration only) $1 \mathrm{M} \mathrm{MES} \mathrm{(2-(N-morpholino)-ethane} \mathrm{sulfonic} \mathrm{acid)} \mathrm{buffer}$ (per $50 \mathrm{ml}: 10.66 \mathrm{~g}$ of MES monohydrate, adjust $\mathrm{pH}$ to 5.6 with $\mathrm{NaOH}$ and filter sterilize).

5. (Agroinfiltration only) YEB (yeast extract broth) Agrobacterium Growth Medium (per l: $5 \mathrm{~g}$ beef extract, $5 \mathrm{~g}$ bacteriological peptone, $5 \mathrm{~g}$ sucrose, $1 \mathrm{~g}$ of yeast extract, 0,492 $\mathrm{g}$ of $\mathrm{MgSO}_{4} \bullet 7 \mathrm{H}_{2} \mathrm{O}$, autoclave) (van der Hoorn et al., 2000).

6. (Agroinfiltration only) MMA agroinfiltration buffer (per l: $20 \mathrm{~g}$ of sucrose, 5 $\mathrm{g}$ of MS salts without vitamins, $1.95 \mathrm{~g} \mathrm{MES,} 2 \mathrm{ml} 1 \mathrm{M} \mathrm{NaOH}, 1 \mathrm{ml}$ of $200 \mathrm{mM}$ acetosyringone. Confirm that $\mathrm{pH}$ is 5.6. If necessary, adjust with $\mathrm{HCL} / \mathrm{NaOH}$ ).

7. Antibiotics: prepare stock concentration of the appropriate antibiotic. Common antibiotic $1000 \times$ stock concentrations: kanamycin $50 \mathrm{mg} / \mathrm{ml}$, spectinomycin $50 \mathrm{mg} / \mathrm{ml}$, ampicillin/carbenicillin $100 \mathrm{mg} / \mathrm{ml}$ (in water) rifampicin $25 \mathrm{mg} / \mathrm{ml}$ (in DMSO), chloramphenicol $34 \mathrm{mg} / \mathrm{ml}$, tetracycline $5 \mathrm{mg} / \mathrm{ml}$ (in ethanol).

8. (Agroinfiltration only) pK7WG2 vector (Gateway) (Karimi et al., 2002) or other CaMV 35s driven plant expression vector.

9. (PVX-agroinfection only) pGR106 vector (Lu et al., 2003) or other (CaMV 35s) PVX encoding vector.

\section{Protein production in Pichia pastoris}

1. pPinka-HC vector (PichiaPink ${ }^{\top M}$, Invitrogen, Carlsbad, USA)

2. Restriction endonucleases and buffers

3. T4 ligase and buffer

4. DH5a, TOP10 or similar competent Escherichia coli cells 
5. LB medium containing ampicillin or carbenicillin $(100 \mu \mathrm{g} / \mathrm{ml})$

6. LBA plates containing ampicillin or carbenicillin $(100 \mu \mathrm{g} / \mathrm{ml})$

7. AOX1 sequencing primers (AOX: 5'-GACTGGTTCCAATTGACAAGC-3', AOX: 3'-GCAAATGGCATTCTGACATCC-5')

8. Target effector gene primers

9. Plasmid DNA purification kit

10. Pichia pastoris strain PichiaPink ${ }^{\mathrm{TM}} 1,2,3$ or 4 (ADE2 mutants, strains $2,3,4$ are also protease deficient strains-see PichiaPink ${ }^{\mathrm{TM}}$ manual

11. Working glycerol stock of PichiaPink ${ }^{\mathrm{TM}}$ strains (see Invitrogen manual)

12. $20 \% \mathrm{w} / \mathrm{v}$ dextrose solution (per l: $200 \mathrm{~g}$ dextrose, autoclave)

13. $1 \mathrm{M}$ sorbitol (per I: $187.17 \mathrm{~g}$ sorbitol)

14. $1 \mathrm{M}$ potassium phosphate buffer, $\mathrm{pH} 6.0$ (per l: $132 \mathrm{ml}$ of $1 \mathrm{M} \mathrm{K}_{2} \mathrm{HPO}_{4}, 868 \mathrm{ml}$ of $1 \mathrm{M} \mathrm{KH}_{2} \mathrm{PO}_{4}$ and confirm that the $\mathrm{pH}$ is $6.0 \pm 0.1$, use phosphoric acid or $\mathrm{KOH}$ to adjust $\mathrm{pH}$ )

15. YNB (per I: $134 \mathrm{~g}$ Yeast Nitrogen Base with ammonium sulfate, without amino acids. Filter sterilize)

16. YPD medium (per l: $10 \mathrm{~g}$ Yeast extract, $20 \mathrm{~g}$ Peptone. Autoclave and add 100 $\mathrm{ml} 20 \%$ Dextrose) and YPD agar plates (YPD medium containing $8 \mathrm{~g} / \mathrm{l}$ agar. Autoclave and add $100 \mathrm{ml} 20 \%$ Dextrose)

17. YPDS medium (YPD containing $1 \mathrm{M}$ sorbitol)

18. PAD selection plates (adenine drop-out media) (see Invitrogen manual)

19. Sterile Milli-Q water (Merck Millipore, Darmstadt, Germany)

20. Electroporation device with yeast transformation setup (e.g. for BioRad gene pulser and $0.1 \mathrm{~cm}$ gap cuvette: $400 \Omega$ resistance, $25 \mu \mathrm{F}$ capacitance and 1.4 $\mathrm{kV}$ voltage)

21. $125 \mathrm{ml}$ and $1 \mathrm{I}$ baffled culture flasks, sterile

22. $500 \mathrm{ml}$ centrifuge bottles, sterile

23. $10 \%$ glycerol (per l: $100 \mathrm{ml}$ glycerol, autoclaved)

24. $10 \%$ methanol (per l: $100 \mathrm{ml}$ absolute methanol, filter sterilized)

25. $0.02 \%$ biotin (per $100 \mathrm{ml}: 20 \mathrm{mg}$ biotin, filter sterile)

26. BMGY (per l: $10 \mathrm{~g}$ yeast extract, $20 \mathrm{~g}$ peptone, $700 \mathrm{ml}$ Milli- $\mathrm{Q}$ water, autoclave. Then add $100 \mathrm{ml}$ of $1 \mathrm{M}$ potassium phosphate $\mathrm{pH} 6.0,100 \mathrm{ml} \mathrm{YNB}, 2 \mathrm{ml}$ of $0.02 \%$ biotin and $100 \mathrm{ml} 10 \%$ glycerol)

27. BMMY (per l: dissolve $10 \mathrm{~g}$ yeast extract and $20 \mathrm{~g}$ peptone in $700 \mathrm{ml} \mathrm{Milli- \textrm {O }}$ water, autoclave. Then add $100 \mathrm{ml}$ of $1 \mathrm{M}$ potassium phosphate $\mathrm{pH} 6.0,100 \mathrm{ml}$ YNB, $2 \mathrm{ml} 0.02 \%$ biotin and $100 \mathrm{ml} 10 \%$ methanol)

28. Baffled or normal flasks

29. 96-deep well plates ( $2 \mathrm{ml}$ capacity)

30. Amicon Ultra $400 \mathrm{ml}$ stirred cell and appropriate filtration membranes (Merck 
Millipore, Darmstadt, Germany)

31. $4 \times$ laemli SDS-PAGE loading buffer (per $10 \mathrm{ml}: 2 \mathrm{ml} 1 \mathrm{M}$ Tris- $\mathrm{HCl} \mathrm{pH} \mathrm{6.8,} 0.8 \mathrm{~g}$ SDS, $4 \mathrm{ml}$ 100\% glycerol, $0.4 \mathrm{ml} 14.7 \mathrm{M} \beta$-mercaptoethanol, $1 \mathrm{ml} 0.5 \mathrm{M}$ EDTA,

$8 \mathrm{mg}$ bromophenol blue)

32. 96-well PCR plates

33. Antibodies raised against HA (hemagglutinin) or His (histidine) epitopes.

\section{Genetic mapping}

1. SSR markers (Milbourne et al., 1998)

2. 4300 DNA Analyzer (LI-COR, Lincoln, USA)

3. LightScanner ${ }^{\circledR}$ System (Bio Fire, Utah, USA)

4. Phire Green Hot Start II DNA Polymerase (Thermo-Fisher Scientific)

5. S. tuberosum Group Phureja DM1-3 genome v4.03 (http://solanaceae. plantbiology.msu.edu/pgsc_download.shtml (Hardigan et al., 2016))

\section{Methods}

\section{Potato plant maintenance and propagation}

Maintain potato plants in vitro in sterile jars containing MS20 medium. Incubate in climate chambers at $24^{\circ} \mathrm{C}$ under long day conditions ( $16 \mathrm{~h}$ light/ $8 \mathrm{~h}$ dark) for two weeks (Du et al., 2014). Then transfer them into pots of sterilized soil in climate regulated greenhouse compartments within the temperature range of $18-22{ }^{\circ} \mathrm{C}$ and under $16 \mathrm{~h} / 8 \mathrm{~h}$ day/night regime (Du et al., 2014).

\section{Agroinfiltration}

1. Inoculate the Agrobacterium strains containing the gene of interest in $15 \mathrm{ml}$ of YEB containing $1.5 \mu \mathrm{l}$ of $200 \mathrm{mM}$ acetosyringone solution, $150 \mu \mathrm{l}$ of $1 \mathrm{M} \mathrm{MES}$ buffer and the appropriate antibiotics.

2. Incubate on a shaking incubator for $24-48 \mathrm{~h}$ at $28^{\circ} \mathrm{C}$ at $200 \mathrm{rpm}$ until the culture has grown to an $\mathrm{OD}_{600}$ of approximately 1.

3. Harvest the cells by centrifugation at 3,000 x g for $10 \mathrm{~min}$. Decant supernatant and resuspend the pellet in freshly made MMA buffer to an $\mathrm{OD}_{600}$ of 0.4 . Gently vortex the cells. For co-infiltration of two strains, mix the cultures in a 1:1 ratio.

4. Incubate the bacterial strains in MMA for 1-6 h at room temperature before infiltrations.

5. Use a $1 \mathrm{ml}$ needleless syringe to infiltrate the lower side of the potato leaf. Use around 4-5 weeks old plants grown from in vitro rooted plantlets (see note 1 and 3). A successful infiltration becomes visible by a change in colour of the infiltrated area from light green to dark green. 
6. Use three plants for agroinfiltration with each strain and three leaves per plant (see note 3). Be sure to include a negative control (e.g. a strain carrying empty vector) and a positive control (e.g. a co-infiltration of matching avirulence and resistance gene) (see note 4 ).

7. Score for cell death after 3 days of infiltration on a scale from $0 \%$ (no symptoms) to $100 \%$ (confluent cell death) (Du et al., 2014) (Fig. 1) (see note 4, 5 and 6).

\section{PVX agroinfection}

1. Inoculate the Agrobacterium strains containing the gene of interest in $3 \mathrm{ml}$ of YEB. Incubate the cultures at $28^{\circ} \mathrm{C}$, shaking at $200 \mathrm{rpm}$ for $24-48 \mathrm{~h}$.

2. Pipette $100 \mu \mathrm{l}$ of each Agrobacterium strain and spread them on LB agar plates containing the appropriate antibiotics. Incubate at $28^{\circ} \mathrm{C}$ for $24-48 \mathrm{~h}$.

3. Use a bacterial spreader to thoroughly collect the Agrobacterium culture at the centre of the plate. Dip the tip of a toothpick in the Agrobacterium cells.

4. Inoculate each strain on the leaf by piercing the leaf with the toothpick. Use around 2-3 weeks-old plants from in vitro (see note 2). Inoculate at least three plants for each strain and three leaves per plant. Toothpick-inoculate each Agrobacterium strain in duplicate, on each side of the mid vein. Be sure to include a positive (e.g. CRN2) and a negative control (empty pGR106 vector) in every treated leaf (Torto et al., 2003).

5. Score for cell death around the inoculation wound at 14 days post inoculation (Fig. 1) (see note 4 and 5). Record the qualitative/quantitative cell death response (score as 0 for no response, 1 for intermediate and 2 for strong response) for each spot and compare with the negative control. (Du et al., 2014) (see note 4, 5 and 6).

\section{Resistance gene mapping in Solanum}

1. Identify diploid Solanum genotypes that respond to the target effector by agroinfiltration and PVX agroinfection with clear phenotypes (an overview of the map-based cloning strategy is presented in Fig. 2, see note 4 and 5).

2. Cross the genotypes with clear responses $(R)$ with genotypes that do not respond (NR) (Box 2, Fig. 2). Harvest the F1 seeds.

3. Sow $50 \mathrm{~F} 1$ seeds in greenhouse and phenotype the response for the target effector. If the $\mathrm{F} 1$ population shows a 1:1 segregating ratio, it indicates that the target gene is heterozygous in the responding parents.

4. If the F1 population does not show segregation (indicating that the receptor is homozygous in the response parent), select 2-3 F1 response progenies with good phenotypes for a backcrossing with the non-responding genotypes. The resulting $\mathrm{BC} 1$ population should show a segregation for the effector response. 
5. Run about 80 SSR markers that are equally distributed over the potato chromosomes (Milbourne et al., 1998) to determine on which chromosome the resistance gene is located.

6. Test markers spanning the target chromosome (identify known markers from literature or develop new markers based on the published potato genome (PGSC, 2011) (DMv4.03).

7. Sow more seeds to screen a higher number of progeny plants from the same cross with the flanking markers. Maintain the recombinants in vitro for further phenotyping and marker testing.

(a)

(b)

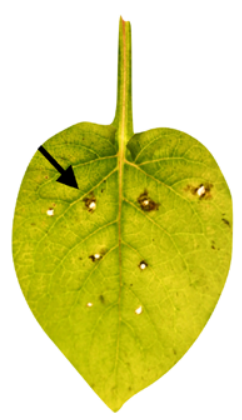

Responding (R)

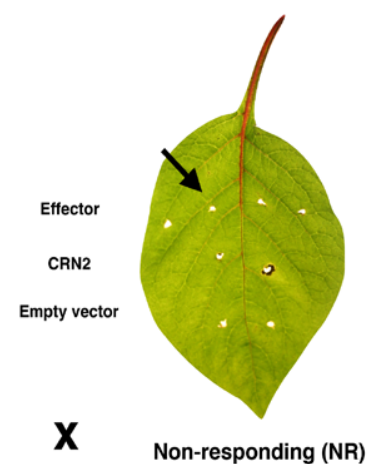

Non-responding (NR)

F1 segregating population
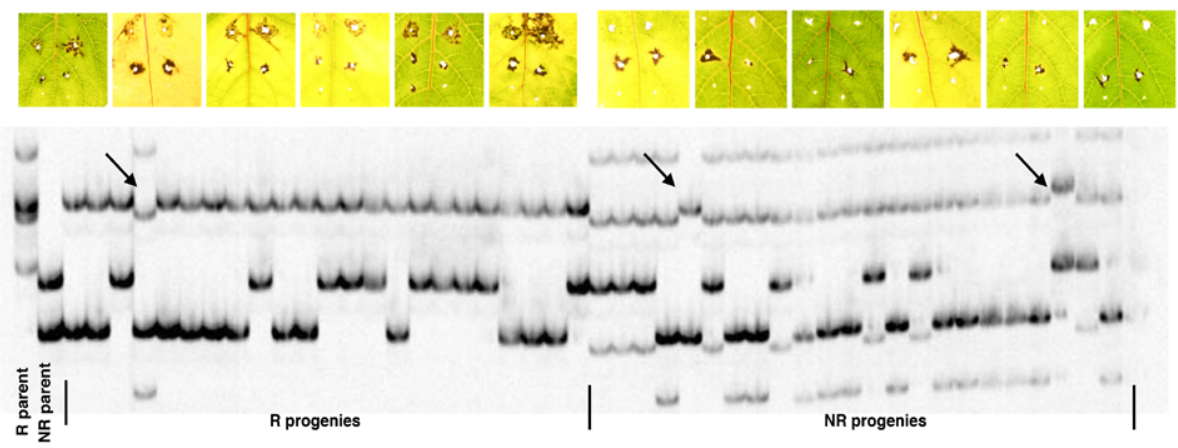

FIGURE 2 | Map-based cloning of surface immune receptors following the effectoromics screening in diploid Solanum species. a) The selected responding (R) Solanum genotype is crossed with a nonresponding (NR) genotype. The F1 progenies are screened for effector responses as described in this chapter. b) The F1 population shows 1:1 segregation ratio. Eighty SSR markers (Milbourne et al., 1998) are used to determine the chromosome where the target gene is located. The depicted SSR marker is linked with the phenotype and three recombinants are indicated (arrows). 


\section{Marker development}

1. Develop single-nucleotide polymorphism (SNP) markers based on the DM v4.03 genome sequence (PGSC, 2011) for fine mapping. Select genes from the target interval and PCR amplify 1,200 bp long fragments. Sequence fragments from $R$ and NR parents.

2. Select SNPs that are heterozygous from R parent and homozygous from NR parent. Design new high resolution melting (HRM) markers to amplify $150 \mathrm{bp}$ amplicons containing the ideal SNP and screen on the population (SNPs cause difference in PCR product melting curve). The target interval will be further narrowed down.

3. Alternatively, new HRM markers can be developed randomly on exon sequences between the target interval from DM. 150 bp small amplicons can be used for SNP screening by the LightScanner system.

Fine mapping

1. Construct $10 \times$ coverage BAC library for the responding genotype. For heterozygous diploid potato genotypes (e.g. 150,000 BAC clones for $900 \mathrm{Mb}$ haploid size $\times 2$ ).

2. Screen the BAC library using the co-segregating markers identified in the previous steps. Use the markers to select BAC clones that are in coupling phase with the resistance gene to create a minimum tiling path covering the region of interest. Sequence the selected BAC clones.

3. Annotate the genes in the sequenced region and select candidate genes based on their predicted function.

4. Clone the candidate genes in a binary expression vector (e.g. pK7WG2) and co-infiltrate with the matching effector in non-responding potato and Nicotiana benthamiana plants to confirm the recognition of the effector from the cloned resistance gene.

5. Generate stable transformants of the candidate gene into a NR potato background (e.g. cultivar Désirée) for further complementation and functional studies.

\section{Apoplastic effector cloning and transformation of Pichia pastoris}

We use the amino acid sequence HHHHHHVKLYPYDVPDYAAA (underlined are the $6 \times$ His and $1 \times$ HA-tag residues with spacer amino acids in between) encoded by the DNA sequence 5'-CATCATCACCATCACCACGTTAAGTTGTACCCATACGACGTTCCAGATTACGCTGCTGCT-3' in $\mathrm{N}^{\prime}$ of the mature effector protein to generate $\mathrm{N}$-terminal $6 \times \mathrm{His}-1 \times \mathrm{xH}$-tagged effector fusions in PichiaPink ${ }^{\mathrm{TM}}$ pPinka-HC (see note 9). 
1. Synthesize codon optimized effector genes for protein production in Pichia pastoris (see note 7 and 9). Six times His and HA tag as well as restriction sites have to be added (Stul in forward primer and Kpnl, Nael, Fsel, or Swal in reverse primer) to facilitate ligation into vector pPinka-HC (secreted expression, high copy) (see note 8).

2. Digest codon optimized effector genes and the pPinka-HC and vector with the appropriate enzymes and continue cloning as described in the manual .

3. Transform competent E. coli with pPinka-HC-effector constructs. Select 5 colonies for colony PCR confirmation, plasmid isolation and sequencing.

4. Sequence 5 clones per construct with $A O X 5^{\prime}$ and $A O X 3^{\prime}$ primers. Be sure to carefully check for the correct insertion of the effector gene in the vector cassette and the absence of any mutation before and following the cloned gene.

5. Prepare $10 \mu \mathrm{g}$ of plasmid DNA to be used for transformation by isolating plasmid DNA and digesting with a restriction enzyme that does not cut within your gene (e.g. one of Mam I, EcoN I, Spe I, or Afl II).

6. Clean up the digest by ethanol/sodium acetate precipitation and washing as described in the manual. Air-dry, and resuspend in $10 \mu \mathrm{L}$ sterile, deionized water. Use immediately or store at $-20^{\circ} \mathrm{C}$.

7. Prepare electro-competent PichiaPink cells as described in the manual on the day of transformation (do not store cells at $-80^{\circ} \mathrm{C}$ as transformation efficiency will drop significantly). Use $80 \mu \mathrm{L}$ of cells and $10 \mu \mathrm{L}$ of plasmid $(10 \mu \mathrm{g}$ total DNA amount) per electro-transformation.

8. After electroporation, immediately add $1 \mathrm{ml}$ of sterile YPDS medium in the cuvette and incubate at $30^{\circ} \mathrm{C}$ for $3-4 \mathrm{~h}$.

9. Plate $500 \mu \mathrm{L}$ in PAD selection plates and incubate at $30^{\circ} \mathrm{C}$ till colonies appear. Usually it takes 3 days for the first transformants to appear (see note 10).

10. Four to five days after transformation, select 10 of the most well developed, white P. pastoris colonies, for each construct (see note 10 and 11).

\section{High throughput protein production screening}

1. From the original transformation plates, patch 8-10 clones in a fresh PAD selection plate and incubate for $2-3$ days at $30^{\circ} \mathrm{C}$.

2. In a 96-deep well plate ( $2 \mathrm{ml}$ capacity volume), add $200 \mu \mathrm{L}$ of BMGY per well and inoculate with each clone.

3. Incubate at $28-30^{\circ} \mathrm{C}$ on a shaking incubator at $300 \mathrm{rpm}$ for $24 \mathrm{~h}$.

4. Spin down to pellet cells by centrifugation $(1,500 \times \mathrm{g}$ for $15 \mathrm{~min})$.

5. Remove supernatants with pipetting and add $300 \mu \mathrm{l}$ of BMMY for inducing expression. 
6. Incubate at $28^{\circ} \mathrm{C}$ in a shaking incubator at $300 \mathrm{rpm}$ for $48 \mathrm{~h}$.

7. Spin down to pellet cells and for each culture collect $150 \mu \mathrm{l}$ supernatant in a clean 96-wells PCR plate.

8. To each supernatant, add $50 \mu$ l of $4 \times$ Laemmli loading buffer and heat to $95^{\circ} \mathrm{C}$ for $10 \mathrm{~min}$.

9. Run SDS-PAGE with all clones per construct and perform western blot with anti-HA or anti-His to detect secreted recombinant proteins.

10. Select the highest producing clone for further protein production. Prepare glycerol stock of this clone by growing it in YPD for $48 \mathrm{~h}$, adding sterile glycerol to $20 \% \mathrm{v} / \mathrm{v}$ and snap freezing in liquid nitrogen.

(a)

\begin{tabular}{cccc|}
\hline Effector protein & $\begin{array}{c}\text { Molecular weight } \\
(\mathbf{k D a})\end{array}$ & $\begin{array}{c}\text { Concentration (BCA) } \\
\boldsymbol{\mu g} / \mathbf{m l}\end{array}$ & $\begin{array}{c}\text { Total } \mu \mathrm{g} \text { CEX } \\
\text { purified protein }\end{array}$ \\
\hline HisHA-INF1 & 12,72 & 263 & 1575 \\
\hline HisHA-SCR74-A10 & 8,05 & 351 & 2103 \\
\hline HisHA-SCR74-G1 & 8,02 & 295 & 1769 \\
\hline HisHA-SCR74-B3b & 8,20 & 1391 & 8347 \\
\hline HisHA-EPI1 & 16,83 & 339 & 2035 \\
\hline HisHA-EPIC2B & 13,84 & 517 & 3102 \\
\hline
\end{tabular}

(b)

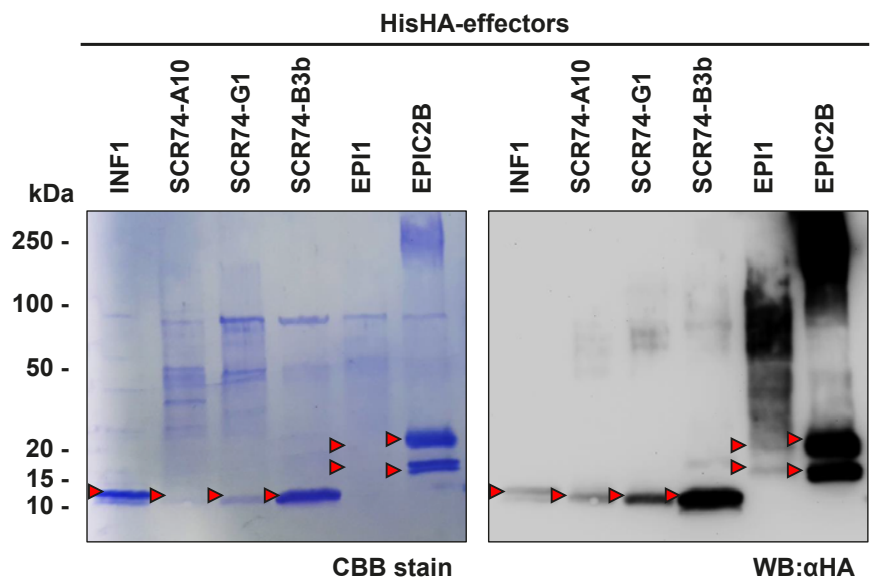

FIGURE 3 | Production of six recombinant HisHA-tagged effectors from Phytophthora infestans using the Pichia pastoris system. Six HisHA tagged effector proteins from $P$. infestans were produced in $P$. pastoris (INF1, SCR74-A10, SCR74-G1, SCR74-B3b, EPI1, EPIC2B), using a $200 \mathrm{ml}$ induction culture, as described. a) Recombinant effectors were purified using cation exchange chromatography (described in Chapter 4). The concentration of the purified proteins was determined by BCA assay (ThermoFisher Scientific) and the total amount of protein obtained in $6 \mathrm{ml}$ of elution volume is shown (*). b) SDS-PAGE of samples in a) was performed, followed by Coomassie brilliant blue (CBB) staining and western blot with anti-HA (Miltenyi Biotech). 


\section{Small scale recombinant effector production}

1. Using the highest protein producing P. pastoris clone (from PAD selection plates or a $-80^{\circ} \mathrm{C}$ glycerol stock), inoculate $5 \mathrm{ml}$ of YPD and grow for one to two days in order to obtain a start culture.

2. Inoculate $25 \mathrm{ml}$ of BMGY with $100 \mu \mathrm{L}$ of the clone pre-culture in a $250 \mathrm{ml}$ baffled flask. Grow at $28^{\circ} \mathrm{C}$ in a shaking incubator (250-300 rpm) until culture reaches an $\mathrm{OD}_{600}$ of 2-6 ( usually 16-20 h).

3. Use this $25 \mathrm{ml}$ culture to inoculate 1 I of BMGY in a 3 or 4 I baffled flask and grow at $28^{\circ} \mathrm{C}$ with vigorous shaking (250-300 rpm) until the culture reaches log phase growth $\left(O D_{600}=2-6\right)$ (usually 6-8 h).

4. Harvest the cells by centrifuging in sterile centrifuge bottles at 1,500-3,000 $\mathrm{x}$ $\mathrm{g}$ for $5 \mathrm{~min}$ at room temperature.

5. Decant the supernatant and resuspend the cell pellet in $200 \mathrm{ml}$ of BMMY medium to induce expression.

6. Transfer the cell suspension in a 2 I baffled flask, cover with an air-porous tape such as AirPore ${ }^{\mathrm{TM}}$ (Qiagen, Venlo, the Netherlands) or PureLink ${ }^{\mathrm{TM}}$ Air Porous Tape (Thermo Fisher Scientific, Waltham, USA). Continue to grow at $28^{\circ} \mathrm{C}$ with shaking at $300 \mathrm{rpm}$.

7. Add $2 \mathrm{ml}$ of $100 \% \mathrm{MetOH}$ every $24 \mathrm{~h}$ to maintain induction.

8. Induce protein expression for 48-72 h.

9. Aliquot the culture in $50 \mathrm{ml}$ conical tubes and centrifuge at $4,000 \times \mathrm{g}$ for 30 min to pellet the cells. Transfer supernatants to new $50 \mathrm{ml}$ conical tubes and repeat centrifugation in order to completely clarify the supernatant.

10. Filter sterilize the supernatants through a $0.45 \mu \mathrm{m}$ syringe filter.

11. Transfer sterilized supernatant in the Amicon Ultra $400 \mathrm{ml}$ stirred cell, equipped with a membrane with a pore size (MWCO) that equals half or less the predicted effector molecular weight.

12. Concentrate the supernatant by applying 5.2 bars pressure of nitrogen gas and medium stirring speed till the volume reaches around $10-20 \mathrm{ml}$. Collect concentrate in a $50 \mathrm{ml}$ tube. Supernatants can be kept for a short term at $4^{\circ} \mathrm{C}$ till purification or be stored at $-80^{\circ} \mathrm{C}$.

13. Purify recombinant apoplastic effector proteins with a method of choice (see note 12).

\section{Infiltration of apoplastic effector proteins into leaf apoplast}

1. Dilute purified tagged apoplastic effector proteins in sterile Milli-Q water at the desired molar concentration. Start by testing different molar concentrations, e.g. $10 \mathrm{nM}$ to $10 \mu \mathrm{M}$ (see note 13 and 14 ).

2. Use a needleless syringe to infiltrate protein solution in the lower side of a fully 
expanded leaf. Use Milli-Q water, buffer or another, non-recognized protein (e.g. a cysteine mutant) as a negative control (see note 14 and 15).

3. Score responses at 3,5 and 7 days post-infiltration, depending on the protein concentration used and the type of response (Fig. 1) (see note 4 and 5).

\section{Notes}

1. Choose young, healthy and fully developed leaves for agro-infiltrations.

2. For high-throughput screening with PVX agroinfection, use 4-5 week old plants. Those plants have big leaves to inoculate more spots than smaller leaves.

3. Eye protection should be worn during the agroinfiltration process. Change gloves when infiltrating with different strains to avoid cross contamination.

4. When scoring agroinfiltration, PVX-agroinfection or protein infiltration experiments, always compare your obtained effector responses with the controls. It is good to realize that intensity of responses also depend on transformation efficiency and sensitivity to Agrobacterium (and PVX) in the particular genetic background. Therefore, be sure to check for background responses to Agrobacterium or PVX.

5. Assay scoring can also be done at different time points, depending on the type of effector and inoculated plant genotypes. In the case of PVX-agroinfection, cell death responses usually start to appear from day 8 , and are optimal at day 14. For agroinfiltration, cell death responses can appear from 2 days and reach a maximum at 5 days post infiltration. For protein infiltration, depending on the concentration used, cell death responses can appear from 2 days and reach a maximum at one week post infiltration. Keep in mind that responses to effectors are not necessarily associated with cell death (Jones and Dangl, 2006; Katagiri and Tsuda, 2010).

6. Cell death responses triggered by PRR may not be observed at temperatures below $20^{\circ} \mathrm{C}$ (Cheng et al., 2013).

7. Most secreted apoplastic effectors are small. Synthesizing is the best option. In addition, when synthesizing, codon optimization is possible which can lead to an increase in protein production yields. Codon optimization services can be requested at most companies.

8. ATG start codon or the yeast consensus Kozak sequence should not be included when cloning in pPinka-HC vector as they are on the a-mating factor pre-sequence. You must add a stop codon at the $3^{\prime}$ of the effector gene, as it is not present in vector.

9. Tag position may affect protein recognition or function. For apoplastic effectors, a small $\mathrm{N}$-terminal tag is used in most of the cases. 
10. When transforming PichiaPink strains, low copy number transformants will appear on the PAD selection plates. Those will have a red-pinkish colour. It is advised not to use those for protein expression.

11. It is not necessary to screen PichiaPink tranformants by PCR. All white colonies should be positive, high copy number transformants.

12. Typically, ion exchange chromatography or immobilized metal affinity chromatography (IMAC) are used. IMAC exploits the metal binding affinity of histidine residues fused to the effector protein. Mainly nickel or cobalt coated beads are utilized for this purpose.

13. Protein concentration is important for an adequate response. Molar concentrations should be used instead of grams.

14. Do not use very high protein concentrations, as they could lead to toxic effects and therefore the experiment will be non-informative. A control for unspecific responses must be performed by including non-responding genotypes in every experiment.

15. Be sure that your protein solutions for infiltration are free of bacterial contamination. Potato plants tend to have a high background response to bacteria.

\section{Acknowledgments}

This work was supported by a NWO-VIDI grant 12378 (ED, XL,DW, VGAAV), the China Scholarship Council Program for Graduate Students (XL), Colciendas (CAG), Veenhuizen Tulp Fonds (CAG), J.R. Simplot Company (PJW), and COST FA1208 $(\mathrm{XL})$. Yeshiwas Alemnew Abate is acknowledged for assistance with effector protein production. 


\section{References}

Ahmad, M., Hirz, M., Pichler, H., and Schwab, H. 2014. Protein expression in Pichia pastoris: recent achievements and perspectives for heterologous protein production. Appl Microbiol Biotechnol 98:5301-5317.

Bolton, M.D., van Esse, H.P., Vossen, J.H., de Jonge, R., Stergiopoulos, I., Stulemeijer, I.J., van den Berg, G.C., Borras-Hidalgo, O., Dekker, H.L., de Koster, C.G., de Wit, P.J., Joosten, M.H., and Thomma, B.P. 2008. The novel Cladosporium fulvum lysin motif effector Ecp6 is a virulence factor with orthologues in other fungal species. Mol Microbiol 69:119-136.

Brondyk, W.H., Richard, R.B., and Murray, P.D. 2009. Selecting an appropriate method for expressing a recombinant protein. Pages 131-147 in: Methods Enzymol, Academic Press.

Cheng, C., Gao, X., Feng, B., Sheen, J., Shan, L., and He, P. 2013. Plant immune response to pathogens differs with changing temperatures. Nat Commun 4:2530.

Du, J., and Vleeshouwers, V.G.A.A. 2014. The Do's and Don'ts of Effectoromics. Pages 257-268 in: PlantPathogen Interactions.

Du, J., Rietman, H., and Vleeshouwers, V.G.A.A. 2014. Agroinfiltration and PVX agroinfection in potato and Nicotiana benthamiana. J Vis Exp:e50971.

Du, J., Verzaux, E., Chaparro-Garcia, A., Bijsterbosch, G., Keizer, L.C., Zhou, J., Liebrand, T.W., Xie, C., Govers, F., Robatzek, S., van der Vossen, E.A., Jacobsen, E., Visser, R.G., Kamoun, S., and Vleeshouwers, V.G.A.A. 2015. Elicitin recognition confers enhanced resistance to Phytophthora infestans in potato. Nat Plants 1:15034.

Haas, B.J., Kamoun, S., Zody, M.C., Jiang, R.H., Handsaker, R.E., Cano, L.M., Grabherr, M., Kodira, C.D., Raffaele, S., Torto-Alalibo, T., Bozkurt, T.O., Ah-Fong, A.M., Alvarado, L., Anderson, V.L., Armstrong, M.R., Avrova, A., Baxter, L., Beynon, J., Boevink, P.C., Bollmann, S.R., Bos, J.I., Bulone, V., Cai, G., Cakir, C., Carrington, J.C., Chawner, M., Conti, L., Costanzo, S., Ewan, R., Fahlgren, N., Fischbach, M.A., Fugelstad, J., Gilroy, E.M., Gnerre, S., Green, P.J., Grenville-Briggs, L.J., Griffith, J., Grunwald, N.J., Horn, K., Horner, N.R., Hu, C.H., Huitema, E., Jeong, D.H., Jones, A.M., Jones, J.D., Jones, R.W., Karlsson, E.K., Kunjeti, S.G., Lamour, K., Liu, Z., Ma, L., Maclean, D., Chibucos, M.C., McDonald, H., McWalters, J., Meijer, H.J., Morgan, W., Morris, P.F., Munro, C.A., O'Neill, K., Ospina-Giraldo, M., Pinzon, A., Pritchard, L., Ramsahoye, B., Ren, Q., Restrepo, S., Roy, S., Sadanandom, A., Savidor, A., Schornack, S., Schwartz, D.C., Schumann, U.D., Schwessinger, B., Seyer, L., Sharpe, T., Silvar, C., Song, J., Studholme, D.J., Sykes, S., Thines, M., van de Vondervoort, P.J., Phuntumart, V., Wawra, S., Weide, R., Win, J., Young, C., Zhou, S., Fry, W., Meyers, B.C., van West, P., Ristaino, J., Govers, F., Birch, P.R., Whisson, S.C., Judelson, H.S., and Nusbaum, C. 2009. Genome sequence and analysis of the Irish potato famine pathogen Phytophthora infestans. Nature 461:393-398.

Hardigan, M.A., Crisovan, E., Hamilton, J.P., Kim, J., Laimbeer, P., Leisner, C.P., Manrique-Carpintero, N.C., Newton, L., Pham, G.M., Vaillancourt, B., Yang, X., Zeng, Z., Douches, D.S., Jiang, J., Veilleux, R.E., and Buell, C.R. 2016. Genome reduction uncovers a large dispensable genome and adaptive role for copy number variation in asexually propagated Solanum tuberosum. Plant Cell 28:388405.

Jones, J.D., and Dangl, J.L. 2006. The plant immune system. Nature 444:323-329.

Jupe, F., Witek, K., Verweij, W., Sliwka, J., Pritchard, L., Etherington, G.J., Maclean, D., Cock, P.J., Leggett, R.M., Bryan, G.J., Cardle, L., Hein, I., and Jones, J.D. 2013. Resistance gene enrichment sequencing (RenSeq) enables reannotation of the NB-LRR gene family from sequenced plant genomes and rapid mapping of resistance loci in segregating populations. Plant J 76:530-544.

Kanneganti, T.-D., Huitema, E., and Kamoun, S. 2007. In planta expression of oomycete and fungal Genes. Pages 35-43 in: Plant-Pathogen Interactions: Methods and Protocols, P.C. Ronald, ed. Humana Press, Totowa, NJ.

Kapila, J., De Rycke, R., van Montagu, M., and Angenon, G. 1997. An Agrobacterium-mediated transient gene expression system for intact leaves. Plant Science 122:101-108.

Karimi, M., Inze, D., and Depicker, A. 2002. GATEWAY vectors for Agrobacterium-mediated plant transformation. Trends Plant Sci 7:193-195.

Katagiri, F., and Tsuda, K. 2010. Understanding the plant immune system. Mol Plant Microbe Interact 23:1531-1536. 
Koncz, C., and Schell, J. 1986. The promoter of TL-DNA gene 5 controls the tissue-specific expression of chimaeric genes carried by a novel type of Agrobacterium binary vector. Mol Gen Genet 204:383-396.

Lazo, G.R., Stein, P.A., and Ludwig, R.A. 1991. A DNA transformation-competent Arabidopsis genomic library in Agrobacterium. Biotechnology (N Y) 9:963-967.

Liu, Z., Zhang, Z., Faris, J.D., Oliver, R.P., Syme, R., McDonald, M.C., McDonald, B.A., Solomon, P.S., Lu, S., Shelver, W.L., Xu, S., and Friesen, T.L. 2012. The cysteine rich necrotrophic effector SnTox1 produced by Stagonospora nodorum triggers susceptibility of wheat lines harboring Snn 1. PLoS Pathog 8:e1002467.

Lu, R., Malcuit, I., Moffett, P., Ruiz, M.T., Peart, J., Wu, A.J., Rathjen, J.P., Bendahmane, A., Day, L., and Baulcombe, D.C. 2003. High throughput virus-induced gene silencing implicates heat shock protein 90 in plant disease resistance. EMBO J 22:5690-5699.

Ma, L.J., van der Does, H.C., Borkovich, K.A., Coleman, J.J., Daboussi, M.J., Di Pietro, A., Dufresne, M., Freitag, M., Grabherr, M., Henrissat, B., Houterman, P.M., Kang, S., Shim, W.B., Woloshuk, C., Xie, X., Xu, J.R., Antoniw, J., Baker, S.E., Bluhm, B.H., Breakspear, A., Brown, D.W., Butchko, R.A., Chapman, S., Coulson, R., Coutinho, P.M., Danchin, E.G., Diener, A., Gale, L.R., Gardiner, D.M., Goff, S., Hammond-Kosack, K.E., Hilburn, K., Hua-Van, A., Jonkers, W., Kazan, K., Kodira, C.D., Koehrsen, M., Kumar, L., Lee, Y.H., Li, L., Manners, J.M., Miranda-Saavedra, D., Mukherjee, M., Park, G., Park, J., Park, S.Y., Proctor, R.H., Regev, A., Ruiz-Roldan, M.C., Sain, D., Sakthikumar, S., Sykes, S., Schwartz, D.C., Turgeon, B.G., Wapinski, I., Yoder, O., Young, S., Zeng, Q., Zhou, S., Galagan, J., Cuomo, C.A., Kistler, H.C., and Rep, M. 2010. Comparative genomics reveals mobile pathogenicity chromosomes in Fusarium. Nature 464:367-373.

Manning, V.A., Hamilton, S.M., Karplus, P.A., and Ciuffetti, L.M. 2008. The Arg-Gly-Asp-containing, solvent-exposed loop of Ptr ToxA is required for internalization. Mol Plant Microbe Interact 21:315-325.

Milbourne, D., Meyer, R.C., Collins, A.J., Ramsay, L.D., Gebhardt, C., and Waugh, R. 1998. Isolation, characterisation and mapping of simple sequence repeat loci in potato. Mol Gen Genet 259:233245.

Mirzadi Gohari, A., Ware, S.B., Wittenberg, A.H., Mehrabi, R., Ben M'Barek, S., Verstappen, E.C., van der Lee, T.A., Robert, O., Schouten, H.J., de Wit, P.P., and Kema, G.H. 2015. Effector discovery in the fungal wheat pathogen Zymoseptoria tritici. Mol Plant Pathol 16:931-945.

Oliver, R.P., Friesen, T.L., Faris, J.D., and Solomon, P.S. 2012. Stagonospora nodorum: from pathology to genomics and host resistance. Annu Rev Phytopathol 50:23-43.

Petersen, T.N., Brunak, S., von Heijne, G., and Nielsen, H. 2011. SignalP 4.0: discriminating signal peptides from transmembrane regions. Nat Methods 8:785-786.

PGSC. 2011. Genome sequence and analysis of the tuber crop potato. Nature 475:189-195.

Saunders, D.G., Win, J., Cano, L.M., Szabo, L.J., Kamoun, S., and Raffaele, S. 2012. Using hierarchical clustering of secreted protein families to classify and rank candidate effectors of rust fungi. PLoS One 7:e29847.

Schmidt, S.M., Houterman, P.M., Schreiver, I., Ma, L., Amyotte, S., Chellappan, B., Boeren, S., Takken, F.L., and Rep, M. 2013. MITEs in the promoters of effector genes allow prediction of novel virulence genes in Fusarium oxysporum. BMC genomics 14:119.

Takken, F.L., Luderer, R., Gabriels, S.H., Westerink, N., Lu, R., de Wit, P.J., and Joosten, M.H. 2000. A functional cloning strategy, based on a binary PVX-expression vector, to isolate HR-inducing cDNAs of plant pathogens. Plant J 24:275-283.

Tan, K.-C., Oliver, R.P., Solomon, P.S., and Moffat, C.S. 2010. Proteinaceous necrotrophic effectors in fungal virulence. Funct Plant Biol 37:907.

Torto, T.A., Li, S., Styer, A., Huitema, E., Testa, A., Gow, N.A., van West, P., and Kamoun, S. 2003. EST mining and functional expression assays identify extracellular effector proteins from the plant pathogen Phytophthora. Genome Res 13:1675-1685.

van der Hoorn, R.A., Laurent, F., Roth, R., and De Wit, P.J. 2000. Agroinfiltration is a versatile tool that facilitates comparative analyses of Avr9/Cf-9-induced and Avr4/Cf-4-induced necrosis. Mol Plant Microbe Interact 13:439-446. 
Vleeshouwers, V.G.A.A., and Oliver, R.P. 2014. Effectors as tools in disease resistance breeding against biotrophic, hemibiotrophic, and necrotrophic plant pathogens. Mol Plant Microbe Interact 27:196-206.

Vleeshouwers, V.G.A.A., Driesprong, J.D., Kamphuis, L.G., Torto-Alalibo, T., van't Slot, K.A., Govers, F., Visser, R.G., Jacobsen, E., and Kamoun, S. 2006. Agroinfection-based high-throughput screening reveals specific recognition of INF elicitins in Solanum. Mol Plant Pathol 7:499-510.

Vleeshouwers, V.G.A.A., Raffaele, S., Vossen, J.H., Champouret, N., Oliva, R., Segretin, M.E., Rietman, H., Cano, L.M., Lokossou, A., Kessel, G., Pel, M.A., and Kamoun, S. 2011. Understanding and exploiting late blight resistance in the age of effectors. Annu Rev Phytopathol 49:507-531.

Vleeshouwers, V.G.A.A., Rietman, H., Krenek, P., Champouret, N., Young, C., Oh, S.K., Wang, M., Bouwmeester, K., Vosman, B., Visser, R.G., Jacobsen, E., Govers, F., Kamoun, S., and van der Vossen, E.A. 2008. Effector genomics accelerates discovery and functional profiling of potato disease resistance and Phytophthora infestans avirulence genes. PLoS One 3:e2875.

Whisson, S.C., Boevink, P.C., Moleleki, L., Avrova, A.O., Morales, J.G., Gilroy, E.M., Armstrong, M.R., Grouffaud, S., van West, P., Chapman, S., Hein, I., Toth, I.K., Pritchard, L., and Birch, P.R. 2007. A translocation signal for delivery of oomycete effector proteins into host plant cells. Nature 450:115-118. 


\section{Chapter 3}

\section{The ELR-SOBIR 1 complex functions as a two- component RLK to mount defense against Phytophthora infestans}

Emmanouil Domazakis

Doret Wouters

Richard G. F. Visser

Sophien Kamoun

Matthieu H. A. J. Joosten

Vivianne G. A. A. Vleeshouwers 
The ELICITIN RESPONSE (ELR) protein from Solanum microdontum can recognize INF1 elicitin of Phytophthora infestans and trigger defense responses. ELR is a receptor-like protein (RLP) that lacks a cytoplasmic signaling domain and is anticipated to require interaction with a signaling-competent receptor-like kinase (RLK). SUPPRESSOR OF BIR1-1 (SOBIR1) has been proposed as a general interactor for RLPs involved in immunity and as such, is a potential interactor for ELR. Here we investigate whether SOBIR1 is required for response to INF1 and resistance to $P$. infestans and whether it associates with ELR. Our results show that virus-induced gene silencing (VIGS) of SOBIR1 in Nicotiana benthamiana leads to loss of INF1-triggered cell death and increased susceptibility to $P$. infestans. Using genetic complementation, we found that the kinase activity of SOBIR1 is required for INF1-triggered cell death. Co-immunoprecipitation experiments showed that ELR constitutively associates with potato SOBIR1 in planta, forming a bipartite receptor complex. Upon INF1 elicitation, this ELR-SOBIR1 complex recruits SOMATIC EMBRYOGENESIS RECEPTOR KINASE 3 (SERK3) leading to downstream signaling activation. Overall, our study shows that SOBIR1 is required for basal resistance to $P$. infestans and for INF1-triggered cell death, and functions as an adaptor kinase for ELR.

Keywords: BAK1/SERK3, cell death, ELICITIN RESPONSE (ELR) receptor-like protein (RLP), INF1 effector, late blight, pattern recognition receptor (PRR), Phytophthora infestans, SUPPRESSOR OF BIR1-1 (SOBIR1). 


\section{Introduction}

Plants rely on cell surface, plasma membrane-spanning pattern-recognition receptors (PRRs) as a first line of apoplastic defense against microbial pathogens. PRRs recognize microbial molecules such as proteins that play a role in defense suppression (so-called effectors) or structural components, referred to as microbeassociated molecular patterns (MAMPs) (Couto and Zipfel, 2016). Two types of PRRs are recognized; those that have an intracellular kinase domain, which are receptor-like kinases (RLKs), and those without such a domain, the receptor-like proteins (RLPs). Leucine-rich repeat (LRR)-containing RLPs recognize MAMPs or effectors. However, as they lack an obvious cytoplasmic signaling domain, they are anticipated to require partner proteins for initiating defense signaling. The extent to which RLP and RLKs associate to enable immune signaling remains poorly understood.

RLPs from diverse plant families (i.e. Brassicaceae and Solanaceae), involved in immunity have been found to constitutively associate with the LRR-RLK SOBIR1 (SUPPRESSOR OF BIR1-1), forming a heterodimeric complex (Gust and Felix, 2014; Liebrand et al., 2014; Bi et al., 2016). Some examples are Ve1, Cf-2, Cf-4, Cf-9, RLP23, RLP30 and RESPONSIVENESS TO BOTRYTIS POLYGALACTURONASES1 (RBPG1, RLP42), which are all RLPs involved in pathogen perception in tomato (Solanum lycopersicum, Sl) or Arabidopsis thaliana (At) (Liebrand et al., 2013; Zhang et al., 2013; Bi et al., 2014; Zhang et al., 2014; Albert et al., 2015). SOBIR1 has been suggested to be a positive regulator of plant defense, and overexpression of AtSOBIR1 in Arabidopsis resulted in a constitutive defense phenotype (Gao et al., 2009).

Both in tomato and potato (Solanum tuberosum, St), two alleles of SOBIR1 are present, named SOBIR1 and SOBIR1-like, with putatively redundant functions (Liebrand et al., 2013; Liebrand et al., 2014). In several plant species, SOBIR1 transcripts have been found to increase upon pathogen challenge or treatments with salicylic acid or pathogen elicitors (Liebrand et al., 2014; Peng et al., 2015). Moreover, SISOBIR1 and SISOBIR1-like, and AtSOBIR1 were found to be required for resistance against several pathogens, including fungi and the oomycetes Hyaloperonospora arabidopsidis and Phytophthora parasitica (Liebrand et al., 2014; Zhang et al., 2014; Peng et al., 2015). It has been proposed that RLP-SOBIR1 complexes are functional equivalents of genuine RLKs in the sense that SOBIR1 provides the kinase domain that is lacking from the RLP (Gust and Felix, 2014; Liebrand et al., 2014; Bi et al., 2016).

Late blight, caused by the oomycete Phytophthora infestans, is the most threatening disease of potato. So far, breeding for late blight resistance has been focused on the introduction of cytoplasmic resistance $(R)$ genes of the nucleotide- 
binding leucine-rich repeat (NLR) class. However, the fast evolving RXLR effector repertoire of $P$. infestans has been shown to promptly defeat any introduced $R$ gene (Vleeshouwers et al., 2011), and resistance mechanisms based on the recognition of more conserved effectors might provide a more durable alternative (Du et al., 2015). Elicitins form a major class of conserved oomycete effectors, having MAMP features, in Phytophthora and Pythium species (Derevnina et al., 2016). Recently, the RLP ELICITIN RESPONSE (ELR) was identified in the wild potato species Solanum microdontum (Sm). ELR specifically recognizes elicitins of Phytophthora spp., and was shown to quantitatively enhance resistance against $P$. infestans in cultivated potato (Du et al., 2015). ELR localizes at the plasma membrane, similar to other RLPs involved in development and immunity (Du et al., 2015). Unlike other MAMPtriggered responses, recognition of elicitins results in a swift cell death response in Solanum and Nicotiana species (Chaparro-Garcia et al., 2011; Du et al., 2015).

Independent of whether the PRR is an LRR-RLP or LRR-RLK, it has been shown that upon elicitor perception there is recruitment of members of the SERK family of LRRRLKs by the activated PRR (Chinchilla et al., 2007; Albert et al., 2015; Postma et al., 2016). The most well-studied member of this family is BAK1 (BRI1-ASSOCIATED KINASE 1), also known as SERK3 (SOMATIC EMPBRYOGENESIS RECEPTOR KINASE 3). Similar to SOBIR1, two SERK3 alleles are recognized in Solanum; SERK3a and SERK3b, with presumably overlapping functions as well (Peng and Kaloshian, 2014). Nicotiana benthamiana (Nb) SERK3 was identified as a component required for INF1-induced cell death (Chaparro-Garcia et al., 2011). In line with this, ELR was found to associate with SERK3/BAK1, and this association was found to be stabilized upon INF1 elicitation (Du et al., 2015). However, whether other co-regulatory RLKs mediate response to INF1 is unknown.

In this study, we employed VIGS and genetic complementation to test whether SOBIR1 is required for resistance to $P$. infestans and INF1-induced cell death. We found that SOBIR1 is required for resistance of $N$. benthamiana to various $P$. infestans isolates and is indispensable for INF1-triggered cell death. By coimmunoprecipitation assays we found that SOBIR1 constitutively associates with ELR in planta, in contrast to the enhanced interaction with SERK3. Furthermore, we demonstrate that the kinase domain of SOBIR1 is required for cell death induction by INF1, while it is not required for interaction with ELR. Overall we provide 
evidence that ELR functions in a tri-partite complex with SOBIR1 and SERK3 in order to trigger downstream signaling upon elicitin perception. Additionally, we show that SOBIR1 supports ELR function, which, along with potential other RLPS also requiring SOBIR1 for their function, mediates resistance to $P$. infestans.

\section{Results}

\section{SOBIR 1 contributes to defense against Phytophthora infestans}

Since SOBIR1 is required for the function of several RLPs and for basal resistance against pathogens, including P. parasitica (Peng et al., 2015), we hypothesized that SOBIR1 could be involved in plant defense against $P$. infestans. To test this, we employed a tobacco rattle virus (TRV)-mediated virus-induced gene silencing (VIGS) approach. N. benthamiana plants were agro-inoculated with $A$. tumefaciens carrying the TRV-NbSOBIR1/-like construct that has previously been shown to knock-down the expression of NbSOBIR1 and NbSOBIR1-like (Liebrand et al., 2013). TRV-GUS (serving as a negative control) and TRV-PDS (targeting phytoene desaturase to monitor the onset of silencing), were included in the experiment (Kumagai et al., 1995; Liu et al., 2002).

Quantitative RT-PCRs confirmed that NbSOBIR1 expression was significantly reduced in the TRV-NbSOBIR1/-like-inoculated plants at three weeks post inoculation, while NbSOBIR1-like was found, as expected, to be merely expressed (Fig. S1) (Liebrand et al., 2013). Leaves were taken from the silenced plants and spot-inoculated with the fluorescent $P$. infestans isolate 88069td (expressing tdTomato red fluorescent protein). Lesion growth was visually examined five days after inoculation and we observed consistently larger lesions on the TRVNbSOBIR1/-like-inoculated leaves as compared to plants inoculated with TRVGUS (Figs. 1a, S2). Molecular quantification of $P$. infestans biomass on inoculated $N$. benthamiana leaves, by measuring the abundance of Piß-tubulin and NbEF1a as an internal standard, confirmed that a much higher pathogen biomass was detected in TRV-NbSOBIR1/-like-inoculated leaves (Fig. 1b). Inoculation with two isolates currently causing late blight epidemics in the UK and the Netherlands, UK3928A and Katshaar, respectively, resulted in a similar finding (Figs. 1b, S2). This result indicates that the observed increase in plant susceptibility upon NbSOBIR1/like silencing is not isolate-specific. Furthermore, these data show that SOBIR1 and SOBIR1-like clearly contribute to resistance against $P$. infestans. 
(a)

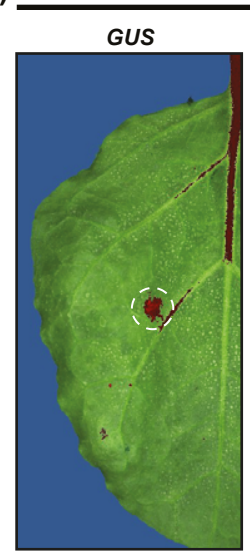

TRV-

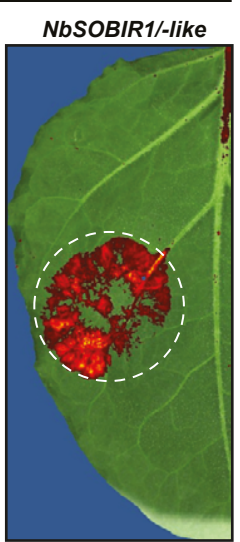

(b)

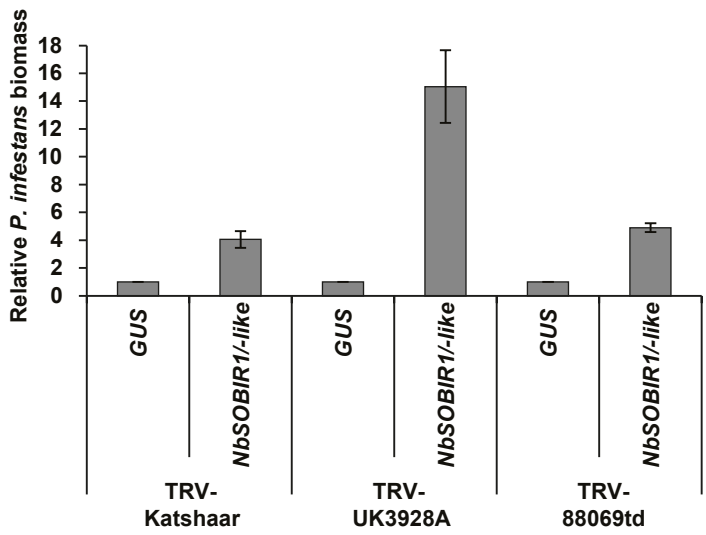

FIGURE 1 | SOBIR1 is required for defense responses against Phytophthora infestans. Four weekold Nicotiana benthamiana plants, inoculated with recombinant TRV carrying either an NbSOBIR1/-like or GUS insert, were inoculated with zoospores obtained from the three $P$. infestans isolates Katshaar, UK3928A, or 88069td. (a) Fluorescent/visible overlay image of mycelial growth of isolate 88069td expressing tdTomato red fluorescent protein on TRV-inoculated $N$. benthamiana at 5 dpi. (b) Relative biomass quantification of $P$. infestans isolates on TRV-inoculated $N$. benthamiana leaves at 5 dpi. Quantification was performed by RT-qPCR and by comparing the amplification of $P$. infestans $\beta$-tubulin to $N$. benthamiana EF1a that was used as an internal standard. Error bars indicate the standard deviation of two technical replicates of one representative experiment. The experiment was repeated three times and gave similar results.

\section{SOBIR 1 is involved in INF 1 -induced cell death in $\mathbf{N}$. benthamiana}

INF1 and other elicitins are known to cause a NbSERK3-dependent cell death in N. benthamiana (Kamoun et al., 1997; Chaparro-Garcia et al., 2011). To investigate whether elicitin-triggered defense signaling in $N$. benthamiana also requires NbSOBIR1, we conducted a VIGS experiment. For this, N. benthamiana plants were agro-inoculated with TRV-NbSOBIR1/-like. Agro-inoculation with TRV-NbSERK3a/b and TRV-GUS were included as positive and negative controls, respectively, while TRV-PDS was included as a visual control for the onset of silencing. At three weeks after the inoculation with TRV, plants were agro-infiltrated to express INF1 or empty vector (EV). After four days, the expected INF1-induced cell-death was evident in the TRV-GUS-inoculated plants, but significantly decreased cell death was detected in leaves of TRV-NbSOBIR1/-like- and TRV-NbSERK3a/b-inoculated $N$. benthamiana plants (Fig. 2a, b). Similar loss of INF1-triggered cell death was observed when the same GUS- and NbSOBIR1/-like-silenced leaves were infiltrated with $1 \mu \mathrm{M}$ of purified INF1 protein (Fig. S3a, b). These data show that NbSOBIR1 is required for the INF1-mediated cell death response in $N$. benthamiana. 
(a)

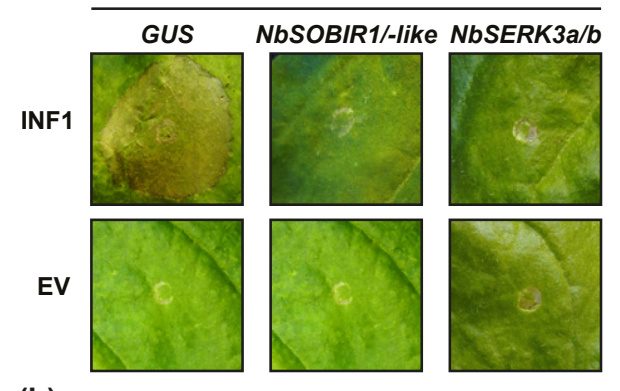

(b)

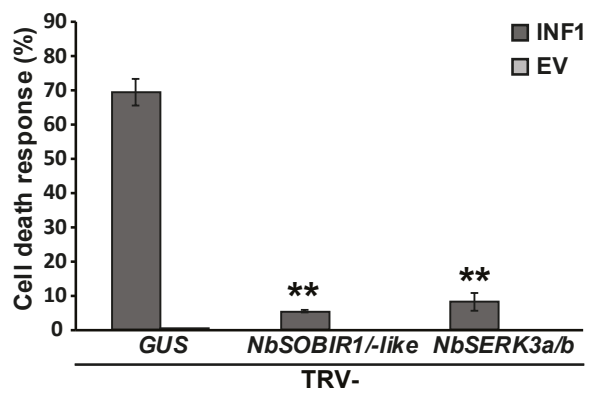

FIGURE 2 | SOBIR1 is required for the cell death response triggered by INF1 elicitin in Nicotiana benthamiana. Four week-old $N$. benthamiana plants, inoculated with TRVNbSOBIR1/-like, TRV-GUS (negative control) or TRV-NbSERK3a/b (positive control), were agro-infiltrated with INF1 or empty vector (EV) at the onset of PDS silencing (not shown). (a) Representative pictures of treated leaves at 4 dpi. (b) Cell death quantification of treated leaves at 4 dpi. Error bars indicate the standard error of three biological repeats $(n=64)$. Asterisks indicate significance at $p<0.01$ (Student's t-test).

\section{Synthetic SOBIR 1 from S. microdontum can complement SOBIR 1 from $\mathbf{N}$. benthamiana}

SOBIR1 is highly conserved in plants, but some degree of diversity occurs (Liebrand et al., 2014). We used PCR-based cloning to identify the homologs of SOBIR1 in S. microdontum, which is the source of ELR. We found that SmSOBIR1 and SmSOBIR1-like homologs share $97.9 \%$ and $99 \%$ amino acid similarity to StStSOBIR1 (Sotub06g029250.1.1) and StSOBIR1-like (Sotub03g023250.1.1), respectively (Fig. S4). To test whether SmSOBIR1 can complement for INF1-induced cell death in NbSOBIR1-/like silenced N. benthamiana plants, we generated a synthetic version that encodes the original (WT) SmSOBIR1 protein sequence from S. microdontum $\left(\right.$ SmSOBIR1syn $\left.{ }^{W T}\right)$, but which is not targeted by the TRV-NbSOBIR1/-like VIGS construct used in VIGS experiments with N. benthamiana (Liebrand et al., 2013) (Figs S5a, S6). To verify that the synthetic gene drives expression of the expected protein, we performed a western blot that confirmed the presence of Myc-tagged SmSOBIR1syn ${ }^{W T}$ in plants silenced for NbSOBIR1/-like (Fig. S5b). Subsequently, we performed a cell-death complementation experiment. For this, we silenced $N$. benthamiana plants by agro-inoculation with TRV-NbSOBIR1/-like and took along TRV-GUS as a negative control, and subsequently transiently co-expressed SmSOBIR1 (control) or the SmSOBIR1syn'WT with INF1. We found that INF1triggered cell death was not affected in the TRV-GUS-inoculated plants, while in 
the TRV-NbSOBIR1/-like-inoculated plants INF1-triggered cell death was severely compromised. Interestingly, SmSOBIR1syn ${ }^{\text {WT }}$ co-expression with INF1 restored the cell death response (Fig. 3). This observation indicates that SmSOBIR1syn ${ }^{\text {WT }}$ complements for the loss of NbSOBIR1/-like in NbSOBIR1/-like-silenced plants.

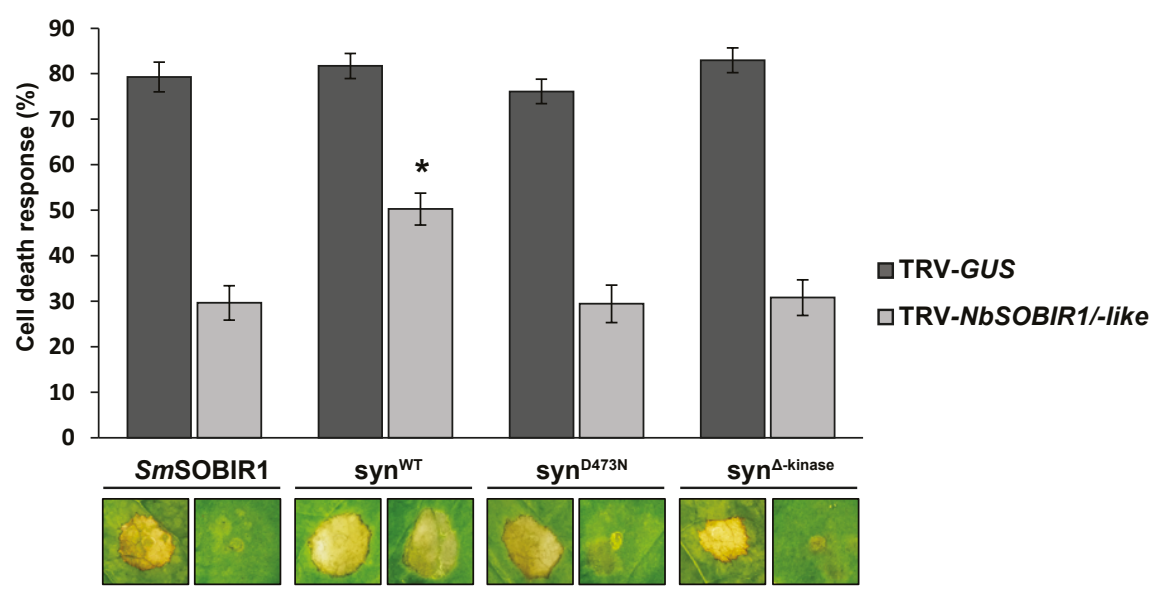

FIGURE 3 | Synthetic versions of SmSOBIR1 complement the loss of INF1-triggered cell death in TRV-NbSOBIR1/-like-inoculated Nicotiana benthamiana. SmSOBIR1 wild type (WT) (control), SmSOBIR1synwT, SmSOBIR1syn ${ }^{\text {D473N }}$ or SmSOBIR1syn ${ }^{\Delta-k i n a s e}$, were transiently co-expressed in TRVGUS or TRV-NbSOBIR1/-like-inoculated plants, together with INF1. Cell death was scored at $5 \mathrm{dpi}$ and representative pictures are shown. Results are an average of three independent biological repeats. The asterisk indicates significance at $p<0.05$ (One-way ANOVA, LSD test).

\section{SOBIR 1 requires a functional kinase domain for mediating INF1-induced cell death}

Next, we investigated whether kinase activity of SOBIR1 is required for cell death induction by INF1. We cloned different versions of SmSOBIR1syn, in which the core catalytic aspartate (D) of the conserved RD kinase motif is substituted by an

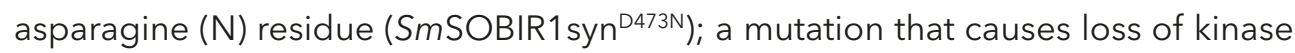
activity for all tested so-called "RD" RLKs tested so far (Schwessinger et al., 2011; Liebrand et al., 2013). In addition, we generated a SmSOBIR1syn mutant that completely lacks the kinase domain (with a deletion of amino acids 333 to 625;

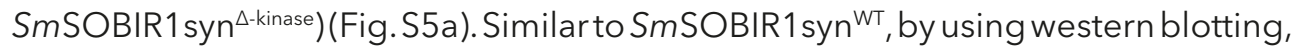
we confirmed that the synthetic SmSOBIR1 mutant versions drive production of the expected protein variants in plants silenced for NbSOBIR1/-like (Fig. S5b). Next, we again proceeded to a cell-death complementation experiment by coexpressing the kinase-inactive SmSOBIR1syn mutants with INF1 in NbSOBIR1/like-silenced N. benthamiana plants. We found that, unlike SmSOBIR1syn'WT, both SmSOBIR1 syn ${ }^{\mathrm{D} 473 \mathrm{~N}}$ and SmSOBIR1 syn ${ }^{\triangle-k i n a s e}$ failed to restore the INF1-triggered cell 
death response, indicating that the kinase activity of SOBIR1 is required for INF1 triggered cell death (Fig. 3).

\section{ELR associates with the co-regulatory RLK SOBIR 1}

In order to investigate whether ELR associates with SmSOBIR1/-like from S. microdontum, we performed co-immunoprecipitation experiments. We generated constructs for transiently expressing C-terminally Myc epitope-tagged SmSOBIR1 and SmSOBIR1-like and co-expressed them with ELR-eGFP in N. benthamiana. The RLP Cf-4 was included as a positive control, and the RLK FLS2 and eGFP alone were used as negative controls (Liebrand et al., 2013). As shown in Fig. 4, immunopurification of ELR-eGFP, Cf-4-eGFP and FLS-2-GFP by using GFP affinity beads and subsequent detection of co-purifying SmSOBIR1-myc and SmSOBIR1like-myc, indicates that, like Cf-4, ELR associates in planta with SmSOBIR1 and SmSOBIR1-like, whereas no interaction of the two SOBIR1 homologs with FLS2 and eGFP was observed.

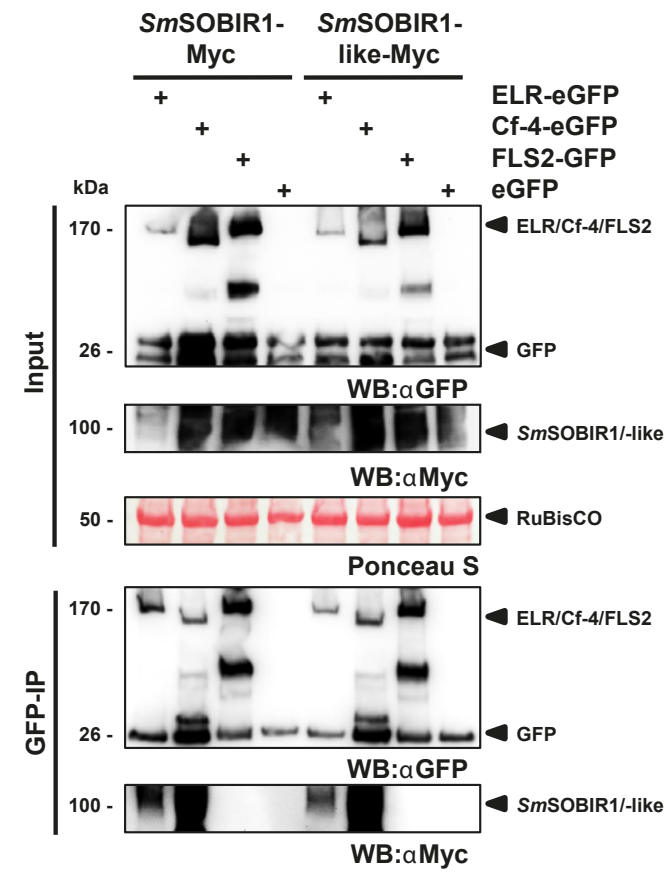

FIGURE 4 | ELR forms a complex with SmSOBIR1 and SmSOBIR1-like. SmSOBIR1-myc and SmSOBIR1-like-myc were transiently co-expressed in Nicotiana benthamiana leaves, together with ELReGFP, Cf-4-eGFP (positive control), FLS2GFP or eGFP (negative controls), as indicated. Total protein was extracted and was subjected to immunoprecipitation using GFP_TrapMA beads to capture ELR, Cf-4 and FLS2. The immunopurified proteins were detected with anti-GFP, while the interaction with SmSOBIR1Myc or SmSOBIR1-like-Myc was assessed with anti-Myc. Ponceau $S$ staining of $\mathrm{RuBis} C \mathrm{C}$ indicates equal protein loading. This figure is representative for three biological repeats. 


\section{The SmSOBIR 1 kinase domain is not required for interaction with ELR}

To test whether the kinase domain of SOBIR1 is required for interaction with ELR, we co-expressed ELR with either an empty vector, SmSOBIR1syn ${ }^{W T}$ or the SmSOBIR1 syn versions either lacking kinase activity or lacking the kinase domain (SmSOBIR1 syn ${ }^{\mathrm{D} 473 \mathrm{~N}}$ and SmSOBIR1syn ${ }^{\Delta-k i n a s e}$, respectively), in $\mathrm{N}$. benthamiana. Our results show that SOBIR1 kinase activity and the kinase domain itself are not required for its interaction with ELR, similar to what has been shown for the interaction between Cf- 4 and SOBIR1, as in all cases the interaction with ELR remains intact (Fig. S7a) (Bi et al., 2016).

In addition to this, we noted an ELR-stabilizing effect when SOBIR1 is co-expressed with this RLP. To confirm this observation, we performed a similar experiment as above. For this, ELR and the different SmSOBIR1 variants were transiently co-expressed in $\mathrm{N}$. benthamiana, total protein was extracted at two days after agro-infiltration, and ELR accumulation was determined by western blotting and signal intensity quantification. In three independent experiments, we found that co-expression of the SmSOBIR1 variants, all accumulating at similar levels and interacting with ELR (Figs. S5b, S7a), led to an increase in the amounts of ELR accumulating, as compared to co-expression with the empty vector (Fig. S8). SmSOBIR1 co-expression with ELR was found to result in an up to 13-fold increase in ELR accumulation. Moreover, both the kinase-active and kinase-inactive versions of SOBIR1, in addition to SmSOBIR1syn completely lacking the kinase domain, have a stabilizing effect on ELR, though a bit lower as compared to SmSOBIR1syn. This indicates that the stabilization effect is likely not directly related to kinase activity of SOBIR1, but is rather based on ELR interaction with SOBIR1.

Summarizing, these results show that the interaction between ELR and SOBIR1 is stabilizing the complex. Moreover, ELR association with SOBIR1 likely requires the extracellular-juxtamembrane, transmembrane and intracellular-juxtamembrane domains of ELR, as proposed for other RLPs (Fig. S8b) (Gust and Felix, 2014; Bi et al., 2016).

\section{ELR functions in a tri-partite complex with SOBIR 1 and SERK3}

It was previously shown that ELR associates with SERK3 and that this association is specifically enhanced by INF1 elicitation. In order to investigate whether the observed constitutive interaction of ELR with SOBIR1 is affected by INF1, we co-expressed ELR with SOBIR1 and SERK3 in N. benthamiana. Two days after agroinfiltration, we infiltrated purified INF1 protein or the buffer in which INF1 was dissolved, and checked whether ELR interacted with SOBIR1 and SERK3 through co-immunoprecipitation and western blotting (Fig. 5). We found that, 
upon 15 min elicitation with $1 \mu \mathrm{M}$ INF1 protein (see Fig. S3b), ELR interaction with SERK3 is enhanced, as expected (Fig. 5) (Du et al., 2015). On the other hand, ELR interaction with SOBIR1 was not affected by INF1 elicitation, indicating that the interaction is constitutive and remains intact. These data show that ELR is present as a constitutive two-component RLK with SOBIR1, and forms a tri-partite ELRSOBIR1-SERK3 complex upon INF1 perception.

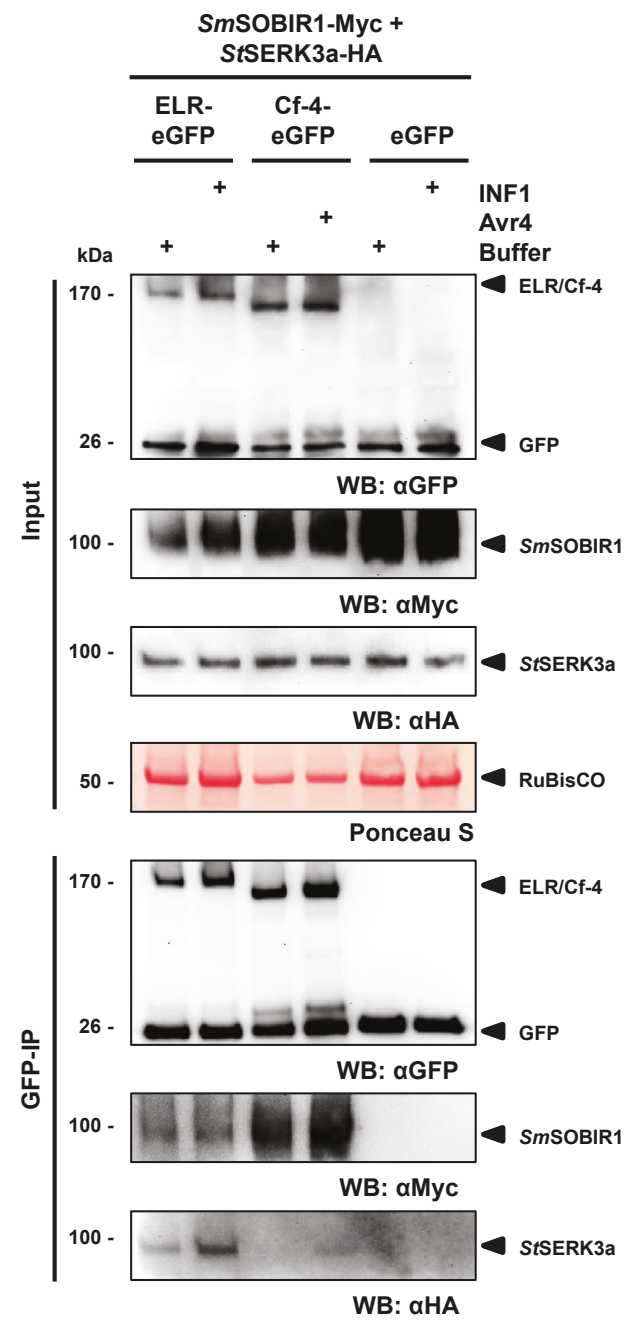

FIGURE 5 | ELR forms a constitutive complex with SOBIR1, while it interacts with SERK3a in an INF1-inducible manner. SmSOBIR1-myc and StSERK3aHA were transiently co-expressed in Nicotiana benthamiana leaves, together with ELR-eGFP, Cf-4-eGFP or eGFP, as indicated. Elicitation was performed at three days post infiltration with $1 \mu \mathrm{M}$ purified INF1 protein (for ELR and eGFP) or $1 \mu \mathrm{M}$ purified Avr4 (for Cf-4). Total protein was extracted and was subjected to immunoprecipitation using GFP TrapMA beads to capture ELR, Cf-4 and eGFP respectively. The immunopurified proteins were detected with anti-GFP, while the interaction with SmSOBIR1Myc or StSERK3a-HA, was assessed with anti-Myc or anti-HA, respectively. Ponceau $\mathrm{S}$ staining of $\mathrm{RuBis} \mathrm{CO}$ indicates equal protein loading. This figure is representative for three biological repeats. 


\section{Discussion}

In this study we show that basal resistance of $N$. benthamiana to $P$. infestans requires NbSOBIR1. This is evident since $N$. benthamiana plants silenced for NbSOBIR1 showed larger lesions and increased $P$. infestans biomass, for a range of different isolates. Our results are in line with the recent finding that resistance against $P$. parasitica of tomato requires SOBIR1 (Peng et al., 2015). Overall, our data support the importance of SOBIR1 in basal defense against pathogens, likely by supporting ELR function and potentially that of other LRR-RLPs as well (Liebrand et al., 2014).

ELR carries a short cytoplasmic tail without any obvious signaling domain and as such, it was hypothesized that additional partner proteins are mediating signal transduction. Indeed, SERK3/BAK1, a common interactor of LRR-containing PRRs, has been found to associate with ELR (Du et al., 2015). Recently, the LRR-RLK SOBIR1 has been shown to constitutively associate with a multitude of RLPs (Gust and Felix, 2014; Liebrand et al., 2014; Zhang et al., 2014; Albert et al., 2015; Bi et al., 2016). In this study we provide evidence that SOBIR1 is also required as a co-regulatory RLK for the response to the elicitin INF1. By gene silencing we have demonstrated that the cell death response to INF1 in N. benthamiana requires SOBIR1, similar to what has been described for ParA1 (Peng et al., 2015). In addition, by employing genetic complementation assays using synthetic SmSOBIR1, we found that the INF1-triggered cell death response requires an active SmSOBIR1 kinase domain. This indicates that the SOBIR1 kinase domain actively takes part in downstream defense signaling initiated by INF1, which is in line with previous studies on ParA1, and Avr4 in Cf-4-expressing plants (Liebrand et al., 2013; Peng et al., 2015). However, the PRRs responsible for elicitin-triggered responses in tomato cv. Summer Sweet and N. benthamiana have not been cloned. Tomato is known to have a close ELR homolog, however, no obvious homologs are found in $N$. benthamiana. Therefore, it remains unknown whether those responses are due to the presence of a putative functional ELR orthologue (Peng et al., 2015).

Biochemical evidence from this work supports the observation that the INF1 receptor physically associates with SOBIR1. Using co-immunoprecipitation, we found that ELR associates in planta with both SmSOBIR1 and its close homolog SmSOBIR1-like and a stabilized complex is formed. This association is constitutive, since it does not require INF1 and remains unaltered upon INF1 elicitation. ELR thus behaves similar to other RLPs involved in immunity, such as Ve1, Cf-2, Cf-4, Cf9, RLP23, RLP30 and RLP42 (Liebrand et al., 2013; Zhang et al., 2013; Bi et al., 2014; Zhang et al., 2014; Albert et al., 2015). Moreover, we have consistently observed a stabilization effect of ELR when SOBIR1 was co-expressed. Although a different setup was used, this finding is complementary to the observation of reduced Cf-4 
and Ve1 protein levels when SOBIR1 was silenced (Liebrand et al., 2013). For Cf-4 it was concluded that SOBIR1 potentially acts as a scaffold protein (Bi et al., 2016), in addition to being required for downstream signaling (Liebrand et al., 2013). For both ELR and Cf-4, kinase activity of SOBIR1 is not required for stabilization, which is in agreement with the hypothesis that the GxxxG dimerization motif present in the trans-membrane domains, in addition to the juxta membrane domains of ELR and SOBIR1, are involved in their interaction as was proposed for many RLP-type LRR receptors (Gust and Felix, 2014; Bi et al., 2016).

ELR has been shown to localize at the plasma membrane (Du et al., 2015). Therefore, it can be assumed that interaction with SOBIR1/SERK3 is also occurring at this location, similar to what was observed for Cf-4 (Postma et al., 2016). C. fulvum Avr4-induced endocytosis of SOBIR1 in Cf-4-expressing plants has been recently shown in N. benthamiana (Postma et al., 2016). Therefore, it is likely that INF1 elicitation also causes endocytosis of the ELR-SOBIR1 complex. In agreement with this hypothesis, the elicitins cryptogein (from P. cryptogea) and ParA1 (from P. parasitica), have been shown to induce clathrin-mediated endocytosis of SOBIR1 (Leborgne-Castel et al., 2008; Peng et al., 2015). Future studies should address whether this endocytosis is SERK3-dependent as well (Postma et al., 2016).

Studies on elicitin recognition in $N$. benthamiana have revealed the E3 ligase CYS, MET, PRO, AND GLY PROTEIN 1 (CMPG1) to be an important component for the cell death response triggered by INF1 (Bos et al., 2010). CMPG1 acts as a hub for signaling downstream of both MAMP and effector perception, as it is required for the Cf-, Pto- and CELLULOSE-BINDING ELICITOR LECTIN (CBEL)-mediated cell death response as well (Gilroy et al., 2011). Despite the lack of molecular evidence showing interaction of CMPG1 with PRRs, we anticipate that the E3 ligase activity of CMPG1 modulates the first steps downstream of effector perception, possibly through promoting ubiquitination (Gilroy et al., 2011). SOBIR1 seems to be heavily modified as it migrates as a smear on SDS gels as revealed by western blots (i.e. as shown in SOBIR1 bands in Figs. 4, 5), however the type of modifications and their biological relevance have not been reported yet. $P$. infestans is known to secrete AVR3a, an RXLR effector which suppresses INF1-triggered cell death. AVR3a is suppressing MAMP-triggered responses in at least two ways; either by binding to CMPG1 or by blocking receptor endocytosis via association with DYNAMINRELATED PROTEIN 2 (DRP2), a protein involved in cellular trafficking (Bos et al., 2010; Chaparro-Garcia et al., 2015). With the discovery that ELR functions in a complex with SERK3 and SOBIR1, it is now appropriate to test whether CMPG1 is involved in trafficking of activated ELR-SOBIR1 and whether AVR3a is interfering in this process. 
Recently, the cloning of ELR gave insight into the molecular mechanisms involved in apoplastic elicitin perception (Du et al., 2015; Derevnina et al., 2016). Understanding how RLPs such as ELR function is a major step towards their deployment as resistance genes in plant breeding. With our work we show that elicitin recognition and basal defense in Solanaceae requires SOBIR1 which supports ELR function and immunity to $P$. infestans. ELR functions thus similar to Cf-4- and Cf-9- mediated recognition of Avr4 and Avr9, respectively, and the downstream responses also appear to be similar (Liebrand et al., 2013; Postma et al., 2016). We propose that, the ELR-SOBIR1 complex functions as a two component RLK that recruits SERK3 in an INF1-dependent manner. This tripartite complex formation is reminiscent of the well-characterized RLKs FLS2 and EFR which, upon elicitation with their respective ligands flg22 and elf18, are associating with SERK3/BAK1 (Zipfel et al., 2006; Chinchilla et al., 2007; Boller and Felix, 2009). Since PRRs contribute to quantitative resistance and thus offer a lower selection pressure, stacking of ELR with other PRRs such as RLP23 could lead to a more durable resistance against the devastating pathogen $P$. infestans (Albert et al., 2015; Du et al., 2015).

\section{Materials and methods}

\section{Plant material and growth conditions}

Nicotiana benthamiana plants were grown from seeds and maintained in climate controlled greenhouse compartments at $22 / 18{ }^{\circ} \mathrm{C}$ and $16 / 8 \mathrm{~h}$ light day/night regime at $70 \%$ relative humidity. All protein expression and cell death assays were performed under these conditions.

\section{Production and purification of INF 1}

INF1 was produced from a stationary culture of $P$. infestans strain IPO-C, as previously described (Chaparro-Garcia et al., 2011), with some minor modifications. Briefly, $P$. infestans was grown for 4-5 weeks in liquid Plich medium. The mycelium was removed by passing through filter paper and the culture medium was snap-frozen and freeze-dried. The resulting powder was dissolved in $100 \mathrm{ml}$ of $10 \mathrm{mM}$ Tris- $\mathrm{HCl}$, $10 \mathrm{mM} \mathrm{NaCl}$ ( $\mathrm{pH}$ 7.4) buffer. The solution was then dialyzed overnight (3.5 kDa cut off, Spectrum RC dialysis tubing), against the same buffer, at $4^{\circ} \mathrm{C}$. The resulting INF1-containing solution was loaded onto a $10 \mathrm{mM}$ Tris- $\mathrm{HCl}(\mathrm{pH}$ 7.4)-equilibrated Q Sepharose Fast-Flow column (GE Healthcare). Column was washed with three column volumes with the same equilibration buffer. Next, the column was eluted with a linear gradient of $0-500 \mathrm{mM} \mathrm{NaCl}$ in $10 \mathrm{mM}$ Tris- $\mathrm{HCl}(\mathrm{pH} \mathrm{7.4)}$ and fractions 
of $10 \mathrm{ml}$ were collected. The presence of INF1 in the different fractions was assayed by SDS-PAGE, followed by CBB or silver staining. Protein concentration was estimated by BCA assay (Thermo-Fisher Scientific). Purified INF1 was infiltrated in $N$. benthamiana leaves to confirm cell-death inducing activity. Avr4 protein from Cladosporium fulvum has been produced previously in Pichia pastoris (van den Burg et al., 2001).

\section{Binary vectors for Agrobacterium tumefaciens-mediated transient transformation}

Construction of pBin-KS-p35s::ELR-eGFP, pBin-KS-p35s::Cf-4-eGFP, pCAMBIA2300-pAtFLS2::SIFLS2-GFP and pTRV1 has been described (Liu et al., 2002; Liebrand et al., 2012; Liebrand et al., 2013; Du et al., 2015). For cloning of novel constructs, target gene sequences were amplified from cDNA using Phusion proofreading polymerase (Thermo Fisher Scientific), employing primers mentioned in Supplementary Table 1(Table S1). The SmSOBIR1 and SmSOBIR1-like genes, as well as a PDS VIGS fragment (targeting phytoene desaturase and used as a control for gene silencing) were amplified from $S$. microdontum genotype 360-1 (source of ELR) cDNA.

A synthetic (syn) construct of SmSOBIR1 carrying a D473N mutation (SmSOBIR1syn ${ }^{\mathrm{D} 43 \mathrm{~N}}$ ) and synonymous nucleotide changes to enable expression in TRV-NbSOBIR1/-like VIGSed N. benthamiana was synthesized (Genscript) (Figs. S4a, S5). Using overlap extension PCR, the wild type version (SmSOBIR1 syn ${ }^{W T}$ ) was reconstituted as described in Liebrand et al. (2013) (see Table S2, Fig. S4). A version of SmSOBIR1syn (nucleotides 1 - 996) lacking the kinase domain (SmSOBIR1 syn ${ }^{\Delta-}$ kinase) was amplified using SmSOBIR1 syn ${ }^{\mathrm{D} 473 \mathrm{~N}}$ as a template.

A GUS VIGS fragment was amplified from the commercial vector pENTR-GUS (Invitrogen). SmSOBIR1, SmSOBIR1-like, SmSOBIR1syn as well as the VIGS fragments for GUS and SmPDS were cloned in pENTR/D-TOPO vector (Invitrogen). The inserts of all entry clones were checked by sequencing and transferred to destination vectors by means of an LR reaction using LR-Clonase II enzyme mix (Invitrogen), resulting in the following constructs: pGWB20-p35s::SmSOBIR1myc, pGWB20-p35s::SmSOBIR1-like-myc, pGWB20-p35s::SmSOBIR1syn ${ }^{w T}-m y c$, pGWB20-p35s::SmSOBIR1syn ${ }^{\text {473N-myc, pGWB20-p35s::SmSOBIR1syn }{ }^{\Delta-k i n a s e}-m y c}$ (-myc refers to C-terminal 10x Myc), pTRV2-GUS and pTRV2-PDS (Table S2). 


\section{Co-immunopurification and immunoblotting}

The proteins under study were transiently expressed in young, fully-expanded leaves of 3 week-old N. benthamiana plants using Agrobacterium-mediated transient transformation (agro-infiltration). At $2 \mathrm{~d}$ post agro-infiltration, leaves were collected, snap-frozen in liquid nitrogen and ground to a fine powder. Protein extraction was performed in modified RIPA buffer, containing IGEPAL CA-630 as a sole detergent and supplemented with EDTA-free protease inhibitor cocktail (Roche), as described previously (Liebrand et al., 2012; Liebrand et al., 2013). Briefly, modified RIPA buffer was added at a ratio of $2 \mathrm{ml} / \mathrm{g}$ of frozen ground plant material and mixed. The mixture was incubated at room temperature with occasional mixing, until all frozen material was thawed. Then, $2 \mathrm{ml}$ of protein extract was centrifuged for $30 \mathrm{~min}$ at $13000 \times \mathrm{g}$ to pellet plant debris. Clarified extracts, from which input samples were collected, were incubated with $15 \mu$ l RIPA-equilibrated GFP-Trap_MA beads (50 \% slurry, Chromotek) for $1 \mathrm{~h}$ at $4^{\circ} \mathrm{C}$. Beads were then washed 5 times with RIPA, after which they were incubated at $95^{\circ} \mathrm{C}$ for $5 \mathrm{~min}$ in $100 \mu \mathrm{l} 2 \mathrm{x}$ Laemli SDS buffer for 10 min, while $150 \mu$ l of input sample was mixed with $50 \mu \mathrm{l} 4 \mathrm{x}$ Laemli SDS buffer and also incubated at at $95^{\circ} \mathrm{C}$ for $5 \mathrm{~min}$. In order to dissolve protein aggregates prior to SDSPAGE, samples were mixed 1:1 with $8 \mathrm{M}$ urea and incubated at room temperature for 10-20 min. The samples were then again incubated at $95^{\circ} \mathrm{C}$ for $5 \mathrm{~min}$, centrifuged at $13000 \times \mathrm{g}$ and proteins present in $35 \mu \mathrm{l}$ of the supernatant were separated by SDS-PAGE using TGX 4-20\% gradient gels (BioRad). Subsequently, proteins were transferred to a PVDF membrane using a MiniProtean wet transfer system (BioRad), following standard procedures. Blots to be incubated with anti-GFP antibodies were blocked in Tris-buffered saline with 0.05\% Tween20 (TBS-T), containing 3\% bovine serum albumin (BSA), while blots to be incubated with aMyc and aHA were blocked with TBS-T containing 5\% skimmed milk. The antibodies were added in TBS-T solution at the following dilutions: aGFP-HRP 1.5:5000 (Miltenyi Biotech), aHA-HRP 1.5:5000 (Miltenyi Biotech), aMyc-HRP 2.5:5000 (Santa Cruz-biotech). For chemoluminescent signal development, SuperSignal West-Femto substrate (ThermoFisher Scientific) was used. Imaging of western blots was done using a G-BOX system (Syngene).

\section{VIGS assays}

VIGS experiments were performed using wildtype $N$. benthamiana plants, as described (Liebrand et al., 2013). Briefly, 2 week-old N. benthamiana seedlings were inoculated by agro-infiltration (agro-inoculation) with 1:1 mixtures of pTRV1 (Liu et al., 2002) in combination with pTRV2::NbSOBIR1/-like (Liebrand et al., 2013), pTRV2::NbSERK3a/b (Heese et al., 2007; Chaparro-Garcia et al., 2011), pTRV2::GUS, or PTRV2::PDS, at a final $\mathrm{OD}_{600}$ of 0.5 using a needleless syringe. 


\section{Agrobacterium transient cell death assays}

For INF1 cell death induction assays, young, fully expanded leaves of 4-5 weekold TRV-GUS- or TRV-NbSOBIR1/-like-inoculated N. benthamiana plants (i.e. 2-3 weeks after VIGS) were used. VIGSed leaves were agroinfiltrated with pCB3023-p35s-INF1 and pCB302-3-p35s-EV (empty vector) (Du et al., 2015), at an $\mathrm{OD}_{600}$ of 0.5. Leaves were visually examined for INF1-triggered cell-death at $4 \mathrm{~d}$ postagroinfiltration. For genetic complementation assays using SmSOBIR1 syn variants, VIGSed plants were co-infiltrated with 1:1 mixtures of Agrobacterium carrying pCB302-3-p35s-INF1, in combination with one of the following constructs: pGWB20-p35s::SmSOBIR1-myc, pGWB20-p35s::SmSOBIR1syn ${ }^{W T}-m y c$, pGWB20-

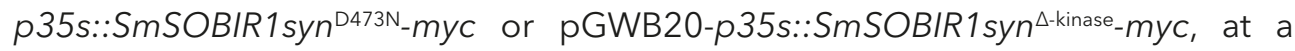
final $\mathrm{OD}_{600}$ of 0.5 . Infiltrated leaves were observed for INF1-induced cell death at $5 \mathrm{~d}$ post-infiltration. In all cases, the percentage of cell death was quantified using scores of $0 \%, 25 \%, 50 \%, 75 \%$ and $100 \%$, based on visual observation of the infiltrated area showing cell death when compared to the total area, as described previously (Du et al., 2014).

\section{Inoculations with $\mathbf{P}$. infestans}

Detached leaf assays with $P$. infestans on VIGSed N. benthamiana were performed as described (Vleeshouwers et al., 1999). Briefly, leaves were placed with their petioles into tap water-saturated floral foam (Oasis) with the abaxial side facing upwards. P. infestans zoospore suspensions were prepared as described previously (Vleeshouwers et al., 1999) and inoculations using these spores were performed twice per leaf, by pipetting $10 \mu \mathrm{l}$ droplets of a suspension of $1 \times 10^{5}$ zoospores/ $\mathrm{ml}$ (in tap water) onto the abaxial side. At $5 \mathrm{dpi}$, pictures were taken under normal or long wave UV-light. UV photos of the fluorescent isolate 88069td (expressing tdTomato red fluorescent protein, a fluorescent protein consisting of a tandem dimer of a dsRed monomeric mutant) (Whisson et al., 2007) were taken using the PathoScreen system (PhenoVation).

\section{RNA extraction and quantitative PCR analyses}

RNA was isolated from TRV-inoculated $N$. benthamiana plants at 3 week post inoculation. RNA extraction was performed using the RNAplant easy kit (Qiagen) and cDNA was synthesized on $1 \mu \mathrm{g}$ of total RNA using Superscript II (Invitrogen), according to manufacturer's instructions. NbSOBIR1 expression was quantified by RT-qPCR by using the expression of $N$. benthamiana ELONGATION FACTOR 1a (EF1a) as a reference (Nicot et al., 2005). Quantitative RT-PCRs were performed on a CFX96 Real-Time System (BioRad). Gene expression data were normalized to the 
expression of NbEF1 $\mathrm{a}$ and the $2^{-\Delta \Delta C t}$ method was used for data analysis (Livak and Schmittgen, 2001). See Table S1 for the primers that were used.

P. infestans biomass quantifications on infected leaves were performed using qPCR. Leaf discs (30 $\mathrm{mm}$ in diameter) were excised from the inoculation spots of each leaf at $5 \mathrm{dpi}$. Per treatment, leaf material was pooled, snap frozen and ground to a fine powder, independently for each biological repeat. Genomic DNA was extracted using the DNeasy Plant kit (Qiagen) and P. infestans biomass was quantified in a similar way as for gene expression, by comparing the relative abundance of $P$. infestans $\beta$-tubulin to that of N. benthamiana EF1 a (see Table S1).

\section{Acknowledgements}

We thank the members of the Kamoun laboratory for useful discussions and feedback. This work was supported by a NWO-VIDI grant 12378 (E.D., D.W., V.G.A.A.V.) and COST Action SUSTAIN FA1208. The authors acknowledge Hanna Rövenich for providing purified Avr4 protein, Pieter J. Wolters for critical reading of the manuscript, Theo van der Lee for assistance with UV imaging of $P$. infestans and Paul Birch and Geert Kessel for providing P. infestans isolates.

\section{Author contributions}

E.D., M.H.A.J., S.K. and V.G.A.A.V. planned and designed the research. E.D. and D.W., performed experiments and analyzed the data. E.D., V.G.A.A.V., R.G.F.V. and M.H.A.J., wrote the manuscript. 


\section{References}

Albert, I., Bohm, H., Albert, M., Feiler, C.E., Imkampe, J., Wallmeroth, N., Brancato, C., Raaymakers, T.M., Oome, S., Zhang, H., Krol, E., Grefen, C., Gust, A.A., Chai, J., Hedrich, R., van den Ackerveken, G., and Nurnberger, T. 2015. An RLP23-SOBIR1-BAK1 complex mediates NLP-triggered immunity. Nat Plants 1:15140.

Bi, G., Liebrand, T.W., Cordewener, J.H., America, A.H., Xu, X., and Joosten, M.H. 2014. Arabidopsis thaliana receptor-like protein AtRLP23 associates with the receptor-like kinase AtSOBIR1. Plant Signal Behav 9:e27937.

Bi, G., Liebrand, T.W., Bye, R.R., Postma, J., van der Burgh, A.M., Robatzek, S., Xu, X., and Joosten, M.H. 2016. SOBIR1 requires the GxxxG dimerization motif in its transmembrane domain to form constitutive complexes with receptor-like proteins. Mol Plant Pathol 17:96-107.

Boller, T., and Felix, G. 2009. A renaissance of elicitors: perception of microbe-associated molecular patterns and danger signals by pattern-recognition receptors. Annu Rev Plant Biol 60:379-406.

Bos, J.I., Armstrong, M.R., Gilroy, E.M., Boevink, P.C., Hein, I., Taylor, R.M., Zhendong, T., Engelhardt, S., Vetukuri, R.R., Harrower, B., Dixelius, C., Bryan, G., Sadanandom, A., Whisson, S.C., Kamoun, S., and Birch, P.R. 2010. Phytophthora infestans effector AVR3a is essential for virulence and manipulates plant immunity by stabilizing host E3 ligase CMPG1. Proc Natl Acad Sci USA 107:9909-9914.

Chaparro-Garcia, A., Wilkinson, R.C., Gimenez-lbanez, S., Findlay, K., Coffey, M.D., Zipfel, C., Rathjen, J.P., Kamoun, S., and Schornack, S. 2011. The receptor-like kinase SERK3/BAK1 is required for basal resistance against the late blight pathogen Phytophthora infestans in Nicotiana benthamiana. PLoS One 6:e16608.

Chaparro-Garcia, A., Schwizer, S., Sklenar, J., Yoshida, K., Petre, B., Bos, J.I., Schornack, S., Jones, A.M., Bozkurt, T.O., and Kamoun, S. 2015. Phytophthora infestans RXLR-WY effector AVR3a associates with dynamin-related protein 2 required for endocytosis of the plant pattern recognition receptor FLS2. PLoS One 10:e0137071.

Chinchilla, D., Zipfel, C., Robatzek, S., Kemmerling, B., Nurnberger, T., Jones, J.D., Felix, G., and Boller, T. 2007. A flagellin-induced complex of the receptor FLS2 and BAK1 initiates plant defence. Nature 448:497-500.

Couto, D., and Zipfel, C. 2016. Regulation of pattern recognition receptor signalling in plants. Nat Rev Immunol 16:537-552.

Derevnina, L., Dagdas, Y.F., De la Concepcion, J.C., Bialas, A., Kellner, R., Petre, B., Domazakis, E., Du, J., Wu, C.H., Lin, X., Aguilera-Galvez, C., Cruz-Mireles, N., Vleeshouwers, V.G.A.A., and Kamoun, S. 2016. Nine things to know about elicitins. New Phytol 212:888-895.

Du, J., Rietman, H., and Vleeshouwers, V.G.A.A. 2014. Agroinfiltration and PVX agroinfection in potato and Nicotiana benthamiana. J Vis Exp:e50971.

Du, J., Verzaux, E., Chaparro-Garcia, A., Bijsterbosch, G., Keizer, L.C., Zhou, J., Liebrand, T.W., Xie, C., Govers, F., Robatzek, S., van der Vossen, E.A., Jacobsen, E., Visser, R.G., Kamoun, S., and Vleeshouwers, V.G.A.A. 2015. Elicitin recognition confers enhanced resistance to Phytophthora infestans in potato. Nat Plants 1:15034.

Gao, M., Wang, X., Wang, D., Xu, F., Ding, X., Zhang, Z., Bi, D., Cheng, Y.T., Chen, S., Li, X., and Zhang, Y. 2009. Regulation of cell death and innate immunity by two receptor-like kinases in Arabidopsis. Cell Host Microbe 6:34-44.

Gilroy, E.M., Taylor, R.M., Hein, I., Boevink, P., Sadanandom, A., and Birch, P.R. 2011. CMPG1-dependent cell death follows perception of diverse pathogen elicitors at the host plasma membrane and is suppressed by Phytophthora infestans RXLR effector AVR3a. New Phytol 190:653-666.

Gust, A.A., and Felix, G. 2014. Receptor like proteins associate with SOBIR1-type of adaptors to form bimolecular receptor kinases. Curr Opin Plant Biol 21:104-111.

Heese, A., Hann, D.R., Gimenez-lbanez, S., Jones, A.M., He, K., Li, J., Schroeder, J.I., Peck, S.C., and Rathjen, J.P. 2007. The receptor-like kinase SERK3/BAK1 is a central regulator of innate immunity in plants. Proc Natl Acad Sci USA 104:12217-12222.

Kamoun, S., van West, P., de Jong, A.J., de Groot, K.E., Vleeshouwers, V.G.A.A., and Govers, F. 1997. A gene encoding a protein elicitor of Phytophthora infestans is down-regulated during infection of potato. Mol Plant Microbe Interact 10:13-20.

Kumagai, M.H., Donson, J., della-Cioppa, G., Harvey, D., Hanley, K., and Grill, L.K. 1995. Cytoplasmic inhibition of carotenoid biosynthesis with virus-derived RNA. Proc Natl Acad Sci USA 92:1679-1683. 
Leborgne-Castel, N., Lherminier, J., Der, C., Fromentin, J., Houot, V., and Simon-Plas, F. 2008. The plant defense elicitor cryptogein stimulates clathrin-mediated endocytosis correlated with reactive oxygen species production in bright yellow-2 tobacco cells. Plant Physiol 146:1255-1266.

Liebrand, T.W., van den Burg, H.A., and Joosten, M.H. 2014. Two for all: receptor-associated kinases SOBIR1 and BAK1. Trends Plant Sci 19:123-132.

Liebrand, T.W., Smit, P., Abd-El-Haliem, A., de Jonge, R., Cordewener, J.H., America, A.H., Sklenar, J., Jones, A.M., Robatzek, S., Thomma, B.P., Tameling, W.I., and Joosten, M.H. 2012. Endoplasmic reticulum-quality control chaperones facilitate the biogenesis of $\mathrm{Cf}$ receptor-like proteins involved in pathogen resistance of tomato. Plant Physiol 159:1819-1833.

Liebrand, T.W., van den Berg, G.C., Zhang, Z., Smit, P., Cordewener, J.H., America, A.H., Sklenar, J., Jones, A.M., Tameling, W.I., Robatzek, S., Thomma, B.P., and Joosten, M.H. 2013. Receptor-like kinase SOBIR1/EVR interacts with receptor-like proteins in plant immunity against fungal infection. Proc Natl Acad Sci USA 110:10010-10015.

Liu, Y., Schiff, M., and Dinesh-Kumar, S.P. 2002. Virus-induced gene silencing in tomato. Plant J 31:777786.

Livak, K.J., and Schmittgen, T.D. 2001. Analysis of relative gene expression data using real-time quantitative PCR and the 2(- $-\triangle \triangle C T)$ Method. Methods 25:402-408.

Nicot, N., Hausman, J.F., Hoffmann, L., and Evers, D. 2005. Housekeeping gene selection for real-time RT-PCR normalization in potato during biotic and abiotic stress. J Exp Bot 56:2907-2914.

Peng, H.C., and Kaloshian, I. 2014. The tomato leucine-rich repeat receptor-like kinases SISERK3A and SISERK3B have overlapping functions in bacterial and nematode innate immunity. PLoS One 9:e93302.

Peng, K.C., Wang, C.W., Wu, C.H., Huang, C.T., and Liou, R.F. 2015. Tomato SOBIR1/EVR homologs are involved in elicitin perception and plant defense against the oomycete pathogen Phytophthora parasitica. Mol Plant Microbe Interact 28:913-926.

Postma, J., Liebrand, T.W., Bi, G., Evrard, A., Bye, R.R., Mbengue, M., Kuhn, H., Joosten, M.H., and Robatzek, S. 2016. Avr4 promotes Cf-4 receptor-like protein association with the BAK1/SERK3 receptor-like kinase to initiate receptor endocytosis and plant immunity. New Phytol 210:627642.

Schwessinger, B., Roux, M., Kadota, Y., Ntoukakis, V., Sklenar, J., Jones, A., and Zipfel, C. 2011. Phosphorylation-dependent differential regulation of plant growth, cell death, and innate immunity by the regulatory receptor-like kinase BAK1. PLoS Genet 7:e1002046.

van den Burg, H.A., de Wit, P.J., and Vervoort, J. 2001. Efficient 13C/15N double labeling of the avirulence protein AVR4 in a methanol-utilizing strain (Mut+) of Pichia pastoris. J Biomol NMR 20:251-261.

Vleeshouwers, V.G.A.A., van Dooijeweert, W., Paul Keizer, L.C., Sijpkes, L., Govers, F., and Colon, L.T. 1999. A laboratory assay for Phytophthora infestans resistance in various Solanum species reflects the field situation. Eur J Plant Pathol 105:241-250.

Vleeshouwers, V.G.A.A., Raffaele, S., Vossen, J.H., Champouret, N., Oliva, R., Segretin, M.E., Rietman, H., Cano, L.M., Lokossou, A., Kessel, G., Pel, M.A., and Kamoun, S. 2011. Understanding and exploiting late blight resistance in the age of effectors. Annu Rev Phytopathol 49:507-531.

Whisson, S.C., Boevink, P.C., Moleleki, L., Avrova, A.O., Morales, J.G., Gilroy, E.M., Armstrong, M.R., Grouffaud, S., van West, P., Chapman, S., Hein, I., Toth, I.K., Pritchard, L., and Birch, P.R. 2007. A translocation signal for delivery of oomycete effector proteins into host plant cells. Nature 450:115-118.

Zhang, L., Kars, I., Essenstam, B., Liebrand, T.W., Wagemakers, L., Elberse, J., Tagkalaki, P., Tjoitang, D., van den Ackerveken, G., and van Kan, J.A. 2014. Fungal endopolygalacturonases are recognized as microbe-associated molecular patterns by the Arabidopsis receptor-like protein RESPONSIVENESS TO BOTRYTIS POLYGALACTURONASES1. Plant Physiol 164:352-364.

Zhang, W., Fraiture, M., Kolb, D., Loffelhardt, B., Desaki, Y., Boutrot, F.F., Tor, M., Zipfel, C., Gust, A.A., and Brunner, F. 2013. Arabidopsis receptor-like protein30 and receptor-like kinase suppressor of BIR1-1/EVERSHED mediate innate immunity to necrotrophic fungi. Plant Cell 25:4227-4241.

Zipfel, C., Kunze, G., Chinchilla, D., Caniard, A., Jones, J.D., Boller, T., and Felix, G. 2006. Perception of the bacterial PAMP EF-Tu by the receptor EFR restricts Agrobacterium-mediated transformation. Cell 125:749-760. 


\section{Supplementary information}

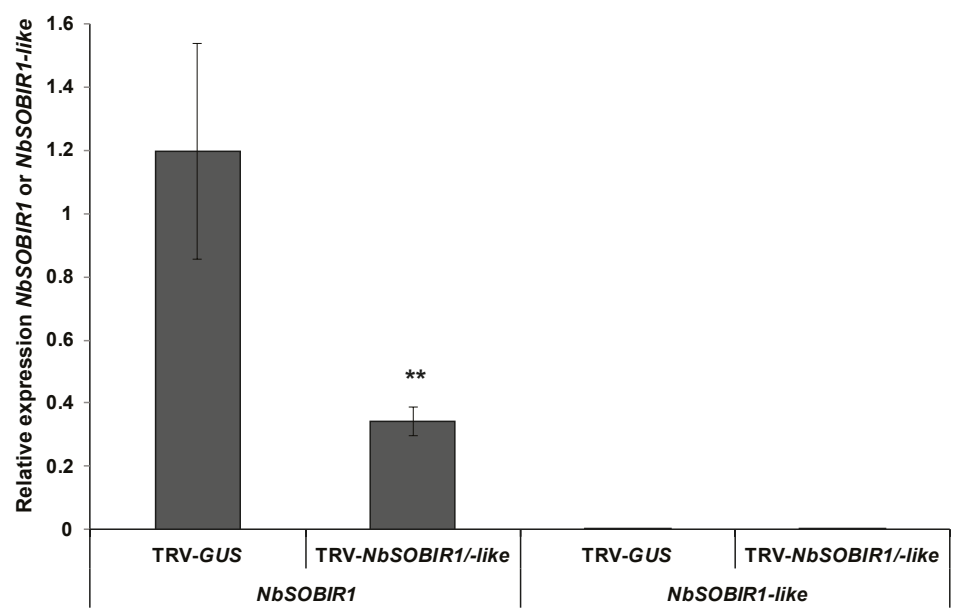

FIGURE S1 | NbSOBIR1 is successfully silenced in TRV-NbSOBIR1/-like-inoculated Nicotiana benthamiana. N. benthamiana plants were inoculated with TRV-GUS or TRV-NbSOBIR1/-like and the relative expression of NbSOBIR1 was determined at three weeks post inoculation. Quantitative RT-PCR data for NbSOBIR1 were normalized to the expression of the NbEF1 a gene and a relative quantification was performed. Error bars indicate the standard deviation of three biological repeats. Asterisks indicate significance at $p<0.01$ (One-way ANOVA, LSD test).

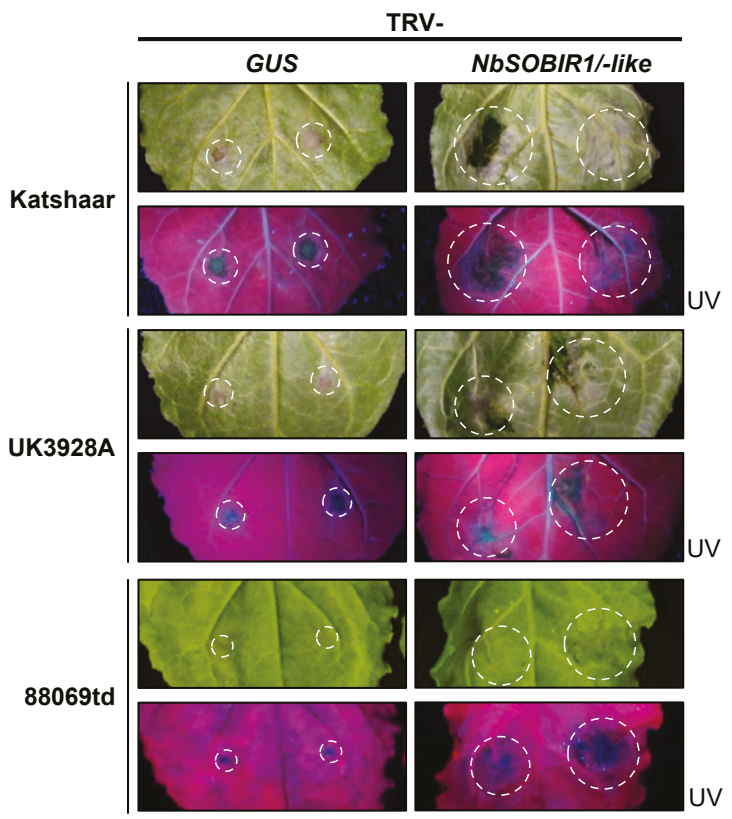

FIGURE S2 | SOBIR1 is required for resistance of Nicotiana benthamiana to Phytophthora infestans. Four week-old Nicotiana benthamiana plants, inoculated with TRV-GUS or TRV-NbSOBIR1/-like (Liebrand et al., 2013), were inoculated with zoospores obtained from three different $P$. infestans isolates (Katshaar, UK3928A and 88069td). Images of representative leaves were taken at 5 days post inoculation (dpi) under normal or UV light. 
Chapter 3

(a)

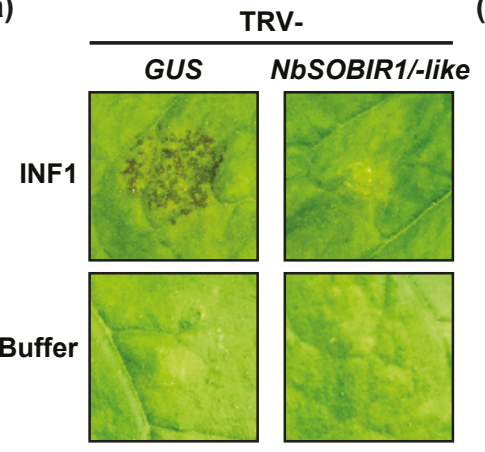

(b)

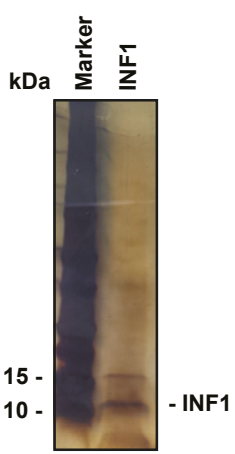

FIGURE S3 | SOBIR1 is required for the cell death response triggered by INF1 protein. Four week-old Nicotiana benthamiana plants, inoculated with TRV-GUS or TRV-NbSOBIR1/-like (Liebrand et al., 2013), were infiltrated with $1 \mu \mathrm{M}$ INF1 protein. (a) Representative pictures from the INF1 protein infiltration taken at 4 days post infiltration. (b) SDS-PAGE and silver staining of the INF1 protein purified from Phytophthora infestans culture filtrate using anion exchange. 
SmSOBI R1_MCD360 St SOBIR SI SOBI R1

SmSOBI R1-I i ke_M

St SOBIR1-I i ke

SmSOBI R1_MCD360

St SOBI R1

SI SOBIR1

St SOBI R1 - I i ke-

$\begin{array}{llll}\text { St } & \text { SOBI R1 - I } & \mathrm{ke} \\ \text { SI SOBI R1- I i ke }\end{array}$

SmSOBI R1_MCD3 60

St SOBI R

SI SOBIR1

SmSOBI R1-I i ke_M

St SOBI R1- I i k e
SI SOBI R1- I i ke

SmSOBI R1 MCD 360 St SOBI R1

SI SOBI R1

St SOBI R1- I l ke
SI SOBI R1-I i ke

SmSOBI R1_MCD3 60

St SOBI R1

SI SOBI R1

SmSOBIR1-I i ke M

St SOBI R1 - I ike

SI SOBI R1-I i ke

SmSOBI R1 MCD 360

St SOBI R1

SI SOBI R1

SmSOBI R1-I i ke_M

St SOBIR1-I i ke

SI SOBI R1-I i ke

SmSOBI R1_MCD3 60 St SOBI R1

SI SOBI R1

SmSOBIR1-I ike M

St SOBIR1- I i ke

SI SOBI R1 - I i ke

St SOBI R1

SI SOBI R1

SmSOBI R1_MCD3 60 St SOBI R1

SI SOBI R

SmSOBI R1-l i ke M

SI SOBI R1-1 i ke

SmSOBI R1 MCD 360

St SOBI R1

SI SOBIR1

SmSOBI R1- I i ke_M

St SOBIR1-I i ke

SI SOBI R1 - I i ke
SI SOBI R1 - I i ke

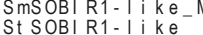

SmSOBI R1 MCD 360

SmSOBI R1 - I i ke _ M

St SOBIR1-I i ke

SI SOBI R1-l i ke

St SOB।R1-1 ike
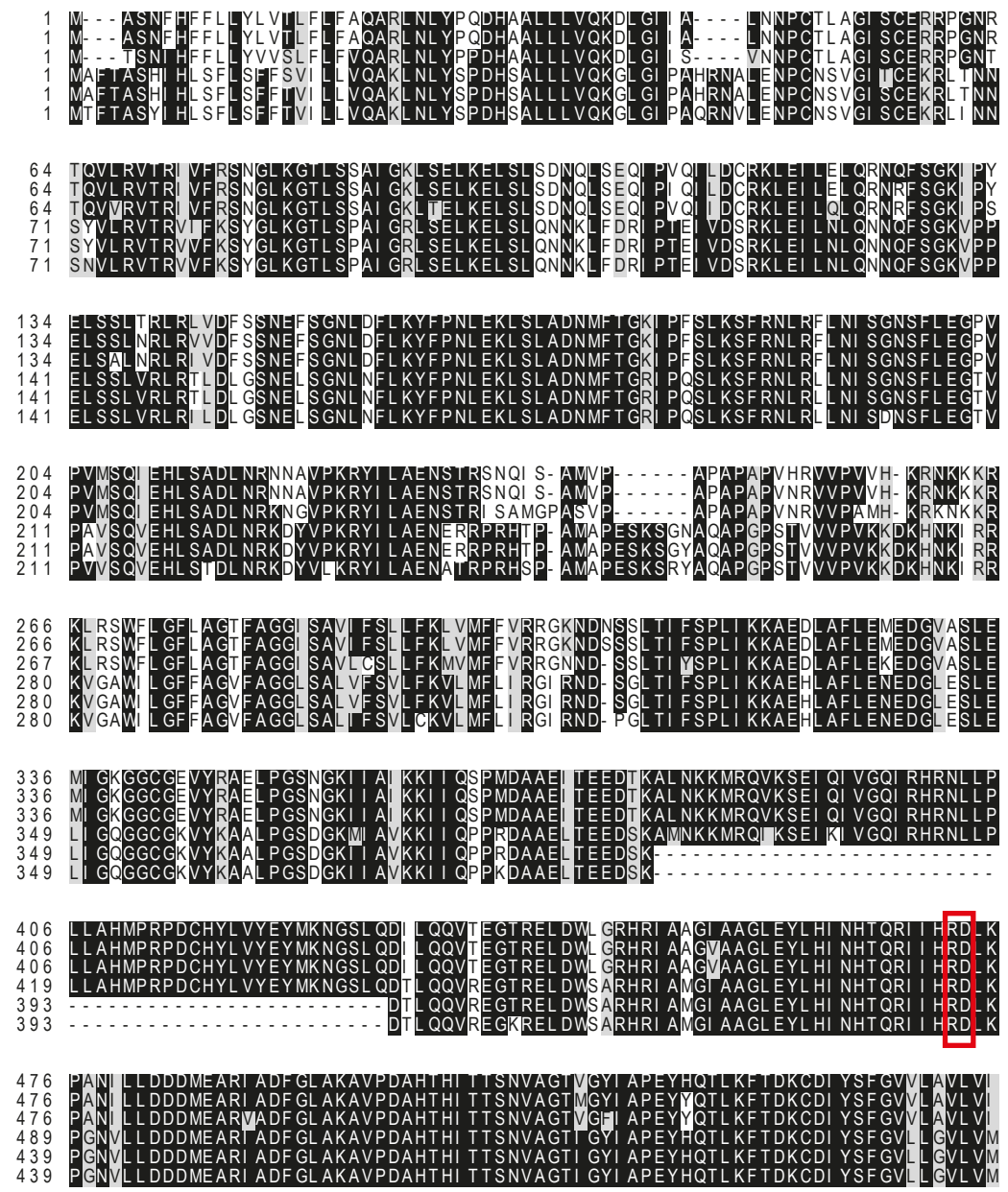

FIGURE S4 | Alignments of SmSOBIR1 and SmSOBIR1-like with StSOBIR1, StSOBIR1-like, SISOBIR1 and SISOBIR1-like. Amino acid sequence alignment of SOBIR1 was created using COBALT, and BOXSHADE was used to visualize conservation. Residues highlighted in black are identical in $>50 \%$ of the six sequences, while residues highlighted in grey are residues with similar properties. The RD motif is highlighted by a red rectangle. 
(a)

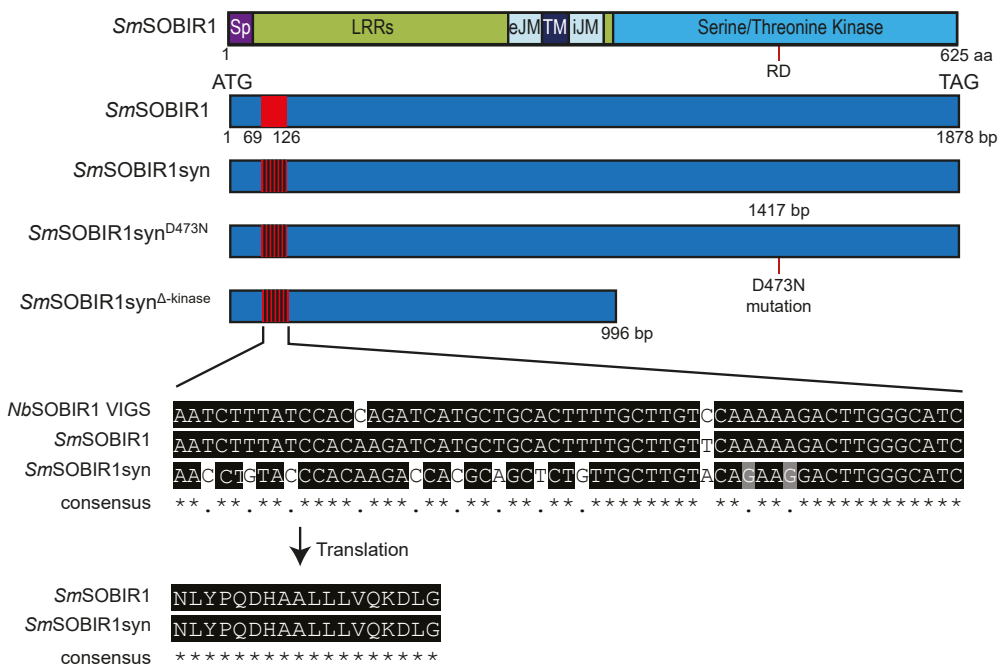

(b)

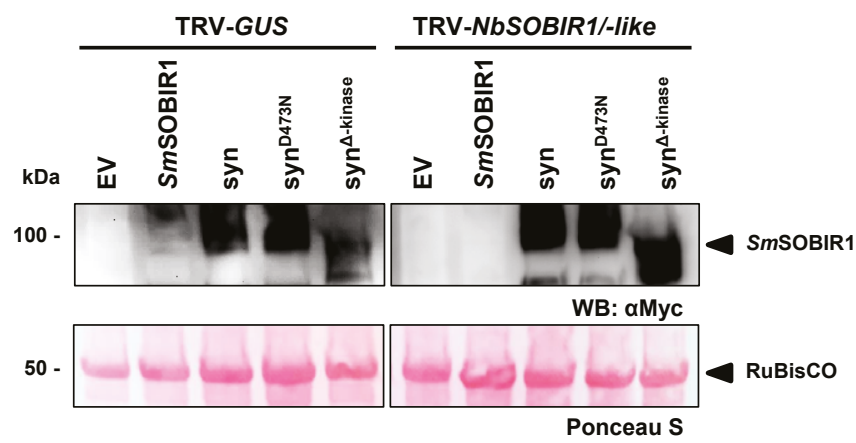

FIGURE S5 | Designing of synthetic versions of SmSOBIR1 (SmSOBIR1syn) and in planta protein detection. (a) Schematic overview of the synthetic constructs of SmSOBIR1 used in this study. In red is the SmSOBIR1 sequence that is targeted by the TRV-NbSOBIR1/-like construct. Protein (top) and gene models are scaled to represent the actual domain positions. Alignments show the nucleotide differences between SmSOBIR1 and SmSOBIR1synWT sequences, while the translated amino acid sequence remains identical. (b) Western blot showing the detection of SmSOBIR1 syn variants in TRVGUS or TRV-NbSOBIR1/-like-inoculated plants. Wild type SmSOBIR1 (WT) and empty vector (EV) were used as controls. 
SmSOBIR1 MCD360 NbSOBIR1 VIGS SmSOBIR1 syn SmSOBIR1-like M NbSOBIR1-like V

SmSOBIR1 MCD360 NbSOBIR1 VIGS SmSOBIR1syn SmSOBIR1-like M NbSOBIR1-like

SmSOBIR1 MCD360 NbSOBIR1 VIGS SmSOBIR1syn SmSOBIRI-like M NbSOBIR1-like V

SmSOBIR1 MCD360 NbSOBIR1 VIGS SmSOBIR1syn SmSOBIRI-like M NbSOBIR1-like

SmSOBIR1_MCD360 NbSOBIR1 VIGS SmSOBIR1syn SmSOBIR1-like M NbSOBIR1-like V

SmSOBIR1 MCD360 NbSOBIR1 VIGS SmSOBIR1syn SmSOBIR1-like_M NbSOBIR1-like

SmSOBIR1_MCD360 NbSOBIR1 VIGS SmSOBIR1syn SmSOBIRI-like M 421 NbSOBIR1-like V

SmSOBIR1_MCD360 NbSOBIR1 ${ }^{-}$VIGS SmSOBIR1syn SmSOBIR1-like_M NbSOBIR1-like V

SmSOBIR1_MCD360 NbSOBIR1 VIGS SmSOBIR1syn SmSOBIRI-like M 561 NbSOBIRI-like $\mathrm{V}$
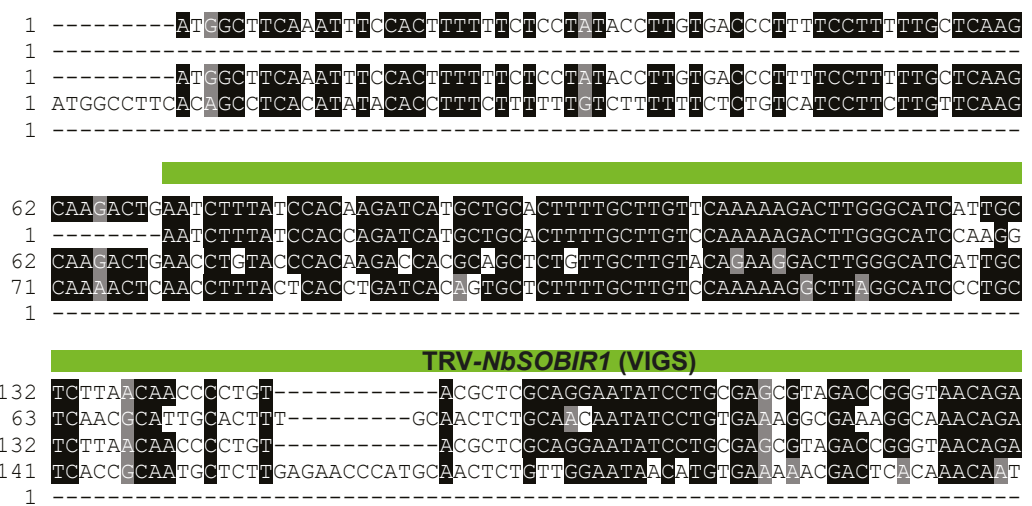

\section{TTGGCAAACTCTCTGAGCTCAAAGAGCTTTCTCTTTCCGACAATCAACTATCTGAACAAATCCCAGTTCA 260 TTGGCAAACTCTCTGAGCTCAAAGAGCTTTCTCTTTCCGACAATCAACTATCTGAACAAATCCCAGTTCA
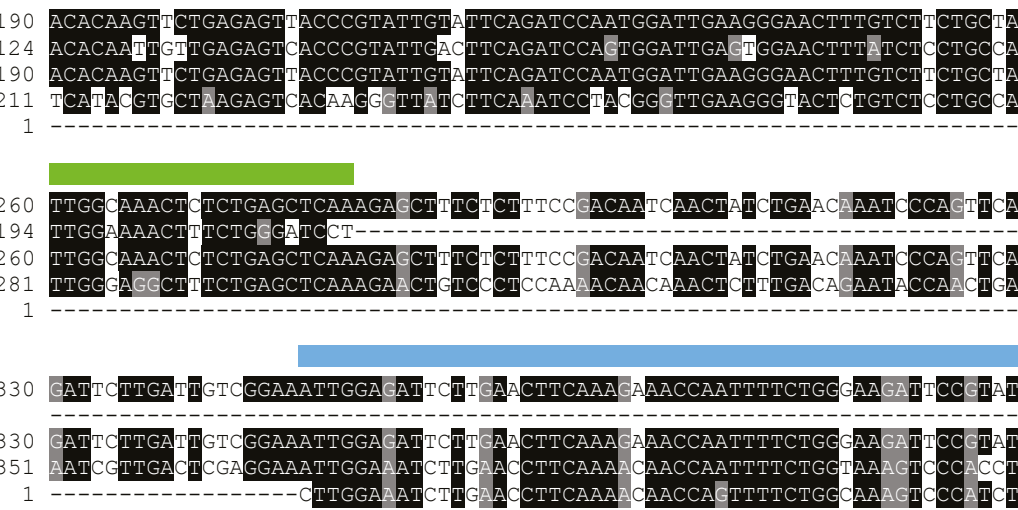

TRV-NbSOBIR1-like (VIGS)
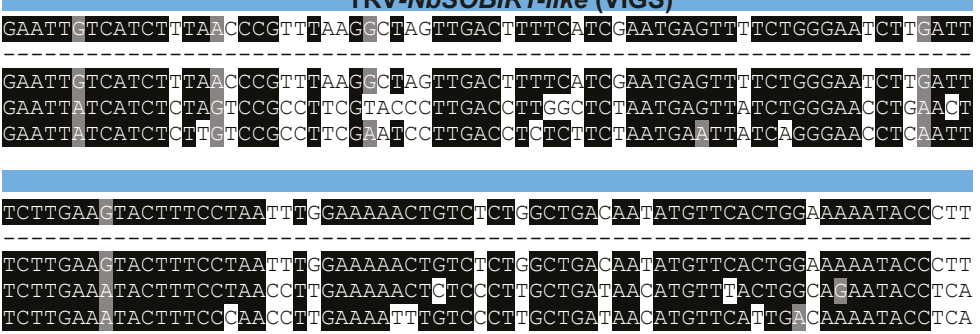

FIGURE S6 | DNA alignment of SmSOBIR1, SmSOBIR1syn ${ }^{W T}$ and SmSOBIR1-like with the TRVNbSOBIR1/-like VIGS fragments. DNA sequence alignment of SOBIR1 was created using MUSCLE, and BOXSHADE was used to visualize conservation. Nucleotides highlighted in black are identical in all sequences while residues highlighted in grey are residues identical in $>50 \%$ of the sequences. The positions of SmSOBIR1 that are targeted by the TRV-NbSOBIR1/-like construct are highlighted with a green or blue line, respectively, above the sequence. 
SmSOBIR1 MCD360 NbSOBIR1_VIGS SmSOBIR1syn

SmSOBIR1-like NbSOBIRI-like V

SmSOBIR1 MCD360 NbSOBIR1 VIGS SmSOBIR1 $\overline{\text { syn }}$

SmSOBIR1-like NbSOBIR1-like V

SmSOBIR1 MCD360 NbSOBIR1 VIGS SmSOBIR1 syn SmSOBIR1-like M NbSOBIR1 like $\mathrm{V}$

SmSOBIR1_MCD360 NbSOBIR1 VIGS SmSOBIR1syn SmSOBIR1-like M NbSOBIR1-like_V

SmSOBIR1_MCD360 NbSOBIR1 VIGS SmSOBIR1syn SmSOBIR1-like M NbSOBIR1-like V

SmSOBIR1_MCD360 NbSOBIR1 VIGS SmSOBIR1syn SmSOBIR1-like_M NbSOBIR1-like ${ }^{-}$
610 CCTGTCATGAGTCAAATTGAGCATTATCAGCAGATTTAATCGAAACAATGCCGTTCCCAAACGTTACA 610 CCTGTCATGAGTCAAATTGAGCATTTATCAGCAGATTTAAATCGAAACAATGCCGTTCCCAAACGTTACA 631 CCTGCCGTGAGTCAAGTTGAGCA
680 TTCTTGCTGAGAATCAACAAGTCAAATAGATATCTGAATGGTCCCTGCTCCAGCTCCAGCACCGGT 680 TTCTTGCTGAGAATTCAACAAGG TCAAATCA ATATCTGCAATGGTCCCTGCTCCAGCTCCAGCACCGG TTCTTGCTGAGAACGA AAGAAGGCAAGACACACCCCTGCAATGGCACCAGAGTCCAAATCAGGAAATGC
750 CCATCGTG

-TTGTACCGG---TGGTGAATAAACGTAACAAGAAAAAAGAAG

750 CCATCGT

TCCAGGACCTAGTACAGTTGTAG

TGTACCGG---TGGTGCAT
AGTACCAGTAAAAAAAAAAC
SmSOBIR1_MCD360 1009 NbSOBIR1 VIGS SmSOBIR1syn SmSOBIRI-like M 1048 NbSOBIR1-like_V
799

799

841 TTA GATCTTGGTTCTTGGTTTCCTAGCTGGAACTTTTGCTGGGG TATATCTGCTGTGATCTTTTCGT TTAAGATCTTGTTTCTTGGTTTCCTAGCTGGAACTTTTGCTGGGG TATATCTGCTGTGATCTTTTCGT GCTGGA TTTTCGCTGGGGGCTTATCGGCCTTG TCTTCTCCG

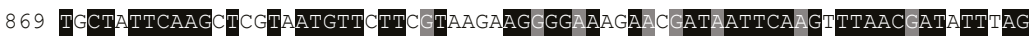
869 TGCTATTCAAGCTCGTAATGTTCTTCGTAAGAAGGGGAAAMACGATAATTCAAGTTTAACGATATTTAC 911 ICCTCTTCAAGGIGCTIATGTTTITAAIC---AGAGGGATCAGAAATGATTCAGGCTTAACAATTTICAG 939

978

\section{TCCGTTGATCAAGAAAGCGAGGACTTGGCTTTCTTA GAGAT GAAGATGGAGTAGATCACTT GAAATC TCCGTTGATCAAGAAAGCGGAGGACTTGGCTTTCTTAGAGATGGAAGATGGAGTAGCATCACTTGAAAT TCCATTGATTAAGAAAGCCGAGACTTGGCCTTTCT GAGAACGAAGATGGATTGGAATCACTAGAACTC}

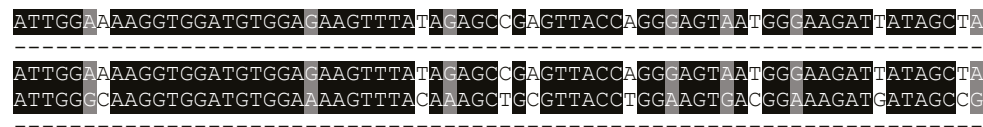

SmSOBIR1_MCD360 1079 NbSOBIR1 VIGS SmSOBIR1syn SmSOBIR1-like_M 1118 NbSOBIR1-like_V

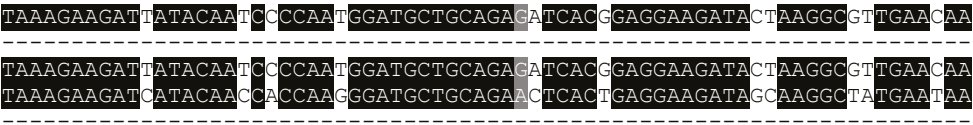

GAAAATGCGTCAAGTAAATCAGAAATTCAAATTGTAGGTCAAATCAGACACCGGAATCTGCTTCCATTA GAAAATGCGTCAAGTTAAATCAGAAATTCAAATTGTAGGTCAAATCAGACACCGGATTTGCTTCCATTA NbSOBIR1_VIGS SmSOBIR1syn

1149 SmSOBIR1-like_M 1188 NbSOBIR1-like $\mathrm{V}$
AAAATTGTAGGTCAAATCAGACACCGGAATT

TGCTTCCCCTP
SmSOBIR1 MCD360 1219 NbSOBIR1 VIGS SmSOBIR1syn

SmSOBIR1-like_M 1258 NbSOBIR1-like-V
CTGGCGCATATGCCAAGGCCAGACTGTCATTACTTGGTGTATGAATATATGAAAAATGGGAGTTTACAGG CTGGCGCATATGCCAAGGCCAGACTGTCATTACTTGGTGTATGAATATATGAAAAATGGGAGTTTACAGG CTGGCACATATGCCAAGACCAGACTGCCATTACTTGGTCTATGA TACATGAAAAATGGGAGCTTACAGG

FIGURE S6 | Continued 
SmSOBIR1_MCD360 1289 NbSOBIR1 VIGS SmSOBIR1 syn SmSOBIR1-like M 1328 NbSOBIR1-like_V

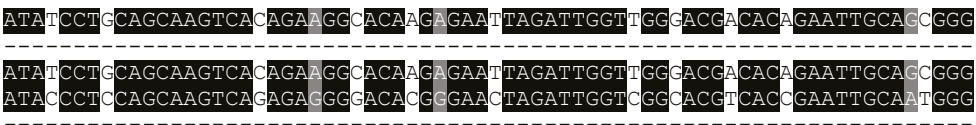

SmSOBIR1_MCD360 1359 NbSOBIR1 ${ }^{-}$VIGS

SmSOBIR1syn

1359 SmSOBIRI-like M 1398 NbSOBIR1-like_V

\section{ATAGCTGCTGGTCTTGAGTATCTCCATATAAACCATACTCAACGCATAATTCACAGAGATCTAAAGCCA AATAGCTGCTGGTCTTGAGTATCTCCATATAAACCATACTCAACGCATAATTCACAGAGATCTAAAGCCA GAGTATCTCCATATAAAT CATACTCAGCGTATAATTCACAGAGATCTAAAGCCA}

SmSOBIR1_MCD360 1429 NbSOBIR1 ${ }^{-}$VIGS

$\begin{array}{lr}\text { SmSOBIR1syn } & 1429 \\ \text { SmSOBIR1-like M } & 1468\end{array}$ NbSOBIR1-like_V

\section{GCAAATATCCTACTTGATGATGACATGGAAGCTCGAATAGCTGATTTGGGCTTGCAAAGGCAGTTCCAG GCAAATATCCTACTTGATGATGACATGGAAGCTCGAATA GC T GATTTTGGGCTTGCAAAGGCA GTTCCAG
GGCATGTCCTCCTTGATGATGACATGGAAGCTCGAATTGAAGATTGGCCTTGCAAAGGCTGTCCCAG}

SMSOBIR1_MCD360 1499 NbSOBIR1 VIGS SmSOBIR1syn

1499 SmSOBIRI-like M 1538 NbSOBIRI-like_V

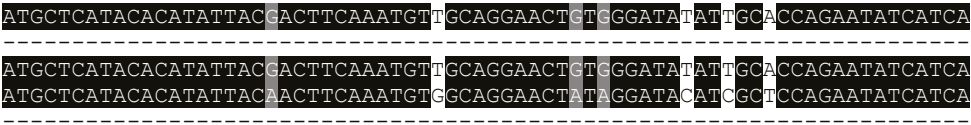
NbSOBIR1_VIGS SmSOBIR1s̄yn

1569 SmSOBIRI-like M 1608 NbSOBIR1-like_V

SmSOBIR1_MCD360 1639 NbSOBIR1 VIGS SmSOBIR1s̄yn

SmSOBIR1-like_M 1678 NoSOBIR1-like - V

SmSOBIR1 MCD360 1709 NbSOBIR1_VIGS SmSOBIR1'syn NbSOBIR1-like_V

SmSOBIR1 MCD360 1779 NbSOBIR1_VIGS SmSOBIR1'syn

1779 SmSOBIR1-like M 1818 NbSOBIR1-like_V

SmSOBIR1_MCD360 1849 NbSOBIR1_VIGS SmSOBIR1s̄yn 1849 SmSOBIR1-like_M 1888 NbSOBIR1-like V
TTACAGACAAGTGTATATATACAGCTTCGGTGTGGTGCTAGCTGTGTTGGTTATCGGA GACACT GAAGTTTACAGACAAGTGTGATATATACAGCTTCGGTGTGGTGCTAGCTGTGTTGGTTATCGGA GACACTAAAGTTCACTGATAAGTGTGATATATACAGCTTCGGGGTGCTTCTAGGCGTGCTAGTTATGGGA

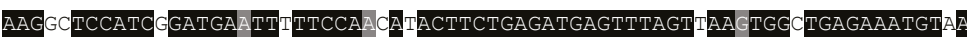 AAGGCTCCATCGGATGAATTTTCCAACATACTTCTGAGATGAGTTTAGTTAAGTGGCTGAGAAATGTA TCCATCT

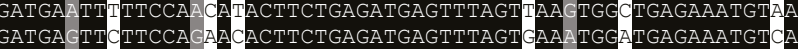

TGACTTCTGATGATCCTAAAAAGCAATTGATCCTAAGCTGATAGGAAATGGATATGAGGAGCAAATGCT TGACTTCTGATGATCCTAAA A AGCAATTATCCTAAGCTGATAGGAAATGGATATGAGGAGCAAATGCT TGACTTCTGATGATCCAAACAGAGCAATTGATCCAAAGCTGATGGGTAATGGAAATGAGGACCAAATGCT
TTTGGTTCTCAAGATAGCTTGCTTTTGTACTCTCAAAATCCAAAGGAGAGGCCTGGCAGTAAGGATGTT TTTGGTTCTCAAGATAGCTTGCTTTTGTACTCTCGACAATCCAAAGGAGAGGCCTGGCAGTAAGGATGTT TTTGGTTCTCAAGATTGCTGCTTTTGTACCCTGGAGAATCCTAAGGAGAGGCCTAATAGTAAGGATGTT

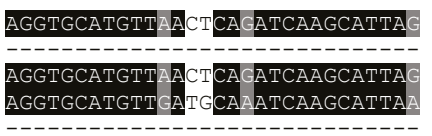

FIGURE S6 | Continued 
(a)

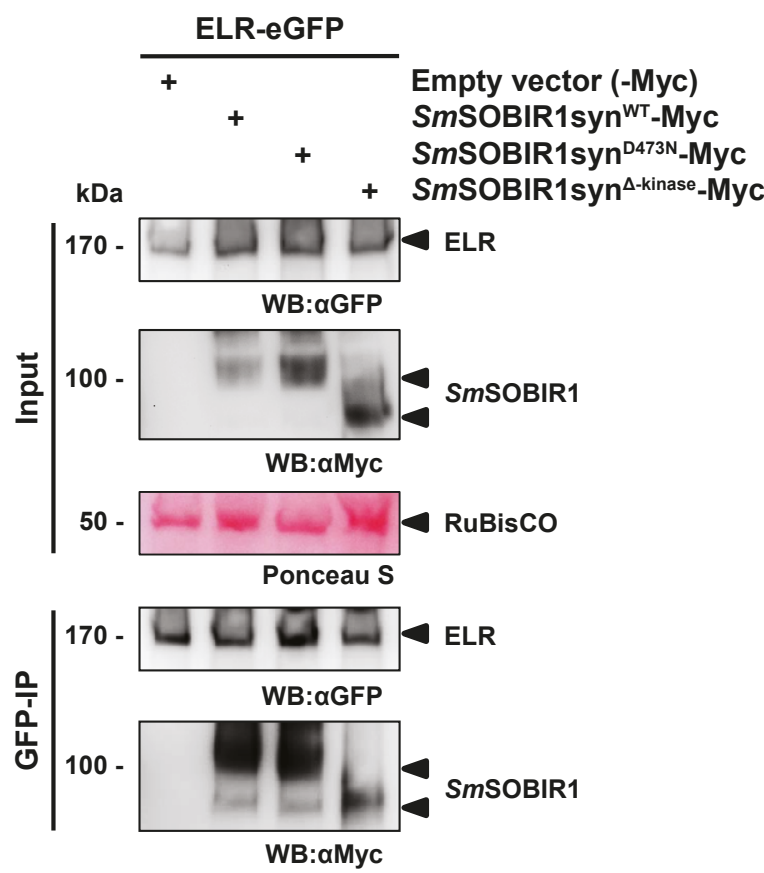

(b)

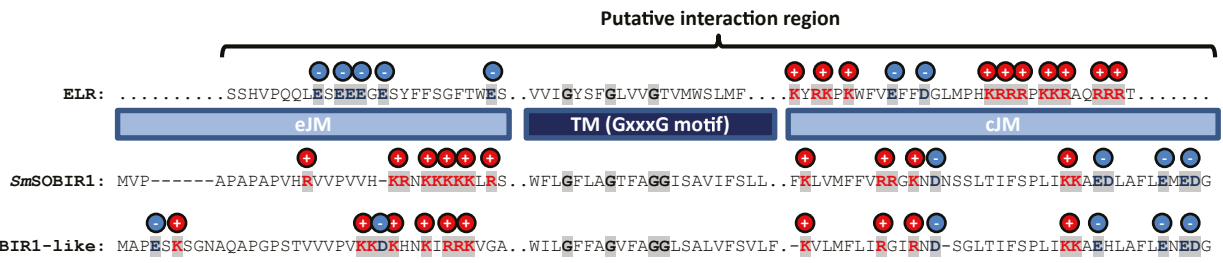

FIGURE S7 | Kinase activity of SOBIR1 and its kinase domain are not required for its association with ELR. (a) ELR-eGFP was transiently co-expressed in Nicotiana benthamiana in combination with empty vector (EV) or SmSOBIR1syn variants (SmSOBIR1synWT, SmSOBIR1syn ${ }^{\text {D473N }}$ or SmSOBIR1syn ${ }^{\Delta}$ kinase). Total protein was extracted and was subjected to immunoprecipitation using GFP_TrapMA beads to capture ELR. The immunopurified proteins were detected with anti-GFP, while the interaction with SmSOBIR1syn variants was assessed with anti-Myc. Ponceau S staining of RuBisCO indicates equal protein loading. This figure is representative for three biological repeats. (b) Schematic representation of the putative interaction site between the extracellular-juxtamembrane (eJM), transmembrane (TM) and intracellular-juxtamembrane (iJM) domains of ELR and SmSOBIR1 based on Gust and Felix (2014) and $\mathrm{Bi}$ et al. (2016). Charged amino acids are indicated by highlighting and a symbol according to charge (+ for positive or - for negative charge). The GxxxG motif in the TM is also highlighted. 


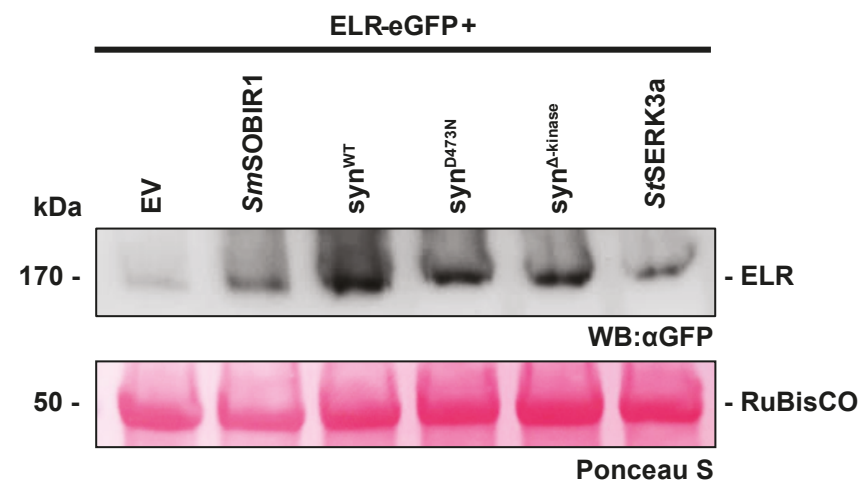

\begin{tabular}{|c|c|c|c|c|c|c|}
\hline & \multicolumn{7}{|c|}{ ELR-eGFP + } \\
\hline $\begin{array}{c}\text { Relative band } \\
\text { intensity }\end{array}$ & EV & $\begin{array}{c}\text { SmSOBIR1 } \\
- \text { Myc }\end{array}$ & $\begin{array}{c}\text { SmSOBIR1syn } \\
- \text { Myc }\end{array}$ & $\begin{array}{c}\text { SmSOBIR1syn } \\
\text { D473N-Myc }\end{array}$ & $\begin{array}{c}\text { SmSOBIR1syn } \\
\Delta-\text {-kinase-Myc }\end{array}$ & $\begin{array}{c}\text { StSERK3a } \\
\text {-HA }\end{array}$ \\
\hline Experiment 1 & $1.0 \times$ & $4.6 \times$ & $13.0 \times$ & $6.4 \times$ & $5.7 \times$ & $1.9 \times$ \\
\hline Experiment 2 & $1.0 \times$ & - & $12.2 \times$ & - & - & - \\
\hline Experiment 3 & $1.0 \times$ & - & - & $6.2 \times$ & - & - \\
\hline
\end{tabular}

FIGURE S8 | SmSOBIR1 stabilizes ELR independently of its kinase activity. ELR-eGFP was transiently co-expressed in Nicotiana benthamiana with empty vector (EV), SmSOBIR1, SmSOBIR1synWT, SmSOBIR1syn ${ }^{\mathrm{D} 473 \mathrm{~N}}$ or SmSOBIR1syn ${ }^{\Delta-k i n a s e}$. Total protein was extracted and western blotting was performed with anti-GFP to visualize ELR accumulation. Quantification of ELR band intensity was performed with imageJ. Relative band intensity results were obtained by comparing the signal intensity of the SOBIR1 and SERK3a agroinfiltrations to the EV agroinfiltration of each experiment. Ponceau S staining of RuBisCO indicates equal protein loading. Data from three independent experiments are shown. 
Table S1. Constructs used in this study.

\begin{tabular}{|c|c|c|c|c|c|}
\hline 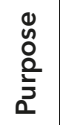 & Construct & Binary vector & Notes & $\begin{array}{l}\text { A. tumefaciens } \\
\text { strain }\end{array}$ & References \\
\hline \multirow{3}{*}{ 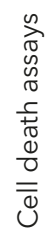 } & INF1 & pCB302-3 & & AGL1 & (Du et al., 2015) \\
\hline & Empty vector & pCB302-3 & & AGL1 & (Du et al., 2015) \\
\hline & Empty-Myc & pGWB20 & $\begin{array}{l}\text { Empty vector } \\
C^{\prime} 10 \times \text { Myc }\end{array}$ & AGL1 & This study \\
\hline \multirow{9}{*}{ 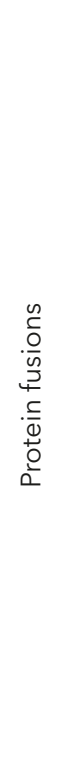 } & ELR-eGFP & $\begin{array}{l}\text { pBin-KS-GWY-35s- } \\
\text { eGFP }\end{array}$ & $C^{\prime}$ eGFP & $\mathrm{C} 58 \mathrm{C} 1$ & (Du et al., 2015) \\
\hline & Cf-4-eGFP & $\begin{array}{l}\text { pBin-KS-GWY-35s- } \\
\text { eGFP }\end{array}$ & $C^{\prime}$ eGFP & $\mathrm{C} 58 \mathrm{C} 1$ & $\begin{array}{c}\text { (Liebrand et al., } \\
\text { 2012) }\end{array}$ \\
\hline & StSERK3a-HA & pGWB14 & $\mathrm{C}^{\prime} 3 \times \mathrm{HA}$ & GV3101 & (Du et al., 2015) \\
\hline & Empty-eGFP & $\begin{array}{l}\text { pBin-KS-GWY-35s- } \\
\text { eGFP }\end{array}$ & $\begin{array}{l}\text { Empty vector, } \\
\text { C' }^{\prime} \text { eGFP }\end{array}$ & AGL1 & This study \\
\hline & SmSOBIR1-Myc & pGWB20 & $C^{\prime} 10 \times$ Myc & AGL1 & This study \\
\hline & SmSOBIR1-like-Myc & pGWB20 & $C^{\prime} 10 \times$ Myc & AGL1 & This study \\
\hline & SmSOBIR1 syn-Myc & pGWB20 & $C^{\prime} 10 \times$ Myc & AGL1 & This study \\
\hline & SmSOBIR1 syn ${ }^{\text {D473N-Myc }}$ & pGWB20 & $C^{\prime} 10 \times$ Myc & AGL1 & This study \\
\hline & SmSOBIR1 syn $\triangle$-kinase_Myc & pGWB20 & $C^{\prime} 10 \times$ Myc & AGL1 & This study \\
\hline \multirow{5}{*}{ 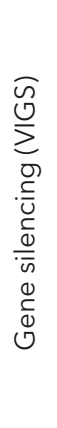 } & pTRV1 & & TRV-VIGS & GV3101 & (Liu et al., 2002) \\
\hline & pTRV2-GUS & & TRV-VIGS & AGL1 & This study \\
\hline & pTRV2-StPDS & & TRV-VIGS & AGL1 & This study \\
\hline & pTRV2-NbSERK3a/3b & & TRV-VIGS & $\mathrm{C} 58 \mathrm{C} 1$ & $\begin{array}{l}\text { (Heese et al., } \\
2007)\end{array}$ \\
\hline & pTRV2-NbSOBIR1/-like & & TRV-VIGS & $\mathrm{C} 58 \mathrm{C} 1$ & $\begin{array}{l}\text { (Liebrand et al., } \\
\text { 2013) }\end{array}$ \\
\hline
\end{tabular}


Table S2. Primers used in this study.

\begin{tabular}{|c|c|c|c|}
\hline Primer name & Purpose & Sequence $5^{\prime} \rightarrow 3^{\prime}$ & References \\
\hline StSOBIR Fwd & Cloning & CACCATGGCTTCAAATTTCCACTTTTTTCT & This study \\
\hline StSOBIR Rev & Cloning & ATGCTTGATCTGAGTTAACATGCA & This study \\
\hline StSOBIR-like Fwd & Cloning & CACCATGGCCTTCACAGCCTCACA & This study \\
\hline StSOBIR-like Rev & Cloning & ATGCTTGATCTGCATCAACATGC & This study \\
\hline GUS 1-240 VIGS Fwd & Cloning & CACCCATGGTCCGTCCTGTAGAAA & This study \\
\hline GUS 1-240 VIGS Rev & Cloning & GCCCAACCTTTCGGTATAAA & This study \\
\hline 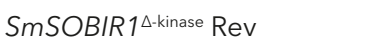 & Cloning & TGCTACTCCATCTTCCATCTCT & This study \\
\hline Sm/NbPDS VIGS Fwd & Cloning & CACCAACTAAACCATTGGAGATTGTTATTG & This study \\
\hline Sm/NbPDS VIGS Rev & Cloning & TTAATCCCTAATTCTCCAAACAGG & This study \\
\hline NbSOBIR1 qRT-PCR Fwd & qPCR & CTTAGAAAAACTCTCTTTAGC & (Liebrand et al., 2013 \\
\hline NbSOBIR1 qRT-PCR Rev & qPCR & TATGGATTGGAGTGACATTATG & (Liebrand et al., 2013 \\
\hline NbSOBIR1-like qRT-PCR Fwd & qPCR & GCAATTGTAGTACCAGTACAC & (Liebrand et al., 2013 \\
\hline NbSOBIR1-like qRT-PCR Rev & qPCR & AATCAATGGACTGAAAAC & (Liebrand et al., 2013 \\
\hline Piß-tubulin qPCR Fwd & qPCR & GGTCGTGGAGCCCTATAACG & This study \\
\hline Piß-tubulin qPCR Rev & qPCR & GTCACCATAAGTGGGGGTGG & This study \\
\hline St/NbEF1a qPCR Fwd & qPCR & TGACCAAGATTGACAGGCGT & This study \\
\hline St/NbEF1a qPCR Rev & qPCR & GCAAAACGACCCAATGGTGG & This study \\
\hline
\end{tabular}





\section{Chapter 4}

\section{ELR binds elicitins from Phytophthora species to trigger SOBIR 1 / SERK3-mediated cell death}

Emmanouil Domazakis

Jan Lochman

Richard G. F. Visser

Matthieu H. A. J. Joosten

Vivianne G. A. A. Vleeshouwers 
- Several pairs of pattern-recognition receptors (PRRs) with apoplastic ligands have been described but in many cases, the actual evidence for ligand binding is lacking. The receptorlike protein (RLP) ELR causes cell death with various elicitins of Phytophthora species and in this study, we investigated whether ELR can associate with elicitins.

- We performed in planta and in vitro co-immunoprecipitation of ELR with several affinity-tagged elicitins as well as in planta transient co-expression assays.

- We found that ELR physically associates with elicitins INF1, ParA1 and $\beta-C R Y$, which leads to cell death induction. ELR also triggers cell death with INF2A and CRY2. Remarkably, a $C^{\prime}$ tagged INF1 and $\beta$-CRY cross-linked dimer ( $\beta$-CRYDIM) were unable to induce cell death, despite of their binding to ELR.

- Co-immunoprecipitation experiments showed that $C^{\prime}$-tagged INF1 prevents association of ELR with its co-receptors SOBIR1 and SERK3 that are required for the active receptor complex formation, and $\beta$-CRYDIM caused inhibition of ELR- association with SOBIR1 but not with SERK3.

- Together, we demonstrate that ELR is a genuine PRR that binds elicitins of Phytophthora species. Moreover, we provide the first report of ligand-mediated inhibition of ELR-SOBIR1SERK3 signaling complex formation in vivo. This mechanistic uncoupling could find use in plant immune signaling studies. 


\section{Introduction}

A major part of a plant's defense against microbes depends on the effective detection of microbe-associated molecular patterns (MAMPs). MAMPs are recognized in the plant apoplast, typically by membrane-localized pattern recognition receptors (PRRs) (Couto and Zipfel, 2016). All plant PRRs that have been identified so far contain a variable number of leucine-rich repeats (LRR), lysine motifs or lectin domains in the ecto-domain, a transmembrane domain and may contain a kinase domain. LRR-type receptor-like protein (RLPs) and receptorlike kinases (RLKs) predominantly recognize proteinaceous MAMPs or effectors. Despite the increasing number of PRRs discovered in the past 20 years, for most of them it has not been determined whether they are indeed true receptors or just involved in the complex (Dodds and Rathjen, 2010; Zipfel, 2014; Boutrot and Zipfel, 2017; Tang et al., 2017). Especially for RLPs, evidence of binding for MAMPs/effectors has been reported only for fungal endo-polygalacturonases and ethylene-induced xylanase and the widely conserved pattern nlp20, which bind to RLP42/RBPG1, LeEIX2 and RLP23, respectively (Ron and Avni, 2004; Zhang et al., 2014; Albert et al., 2015; Boutrot and Zipfel, 2017). So far, binding of oomycetespecific proteins to a host PRR has not been reported.

Elicitins are a family of structurally conserved extracellular proteins specific to Phytophthora and Pythium (Ponchet et al., 1999). Elicitins have features of oomycete MAMPs, as they have been shown to induce localized cell death, salicylic acid-, jasmonic acid- and ethylene- dependent accumulation as well as systemic resistance (SR) on several responding plant genotypes across various families (Vleeshouwers et al., 2006; Derevnina et al., 2016). The Solanaceaous Nicotiana benthamiana, N. tabacum and S. microdontum mount a specific cell death response to INF1 elicitin (Kamoun et al., 1998; Huitema et al., 2005; Vleeshouwers et al., 2006; Du et al., 2015). All elicitins share a highly conserved 98-amino-acid elicitin domain, which contains six cysteine (Cys) residues at conserved positions for the formation of disulphide bridges (Jiang et al., 2006; Derevnina et al., 2016). Elicitins of the canonical class ELI-1 consist of a signal peptide and the elicitin domain only. All other elicitin classes possess an additional $C^{\prime}$-terminal extension, which is of variable length and is putatively related to oomycete plasma membrane or cell wall anchoring (Qutob et al., 2003).

ELR, a RLP from the wild potato Solanum microdontum specifically responds to various elicitins of diverse Phytophthora species (Du et al., 2015). The recognition spectrum ranges from elicitins belonging to elicitin class ELI-1 (e.g. INF1, RAMA1, ParA1, CRY2), ELI-2 (e.g. INF2A) and ELI-4 elicitins (e.g. INF5, INF6) (Jiang et al., 2006; Du et al., 2015) (Fig. S1). Elicitins do not seem to share a conserved stretch 
of amino acids, as it is found in bacterial flagellin, EF-Tu or NLPs (Felix et al., 1999; Kunze et al., 2004; Bohm et al., 2014), but rather the conserved structure of elicitins is likely recognized by ELR (Derevnina et al., 2016). In line with this, elicitins that are recognized by ELR share rather low amino acid similarities, ranging from $45-65 \%$ (Du et al., 2015).

ELR is lacking a cytoplasmic kinase domain and thus incapable of downstream signaling. Recently it was shown that ELR physically associates with SOBIR1 in a ligand-independent manner, and associates with SERK3 upon induction with elicitins (Du et al., 2015; Domazakis et al., 2018). Both SOBIR1 and SERK3 are required for ELR function and for basal resistance to pathogens including Phytophthora infestans (Chaparro-Garcia et al., 2011; Liebrand et al., 2014; Peng et al., 2015; Domazakis et al., 2018).

In this study, we provide evidence that ELR physically associates with INF1 elicitin using in planta and in vitro setups. We tested diverse additional elicitins of different Phytophthora species and correlated physical interaction with the receptor with the occurrence of ELR-mediated cell death responses. Our data render ELR as a genuine PRR, which associates with various members of the elicitin family of Phytophthora species, however, its association with downstream interactors depends on the oligomeric state of elicitins.

\section{Materials and methods}

\section{Plant materials}

Nicotiana benthamiana plants used were derived from seeds. Solanum hjertingii genotype 349-3 (HJT349-3) plants were clonally propagated in vitro on Murashige and Skoog (MS) medium supplemented with $20 \% \mathrm{w} / \mathrm{v}$ sucrose as described (Murashige and Skoog, 1962; Du et al., 2015). Seedlings of N. benthamiana as well as well-rooted HJT349-3 plantlets were transferred to pots with disinfected soil in a climate-regulated greenhouse compartment $\left(22 / 18^{\circ} \mathrm{C}\right.$ and $16 / 8 \mathrm{~h}$ light day/ night regime at $70 \%$ relative humidity) where they were grown for 3 weeks prior to agroinfiltration experiments. The transient protein expression and cell death assays were performed under the same conditions.

\section{Binary vectors for Agrobacterium tumefaciens-mediated transienttransformation}

Construction of pBin-KS-p35s:ELR-eGFP, pBin-KS-p35s:Cf-4-eGFP, pBin-KSp35s:eGFP, pCB302-3-p35s:INF1, pGWB20-p35s-SmSOBIR1-Myc, pGWB14p35s-StSERK3A-HA and pTRV1 has been described (Du et al., 2015; Liebrand et 
al., 2013; Liu et al., 2002). Elicitin constructs lacking the native signal peptide and carrying PR1Sp (tobacco PR1 signal peptide) and two N'-HA-tags were synthesized in pUC57 (Genscript). Those elicitins included INF1, INF1 ${ }^{\mathrm{C} 23 \mathrm{~S}}$, ParA1, $\beta-C R Y$ and PYU1 and the elicitin domains of INF2A (a.a. 21-118), INF2B (a.a. 21-118), CRY2 (a.a. 21-118) and INL1 (a.a. 19-104) (elicitin domains according to (Jiang et al., 2006)) (Figs. S1a, b, S2a, b). Genes were amplified using Phusion DNA polymerase (Thermo Fisher Scientific) and were cloned in pENTR/D-TOPO. Then the genes were recombined to pK7WG2 binary vector (Karimi et al., 2002) by LR reaction (Invitrogen). To obtain $\mathrm{C}^{\prime}$-HA-tagged INF1, the native ORF lacking a stop codon was amplified with its native signal peptide from pGR106-INF1 vector in a similar way (Du et al., 2015). pENTR-INF1 was recombined to pGWB14 vector (Nakagawa et al., 2007) to obtain the $C^{\prime}$-HA-tagged fusion construct pGWB14:p35s-INF1-3HA (Fig. S2a). Final constructs were transformed in A. tumefaciens stain AGL1.

\section{Agrobacterium transient cell death assays}

For elicitin cell death induction assays, young, fully expanded leaves of 3 wk-old $N$. benthamiana or $N$. tabaccum SR1 plants were agroinfiltrated with pK7WG2empty vector (EV), pCB132:p35s-INF1, pK7WG2:p35s-PR1Sp2HA-elicitins constructs or pGWB14:p35s -INF1-3HA at an OD $_{600}$ of 0.2. Similarly, Solanum hjertingii 349-3 plants were co-infiltrated with 1:1 mixtures of $A$. tumefaciens carrying pK7WG2:p35s-ELR $\left(\mathrm{OD}_{600}=0.15\right)$ with pK7WG2-EV, pCB132:p35s-INF1 or pK7WG2:p35s-PR1Sp2HA-elicitins constructs $\left(O D_{600}=0.1\right)$. Leaves were visually examined for cell-death at 3-5 dpi. Cell death quantifications were performed as described previously (Du and Vleeshouwers, 2014).

\section{Co-immunoprecipitations and immunoblotting}

In planta protein interactions were performed by transient expression in young fully-expanded leaves of 3 wk-old N. benthamiana using Agrobacterium-mediated transformation followed by co-immunoprecipitation. At $2 \mathrm{~d}$ post infiltration, leaves were collected, snap-frozen in liquid nitrogen and ground to a fine powder. Protein extraction, co-immunoprecipitation and western blot with aGFP-HRP and aHA-HRP was performed as described (Domazakis et al., 2018). For detection of lined ubiquitin, the aUb-FK2-HRP was used (Enzo Life Sciences) (detects $\mathrm{K}^{29}{ }_{-}, \mathrm{K}^{48}{ }_{-}$, and $\mathrm{K}^{63}$-linked mono- and polyubiquitinylated proteins) at a dilution of 2:5000.

\section{Protein infiltration assays}

Protein infiltrations for co-receptor competition assays with $\beta$-CRY, or the $\beta$-CRY covalently cross-linked dimer ( $\beta$-CRYDIM) (Uhlíková et al., 2016) were performed 
by using $100 \mathrm{nM}$ of each protein was infiltrated in N. benthamiana leaves. Then the infiltrated leaves were incubated for one hour. Subsequently leaf material was collected for protein extraction and immunoprecipitation. For $\beta-C R Y$ and $\beta-C R Y D I M$ cell death assays in N. tabacum, $20 \mathrm{nM}$ of purified protein was used. Elicitations with INF1 derived from $P$. infestans were performed by infiltrating a buffer or $1 \mu \mathrm{M}$ purified INF1 protein and incubating for $15 \mathrm{~min}$, as described (Domazakis et al., 2018).

\section{Production and purification of recombinant proteins}

Recombinant His-HA-INF1 and His-HA-SCR74 (variant B3b, NCBI accession AY723717.1, (Liu et al., 2005)) were synthesized and codon optimized for expression in Pichia pastoris. Codon optimized genes were designed to carry N'His-HA tags as described previously (Domazakis et al., 2017) (Fig. S2b). Genes were synthesized with flanking restriction sites for Stul and Kpnl to facilitate cloning and were obtained in pUC57 vector (GenScript). Genes were cloned in frame with the a-mating factor in pPinka-HC vector (Invitrogen) enabling protein secretion. $P$. pastoris PichiaPink ${ }^{T M}$ strain 1 (Invitrogen) was transformed by electroporation and high protein producing clones were selected using a high throughput screening method (Domazakis et al., 2017). For protein expression, yeast cultures were first grown in $1 \mathrm{I}$ of $\mathrm{BMGY}$ at $28^{\circ} \mathrm{C}, 250 \mathrm{rpm}$ shaking, till $\mathrm{OD}_{600}=2-6$ in a 3 I conical flask. Cells were pelleted by centrifugation and were resuspended in $200 \mathrm{ml}$ of BMMY containing $1 \% \mathrm{MetOH}$ at $28^{\circ} \mathrm{C}, 300 \mathrm{rpm}$ shacking, for induction in a 2 I conical flask. Induction was maintained for $48 \mathrm{hrs}$ with extra MetOH to $1 \% \mathrm{v} / \mathrm{v}$ added every $24 \mathrm{hrs}$. After $48 \mathrm{hrs}$, the cultures were harvested and the cells were removed by centrifugation. Supernatants were filter sterilized through a $0.22 \mu \mathrm{m}$ syringe filter. A pressurized Amicon stirred cell concentrator (Millipore) combined with a $3 \mathrm{kDa}$ exclusion filter was used to concentrate the supernatants to a volume of $\sim 10 \mathrm{ml}$. Purification was performed using cation exchange. A column was assembled with SP sepharose. Beads were equilibrated with 10 volumes of acetic acid buffer (50 $\mathrm{mM}$ acetic acid, $\mathrm{pH}$ 4.5). Concentrated yeast supernatants containing effectors were diluted five times in acetic acid buffer and were slowly loaded to the column. Column was then washed with five volumes of acetic acid buffer and proteins were eluted by applying five volumes of elution buffer $(10 \mathrm{mM}$ Tris, $500 \mathrm{mM} \mathrm{NaCl}, \mathrm{pH}$ $=8$ ) and collecting several fractions. Protein containing fractions were obtained by measuring A280 absorbance, SDS-PAGE and western blotting. Protein concentrations were determined using BCA assay (Thermo Fisher Scientific). 


\section{In vitro binding assay}

A. tumefaciens strains carrying ELR-eGFP or Cf-4-eGFP were infiltrated in N. benthamiana at an $\mathrm{OD}_{600}$ of 1 and 0.8 , respectively. Two days after agroinfiltration, leaves were collected and were snap frozen in liquid nitrogen. Leaves were ground to a fine powder and RIPA extraction buffer was added at $2 \mathrm{ml} / \mathrm{g}$ of material. Then the extract was diluted at a ratio of 1:3 in binding buffer (100 mM MES, $10 \mathrm{mM}$ $\mathrm{NaCl}, 3 \mathrm{mM} \mathrm{MgCl}_{2}, \mathrm{pH}=6$ (Saur et al., 2016)) and $2 \mathrm{ml}$ was applied to the His-HAINF1- or His-HA-SCR74- bound beads. The mixture was incubated for $1 \mathrm{hr}$ at $4^{\circ} \mathrm{C}$. Co-immunoprecipitation was performed as described above.

\section{Results and discussion}

\section{ELR associates with INF 1 in planta}

To study whether ELR associates with INF1 in co-immunoprecipitation experiments, we generated both $\mathrm{N}^{\prime}$ - and $\mathrm{C}^{\prime}$-tagged versions of INF1. $\mathrm{N}^{\prime}$-tagged INF1 was designed with a tobacco pathogenesis-related protein 1 (PR1) signal peptide (Sp) and a $2 \times$ HA tag (PR1Sp-2HA-INF1), while $C^{\prime}$-tagged INF1 was cloned with its native signal peptide, fused to $3 \times \mathrm{HA}$ (Fig. S2a). To test whether ELR associates with INF1 in planta, we co-expressed the HA-tagged versions of INF1 with ELR-eGFP (Du et al., 2015), and used Cf-4-eGFP or eGFP as positive and negative controls for ELR-eGFP, respectively. In addition, we included a cysteine mutant of INF1 (PR1Sp$2 \mathrm{HA}-\mathrm{INF}^{\left.{ }^{\mathrm{C} 23 \mathrm{~S}}\right)}$, lacking in structure one of the three disulfide bridges, which leads to decreased cell death (Kamoun et al., 1997), as another negative control for INF1. After performing co-immunoprecipitation, we found that ELR specifically immunopurifies with INF1. ELR associated with both $\mathrm{N}^{\prime}$ - and $\mathrm{C}^{\prime}$-tagged INF1, indicating that tagging position does not affect the interaction with the receptor (Fig. 1a). As expected, Cf-4 and eGFP were not able to associate with any tagged INF1, whereas the INF1 ${ }^{\mathrm{C} 23 \mathrm{~S}}$ mutant did show severely reduced interaction with ELR in line with the reduced cell death phenotype (Kamoun et al., 1997). Interestingly, we noticed that INF1 migrates as a double band in the total protein extract, while after immunoprecipitation of ELR, only a single band is found (Fig. 1a, inputs). We consider that the upper band in INF1 corresponds to the unprocessed version of the protein while the lower band, which associates with ELR, corresponds to the mature protein form. In sum, these data show that ELR specifically associates with INF1 in planta and that this interaction occurs with the mature form of the effector, likely in the plant apoplast. 
(a)

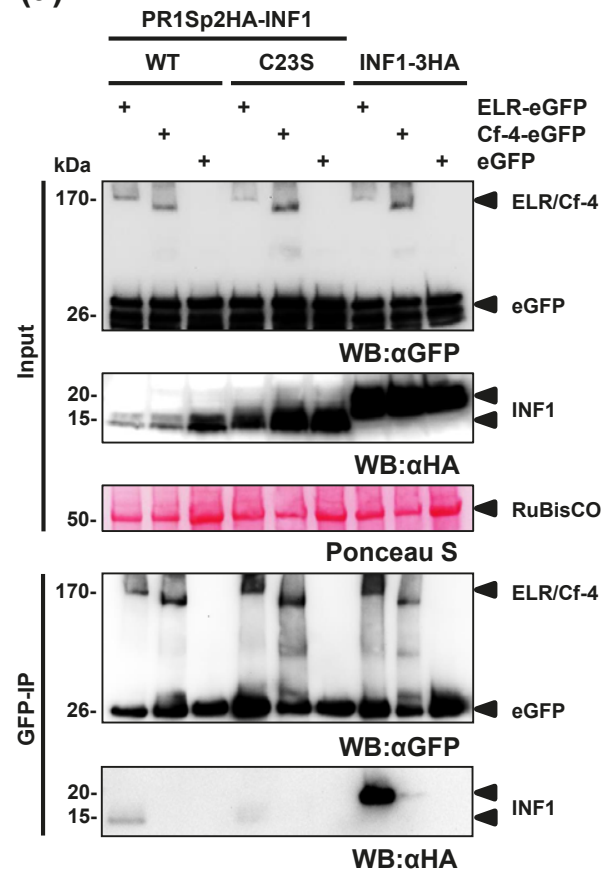

(b)

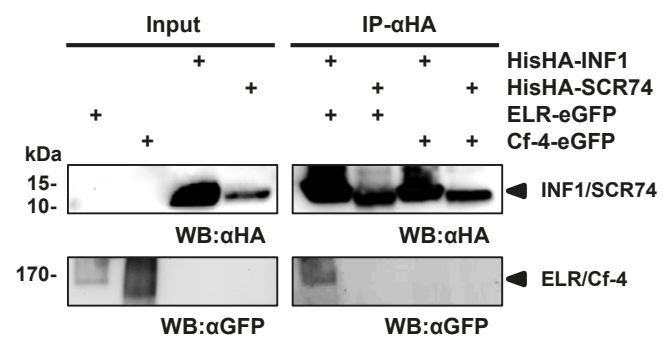

(c)

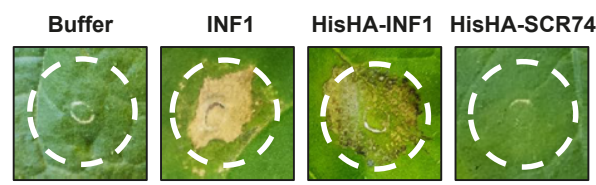

FIGURE 1 | ELR associates with INF1 elicitin in planta and under in vitro conditions. (a) N-terminal HA-tagged INF1 wild type (PR1Sp-2HA-INF1'TT), the INF1 ${ }^{\text {c23s }}$ cysteine mutant (PR1Sp-2HA-INF1 ${ }^{\text {C23S }}$ ) or C-terminal HA-tagged INF1 (INF1-3HA) were co-expressed with ELR-eGFP, Cf-4-eGFP or GFP in Nicotiana benthamiana. Total protein was extracted at 2 days post infiltration and was subjected to immunoprecipitation using anti-GFP beads to capture ELR-eGFP, Cf-4-eGFP and GFP. The immunopurified proteins were detected with anti-GFP, while their interaction with INF1 was assessed with anti-HA antibodies. Ponceau S staining of RuBisCO indicates equal protein loading. Results are representative of three biological repeats. (b) Purified recombinant HisHA-INF1 or HisHA-Scr74 were incubated at an saturating amount ( 500 pmol each) with anti-HA beads for $30 \mathrm{~min}$. Subsequently, beads were washed and a diluted ELR-eGFP- or Cf-4-eGFP-containing extract (from transiently transformed $N$. benthamiana) was incubated with the beads. After a $1 \mathrm{~h}$ incubation, samples were separated with SDS-PAGE and western blotting was performed. The immunopurified effector proteins HisHA-INF1 and HisHA-SCR74 were detected with anti-HA antibodies, while the interaction with ELR was assessed with anti-GFP. Ponceau S or CBB staining indicate equal loading. Results are representative of two biological repeats. (c) Functionality test of $1 \mu \mathrm{M}$ recombinant HisHA-INF1 and HisHA-Scr74 proteins in $N$. benthamiana, compared to INF1 produced in P. infestans culture filtrate.

\section{ELR associates with INF 1 in vitro}

To further validate the association between ELR and INF1, we designed an in vitro binding assay with purified INF1 protein. His-HA tagged INF1 as well as an unrelated protein SCR74 were produced in Pichia pastoris (Liu et al., 2005; Domazakis et al., 2017) and purified using cation exchange. To test for association, ELR-eGFP and Cf-4-eGFP receptors were transiently expressed in N. benthamiana as described above and were tested for association with effector proteins. First, 
the His-HA-INF1 and His-HA-SCR74 proteins were immuno-absorbed in antiHA beads at saturating amounts. Diluted $N$. benthamiana extract containing either ELR-eGFP or Cf-4-eGFP was applied to the beads in binding buffer. After incubation and washing, we found that ELR-eGFP is specifically being captured from the plant extract by INF1 but not by the control protein SCR74 (Fig. 1b). In contrast, Cf-4-eGFP was not associating with either of these effectors, as expected. As a control, we confirmed that the recombinant His-HA-INF1 is recognized in N. benthamiana similar to INF1 from P. infestans, as expected, while His-HA-SCR74 is not recognized (Fig. 1C). These data show that ELR specifically associates with INF1 and complements the in planta observations.

\section{AVR3a does not affect binding of ELR to INF 1 but alters protein ubiquitination}

Several cytoplasmic effectors from Phytophthora sojae and P. infestans are able to suppress INF1 response (Bos et al., 2006; Oh et al., 2009; Wang et al., 2011; Zheng et al., 2014; Derevnina et al., 2016). Among the most studied RxLR effectors with such function is AVR3a. We hypothesized that the (cytoplasmic) AVR3a protein is unlikely to cause inhibition of ELR binding with INF1 since that occurs in the apoplast. To test this hypothesis, we co-expressed ELR with INF1 in $N$. benthamiana, together with untagged $A V R 3 a^{\mathrm{KI}}$ and $\mathrm{AVR} 3 \mathrm{a}^{\mathrm{EM}}$, that represent the avirulence and virulence allele of AVR3a, respectively (Bos et al., 2009). After coimmunoprecipitation, we found that co-expression with either AVR3a allele does not affect binding of ELR to INF1, as expected (Fig. S3). However a reduction in the accumulation of both ELR and INF1 proteins could be observed.

AVR3a is known to interact and inhibit the E3 ubiquitin ligase CMPG1 and to interact with DRP2, a protein involved in receptor-mediated protein endocytosis (Bos et al., 2010; Chaparro-Garcia et al., 2015). In both cases, AVR3a seems to interfere with receptor internalization, where ubiquitination is an important component. To test what is the effect of AVR3a on ELR ubiquitination, we performed western blot with an antibody recognizing linked ubiquitin. We found that $A V R 3 a^{\mathrm{KI}}$ and $A \mathrm{VR} 3 \mathrm{a}^{\mathrm{EM}}$ are both causing a profound decrease in total protein ubiquitination (Fig. S3, inputs) which is also observed after immunoprecipitation of ELR. Interestingly, similar results were reported previously where AVR3a ${ }^{\mathrm{KI}}$ was found to decrease smearing (indication of ubiquitination) of observed western blot bands when co-expressed with the RLKs FLS2, EFR and BAK1 (see Fig. A2.3., (Chaparro-Garcia, 2012)). From those preliminary findings we can hypothesize that AVR3a is not inhibiting interaction of ELR with INF1, but rather plays a role in inhibiting downstream signaling by affecting ubiquitination (Bos et al., 2010; Chaparro-Garcia et al., 2015). 


\section{ELR associates in planta with ELI-1 elicitins}

In contrast to other PRRs that recognize small epitopes of their cognate MAMP and often do not lead to cell death, ELR seems to recognize some structural domain of elicitins and can induce cell death in plants (Du et al., 2015). For studying whether the cell death inducing activity by the various elicitins is associated with their binding ability to ELR, we generated affinity tagged versions of diverse elicitin domains from various Phytophthora and one Pythium species. More specifically, $\mathrm{N}^{\prime}$-HA-tagged elicitin domains of INF1, INF2A, INF2B, INL1 from P. infestans, ParA1 from $P$. parasitica, CRY2 from P. cryptogea and PYU1 from Pythium ultimum. The tested elicitins belong to two different classes, i.e. ELI-1 and ELI-2 with INL1 (class ELL) and PYU1 serving as outgroups (Fig. S1a, b, c) and share 23-94\% amino acid identity to INF1. Subsequent agro-coinfiltrations were performed with ELR in Solanum hjertingii, a wild Solanum genotype that does not respond to elicitins (Fig. 2a, b). We found that the tagged elicitins INF1, ParA1, CRY2 (ELI-1) and INF2A (ELI-2) induced significant cell death when co-expressed with ELR at 3 days postinfiltration, as expected (Du et al., 2015) (Fig. 2a, b). To further confirm the cell death inducting activity of those elicitins, we agroinfiltrated them in Nicotiana tabacum, a species well known for responding to elicitins (Ricci et al., 1989; Huitema et al., 2005; Hoeberichts et al., 2013). In tobacco, additional cell death is found for INF2B compared to ELR, similar to what has been described (Huitema et al., 2005). In addition, the INF1 ${ }^{\text {C23S }}$ mutant induced cell death in this plant, as a possible result of relatively high concentration of in planta expressed protein together with higher sensitivity of Nicotiana plants to elicitins (Vleeshouwers et al., 2006) (Fig. S4).

To investigate whether elicitin-induced cell death activity is associated with their binding ability with ELR, we performed an in planta co-immunoprecipitation experiment of ELR-eGFP with the diverse tagged elicitins. N'-HA-tagged INF1 and INF1 ${ }^{\text {C23S }}$ were used as positive and negative controls, respectively (Fig. 2c). We found that, besides INF1, ELR interacts with ParA1 and $\beta$-CRY, which also belongs to the same ELI-1 class (Fig. S1C). CRY2 and INF2A (Fig. S1a, b) that share a lower amino acid identities to INF1 (74\% and 52\%, respectively), may exhibit lower affinity to ELR and remain below the detection threshold of our assay, however in planta, these elicitins trigger significant cell death when co-expressed with the receptor (Du et al., 2015) (Fig. 2a, b). Overall, these data confirm that ELR is able to recognize and associate with elicitins beyond $P$. infestans and is supported by co-immunoprecipitation experiments for three ELI-I elicitins. 
(a)

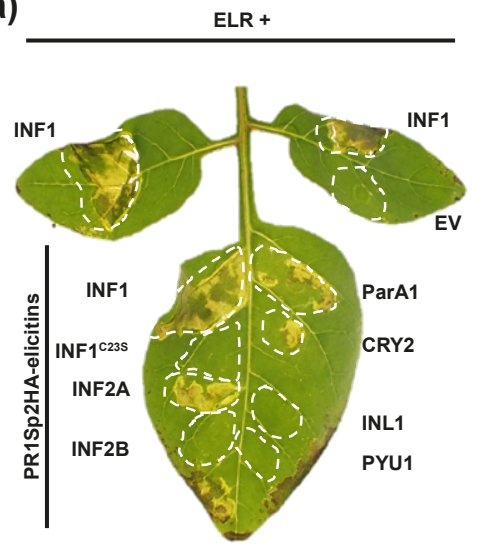

(b)

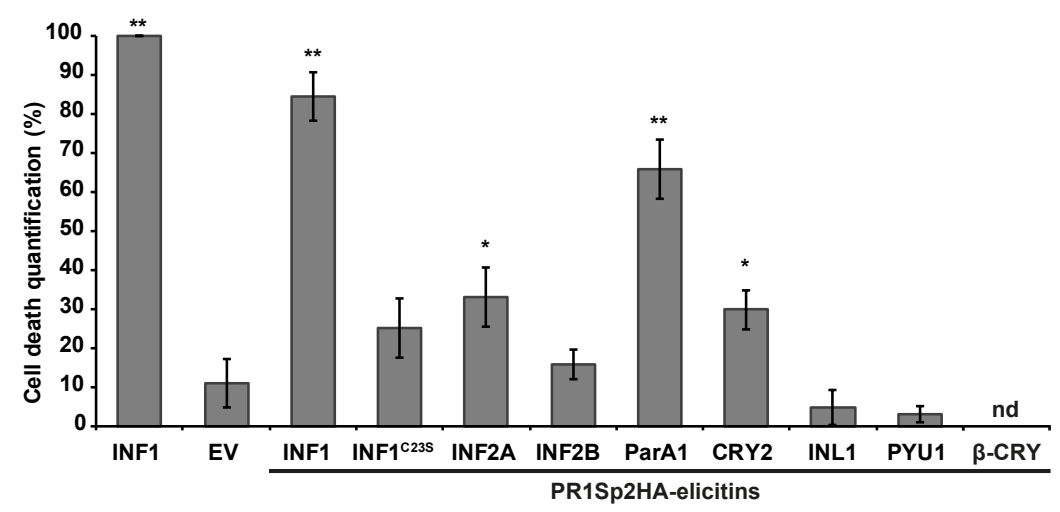

(c) ELR-eGFP + PR1Sp2HA-elicitins
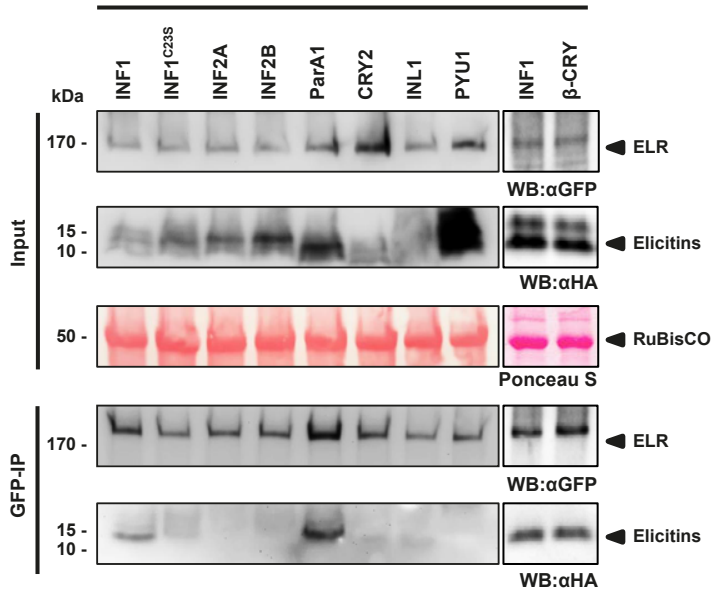

FIGURE 2 |ELR recognizes diverse elicitins and associates in planta with elicitins ParA1 and $\beta$-CRY from Phytophthora parasitica and $P$. cryptogea, respectively. Seven diverse elicitins (ParA1, CRY2, $\beta$-CRY, INF2A, INF2B, INL1 and PYU1) were tested for recognition by ELR together with INF1 and INFC23S as controls. (a) N-terminal HA-tagged elicitin recognition in Solanum hjertinjii 349-5 upon their transient co-expression with ELR (data not available for $\beta$-CRY). (b) quantification of cell death phenotypes from experiment (a). (c) Co-immunoprecipitation of ELR with $\mathrm{N}$-terminal HA-tagged elicitins. Total protein was extracted at 2 days post infiltration and was subjected to immunoprecipitation using anti-GFP beads to capture ELR. The immunopurified proteins were detected with anti-GFP, while the interaction with elicitins was assessed with anti-HA antibodies. Ponceau S staining of RuBisCO indicates equal protein loading. Results are representative of three biological repeats.

\section{Binding to ELR and cell death induction can be uncoupled}

Adding affinity tags to proteins is known to sometimes affect their function or interaction with other proteins. For example, $C^{\prime}-\mathrm{HA}$ tagging of BAK1 showed decreased reactive oxygen species (ROS) signaling potency while it did not affect association with FLS2 (Ntoukakis et al., 2011; Schwessinger et al., 2011). As described above, agroinfiltration of $\mathrm{N}^{\prime}$-terminal tagged elicitins led to cell death 
but the $C^{\prime}$-tagged INF1-3HA did not (Fig. S5a, b, c). This finding was unexpected, since this INF1-3HA version is still able to associate with ELR (Figs. 1, S5d). Since $3 \times \mathrm{HA}$ tag is relatively small, we hypothesized that a potential oligomerization may be happening to INF1-3HA that is leading to increased size and is thereby preventing association with downstream interactors. In line with this, elicitins cinnamomin (87\% identity to INF1) (Rodrigues et al., 2006) and $\beta$-CRY (79\% identity to INF1) (Uhlíková et al., 2016) can dimerize through helix A interactions (Fig. S6d), and elicitins POD-1 and POD-2 can form heterohexamers (Takenaka et al., 2011). An important role in the POD-1/POD-2 heterohexamer structure stabilization has a $C^{\prime}$ extension terminated by Cys residue (Takenaka et al., 2011), which was reminiscent of the extra Cys in the 3HA-tag of INF1-3HA (Fig. S6a, b, c). Indeed, in contrast to PR1Sp2HA-INF1, the majority of INF1-3HA protein migrates as a band of about $120 \mathrm{kDa}$ under non-reducing SDS-PAGE after agroinfiltration in N. benthamiana, which may correspond to the INF1 hexamer form (Fig. S6b, c). Under reduction conditions, the band of $20 \mathrm{kDa}$ is observed, as expected.

We have shown that ELR associates with both SERK3 and SOBIR1 (Domazakis et al., 2018). To test whether formation of INF1-3HA polymer affects the interaction of co-receptors downstream of ELR binding, we simultaneously co-expressed ELR N'- and C'-tagged INF1 together with SOBIR1 and SERK3. Cf-4 was used as a negative control. After co-immunoprecipitation with aGFP, we found that in all cases, ELR was able to interact with both INF1 versions, as expected (Figs. 1, S5d). Intriguingly, upon co-expression of ELR with INF1-3HA, interaction with SOBIR1 was severely decreased while interaction with SERK3 was almost completely abolished. In contrast, when PR1Sp2HA-INF1 was used, interaction of ELR with both SOBIR 1 and SERK3 was evident, as expected (Fig. S5d). From this we conclude that $C^{\prime}$-3HA-tagged INF1 binding to ELR is indeed inhibiting the formation of the signaling potent ELR-SOBIR1-SERK3 complex (Domazakis et al., 2018).

\section{Elicitin dimerization leads to reduced ELR-mediated cell death}

ELI-1 $\beta$-CRY elicitin can form dimers, which cause less cell death than the monomers when infiltrated in tobacco (Gooley et al., 1998; Ponchet et al., 1999). More specifically, a chemically cross-linked dimer of $\beta$-CRY ( $\beta$-CRYDIM) was largely compromised in induction of cell death (Uhlíková et al., 2016). Hence, to strengthen our conclusions with $C^{\prime}$-3HA-tagged INF1, we tested whether the $\beta$-CRYDIM loss of cell death induction with ELR is due to co-receptor competition as well. To test this, we co-expressed ELR together with SOBIR1 and SERK3 in N. benthamiana leaves and two days later, we infiltrated leaves with $\beta$-CRY and $\beta$-CRYDIM purified proteins. After co-immunoprecipitation, we found that, similarly to INF1-3HA, treatment with $\beta$-CRYDIM abolished the interaction of ELR with SOBIR1 whereas the 
interaction with SERK3 remained unchanged (Fig. S7a). This potentially explains the observed accumulation of PR1 and PR5 transcripts (Fig. S7b, c, d). Indeed, from studies on FLS2 it is known that ROS burst and MAPK3/6 activation are two independent early events (Xu et al., 2014). SOBIR1 is clearly connected to ROS production, endocytosis and activation of cell death in Arabidopsis (Gao et al., 2009) and tomato (Peng et al., 2015) and loss of its interaction with ELR is expected to negatively affect cell death induction upon INF1 perception. Those observations further support the previous conclusion with $C^{\prime}-3 H A$-tagged INF1, and are in agreement with the notion that both SOBIR1 and SERK3 are required to obtain a signal reaching the threshold for cell death (Mur et al., 2008; ChaparroGarcia et al., 2011; Adachi et al., 2015; Domazakis et al., 2018). However, the difference in the competition rates for SERK3 and SOBIR1 likely depends on the elicitin oligomer size or it is due to their binding in distinct parts of ELR.

\section{The $\boldsymbol{\omega}$-loop region of elicitins is likely involved in ELR binding}

Elicitin dimerization leaves the $\omega$-loop region found opposite of helix $A$ exposed. Previously, within $\omega$-loop an important role of residue Leu41 in the binding process to the potential partner in plant responsible for defense response was proved (Dokládal et al., 2012). Interestingly, the less active proteins INF2A and INF2B (compare to INF1, ParA1, CRY2, $\beta$-CRY) contain within the $\omega$-loop region at position 43 an Asp residue, instead of Thr (Fig. S6e). This fact could influence proteinbinding activity to ELR and lead to weakened interaction. We thus hypothesize that the potential binding site of elicitins to ELR is located in this $\omega$-loop region.

\section{Binding of INF 1 to ELR triggers changes in co-receptor accumulation and phosphorylation dynamics}

Binding of ligands to PRRs is known to trigger spatio-temporal changes in PRR/ co-receptor complexes (Bücherl et al., 2017). To study the effect of INF1 on the ELR/SOBIR1/SERK3 complex, we performed agro-coinfiltration of ELR and coreceptors in N. benthamiana, followed by INF1 elicitation. When ELR and SOBIR1 were co-expressed, a stabilization of ELR was observed, as expected (Domazakis et al., 2018). However, INF1 elicitation led to a rapid decrease in the accumulation of both ELR and SOBIR1 (Fig. S8a, b). This effect was not evident when ELR was coexpressed with both SOBIR1 and SERK3. In contrast, when ELR was co-expressed with SERK3 alone, there was no significant change in its accumulation upon INF1 elicitation (Fig. S8a, b). 
For monitoring the phosphorylation status of the elicitin perception complex, ELR, SOBIR1 and SERK3 were co-expressed and samples were collected with or without INF1 elicitation. Immunoprecipitations were performed for capturing ELR, SOBIR1 or SERK3 and samples were separated in a special gel (Phos-Tag) which causes phosphorylated proteins to migrate slower (Kinoshita et al., 2006). Using this method, we found that ELR is not phosphorylated, as expected by its lack of kinase domain. SERK3 on the other hand showed that it is constitutively phosphorylated in two states, with INF1 elicitation inducing one state over the other (Fig. S8b). For SOBIR1, we also found that it is phosphorylated, likely in two stages as well. However, INF1 elicitation resulted in a severe decrease in its accumulation, and the phosphorylated bands could not be discriminated. We conclude that INF1 elicitation causes changes in the dynamics of the ELR complex accumulation and co-receptor phosphorylation status. This is in line with previous findings where the formation of SOBIR1-containing endosomes upon elicitation with ParA1 elicitin was described (Peng et al., 2015). We thus hypothesize that the rapid decrease in ELR and SOBIR1 accumulation upon INF1 elicitation is due to the formation of endosomes, which are insoluble in our assays while SERK3 is likely not present in these vesicles, remaining soluble.

\section{Conclusion}

Reverse genetics using effector screens led to the identification of ELR, however, evidence of ELR functioning as a genuine PRR was lacking so far. In this study we demonstrated that ELR is able to bind elicitins. In addition, we have shown that only monomeric elicitins can trigger cell death upon binding to ELR, as elicitin dimers/hexamers are not allowing the normal formation of an ELR-SOBIR1-SERK3 complex. To our knowledge, this is the first report of a co-receptor inhibition by an effector protein and highlights the importance of performing functional tests for any recombinant fusion protein. This mechanistic uncoupling of ELR from co-receptors could be potentially utilized in plant immune signaling studies. For example, by inhibiting ELR/SOBIR1/SERK3 (with INF1-3HA) or ELR/SOBIR1 (with $\beta$-CRYDIM) complex formation, studies on RLPs-mediated signaling could be facilitated. Finally, the use of immobilized INF1 on a matrix to identify ELR suggests the potential of using immobilized effectors for identifying their respective PRRs using proteomics in transformation-recalcitrant plant species (Boutrot and Zipfel, 2017). 


\section{References}

Adachi, H., Nakano, T., Miyagawa, N., Ishihama, N., Yoshioka, M., Katou, Y., Yaeno, T., Shirasu, K., and Yoshioka, H. 2015. WRKY transcription factors phosphorylated by MAPK regulate a plant immune NADPH oxidase in Nicotiana benthamiana. Plant Cell 27:2645-2663.

Albert, I., Bohm, H., Albert, M., Feiler, C.E., Imkampe, J., Wallmeroth, N., Brancato, C., Raaymakers, T.M., Oome, S., Zhang, H., Krol, E., Grefen, C., Gust, A.A., Chai, J., Hedrich, R., van den Ackerveken, G., and Nurnberger, T. 2015. An RLP23-SOBIR1-BAK1 complex mediates NLP-triggered immunity. Nat Plants 1:15140.

Bohm, H., Albert, I., Oome, S., Raaymakers, T.M., van den Ackerveken, G., and Nurnberger, T. 2014. A conserved peptide pattern from a widespread microbial virulence factor triggers patterninduced immunity in Arabidopsis. PLoS Pathog 10:e1004491.

Bos, J.I., Chaparro-Garcia, A., Quesada-Ocampo, L.M., McSpadden Gardener, B.B., and Kamoun, S. 2009. Distinct amino acids of the Phytophthora infestans effector AVR3a condition activation of R3a hypersensitivity and suppression of cell death. Mol Plant Microbe Interact 22:269-281.

Bos, J.I., Kanneganti, T.D., Young, C., Cakir, C., Huitema, E., Win, J., Armstrong, M.R., Birch, P.R., and Kamoun, S. 2006. The C-terminal half of Phytophthora infestans RXLR effector AVR3a is sufficient to trigger R3a-mediated hypersensitivity and suppress INF1-induced cell death in Nicotiana benthamiana. Plant J 48:165-176.

Bos, J.I., Armstrong, M.R., Gilroy, E.M., Boevink, P.C., Hein, I., Taylor, R.M., Zhendong, T., Engelhardt, S., Vetukuri, R.R., Harrower, B., Dixelius, C., Bryan, G., Sadanandom, A., Whisson, S.C., Kamoun, S., and Birch, P.R. 2010. Phytophthora infestans effector AVR3a is essential for virulence and manipulates plant immunity by stabilizing host E3 ligase CMPG1. Proc Natl Acad Sci USA 107:9909-9914.

Boutrot, F., and Zipfel, C. 2017. Function, discovery, and exploitation of plant pattern recognition receptors for broad-spectrum disease resistance. Annu Rev Phytopathol 55:257-286.

Bucherl, C.A., Jarsch, I.K., Schudoma, C., Segonzac, C., Mbengue, M., Robatzek, S., MacLean, D., Ott, T., and Zipfel, C. 2017. Plant immune and growth receptors share common signalling components but localise to distinct plasma membrane nanodomains. eLife 6:e25114.

Chaparro-Garcia, A. 2012. Molecular basis of plant cell death suppression by the Phytophthora infestans effector AVR3a (PhD dissertation), University of East Anglia.

Chaparro-Garcia, A., Wilkinson, R.C., Gimenez-lbanez, S., Findlay, K., Coffey, M.D., Zipfel, C., Rathjen, J.P., Kamoun, S., and Schornack, S. 2011. The receptor-like kinase SERK3/BAK1 is required for basal resistance against the late blight pathogen Phytophthora infestans in Nicotiana benthamiana. PLoS One 6:e16608.

Chaparro-Garcia, A., Schwizer, S., Sklenar, J., Yoshida, K., Petre, B., Bos, J.I., Schornack, S., Jones, A.M., Bozkurt, T.O., and Kamoun, S. 2015. Phytophthora infestans RXLR-WY effector AVR3a associates with dynamin-related protein 2 required for endocytosis of the plant pattern recognition receptor FLS2. PLoS One 10:e0137071.

Couto, D., and Zipfel, C. 2016. Regulation of pattern recognition receptor signalling in plants. Nat Rev Immunol 16:537-552.

Derevnina, L., Dagdas, Y.F., De la Concepcion, J.C., Bialas, A., Kellner, R., Petre, B., Domazakis, E., Du, J., Wu, C.H., Lin, X., Aguilera-Galvez, C., Cruz-Mireles, N., Vleeshouwers, V.G.A.A., and Kamoun, S. 2016. Nine things to know about elicitins. New Phytol 212:888-895.

Dodds, P.N., and Rathjen, J.P. 2010. Plant immunity: towards an integrated view of plant-pathogen interactions. Nat Rev Genet 11:539-548.

Dokládal, L., Obořil, M., Stejskal, K., Zdráhal, Z., Ptáčková, N., Chaloupková, R., Damborský, J., Kašparovský, T., Jeandroz, S., Žd'árská, M., and Lochman, J. 2012. Physiological and proteomic approaches to evaluate the role of sterol binding in elicitin-induced resistance. J Exp Bot 63:2203-2215.

Domazakis, E., Wouters, D., Visser, R.G.F., Kamoun, S., Joosten, M.H.A.J., and Vleeshouwers, V.G.A.A. 2018. The ELR-SOBIR1 complex functions as a two-component RLK to mount defense against Phytophthora infestans Mol Plant Microbe Interact (Accepted).

Domazakis, E., Lin, X., Aguilera-Galvez, C., Wouters, D., Bijsterbosch, G., Wolters, P.J., and Vleeshouwers, V.G.A.A. 2017. Effectoromics-based identification of cell surface receptors in potato. Pages 337353 in: Plant Pattern Recognition Receptors: Methods and Protocols, L. Shan and P. He, eds. Springer, New York. 
Du, J., and Vleeshouwers, V.G.A.A. 2014. The Do's and Don'ts of Effectoromics. Pages 257-268 in: PlantPathogen Interactions.

Du, J., Verzaux, E., Chaparro-Garcia, A., Bijsterbosch, G., Keizer, L.C., Zhou, J., Liebrand, T.W., Xie, C., Govers, F., Robatzek, S., van der Vossen, E.A., Jacobsen, E., Visser, R.G., Kamoun, S., and Vleeshouwers, V.G.A.A. 2015. Elicitin recognition confers enhanced resistance to Phytophthora infestans in potato. Nat Plants 1:15034.

Felix, G., Duran, J.D., Volko, S., and Boller, T. 1999. Plants have a sensitive perception system for the most conserved domain of bacterial flagellin. Plant J 18:265-276.

Gao, M., Wang, X., Wang, D., Xu, F., Ding, X., Zhang, Z., Bi, D., Cheng, Y.T., Chen, S., Li, X., and Zhang, Y. 2009. Regulation of cell death and innate immunity by two receptor-like kinases in Arabidopsis. Cell Host Microbe 6:34-44.

Gooley, P.R., Keniry, M.A., Dimitrov, R.A., Marsh, D.E., Keizer, D.W., Gayler, K.R., and Grant, B.R. 1998. The NMR solution structure and characterization of $\mathrm{pH}$ dependent chemical shifts of the $\beta$-elicitin, cryptogein. J Biomol NMR 12:523-534.

Hoeberichts, F.A., Davoine, C., Vandorpe, M., Morsa, S., Ksas, B., Stassen, C., Triantaphylides, C., and van Breusegem, F. 2013. Cryptogein-induced transcriptional reprogramming in tobacco is light dependent. Plant Physiol 163:263-275.

Huitema, E., Vleeshouwers, V.G.A.A., Cakir, C., Kamoun, S., and Govers, F. 2005. Differences in intensity and specificity of hypersensitive response induction in Nicotiana spp. by INF1, INF2A, and INF2B of Phytophthora infestans. Mol Plant Microbe Interact 18:183-193.

Jiang, R.H., Tyler, B.M., Whisson, S.C., Hardham, A.R., and Govers, F. 2006. Ancient origin of elicitin gene clusters in Phytophthora genomes. Mol Biol Evol 23:338-351.

Kamoun, S., van West, P., Vleeshouwers, V.G.A.A., de Groot, K.E., and Govers, F. 1998. Resistance of Nicotiana benthamiana to Phytophthora infestans is mediated by the recognition of the elicitor protein INF1. Plant Cell 10:1413-1426.

Kamoun, S., van West, P., de Jong, A.J., de Groot, K.E., Vleeshouwers, V.G.A.A., and Govers, F. 1997. A gene encoding a protein elicitor of Phytophthora infestans is down-regulated during infection of potato. Mol Plant Microbe Interact 10:13-20.

Karimi, M., Inze, D., and Depicker, A. 2002. GATEWAY vectors for Agrobacterium-mediated plant transformation. Trends Plant Sci 7:193-195.

Kinoshita, E., Kinoshita-Kikuta, E., Takiyama, K., and Koike, T. 2006. Phosphate-binding tag, a new tool to visualize phosphorylated proteins. Mol Cell Proteomics 5:749-757.

Kunze, G., Zipfel, C., Robatzek, S., Niehaus, K., Boller, T., and Felix, G. 2004. The N terminus of bacterial elongation factor Tu elicits innate immunity in Arabidopsis plants. Plant Cell 16:3496-3507.

Liebrand, T.W., van den Burg, H.A., and Joosten, M.H. 2014. Two for all: receptor-associated kinases SOBIR1 and BAK1. Trends Plant Sci 19:123-132.

Liu, Z., Bos, J.I., Armstrong, M., Whisson, S.C., da Cunha, L., Torto-Alalibo, T., Win, J., Avrova, A.O., Wright, F., Birch, P.R., and Kamoun, S. 2005. Patterns of diversifying selection in the phytotoxinlike scr74 gene family of Phytophthora infestans. Mol Biol Evol 22:659-672.

Mur, L.A.J., Kenton, P., Lloyd, A.J., Ougham, H., and Prats, E. 2008. The hypersensitive response; the centenary is upon us but how much do we know? J Exp Bot 59:501-520.

Murashige, T., and Skoog, F. 1962. A revised medium for rapid growth and bio assays with tobacco tissue cultures. Physiol Plant 15:473-497.

Nakagawa, T., Kurose, T., Hino, T., Tanaka, K., Kawamukai, M., Niwa, Y., Toyooka, K., Matsuoka, K., Jinbo, T., and Kimura, T. 2007. Development of series of gateway binary vectors, pGWBs, for realizing efficient construction of fusion genes for plant transformation. J Biosci Bioeng 104:34-41.

Ntoukakis, V., Schwessinger, B., Segonzac, C., and Zipfel, C. 2011. Cautionary notes on the use of C-terminal BAK1 fusion proteins for functional studies. Plant Cell 23:3871-3878.

Oh, S.K., Young, C., Lee, M., Oliva, R., Bozkurt, T.O., Cano, L.M., Win, J., Bos, J.I., Liu, H.Y., van Damme, M., Morgan, W., Choi, D., van der Vossen, E.A., Vleeshouwers, V.G.A.A., and Kamoun, S. 2009. In planta expression screens of Phytophthora infestans RXLR effectors reveal diverse phenotypes, including activation of the Solanum bulbocastanum disease resistance protein Rpi-blb2. Plant Cell 21:2928-2947. 
Peng, K.C., Wang, C.W., Wu, C.H., Huang, C.T., and Liou, R.F. 2015. Tomato SOBIR1/EVR homologs are involved in elicitin perception and plant defense against the oomycete pathogen Phytophthora parasitica. Mol Plant Microbe Interact 28:913-926.

Ponchet, M., Panabieres, F., Milat, M.L., Mikes, V., Montillet, J.L., Suty, L., Triantaphylides, C., Tirilly, Y., and Blein, J.P. 1999. Are elicitins cryptograms in plant-oomycete communications? Cell Mol Life Sci 56:1020-1047.

Qutob, D., Huitema, E., Gijzen, M., and Kamoun, S. 2003. Variation in structure and activity among elicitins from Phytophthora sojae. Mol Plant Pathol 4:119-124.

Ricci, P., Bonnet, P., Huet, J.C., Sallantin, M., Beauvais-Cante, F., Bruneteau, M., Billard, V., Michel, G., and Pernollet, J.C. 1989. Structure and activity of proteins from pathogenic fungi Phytophthora eliciting necrosis and acquired resistance in tobacco. Eur J Biochem 183:555-563.

Rodrigues, M.L., Archer, M., Martel, P., Miranda, S., Thomaz, M., Enguita, F.J., Baptista, R.P., Pinho e Melo, E., Sousa, N., Cravador, A., and Carrondo, M.A. 2006. Crystal structures of the free and sterolbound forms of beta-cinnamomin. Biochim Biophys Acta 1764:110-121.

Ron, M., and Avni, A. 2004. The receptor for the fungal elicitor ethylene-inducing xylanase is a member of a resistance-like gene family in tomato. Plant Cell 16:1604-1615.

Saur, I.M., Kadota, Y., Sklenar, J., Holton, N.J., Smakowska, E., Belkhadir, Y., Zipfel, C., and Rathjen, J.P. 2016. NbCSPR underlies age-dependent immune responses to bacterial cold shock protein in Nicotiana benthamiana. Proc Natl Acad Sci USA 113:3389-3394.

Schwessinger, B., Roux, M., Kadota, Y., Ntoukakis, V., Sklenar, J., Jones, A., and Zipfel, C. 2011. Phosphorylation-dependent differential regulation of plant growth, cell death, and innate immunity by the regulatory receptor-like kinase BAK1. PLoS Genet 7:e1002046.

Takenaka, S., Yamaguchi, K., Masunaka, A., Hase, S., Inoue, T., and Takahashi, H. 2011. Implications of oligomeric forms of POD-1 and POD-2 proteins isolated from cell walls of the biocontrol agent Pythium oligandrum in relation to their ability to induce defense reactions in tomato. J Plant Physiol 168:1972-1979.

Tang, D., Wang, G., and Zhou, J.M. 2017. Receptor kinases in plant-pathogen interactions: more than pattern recognition. Plant Cell 29:618-637.

Uhlikova, H., Oboril, M., Klempova, J., Sedo, O., Zdrahal, Z., Kasparovsky, T., Skladal, P., and Lochman, J. 2016. Elicitin-Induced distal systemic resistance in plants is mediated through the protein-protein interactions influenced by selected lysine residues. Front Plant Sci 7:59.

Vleeshouwers, V.G.A.A., Driesprong, J.D., Kamphuis, L.G., Torto-Alalibo, T., van't Slot, K.A., Govers, F., Visser, R.G., Jacobsen, E., and Kamoun, S. 2006. Agroinfection-based high-throughput screening reveals specific recognition of INF elicitins in Solanum. Mol Plant Pathol 7:499-510.

Wang, Q., Han, C., Ferreira, A.O., Yu, X., Ye, W., Tripathy, S., Kale, S.D., Gu, B., Sheng, Y., Sui, Y., Wang, X., Zhang, Z., Cheng, B., Dong, S., Shan, W., Zheng, X., Dou, D., Tyler, B.M., and Wang, Y. 2011. Transcriptional programming and functional interactions within the Phytophthora sojae RXLR effector repertoire. Plant Cell 23:2064-2086.

Xu, J., Xie, J., Yan, C., Zou, X., Ren, D., and Zhang, S. 2014. A chemical genetic approach demonstrates that MPK3/MPK6 activation and NADPH oxidase-mediated oxidative burst are two independent signaling events in plant immunity. Plant J 77:222-234.

Zhang, L., Kars, I., Essenstam, B., Liebrand, T.W., Wagemakers, L., Elberse, J., Tagkalaki, P., Tjoitang, D., van den Ackerveken, G., and van Kan, J.A. 2014. Fungal endopolygalacturonases are recognized as microbe-associated molecular patterns by the Arabidopsis receptor-like protein RESPONSIVENESS TO BOTRYTIS POLYGALACTURONASES1. Plant Physiol 164:352-364.

Zheng, X., McLellan, H., Fraiture, M., Liu, X., Boevink, P.C., Gilroy, E.M., Chen, Y., Kandel, K., Sessa, G., Birch, P.R.J., and Brunner, F. 2014. Functionally redundant RXLR Effectors from Phytophthora infestans act at different steps to suppress early flg22-triggered immunity. PLoS Pathog 10:e1004057.

Zipfel, C. 2014. Plant pattern-recognition receptors. Trends Immunol 35:345-351. 


\section{Supplementary information}

(a)
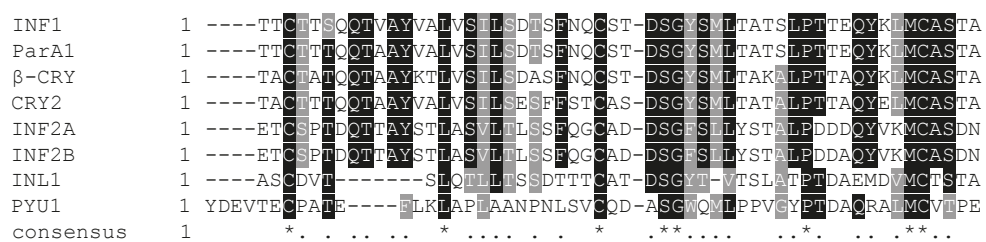

INF1

ParA1

$\beta-C R Y$

CRY2

INE2A

INF2B

INL1

PYU1

consensus

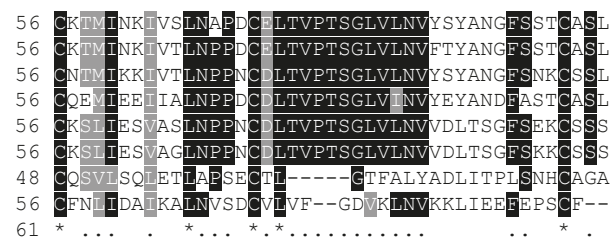

(b)

\begin{tabular}{ccccccccc}
\hline Elicitin & INF1 & ParA1 & $\boldsymbol{\beta}$-CRY & CRY2 & INF2A & INF2B & INL1 & PYU1 \\
\hline INF1 & ID & & & & & & & \\
ParA1 & $94 \%$ & ID & & & & & & \\
\hline $\boldsymbol{\beta}$-CRY & $81 \%$ & $83 \%$ & ID & & & & & \\
CRY2 & $74 \%$ & $77 \%$ & $73 \%$ & ID & & & & \\
INF2A & $52 \%$ & $53 \%$ & $56 \%$ & $52 \%$ & ID & & & \\
\hline INF2B & $51 \%$ & $53 \%$ & $57 \%$ & $53 \%$ & $97 \%$ & ID & & \\
INL1 & $27 \%$ & $29 \%$ & $32 \%$ & $33 \%$ & $31 \%$ & $32 \%$ & ID & \\
\hline PYU1 & $30 \%$ & $30 \%$ & $31 \%$ & $32 \%$ & $30 \%$ & $31 \%$ & $23 \%$ & ID \\
\hline
\end{tabular}

(c)

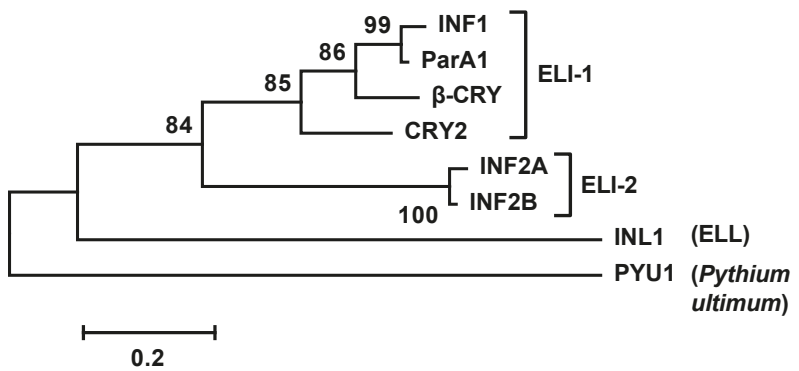

FIGURE S1 | Characteristics of elicitins used in this study. (a) The elicitin domains of eight elicitins from Phytophthora sp. and Pythium ultimum were aligned using COBALT, and BOXSHADE was used to visualize conservation. Residues identical in all sequences are highlighted in black while those identical in $>80 \%$ of the sequences are highlighted in grey. (b) Percentages of amino acid sequence identity of the elicitin domain between the different elicitins. (c) Neighbor-joining phylogenetic tree was created based on the 98 amino acid elicitin domain using MEGA 5.1. Bootstrap support values (1000 replicates) above $50 \%$ are given next to branches. 
(a)

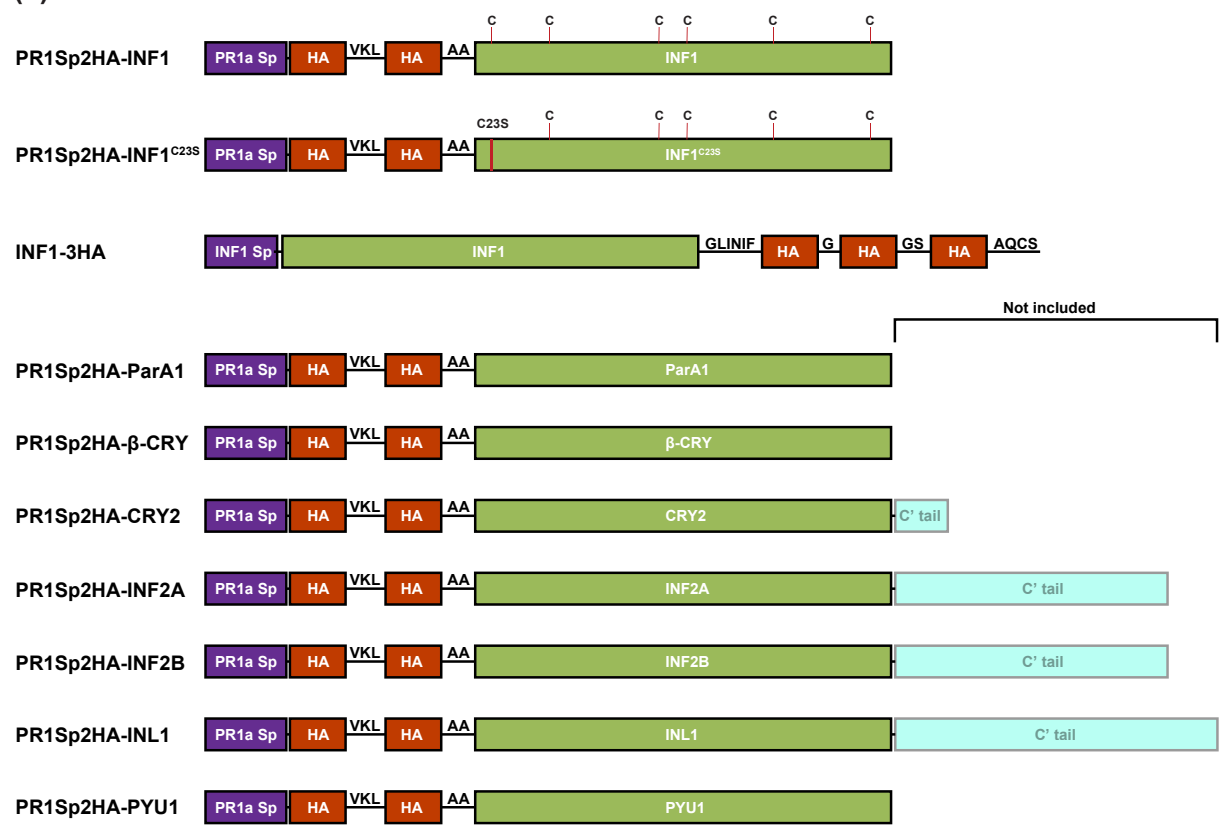

(b)

HisHA-INF1

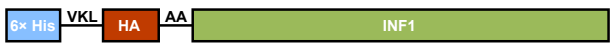

HisHA-SCR74

FIGURE S2 | Overview of affinity tagged elicitins used in this study. Effector constructs used for (a) transient expression in planta using Agrobacterium tumefaciens or for (b) recombinant protein expression in Pichia pastoris. Pathogenesis-related protein 1a (PR1a) or native INF1 signal peptides (Sp) were used while effectors were carrying hemagglutinin (HA) or histidine (His) tags, as indicated. 


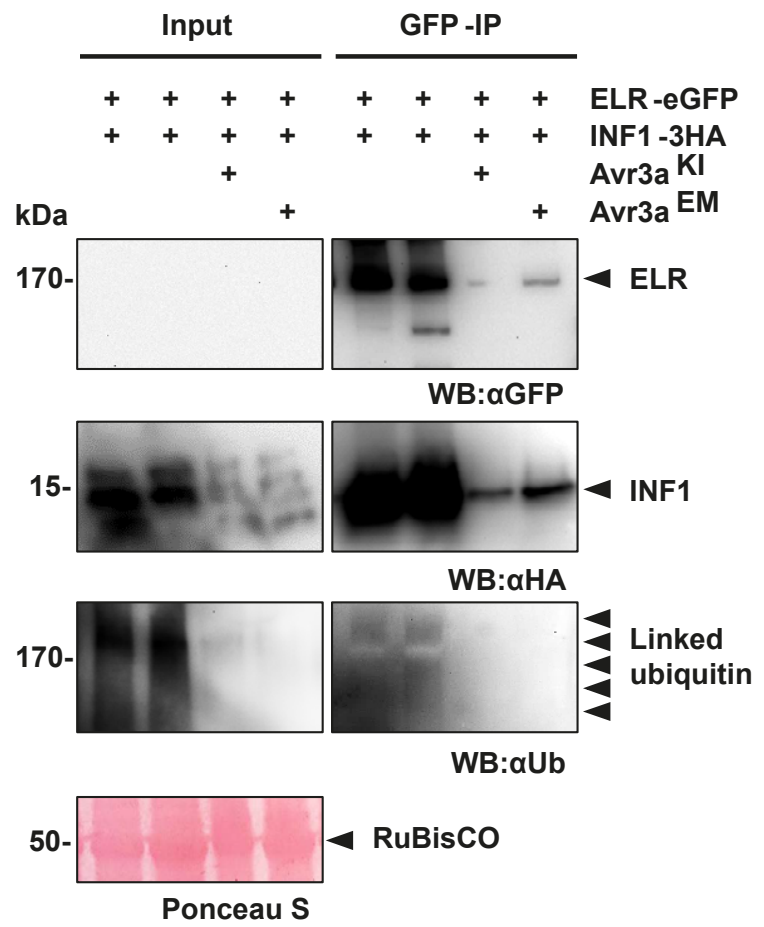

FIGURE S3 | Avr3a co-expression affects protein ubiquitination but not ELR binding with INF1. ELReGFP was co-expressed with INF1-3HA and Avr3a ${ }^{\mathrm{KI}}$ or Avr3a EMin Nicotiana benthamiana. Total protein was extracted at 2 days post infiltration and was subjected to immunoprecipitation using anti-GFP beads to capture ELR-eGFP. The immunopurified ELR was detected with anti-GFP, while its interaction with INF1 was assessed with anti-HA antibodies. Linked ubiquitin was detected with anti-Ub antibody. Ponceau S staining of RuBisCO indicates equal protein loading. Results are preliminary, from one experiment. 


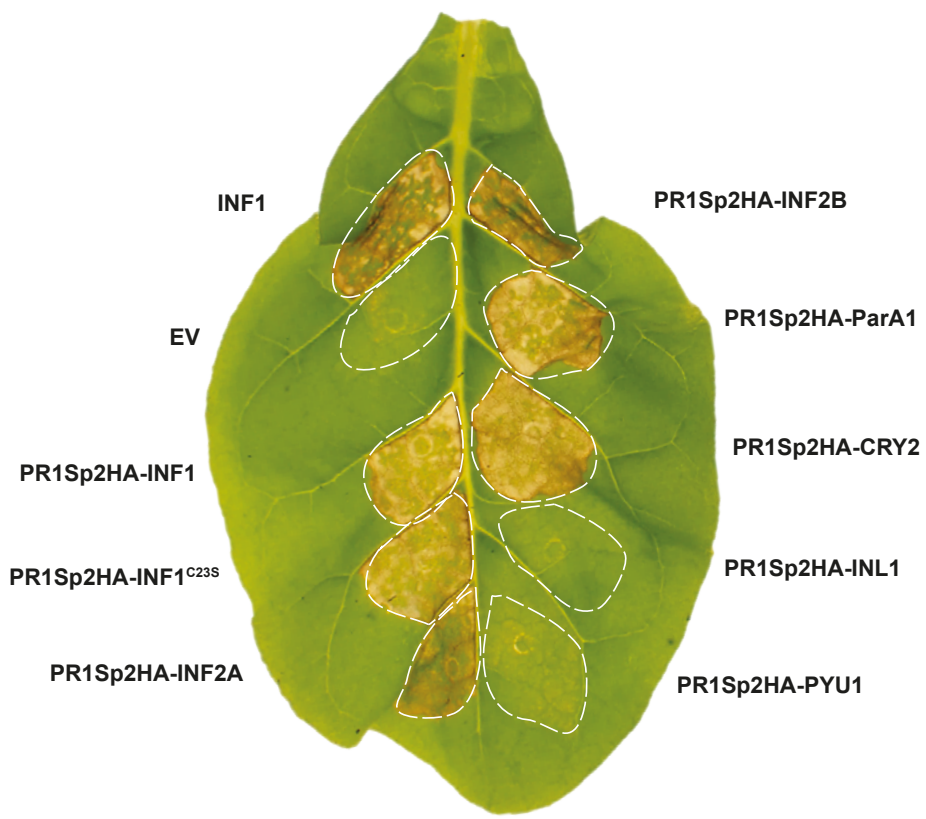

FIGURE S4 | N-terminal-HA-tagged elicitins are recognized in tobacco. $\mathrm{N}$-terminal-HA-tagged elicitins (PR1Sp-2HA-) were transiently expressed in Nicotiana tabacum SR1 for testing for cell death induction. Non-tagged INF1 and empty vector (EV) were used as controls. A representative leaf, photographed at $3 \mathrm{dpi}$, is shown. 
(a)

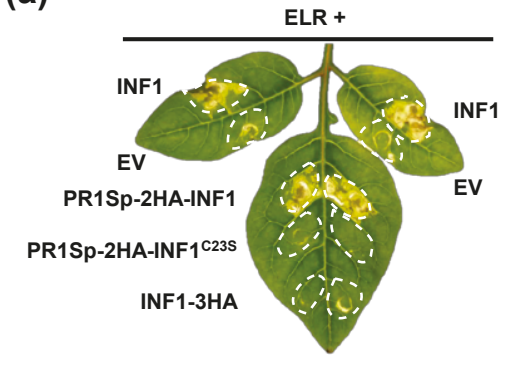

(b)

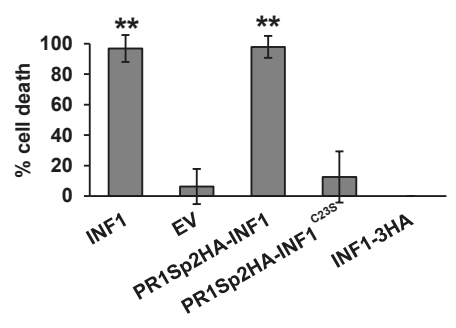

(c)

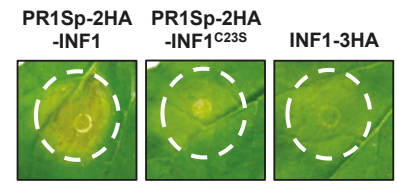

(d)

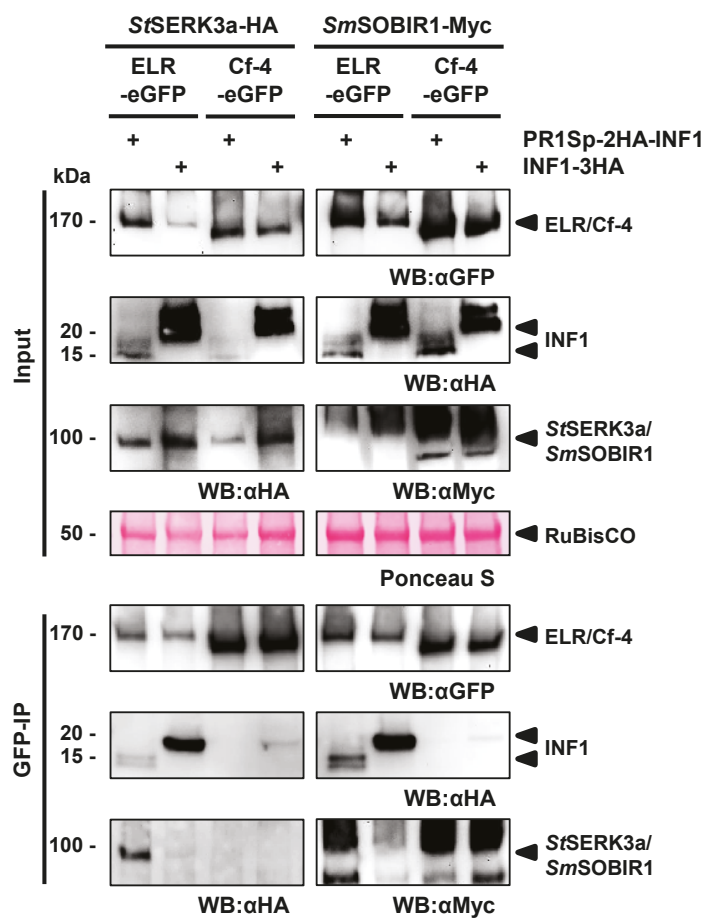

FIGURE S5 | C-terminal 3HA tagging of INF1 causes Inhibition of the interaction between ELR, SOBIR1 and SERK3, abolishing cell death induction. $(a, b)$ N-terminal HA tagged PR1Sp-2HA-INF1 and the PR1Sp-2HA-INF1 ${ }^{\mathrm{C} 23 S}$ mutant or C-terminal HA-tagged INF1 was transiently expressed in Solanum hjertingii 349-3 (together with ELR) or (c) in N. benthamiana. Photos of cell death responses were obtained at $3 \mathrm{dpi}$ (S. hjertinjii) or $5 \mathrm{dpi}$ (N. benthamiana). (d) N-terminal (PR1Sp-2HA-INF1) and C-terminal (INF1-3HA) HA-tagged INF1 was transiently co-expressed with ELR and StSERK3a or with ELR and SmSOBIR1 in Nicotiana benthamiana. Cf-4 was used as a negative control. Total protein was extracted and was subjected to immunoprecipitation using anti GFP beads to capture ELR-eGFP and Cf-4-eGFP. The immunopurified proteins were detected with anti-GFP, while the interaction with StSERK3a-HA, SmSOBIR1-Myc or HA-tagged INF1, as a result of co-immunoprecipitation of the latter proteins with the eGFP-tagged proteins, was assessed with anti-HA or anti-Myc, respectively. Ponceau $\mathrm{S}$ staining of RuBisCO indicates equal protein loading. 
a)

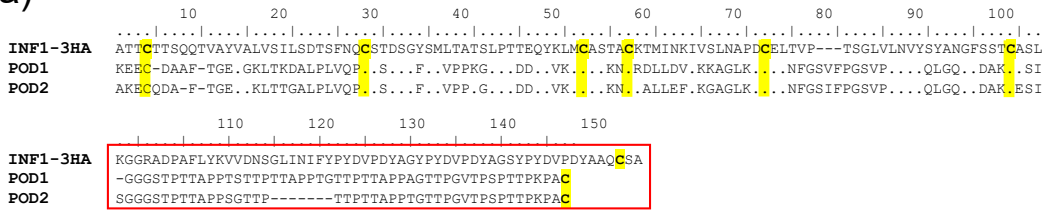

b)

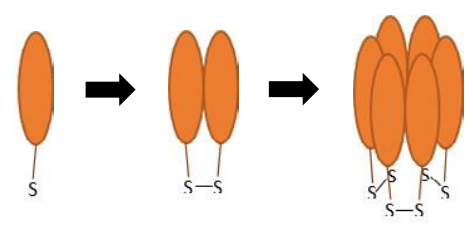

d)

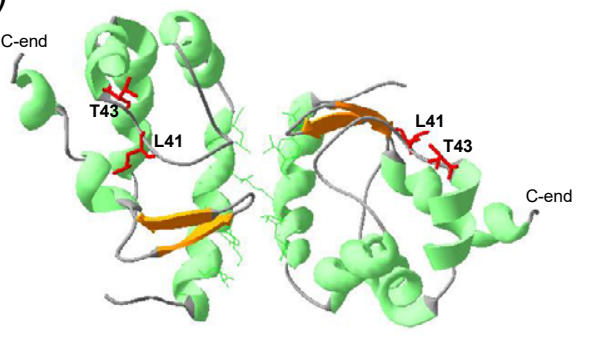

c)

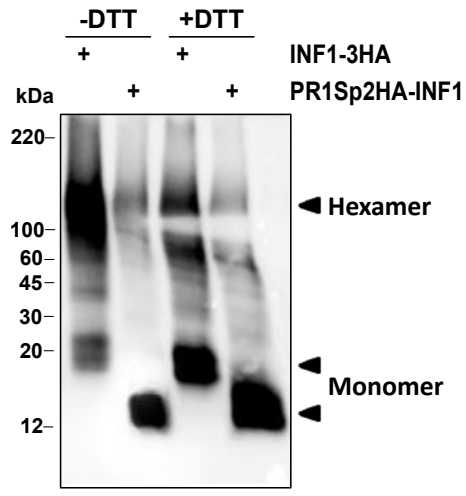

e)

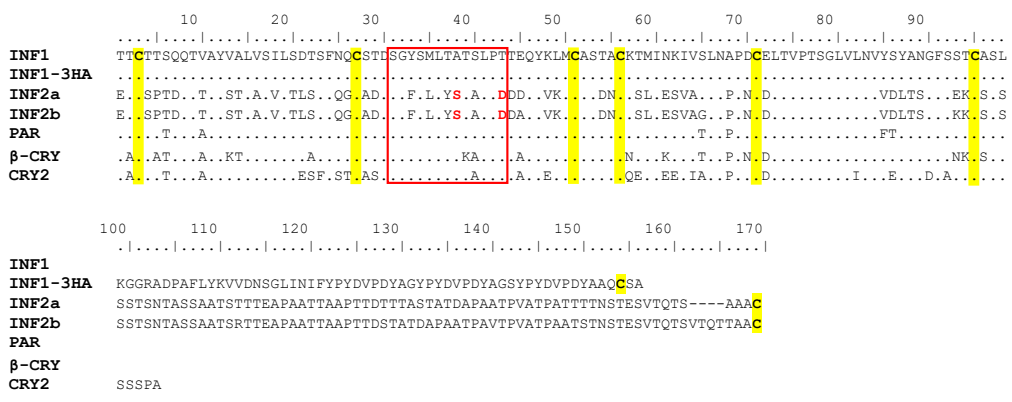

FIGURE S6 | Oligomerization of INF1-3HA and structure motifs likely involved in interaction with ELR. (a) Sequence alignment of INF1-3HA protein with elicitins POD1 and POD2 from Pythium oligandrum. C-terminal tails are framed in red. (b) Model of INF1-3HA oligomerization with disulfide bonds between the Cys7 residues. (c) N-terminal (PR1Sp2HA-INF1) and C-terminal (INF1-3HA) HA-tagged INF1 was transiently expressed in Nicotiana benthamiana. Total protein was extracted and subjected to SDSPAGE under reducing (+DTT) and non-reducing (-DTT) conditions. INF1-3HA protein was detected with anti-HA. (d) The structure of cinnamomin dimer loaded with sterol visualized using the VMD program (Humphrey et al., 1996). The surface-exposed residues located in omega loop region (Leu41, Thr43), are shown in red. (e) Sequence alignment of seven elicitins used in this study. The $\omega$-loop region is framed in red while the residues with assumed role in the interaction with ELR are marked in red as well. 
a)

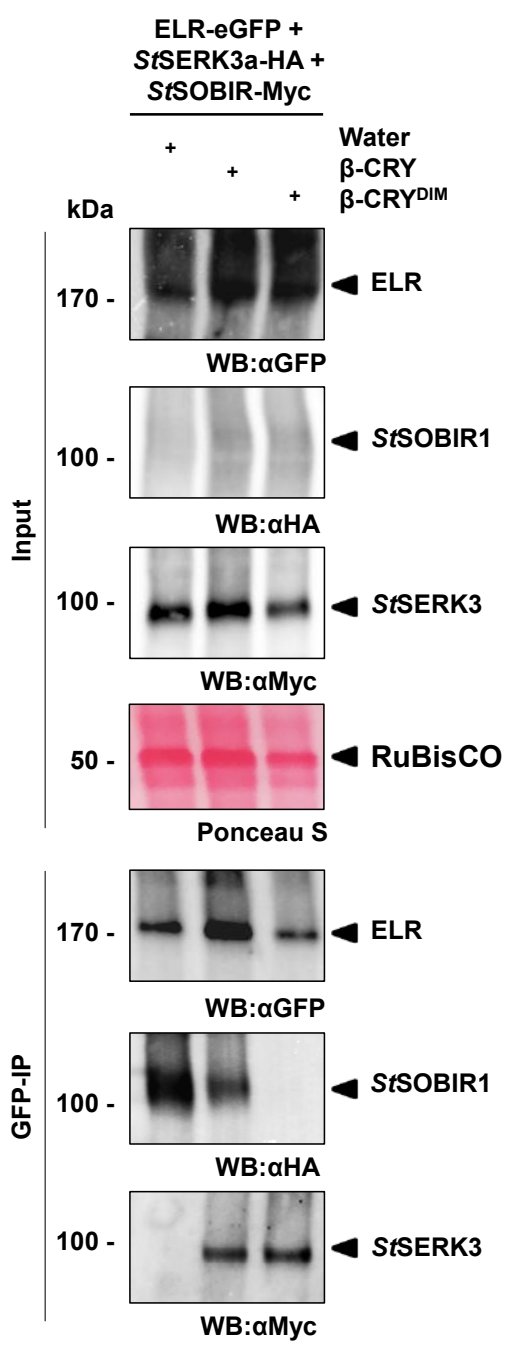

b)

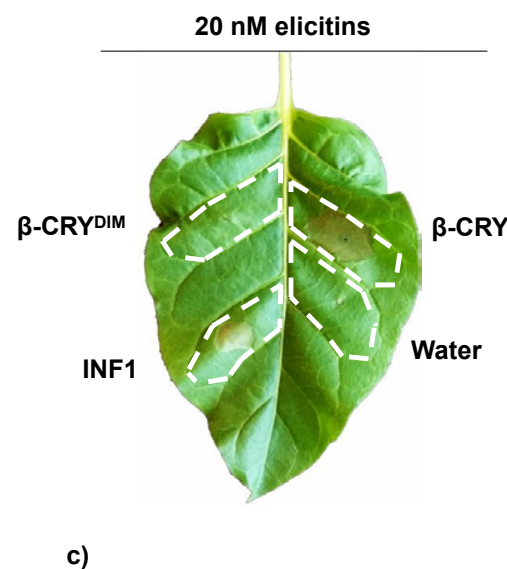

c)

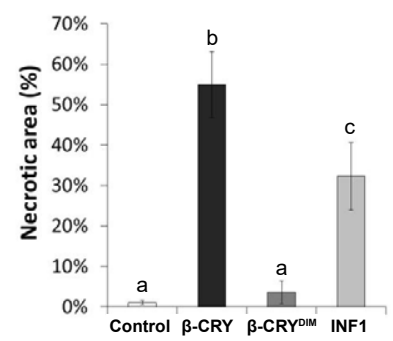

d)

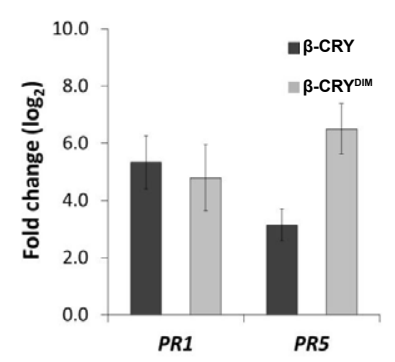

FIGURE S7 | A covalently cross-linked dimer of $\beta$-CRY causes inhibition of the interaction between ELR and SOBIR1 and suppresses the elicitin-induced cell death. (a) Water, $\beta$-CRY or $\beta$-CRY covalently cross-linked dimer ( $\beta$-CRYDIM) (Uhlíková et al., 2016) were infiltrated into Nicotiana benthamiana leaves transiently expressing StSERK3a-HA, StSOBIR1-Myc and ELR-eGFP. Immunoprecipitation was performed using anti GFP beads to capture ELR-eGFP. Immunopurified ELR was detected with anti-GFP, while the interaction of ELR with StSERK3a-HA or StSOBIR1-Myc, as a result of co-immunoprecipitation of the latter proteins with eGFP-tagged ELR, was assessed with anti-HA or anti-Myc antibodies, respectively. Ponceau S staining of RuBisCO indicates equal protein loading. (b, c) Water and $20 \mathrm{nM}$ proteins $\beta$-CRY or $\beta$-CRYDIM crosslinked dimer and INF1) were infiltrated into the Nicotiana tabacum leaves. A representative leaf, photographed at $2 \mathrm{~d}$ post treatment, is shown together with analysis of necrotic area relative to the total area of the infiltrated sector. In (c) each bar represents the standard error of four replicates from three different experiments. A student's t-test with $p \leq 0.01$ was used to determine whether differences were statistically significant. Different letters denote a significant 
difference. (d) Effect of $20 \mathrm{nM} \beta-C R Y$ and $\beta$-CRYDIM proteins on the accumulation of transcripts for PR1a and PR5 in N. tabacum leaves. Gene expression relative to a water treated control was calculated at 48 hours after protein infiltration using the $\Delta \Delta \mathrm{Ct}$ method (Livak and Schmittgen, 2001). The values given in the graphs are the $\log _{2}$ values of relative quantification. Error bars indicate standard deviation. A greater than two-fold change in transcript accumulation was taken as significant.

(a)
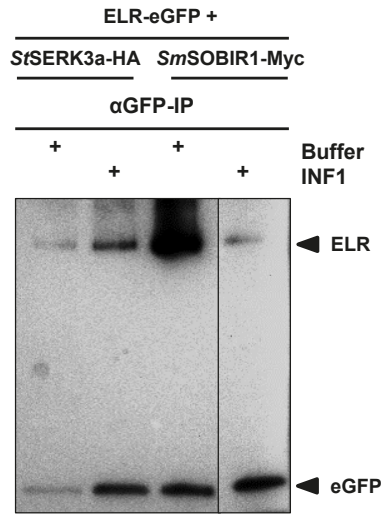

WB: aGFP

Normal SDS-PAGE

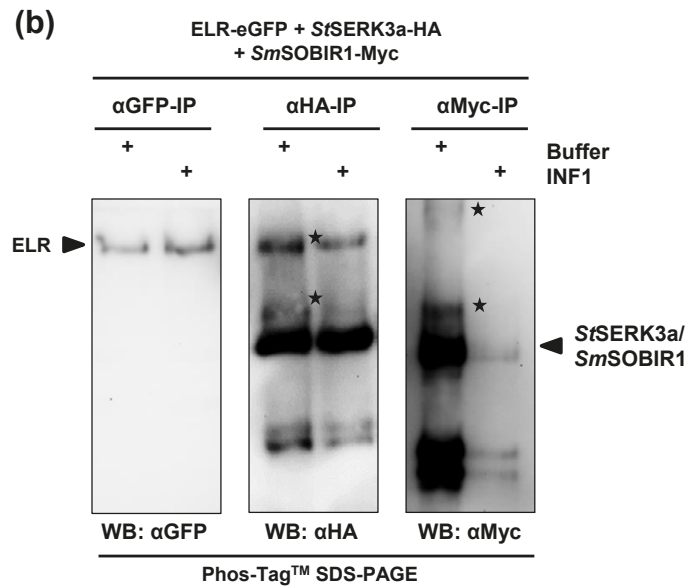

FIGURE S8 | Protein accumulation and phosphorylation dynamics of the ELR-SOBIR1-SERK3a complex upon elicitation by INF1. ELR-eGFP was transiently co-expressed in Nicotiana benthamiana with StSERK3a-HA or SmSOBIR1-Myc, or both. N. benthamiana leaves were elicited with INF1 or buffer, and after 15 min the leaves were analyzed. (a) Total protein was extracted and was subjected to immunoprecipitation using anti-GFP beads to capture ELR. The immunopurified proteins were separated by SDS-PAGE and western blot was performed with anti-GFP to detect ELR. (b) Total protein was extracted and was subjected to immunoprecipitation using anti-GFP, anti-HA or anti-Myc beads to capture ELR-eGFP, StSERK3a-HA or SmSOBIR1-Myc, respectively, under conditions to preserve the protein phosphorylation status (Phospho-STOP). The immunopurified proteins were separated by Phos-Tag ${ }^{\text {TM }}$ SDS-PAGE and western blot was performed with anti-GFP, anti-HA or anti-Myc to detect ELR-eGFP, StSERK3a-HA or SmSOBIR1-Myc, respectively. Asterisks (*) indicate the potential phosphorylated bands of StSERK3a or SmSOBIR1. 



\section{Chapter 5}

\section{Targeted mutagenesis of ELR in wild Solanum species using CRISPR/Cas9}

Emmanouil Domazakis

Dorien Oppelaar

Marjan Bergervoet

Carolina Aguilera-Galvez

Doret Wouters

Juan Du

Richard G.F. Visser

Vivianne G.A.A. Vleeshouwers 
ELR encodes for a receptor-like protein (RLP) which recognizes INF1 and other elicitins and enhances resistance to $P$. infestans when overexpressed in cultivated potato. However, in potato it has so far been impossible to estimate what the resistance contribution of a single RLP is to a pathogen in its native genetic background. In this study, we used CRISPR/Cas9-mediated genome editing to target $E L R$ in wild Solanum. A construct containing two singleguide RNAs was developed, targeting the DNA region between LRR3-6 which is found specifically in functional ELR orthologs. Using a transient expression assay in Nicotiana benthamiana, we found that the construct was effective in creating mutations in ELR. This finding prompted us into attempting stable transformation of S. microdontum, S. microdontum subsp. gigantophyllum, S. edinense, S. papita, S. phureja and S. chacoense. While we were unable to obtain transformants of $S$. microdontum, we obtained a few positive transformants in each of the other species. These transformants were subsequently screened for altered responses to INF1 using PVX agroinfection. Transformants with decreased INF1 response were found in S. papita and S. edinense and were screened for the presence of ELR mutations. Using enrichment approaches, heterozygous ELR mutations were detected in these transformants which could explain the reduction of INF1-triggered cell death. Results from this study indicate that the CRISPR/Cas9 as a method of targeted genome editing on PRRs is possible in several different wild Solanum species. However, to obtain homozygous mutants, either a high number of transformants need to be screened or crossing experiments with positive transformants should be carried out. 


\section{Introduction}

Potato is the third most important food crop in the world and the most important non-grain crop (Barrell et al., 2013). Hence, the production of potato tubers is playing an important role in the modern diet of almost all people worldwide. In most countries, the major threat to potato cultivation is late blight caused by the oomycete Phytophthora infestans, notorious for causing the Irish potato famine in the mid-18 $8^{\text {th }}$ century. Breeding for disease resistance against this pathogen has become the main subject in developing new potato varieties. So far, breeding efforts to obtain late blight-resistant potato cultivars were focused on the introduction of resistance $(R)$ genes, encoded by nucleotide-binding, leucine-rich repeat (NLR) type of immune receptors (Vleeshouwers et al., 2011a).

NLR genes encode cytoplasmic receptors which upon recognition of the cognate avirulence (Avr) gene products of pathogens provide a strong, often qualitative, resistance. However, virulent pathogen races evolve quickly, evading the recognition from these receptors (Haas et al., 2009; Raffaele et al., 2010b; Vleeshouwers et al., 2011a). This selection, in combination with the highly evolving nature of $P$. infestans led to the so called 'breaking' of most introduced NLR genes so far. Despite the large number of NLRs cloned so far, any single introduction in potato cultivars failed to provide sustained pathogen control indicating that either multiple NLRs should be introduced simultaneously and/or that alternative layers of resistance should be explored.

Pattern recognition receptors (PRRs) have been reported as the first line of recognition of self- or microbe-derived molecules being microbe associated molecular patterns (MAMPs) or apoplastic effectors. This recognition triggers a defense response which in many cases results in quantitative resistance against pathogens (Jones and Dangl, 2006). Recent studies have investigated whether immunity that is triggered upon perception of apoplastic pathogen elicitors can enhance late blight resistance. Previous work in our group led to the identification of ELR (Du et al., 2015), a PRR that recognizes several elicitins, a highly conserved family of secreted effectors of Phytophthora and Pythium spp. ELR was cloned from the wild potato species $S$. microdontum. It encodes a receptor-like protein (RLP) which provides broad spectrum recognition of various elicitins in potato. ELR is a 1094 amino acid long protein which consists of seven major domains typical for RLPs. Domain A contains a 23 amino acid long signal peptide, domain $B$ contains a Cys-rich N-terminus, domain $C$ is divided in three subdomains, of which $\mathrm{C} 1$ and $\mathrm{C} 3$ are leucine rich repeats (LRRs) and C2 is a non-LRR island. Domain $D$ is a spacer, domain $F$ is a transmembrane domain while domain $G$ is a short cytoplasmic domain. When ELR was transformed into cultivated potato, it 
was found to confer partial resistance to $P$. infestans in laboratory infection assays, likely by mounting elicitin-triggered cell death (Du et al., 2015).

Functional characterization of genes by reverse genetics is an important part of modern molecular biology. Despite numerous successful interfamily transfers of PRRs into crops including potato, by means of stable overexpression, gene functional studies based on actual mutants were only possible in Arabidopsis or other diploid model systems. For potato, this was due to the polyploidy and heterozygosity of cultivated potato $S$. tuberosum $(2 n=4 x=48)$ as well as other wild Solanum spp. (PGSC, 2011), which renders random mutagenesis approaches such as ethyl methanesulfonate (EMS), T-DNA insertion or irradiation very difficult. However, recent developments in genome editing technologies such as clustered regularly interspaced short palindromic repeats (CRISPR) and transcription activator-like effector nuclease (TALEN) have enabled the easier generation of mutants in many non-model crops including polyploids such as potato and wheat (Belhaj et al., 2013; Wang et al., 2014; Butler et al., 2015; Wang et al., 2015). Specifically, the application of CRISPR/Cas9 technology for plant genome editing has been developing rapidly in the last couple of years and holds great promise for genome manipulation of polyploid crops.

Previous work in our group has identified 32 Solanum spp. (Rietman, 2011) that show a cell death response upon PVX agroinfection with INF1. Eight functional ELR homologs have been cloned from S. edinense, S. papita, S. phureja, S. microdontum subsp. gigantophyllum and $S$. chacoense, which are resistant to $P$. infestans and show response to INF1 (Du, 2014; Vleeshouwers et al., 2011 b). Several paralogs of ELR are found in the genome of cultivated potato. Interestingly, these homologs lack a stretch of 108 amino acids, which form the LRR3-6 in ELR and do not seem to respond to INF1 (Du et al., 2015).

In this study, we aimed to investigate whether CRISPR/CRISPR-associated protein 9 (Cas9) can be used for inducing targeted mutations in Solanum and serve as a tool for gene functional analysis. As a model, we have selected to knock-out the ELR gene. The species S. microdontum (source of ELR) has been reported to be recalcitrant to transformation with Agrobacterium tumefaciens (Rakosy-Tican L, 2004). Nonetheless, we attempted transformation of this species but did also include additional species carrying a functional ELR like S. edinense, S. papita, S. phureja, S. microdontum subsp. gigantophyllum and S. chacoense (Du, 2014). If successful, this approach will be used to develop wild potato mutants of ELR orthologues to determine the contribution of ELR to resistance against $P$. infestans in the native background. 


\section{Materials and methods}

\section{Plant materials}

Solanum genotypes were clonally propagated in vitro on Murashige and Skoog (MS) medium supplemented with $20 \% \mathrm{w} / \mathrm{v}$ sucrose as described (Murashige and Skoog, 1962; Du et al., 2015). For experiments, top shoots were transferred to fresh growth medium at $25^{\circ} \mathrm{C}$. After allowing $1-2$ weeks (wks) for rooting, plantlets were transferred to jiffy pots with disinfected soil in a climate-regulated greenhouse compartment $\left(22 / 18^{\circ} \mathrm{C}\right.$ and $16 / 8 \mathrm{~h}$ light day/night regime at $70 \%$ relative humidity. Supplemental light of $100 \mathrm{~W} / \mathrm{m}^{2}$ was applied when the natural light intensity was below a $150 \mathrm{~W} / \mathrm{m}^{2}$ threshold). Two wks later, the plants were transferred to bigger pots and allowed to grow for an additional 2 wks (till ready for PVX-agroinfection) under the same conditions.

Nicotiana benthamiana plants used in this study were derived from seeds and were maintained under the same greenhouse growth conditions as mentioned above.

\section{CRISPR/Cas9 cloning}

The ELR-targeting construct used for CRISPR/Cas9 mutagenesis has been developed using the Golden Gate (GG) method (Weber et al., 2011) as following. ELR-specific single guide RNA 1 (sgRNA1-CCGATGGAGAAATTTGAGGCATC) and 2 (sgRNA2-CCTTGTTAACAATTTCTTTTATC) were PCR amplified using primers ELRsgRNA1 Bsal Fwd or ELRsgRNA2 Bsal Fwd, respectively with sgRNA Bsal Rev (Table 2) with plasmid gRNA_GFP_T1 as a template (Mali et al., 2013). sgRNA1 PCR product was cloned in plCH47751 and simultaneously placed behind the Arabidopsis thaliana AtU6p promoter found in the level 0 module vector pICSL01009::pAtU6 (Nekrasov et al., 2013) with a cut-ligation protocol using Bsal and T4-ligase (Thermo Fisher Scientific). sgRNA2 was cloned in plCH47761 and similarly fused to pAtU6 as sgRNA1 using the same cut-ligation procedure (Weber et al., 2011). Those level 1 constructs were verified by sequencing using primer sgRNA Bsal Rev (Table 2). The human codon optimized, GG domesticated hCas9 level 0 module, plCH47742::p35s::Cas9-TNOS was combined with pICH47732::pNOS::BAR-TOCS (BAR confers phosphinothricin-PPT resistance in plant), plCH47751::pAtU6::sgRNA1, plCH47761::pAtU6::sgRNA2 and linker plCH41780 and cloned in pAGM4723 in a single cut-ligation reaction with Bbsl and T4-ligase (Thermo Fisher Scientific) (Weber et al., 2011). pAGM4723 was a gift from Sylvestre Marillonnet (Addgene plasmid \# 48015). The resulting binary vector pAGM4723::pNOS:BAR-p35s:hCas9-pAtU6::sgRNA1-pAtU6::sgRNA2 was 
confirmed by HindIII (Thermo Fisher Scientific) digestion and was transformed into Agrobacterium tumefaciens strain AGL1.

\section{Plant genomic DNA extraction}

Genomic DNA (gDNA) was isolated from leaflets of in vitro grown potato plants. Approximately 100-150 mg of leaf tissue was collected in $2 \mathrm{ml}$ tubes and snap frozen in liquid nitrogen. Two $3 \mathrm{~mm}$ tungsten carbide beads (Qiagen) were added to each frozen leaf sample before grinding using TissueLyser II (Qiagen) or the RETSCH machine (RETSCH, Germany) using manufacturer instructions. Then gDNA was isolated using the microprep method (Fulton et al., 1995; Jo et al., 2014). Dried gDNA pellets were resolved in MilliQ water. DNA concentrations were determined with Nanodrop (Thermo Fisher Scientific).

\section{Nicotiana benthamiana transient CRISPR/Cas9 efficiency testing}

Transient co-expressions were performed as described previously (Du et al., 2014; Domazakis et al., 2017). A. tumefaciens strains carrying pBin-KS-p35s::ELReGFP (Du et al., 2015) and pAGM4723::pNOS:BAR-p35s:hCas9-pAtU6::sgRNA1pAtU6::sgRNA2 suspension cultures in infiltration medium were mixed $1: 1$ at a final $O D_{600}=1$ each. The leaves of $4 \mathrm{wk}$-old $N$. benthamiana plants were infiltrated using a needleless syringe. Soon after agroinfiltration, leaf disks from the treated area were collected and labeled as the $0 \mathrm{~h}$ sample (negative control treatment, not containing any induced mutations). Then, $48 \mathrm{hrs}$ later, leaf disks from the infiltration site were also collected and were labelled as the 48 hrs sample. Genomic DNA (gDNA) extraction was performed as described above and samples were subjected to mutation enrichment using restriction digestion, similar to what has been described (Nekrasov et al., 2013). Briefly, 100 - 500 ng of isolated gDNA from both $0 \mathrm{hr}$ and $48 \mathrm{hr}$ treatments were digested with Rsal for at least $5 \mathrm{hrs}$ at $37^{\circ} \mathrm{C}$, as indicated in fig. 2. This enzyme cuts only once between the selected $E L R$ fragment amplified by primers ELR $190 \mathrm{Fwd}$ and ELR 728 Rev. PCR was performed with Phusion polymerase (Thermo Fisher Scientific) on 50 ng from each sample before and after Rsal digestion followed by cloning of the divergent band in pCRBluntll-TOPO vector (Thermo Fisher Scientific). Plasmid DNA was isolated from several Escherichia coli and bi-directional Sanger sequencing was performed using commercial M13 forward and reverse primers.

\section{Agrobacterium-mediated transformation of Solanum}

Wild Solanum transformation was performed using internodal explants, as described previously (Fillatti etal., 1987; Hoekema etal., 1989; Beaujean etal., 1998). Transformed shoots were regenerated in MS media containing 4-10 $\mu \mathrm{g} / \mathrm{ml}$ PPT for 
selection while $1 \mathrm{mg} / \mathrm{l}$ zeatine riboside was used for shoot induction instead of normal zeatine. Apparent regenerated shoots from each callus were transferred to fresh MS media with PPT selection for further growth and rooting. Each regenerant was given a code and was propagated individually (Fig. 3b). Upon sufficient rooting and growth in vitro, plantlets were transferred to greenhouse for phenotyping and PVX agroinfection screening and were tested by PCR for the presence of the pAGM4723::pNOS:BAR-p35s:hCas9-pAtU6::sgRNA1-pAtU6::sgRNA2 cassette using primers Cas9_6F and RB-F1 (Table 2) and DreamTaq polymerase (Thermo Fisher Scientific). Primers StEF1 a qPCR Fwd and StEF1 a qPCR Rev were used as an internal control for DNA quality and ELR 190 Fwd and ELR 1206 Rev were used as internal controls for the presence of ELR (Table 2).

\section{PVX agroinfection}

PVX agroinfection was carried out as described previously (Du et al., 2014; Domazakis et al., 2017). A. tumefaciens GV3101 strains carrying pGR106-INF1, pGR106 empty vector (negative control) or pGR106-CRN2 (positive control encoding crinkling and necrosis 2 (CRN2), a nonspecific cell death inducer (Torto et al., 2003) were used in the experiments (Du et al., 2015). PVX agroinfection was performed on fully expanded leaves of 3-4 wk-old plants growing in the greenhouse by toothpick inoculation. Cell death was scored at $14 \mathrm{dpi}$.

\section{Results}

\section{Design of ELR-targeting CRISPR/Cas9 and off-target prediction}

Since the functionality of ELR homologs has been linked to the presence of four additional LRRs (LRR 3-6) in the C1 domain of ELR (Du 2014, Du et al., 2015), this region was selected for designing the CRISPR/Cas9 sgRNAs (Fig. 1). Namely, two sgRNAs were designed based on ELR from S. microdontum 360-1. The sgRNA2 was selected containing a restriction site $(\mathrm{Hpal})$ to facilitate mutation detection using digestion and PCR (Belhaj et al., 2013; Nekrasov et al., 2013; Zischewski et al., 2017). Theoretical off-target predictions using Cas-OFFinder (Bae et al., 2014) and the latest version of the potato genome (S. tuberosum DM16R44 PGSC v4.03) indicated that the sgRNAs are specific since there is no other region with $100 \%$ match. When allowing for two mismatches, a total of 12 off-targets could be found for sgRNA1 and only one for sgRNA2 (Table 1). Among those, eight putative offtargets are found in non-gene regions while four are found on ORFs belonging to three genes PGSC0003DMG400015351, PGSC0003DMG400002910 (2×) and PGSC0003DMG400002887, the latter two being proteins putatively involved in signaling (Table 1 ). 


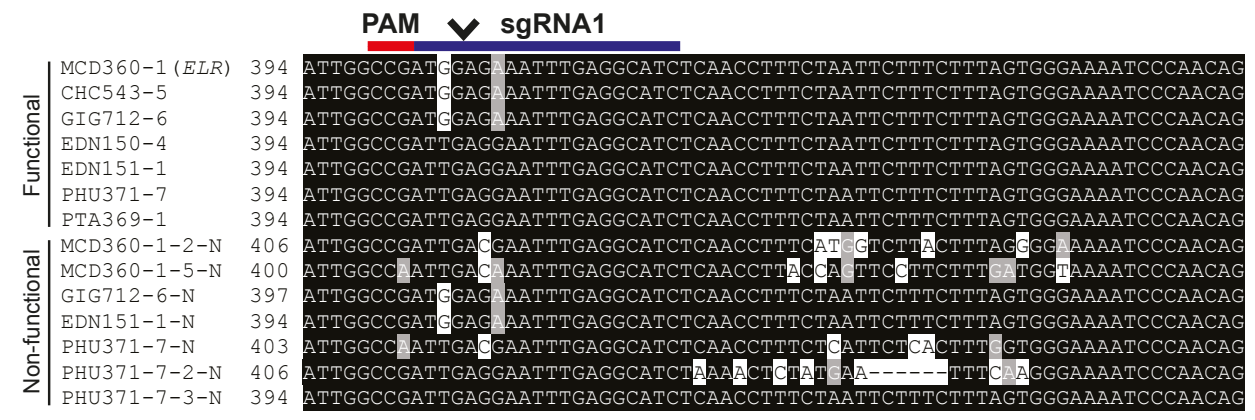

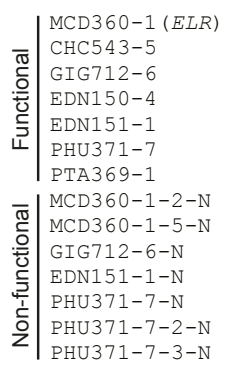

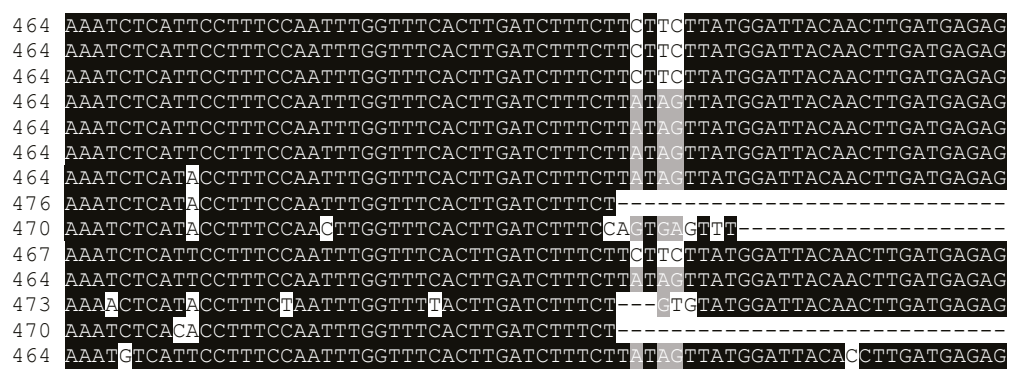

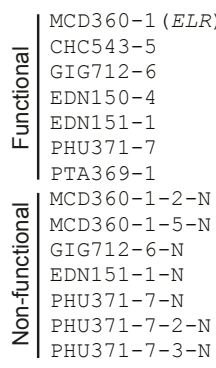

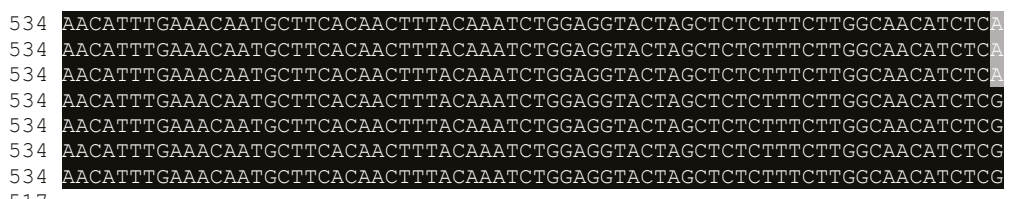

517

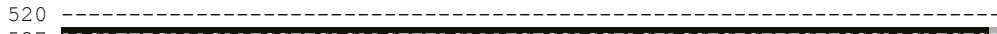

537 AACATTTGAAACAATGCTTCACAACTTTACAAATCTGGAGGTACTAGCTCTCTTTCTTGGCAACATCTC

534

540

AACATTTGAAACAATGCTTCACAACTTTACAAATCTGGAGGTACTAGCTCTCTTTCTTGGCAACATCTCC
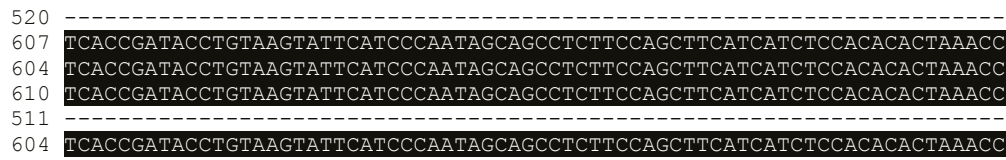

FIGURE 1 | Design of ELR-targeting sgRNAs for CRISPR/Cas9-induced mutagenesis. DNA sequence alignment of cloned functional and non-functional ELR homologs was created using COBALT and BOXSHADE was used to visualize conservation. The positions of sgRNA1 $\left(3^{\prime}-5^{\prime}\right)$ and sgRNA2 $\left(3^{\prime}-5^{\prime}\right)$ as well as the PAM motifs $\left(3^{\prime}-5^{\prime}\right)$ are indicated. The red rectangle indicates the cutting position of Hpal restriction endonuclease. 


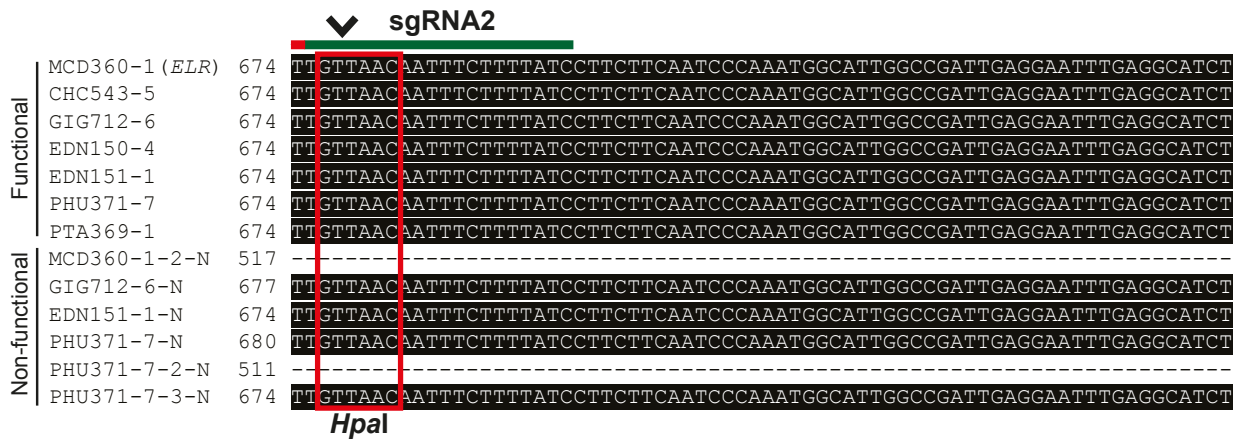

FIGURE 1 | Continued.

TABLE 1 | Prediction of ELR-targetting CRISPR/Cas9 off-targets in potato (PGSG v4.03) using CasOFFinder (Bae et al., 2014).

\begin{tabular}{|c|c|c|c|c|c|}
\hline & sgRNA (+PAM) $5^{\prime} \rightarrow 3^{\prime}$ & Chromosome & Position & Direction & Annotation \\
\hline \multirow{13}{*}{ sgRNA1 } & GATGCCTCAAATTTCTCCATNGG & & & & \\
\hline & GATGCțTCAAATTTCäCCATIGG & ST4.03ch01 & 6053146 & + & - \\
\hline & GATGCțTCAgATTTCTCCATTGG & ST4.03ch01 & 57264338 & - & - \\
\hline & GATGCCTCAAATTTțTCaATCGG & ST4.03ch09 & 51860363 & + & - \\
\hline & GATGCCTCAAATT $\underline{C} C T C \underline{a} A T C G G$ & ST4.03ch12 & 717179 & - & $\begin{array}{l}\text { Conserved gene of } \\
\text { unknown function }\end{array}$ \\
\hline & GATGCCTCAAATT $\underline{c} C T C \underline{a} A T \underline{C G G}$ & ST4.03ch12 & 681383 & - & - \\
\hline & GATGCCTCAAATT $\underline{c} C T C \underline{a} A T \underline{C G G}$ & ST4.03ch12 & 2677409 & + & Cf- $2.1^{2}$ \\
\hline & GATGCCTCAAATT $\underline{c} C T C \underline{a} A T \underline{T G G}$ & ST4.03ch12 & 2546193 & + & - \\
\hline & GATGCCTCAAATTTgTCaATTGG & ST4.03ch12 & 2651873 & + & - \\
\hline & GATGCCTCAAATT只TCaATCGG & ST $4.03 \mathrm{ch} 12$ & 2631306 & + & - \\
\hline & 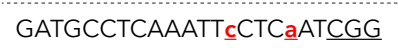 & ST4.03ch12 & 2651552 & + & - \\
\hline & GATGCCTCAAATT_CTC $\underline{a} A T \underline{C G G}$ & ST4.03ch12 & 2903277 & - & $\begin{array}{l}\text { Serine/threonine } \\
\text { protein kinase } 1^{3}\end{array}$ \\
\hline & GATGCCTCAAATT $\underline{C} C T C \underline{a} A T \underline{C G G}$ & ST4.03ch12 & 2902941 & - & $\begin{array}{l}\text { Serine/threonine } \\
\text { protein kinase } 1^{3}\end{array}$ \\
\hline \multirow{2}{*}{ sgRNA2 } & GATAAAAGAAATTGTTAACANGG & & & & \\
\hline & GAT无AAAGAAATTGTTAACAAGG & ST4.03ch12 & 2676839 & + & Cf- $2.1^{2}$ \\
\hline
\end{tabular}




\section{Trial testing of CRISPR/Cas9 in Nicotiana benthamiana}

To examine whether the designed CRISPR/Cas9 construct with two sgRNAs is able to induce the expected mutation on $E L R$, we developed a transient screening assay in $N$. benthamiana. A combination of $A$. tumefaciens carrying a vector containing ELR (pK7WG2-ELR) was co-infiltrated with the CRISPR/Cas9 construct in fully developed $N$. benthamiana leaves. As a negative control, samples from the infiltrated area were collected immediately following infiltration. At $48 \mathrm{~h}$ post agroinfiltration, leaf material was collected. Genomic DNA was extracted from each sample and was subjected to PCR amplification using primers ELR $190 \mathrm{Fwd}$ and ELR $728 \mathrm{Rev}$, with an expected product of $539 \mathrm{bp}$. We hypothesized that if both sgRNAs are active, a deletion will occur in ELR with a size of approximately 273 bp. Since CRISPR/Cas9 mutations are much more rare compared to the unchanged plasmid DNA introduced in the plant, an enrichment approach would be required to obtain possible mutations. Mutation enrichment (Belhaj et al., 2013; Zischewski et al., 2017) was performed by a prolonged digestion with Rsal, a restriction enzyme cutting between the two sgRNA-targeted sites (Fig. 2b). Upon $\mathrm{PCR}$, we found a distinct smaller band in the digested $48 \mathrm{~h}$ samples, indicating a putative mutation event (Fig. 2a). Upon cloning and sequencing of the amplicon, we found that the CRISPR/Cas9 construct induces the expected 273 bp deletion in $E L R$, which derives from cuts within three bases next to the protospacer adjacent motifs (PAM), as expected. Therefore, the designed CRISPR/Cas9 construct was considered suitable to edit ELR and efficient for use in potato transformations.

\section{Transformation of wild Solanum with the ELR-targeting CRISPR/Cas9}

To study the function of ELR in its native background, the designed CRISPR/Cas9 construct was initially transformed in S. microdontum genotypes MCD360-1 and GIG712-5 in order to generate a stable ELR knock-out. However after several attempts, we were unable to obtain S. microdontum transformants using our standard Agrobacterium-mediated transformation protocols. After co-cultivation of explants with Agrobacterium (300 explants per genotype), calli were formed indicating initial transformation of cells, however there was no shoot formation. Since functional ELR homologs exist in several Solanum spp., four different wild potato species which were previously shown to carry a functional $E L R(\mathrm{Du}, 2014)$ were selected; i.e. S. edinense (EDN151-1), S. phureja (PHU371-7), S. papita (PTA369-1) and S. chacoense (CHC543-5). Prior to transformation, those genotypes were confirmed to respond to INF1 using PVX-agroinfection (Fig. 3a, b, c). A total of 19 EDN151-1, 12 PHU371-7, seven PTA369-1 and one CHC543-5 plants were regenerated on selective media after Agrobacterium-mediated introduction of the construct (Fig. 3b). 
(a)

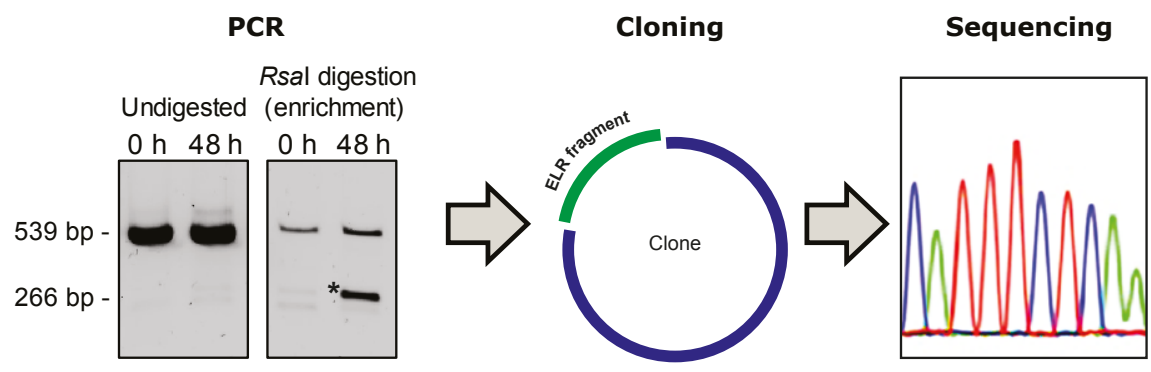

(b)
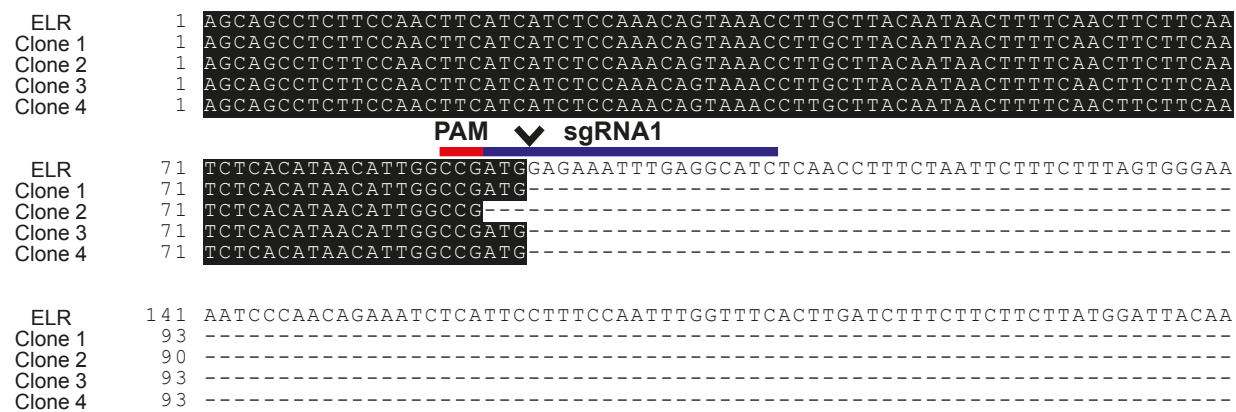

4

Rsal

ELR
Clone 1
Clone 2
Clone 3

211 CTTGATGAGAGAACATTGAAACAATGTTCACAACTTACAAATCTGGAGGTACAGCTCTCTTTCTTG

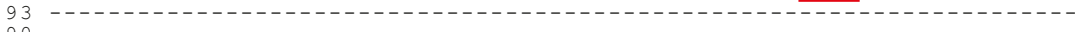
$90-------------------------------------------------------$

Clone 4

ELR
Clone 1
Clone 2
Clone 3

281 GCAACATCTCATCACCGATACCTGTAAGTATTCATCCCAATAGCAGCCTCTTCCAGCTTCATCATCTCCA

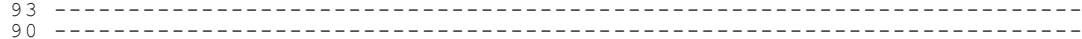

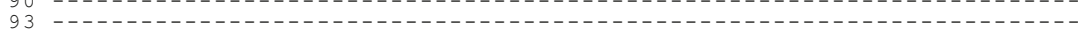
93 PAM

ELR
Clone 1
Clone 2
Clone 3
Clone 4

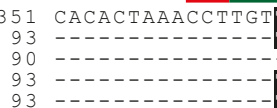
TAACAATTTCTTTTATCCTTCTTCAATCCCAAATGGCATTGGCCGATTGAG
TAACAATTCTTTTATCTTCTTCAATCCCAAATGCATTGGCGATGAG
$-----A T T C T T T A T C C T$ TTTCAATCCCAAATGGATTGGCCGATTGA
TAACAATTCTTTTATCCTTCTTCAATCCCAAATGGCATTGGCCGATTGAG
TAACAATTTCTTTTATCCTTCTTCAATCCCAAATGGCATTGGCCGATT---

FIGURE 2 | Trial testing in Nicotiana benthamiana shows that ELR-targeting CRISPR/Cas9 constructs are functional. $N$. benthamiana leaves were co-infiltrated with a construct carrying ELR and the CRISPR/ Cas9-ELR construct with two sgRNAs designed in this study. Genomic DNA was isolated from $N$. benthamiana at 0 and $48 \mathrm{~h}$ post-co-agroinfiltration. (a) PCR amplification of a partial ELR sequence was performed with or without Rsal digestion, the divergent band (indicated with asterisk, *) was cloned and sequenced. (b) Sanger sequencing results of four independent clones showing the presence of a $273 \mathrm{bp}$ deletion in ELR after CRISPR/Cas9 treatment. 
(a)

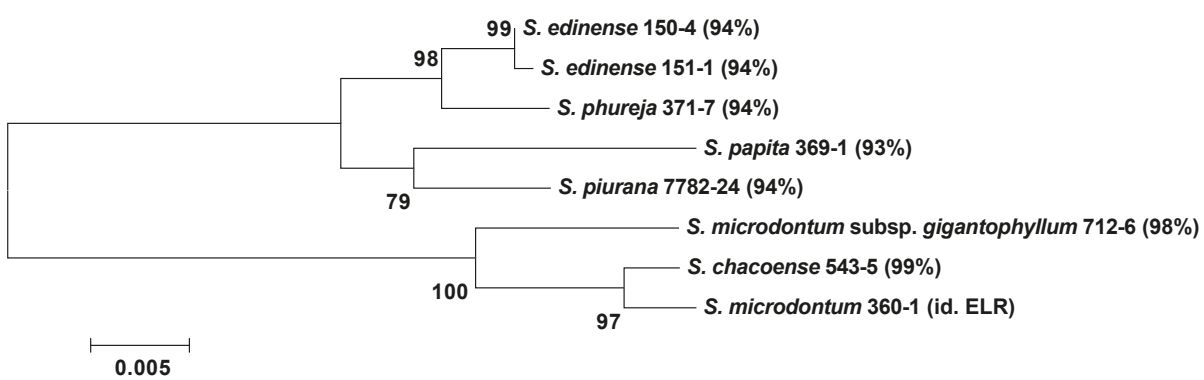

(b)

\begin{tabular}{cccccc}
\hline Solanum sp. & Ploidy & Accession & \# explants & \# regenerants & $\begin{array}{c}\text { \# PCR positive } \\
\text { transformants }\end{array}$ \\
\hline S. edinense (EDN) & $5 n$ & $151-1$ & 300 & $\begin{array}{c}>>20 \\
(19 \text { tested })\end{array}$ & 16 \\
S. phureja (PHU) & $2 n$ & $371-7$ & 300 & 12 & 10 \\
S. papita (PTA) & $4 n$ & $369-1$ & 300 & 7 & 7 \\
$\begin{array}{c}\text { S. microdontumsubsp. } \\
\text { gigantophyllum(GIG) }\end{array}$ & $2 n$ & $712-6$ & 300 & 0 & 0 \\
S. chacoense (CHC) & $2 n$ & $543-5$ & 300 & 1 & 1 \\
S. microdontum(MCD) & $2 n$ & $360-1$ & 300 & 0 & 0 \\
\hline
\end{tabular}

(c)

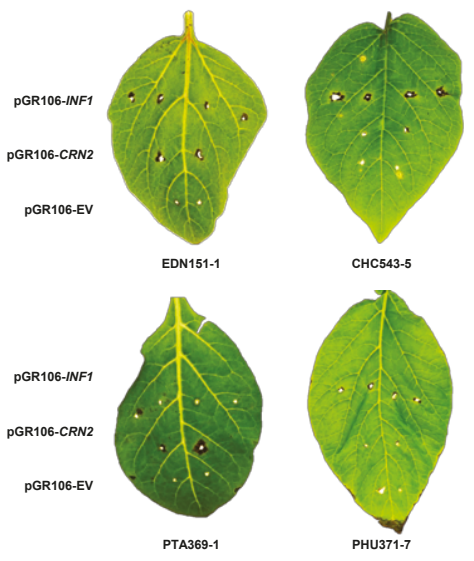

FIGURE 3 | Selection of Solanum carrying a functional ELR for stable transformation using CRISPR/ Cas9. (a) Phylogenetic relationship of ELR homologs cloned from eight different Solanum sp. Amino acid sequences were aligned using MUSCLE and a maximum likelihood phylogenetic tree was created (1000 bootstrap) using MEGA5 software. Numbers in nodes indicate bootstrap values $>50 \%$. (b) Summary of obtained transformants from Agrobacterium tumefaciens-mediated transformation of potato internodes. (c) PVX-agroinfection with INF1, CRN2 (positive control) or empty vector (EV) on leaves of wild Solanum genotypes. Photos were taken at 14 days post inoculation and representative pictures are shown.

\section{PCR confirmation of the integration of CRISPR/Cas9 into wild potato species}

To analyse the identity of the 19 EDN151-1, 10 PHU371-7, seven PTA369-1 and the CHC543-5 regenerants (39 in total) obtained from the transformation, genomic DNA was isolated for PCR confirmation of transgene integration. To do so, a PCR was performed to detect part of the CRISPR/Cas9 transgene using primers Cas9$6 f$ and RB-f1 (Table 2) compared to the respective untransformed genotypes (wild types, WT). Those primers amplify a fragment from the Cas9 to the edge of the right border of the binary vector (Fig. 4a). As internal controls for the DNA quality, the presence of ELR (primers ELR 190 Fwd and ELR 1206 Rev), as well as StEF1a (primers St/NbEF1a qPCR Fwd and St/NbEF1a qPCR Rev) was tested (Fig. 4b). We found that 34 out of 39 regenerants were carrying the CRISPR/Cas9 ELR-targeting 
cassette and were considered actual transformants (Fig. 3b). However, we cannot exclude the possibility that some plants that were negative for the transgene could be derived from incomplete introgression of the right border since they grow on PPT selection media. So we included some non-PCR positive plants in our assays (i.e. EDN151-1 T6, T8 and T10). Overall, about $87 \%$ of the putative transformants of four genotypes were found to carry the CRISPR/Cas9 cassette. From the first experiments, eight of the transformants failed to grow sufficiently (EDN151-1 T15, PTA369-1 T4 and PHU371-7 T5, T6, T9, T10, T11, T12) and were excluded from further experiments, while others exhibited some degree of chlorosis or stunting phenotypes (Fig. 5).

(a)

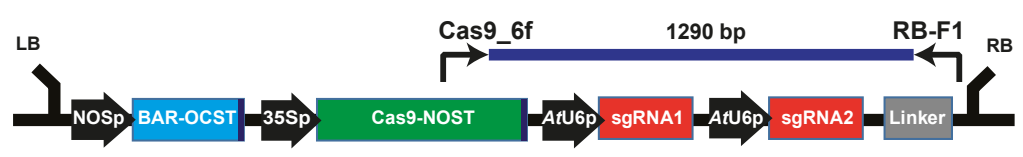

(b)
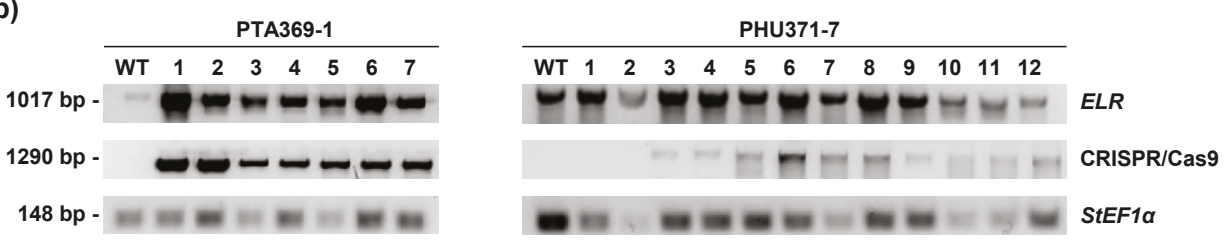

EDN151-1

$\begin{array}{lllllllllllllllllllllllll}\text { WT } 1 & 2 & 3 & 4 & 5 & 6 & 7 & 8 & 9 & 10 & 11 & 12 & 13 & 14 & 15 & 16 & 17 & 18 & 19 & \text { WT } & 1\end{array}$

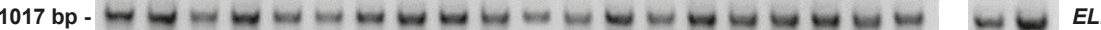

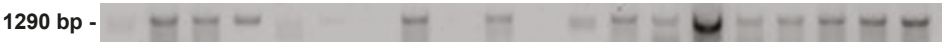

$148 \mathrm{bp}$ -

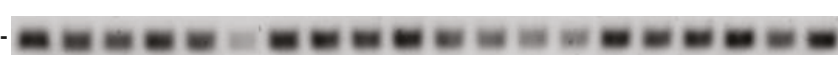

$\begin{aligned} \frac{C H C 543-5}{W T \quad 1} & \\ = & \text { ELR } \\ & \text { CRISPR/Cas9 } \\ = & \text { StEF1 } \alpha\end{aligned}$

FIGURE 4 | PCR confirmation of CRISPR/Cas9 putative transformants. (a) CRISPR/Cas9 cassette used for Solanum transformation. The PCR fragment amplified for checking the transgene introgression is shown as blue line. (b) PCR confirmation of putative transformants obtained for S. papita PTA369-1, S. phureja PHU371-7, S. edinense EDN 151-1 and S. chacoense CHC543-5 with primers amplifying a fragment of the CRISPR/Cas9 construct as shown in (a). To check for DNA quality, fragments of ELR and StEF1a have been amplified as well. 
(a)

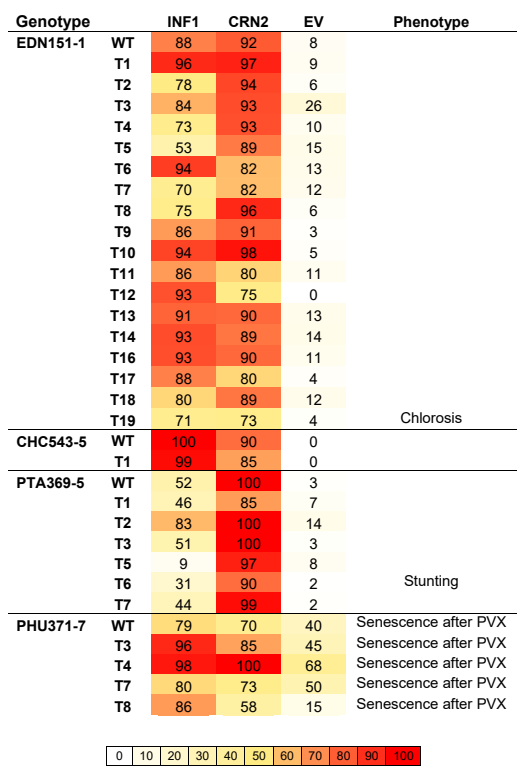

(b)

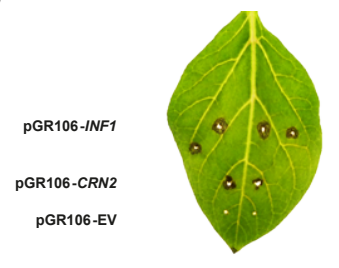

EDN151-1 WT
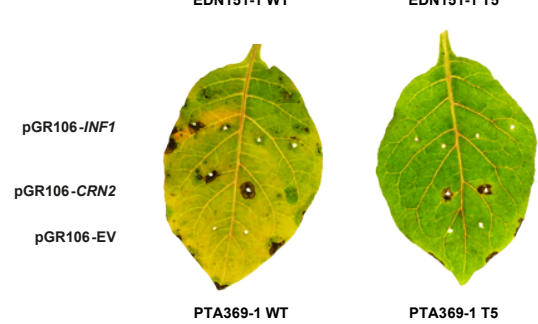

FIGURE 5 | Characterization of CRISPR/Cas9 transformants for response to INF1. CRISPR/Cas9 transformants were subjected to PVX-agroinfection with pGR106-INF1, pGR106-CRN2 or pGR106-EV. (a) Presence-absence of cell death was scored at 14 days post inoculation (dpi) and was expressed as the percentage of inoculation spots showing cell death relative to the total amount of inoculation spots. Data are representative of two biological repeats ( $22 \leq n \leq 400)$. (b) Photos of representative leaves for EDN151-1 WT, T5 and PTA369-1 WT, T5 treated with the same PVX constructs at 14 dpi.

TABLE 2 | Oligonucleotides used in this study.

\begin{tabular}{|c|c|c|}
\hline Primer name & Sequence $\left(5^{\prime} \rightarrow 3^{\prime}\right)$ & Reference \\
\hline Cas9_6f & ATCTCCCGAAGATAATGAGCAGAAG & (Belhaj et al., 2013) \\
\hline RB-F1 & GGATAAACCTTTTCACGCCC & Universal \\
\hline ELRsgRNA1 Bsal Fwd & TGTGGTCTCAATTGATGCCTCAAATTTCTCCATGTTT & \\
\hline ELRsgRNA2 Bsal Fwd & TGTGGTCTCAATTGATAAAAGAAATTGTTAACAGTTT & \\
\hline sgRNA Bsal Rev & TGTGGTCTCAAGCGTAATGCCAACTTTGTAC & (Belhaj et al., 2013) \\
\hline ELR $190 \mathrm{Fwd}$ & AAGTCTTGGAATGAGAGTAGGGA & \\
\hline ELR $728 \mathrm{Rev}$ & CTCAATCGGCCAATGCC & \\
\hline ELR 1206 Rev & AGAGAATTGGCATCCTGCAA & \\
\hline StEF1 a qPCR Fwd & TGACCAAGATTGACAGGCGT & This thesis, Chapter 3 \\
\hline StEF1a qPCR Rev & GCAAAACGACCCAATGGTGG & This thesis, Chapter 3 \\
\hline
\end{tabular}




\section{PVX agroinfection reveals differential cell death response to INF 1 in some CRISPR transformants}

The 26 positive CRISPR/Cas9 transformants plus the three EDN151-1 PCR-negative transformants were transferred to the greenhouse for evaluating their response to INF1 compared to their WT backgrounds. We hypothesized that putative ELR mutants could show a decreased response to INF1, however since some species are polyploids (EDN151-1, PTA369-4), they could be heterozygous for potential mutations and quantitative differences could be expected. PVX-agroinfection with pGR106-INF1 was performed in each transformant. As controls, we used pGR106-CRN2 which encoded a necrosis-inducing protein (Torto et al., 2003; Vleeshouwers et al., 2006) or pGR206-EV (empty vector). Cell death response was scored qualitatively at 14 days post inoculation (dpi) to determine the frequency of cell death (Fig. 5). After comparing the cell death scores of the transformants to their respective WT backgrounds, we found that transformants EDN151-1 T5 and PTA369-1 T5 showed 35\% and 43\% reduction in cell death response to INF1 compared to their respective WT background. Especially for PTA369-1 T5, the response to INF1 was as low as background (EV) (Fig. 5a, b). Interestingly, we observed that PTA369-1 T2 showed an increased cell death response to INF1 (by $31 \%$ ) compared to its WT background, which was unexpected and could likely be due to biological variation. For PHU371-7 and CHC543-5 we did not observe major differences between the transformants and WT backgrounds in terms of INF1 response. In conclusion, two CRISPR/Cas9 transformants showed a consistent reduction in INF1-triggered cell death.

\section{PCR amplification and sequencing identifies putative ELR mutations}

To identify CRISPR/Cas9-induced mutations, a selection of transformants was done based on their responses to INF1. The transformants EDN151-1 T5 and PTA3691 T5 were selected based on the consistently decreased response to INF1, the transformant PTA369-1 T2 based on its higher INF1 response and EDN151-1 T6, T7, T14, T17, PTA369-1 T3, T6 and T7 were selected based on their similar to WT response (background). To identify potential CRISPR/Cas9-induced mutations and to test whether all functional ELR homologs or only a portion have been mutated, we used a restriction enzyme enrichment method prior to PCR amplification (Belhaj et al., 2013; Nekrasov et al., 2013; Zischewski et al., 2017). We hypothesized that any mutation at the sgRNA2 site would cause loss of a chosen restriction site and therefore would enable PCR product amplification following digestion with the restriction endonuclease. On the other hand, we did not expect any mutations at sgRNA1 site, since there are mismatches with our MCD360-1-ELR-targetting CRISPR/Cas 9 construct. Enzyme Hpal was selected as its cutting site is located in 
the sgRNA2 targeting position, exactly on the expected CRISPR/Cas9 cutting site (Fig. 1 ). A 1017 bp region of ELR was amplified with primers ELR $190 \mathrm{Fwd}$ and ELR 1206 Rev (Table 2). PCR amplicons were obtained with proofreading polymerase from samples prior and after Hpal digestion. Without Hpal digestion PCR products were obtained for all samples, except for PTA369-1 T5 functional ELR allele. To search for mutations, enrichment with Hpal was performed by digesting gDNA prior to PCR amplification and repeating on the obtained PCR products to ensure complete digestion. Agarose gel electrophoresis showed that the enrichment was successful, as bands in WT samples had disappeared. On the other hand, transformants of PTA369-1 T2, T6 as well as in EDN151-1 T5 and T17 showed Hpal resistant bands corresponding to the expected ELR PCR product size. Those Hpal-resistant bands as well as the WT bands were excised from gel and DNA was isolated for sequencing (Fig. 6a). Sequencing results have shown that PTA369-1 T2 has a SNP change in a likely functional ELR allele, which causes an amino acid substitution $(\mathrm{V} \rightarrow \mathrm{A})$ while PTA369-1 T6 had a mutation in a likely non-functional ELR allele. For EDN151-1 two Hpal-resistant bands were found. Since we were not able to obtain good sequencing results for the upper band, this PCR product was first cloned. After sequencing three clones, two variant sequences with one carrying a frameshift deletion were found (Fig. 6b). Interestingly, all EDN151-1 T5 Hpal resistant bands had among other changes, an insertion of one $L$ amino acid. The lower band of EDN151-1 T5 was found to contain a mutation leading to an amino acid substitution $(\mathrm{K} \rightarrow \mathrm{T})$, however we were not able to detect the apparent deletion in the sequence, as observed by the smaller band. For EDN151-1 T17, similar sequences were obtained with $\mathrm{T} 5$. It is important to note that most variations were found in sgRNA2 position, as expected while the sequences we obtained were different from the previously cloned ELR homologs in these species (Du, 2014). Overall, following an enrichment strategy, we have identified variations in ELR-like sequences, for four CRISPR/Cas9 transformants which might explain the observed INF1 phenotype. From our data, EDN151-1 T5 potentially contains one deletion which we were not able to sequence fully. However in all cases, cloning of full length genes is required before making any definitive conclusions. 
(a)

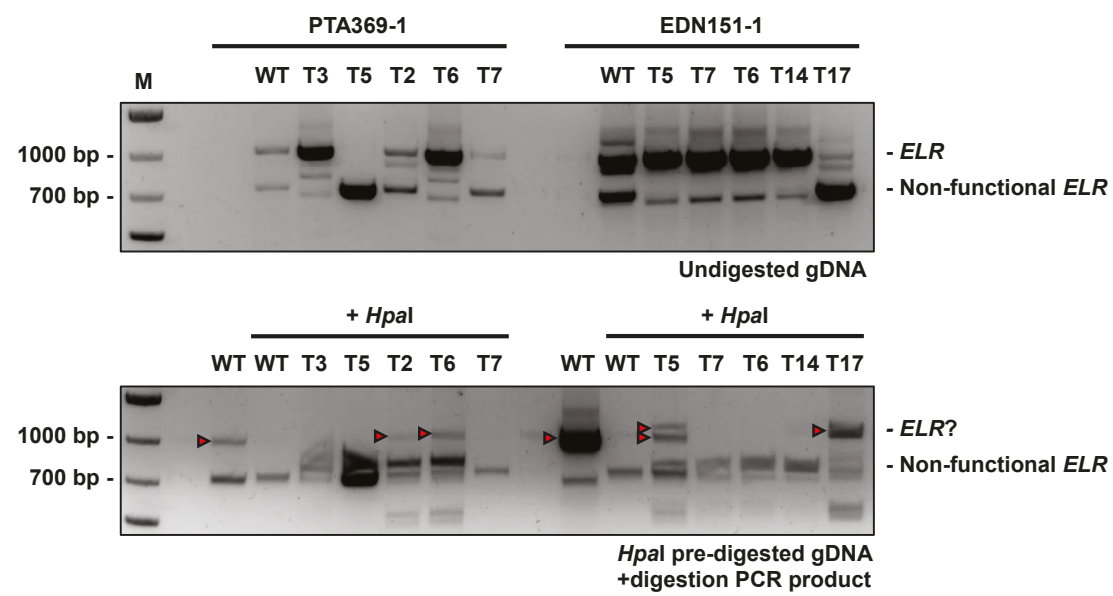

(b)

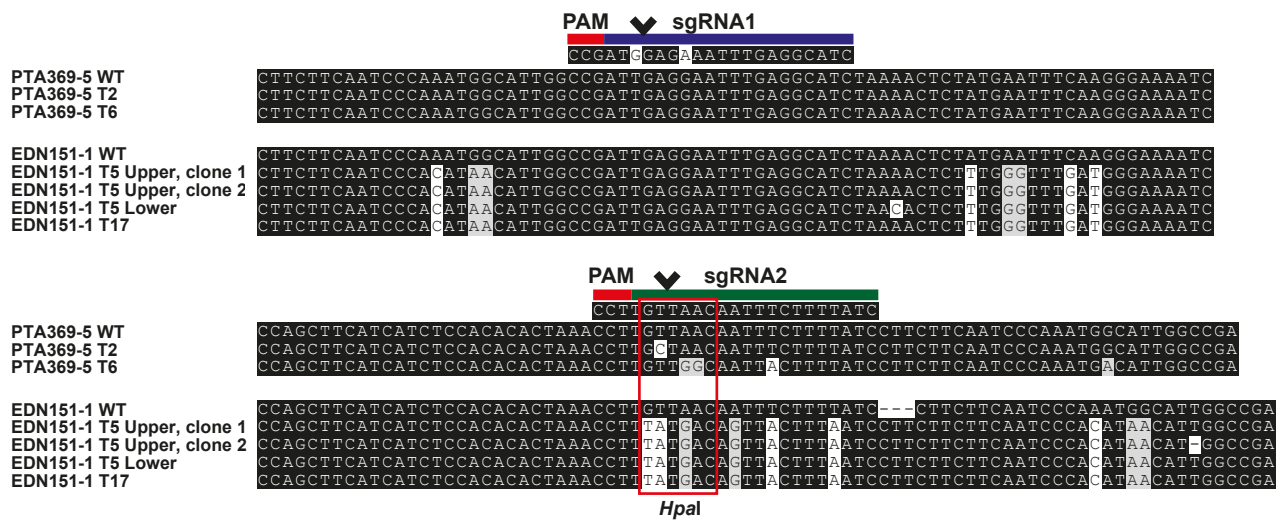

FIGURE 6 | Identification of CRISPR/Cas9-induced ELR mutations in stable potato transformants of S. papita PTA369-1 and S. edinense EDN151-1. PCR using proofreading polymerase was performed on a selection of transformants of S. edinense EDN151-1 and S. papita PTA369-1. (a) PCR before and after double digestion with Hpal. Bands indicated with a red arrow were excised from gel and DNA was isolated and sequenced directly. In the case of EDN151-1 T5, two bands were obtained and the upper one was cloned prior to sequencing. (b) Sequencing results obtained from the indicated bands. Highlighted in red box is the Hpal restriction site. Alignments were performed using Clustal Omega and BOXSHADE was used for visualization. 


\section{Discussion}

ELR is the PRR responsible for elicitin recognition in Solanum (Chapter 4). ELR was initially identified in S. microdontum and its overexpression in S. tuberosum was shown to enhance resistance to P. infestans (Du et al., 2015). However the effect of ELR in late blight resistance was never explored in its native genetic background. In this study we attempted to knock-out ELR in INF1-responding wild Solanum sp. using CRISPR/Cas9-mediated genome editing. We first designed an ELR-targeting CRISPR/Cas9 construct which targets the gene at two positions. This construct was found to have a small number of predicted off targets based on Cas-OFFinder (Bae et al., 2014), all having at least one nucleotide difference. However, based on the study from Cho et al. (2013), the majority of potential off-targets identified could not be targeted by the CRISPR/Cas9 construct since the nucleotide differences are in non-tolerated positions, within the region of the gRNA adjacent to the PAM motif (Carroll, 2013; Cho et al., 2013; Fu et al., 2013; Hsu et al., 2013; Bae et al., 2014; Bortesi and Fischer, 2015). Therefore, we conclude that the construct used is highly specific to $E L R$ and its close homologs with only one putative off-target, namely PGSC0003DMG400002910 that encodes for a Cf-like protein $(60.4 \%$ amino acid identity to ELR).

To enable efficiency testing of the CRISPR/Cas9 construct, we developed an in planta screening assay in N. benthamiana using Agrobacterium co-infiltration. We found that indeed, the construct was able to induce double strand breaks (DSBs) in ELR, at both targeted sites, at the expected positions, creating a $\sim 273 \mathrm{bp}$ deletion in the gene. Since the construct was efficient in generating the expected mutation, we attempted to transform wild Solanum sp. which were known to have a functional ELR homolog (Du, 2014). We found that it was not possible to obtain transformants in the S. microdontum genotypes tested, likely due to the inability of the calli to regenerate shoots. Similar findings with regard to transformation attempts in S. microdontum have been described earlier (Rakosy-Tican L, 2004), which suggests that for $A$. tumefaciens-mediated transformation-recalcitrant species like S. microdontum, other potato transformation protocols or methods need to be explored, e.g. using protoplasts (Andersson et al., 2017). Fortunately, $E L R$ homologs have been cloned from seven additional Solanum sp. (Du, 2014) and we were able to obtain CRISPR/Cas9 transformants for some of these species (for S. papita, S. phureja, S. edinense, S. chacoense). Among those, S. edinense gave the most transformants in numbers surpassing the routinely transformed S. tuberosum cv. Désirée, indicating that this wild species is highly amenable to Agrobacterium transformation. 
Obtained transformants were transferred to the greenhouse where they were evaluated for their response to INF1. While most transformants did grow similar to their respective wild type background, some showed impaired growth or phenotype. Especially for S. phureja, from the 12 regenerants obtained, five showed severe stunting and four were lost before getting to the greenhouse for screening. This species also seems to suffer from PVX-induced senescence.

To identify CRISPR/Cas9 induced mutations in the transformants, we utilized mutation enrichment with a restriction enzyme cutting at the expected DNA modifying site of sgRNA2 (Zischewski et al., 2017). We found two S. papita and two S. edinense transformants which carry mutations in ELR or its close homologs. Based on the INF1 cell death screens, the majority of those mutations are likely either heterozygous or in a non-functional allele. For example, EDN151-1 T5 was shown to contain a mutation and the phenotype was a 35\% decreased INF1 cell death. In another plant, PTA369-1 T5, a deletion mutation could be detected in ELR and response to INF1 was found to be not higher than the negative control. However, the previously identified ELR orthologue in this species had two mismatches present in the $3^{\prime}$ end of the sgRNA1 target site (Du, 2014). CRISPR-Cas9 has been reported to tolerate mismatches in the $5^{\prime}$ site but not the $3^{\prime}$ site of sgRNAs (Fu et al. 2013, Hsu et al. 2013, Carroll, 2013). Interestingly another transformant of S. papita (PTA369-5 T2), showed around 31\% increased INF1 cell death response and was found to carry a mutation which leads to an amino acid substitution in the functional ELR protein. This could hint to the potential importance of this amino acid for response to INF1, but it requires further experimental confirmation.

So far, it was very hard to perform reverse genetics in potato due to its autotetraploid nature and the difficulty of obtaining mutants with similar genetic background to a reference (Uitdewilligen et al., 2013). In this chapter we attempted to create homozygous ELR mutants in wild Solanum sp. using CRISPR/Cas9-mediated genome editing. The functionality of reagents was assessed prior to transforming the wild potato genotypes in a transient co-expression setup. Obtained transformants showed differential responses to INF1 effector and we were able to pinpoint putative CRISPR/Cas9-induced alterations in ELR for a few of them. Our results show the potential of genome editing using CRISPR in potato and highlight that a high number of transformants needs to be rigorously screened for finding desired mutations, which is a challenge for multicopy genes or polyploid plants. The plants PTA369-5 T5 (likely to carry ELR mutation) and EDN151-1 T5 (heterozygous ELR mutations) that we obtained could be used for testing their response to $P$. infestans infection and complement the existing results on the ELR involvement in resistance using overexpression (Du et al., 2015). However, to increase chances of finding full ELR knock-outs in these species, a new CRISPR/ Cas 9 has to be designed, with more sgRNAs, to increase mutation efficiency. 


\section{Author contributions}

$E D, V G A A V$ and $D O$ designed the research, ED, CAG, DW and MB performed experiments, JD provided sequence information. ED, RV and VGAAV supervised the research and wrote the manuscript.

\section{Acknowledgements}

The authors would like to thank the $1^{\text {st }}$ TALEN \& CRISPR training school (COST FA1208) and Vladimir Nekrasov for sgRNA design and for providing materials and expertise for CRISPR cloning. Xiao Lin is acknowledged for assistance in cloning. 


\section{References}

Andersson, M., Turesson, H., Nicolia, A., Falt, A.S., Samuelsson, M., and Hofvander, P. 2017. Efficient targeted multiallelic mutagenesis in tetraploid potato (Solanum tuberosum) by transient CRISPRCas9 expression in protoplasts. Plant Cell Rep 36:117-128.

Bae, S., Park, J., and Kim, J.S. 2014. Cas-OFFinder: a fast and versatile algorithm that searches for potential off-target sites of Cas9 RNA-guided endonucleases. Bioinformatics 30:1473-1475.

Barrell, P.J., Meiyalaghan, S., Jacobs, J.M., and Conner, A.J. 2013. Applications of biotechnology and genomics in potato improvement. Plant Biotechnol J 11:907-920.

Beaujean, A., Sangwan, R.S., Lecardonnel, A., and Sangwan-Norreel, B.S. 1998. Agrobacteriummediated transformation of three economically important potato cultivars using sliced internodal explants: an efficient protocol of transformation. J Exp Bot 49:1589-1595.

Belhaj, K., Chaparro-Garcia, A., Kamoun, S., and Nekrasov, V. 2013. Plant genome editing made easy: targeted mutagenesis in model and crop plants using the CRISPR/Cas system. Plant Methods 9:39.

Bortesi, L., and Fischer, R. 2015. The CRISPR/Cas9 system for plant genome editing and beyond. Biotechnol Adv 33:41-52.

Butler, N.M., Atkins, P.A., Voytas, D.F., and Douches, D.S. 2015. Generation and inheritance of targeted mutations in potato (Solanum tuberosum L.) using the CRISPR/Cas System. PLoS One 10:e0144591.

Carroll, D. 2013. Staying on target with CRISPR-Cas. Nat Biotechnol 31:807-809.

Cho, S.W., Kim, S., Kim, Y., Kweon, J., Kim, H.S., Bae, S., and Kim, J.S. 2014. Analysis of off-target effects of CRISPR/Cas-derived RNA-guided endonucleases and nickases. Genome Res 24:132-141.

Domazakis, E., Lin, X., Aguilera-Galvez, C., Wouters, D., Bijsterbosch, G., Wolters, P.J., and Vleeshouwers, V.G.A.A. 2017. Effectoromics-based identification of cell surface receptors in potato. Pages $337-$ 353 in: Plant Pattern Recognition Receptors: Methods and Protocols, L. Shan and P. He, eds. Springer, New York.

Du, J. 2014. Elicitin-triggered apoplastic immunity against late blight in potato (PhD dissertation), Wageningen University \& Research.

Du, J., Rietman, H., and Vleeshouwers, V.G.A.A. 2014. Agroinfiltration and PVX agroinfection in potato and Nicotiana benthamiana. J Vis Exp:e50971.

Du, J., Verzaux, E., Chaparro-Garcia, A., Bijsterbosch, G., Keizer, L.C., Zhou, J., Liebrand, T.W., Xie, C., Govers, F., Robatzek, S., van der Vossen, E.A., Jacobsen, E., Visser, R.G., Kamoun, S., and Vleeshouwers, V.G.A.A. 2015. Elicitin recognition confers enhanced resistance to Phytophthora infestans in potato. Nat Plants 1:15034.

Fillatti, J.J., Kiser, J., Rose, R., and Comai, L. 1987. Efficient transfer of a glyphosate tolerance gene into tomato using a binary Agrobacterium tumefaciens vector. Nat Biotechnol 5:726-730.

Fu, Y., Foden, J.A., Khayter, C., Maeder, M.L., Reyon, D., Joung, J.K., and Sander, J.D. 2013. Highfrequency off-target mutagenesis induced by CRISPR-Cas nucleases in human cells. Nat Biotechnol 31:822-826.

Fulton, T.M., Chunwongse, J., and Tanksley, S.D. 1995. Microprep protocol for extraction of DNA from tomato and other herbaceous plants. Plant Molecular Biology Reporter 13:207-209.

Haas, B.J., Kamoun, S., Zody, M.C., Jiang, R.H., Handsaker, R.E., Cano, L.M., Grabherr, M., Kodira, C.D., Raffaele, S., Torto-Alalibo, T., Bozkurt, T.O., Ah-Fong, A.M., Alvarado, L., Anderson, V.L., Armstrong, M.R., Avrova, A., Baxter, L., Beynon, J., Boevink, P.C., Bollmann, S.R., Bos, J.I., Bulone, V., Cai, G., Cakir, C., Carrington, J.C., Chawner, M., Conti, L., Costanzo, S., Ewan, R., Fahlgren, N., Fischbach, M.A., Fugelstad, J., Gilroy, E.M., Gnerre, S., Green, P.J., Grenville-Briggs, L.J., Griffith, J., Grunwald, N.J., Horn, K., Horner, N.R., Hu, C.H., Huitema, E., Jeong, D.H., Jones, A.M., Jones, J.D., Jones, R.W., Karlsson, E.K., Kunjeti, S.G., Lamour, K., Liu, Z., Ma, L., Maclean, D., Chibucos, M.C., McDonald, H., McWalters, J., Meijer, H.J., Morgan, W., Morris, P.F., Munro, C.A., O'Neill, K., Ospina-Giraldo, M., Pinzon, A., Pritchard, L., Ramsahoye, B., Ren, Q., Restrepo, S., Roy, S., Sadanandom, A., Savidor, A., Schornack, S., Schwartz, D.C., Schumann, U.D., Schwessinger, B., Seyer, L., Sharpe, T., Silvar, C., Song, J., Studholme, D.J., Sykes, S., Thines, M., van de Vondervoort, P.J., Phuntumart, V., Wawra, S., Weide, R., Win, J., Young, C., Zhou, S., Fry, W., Meyers, B.C., van West, P., Ristaino, J., Govers, F., Birch, P.R., Whisson, S.C., Judelson, H.S., and Nusbaum, C. 2009. Genome sequence and analysis of the Irish potato famine pathogen Phytophthora infestans. Nature 461:393-398. 
Hoekema, A., Huisman, M.J., Molendijk, L., van den Elzen, P.J.M., and Cornelissen, B.J.C. 1989. The genetic engineering of two commercial potato cultivars for resistance to potato virus $X$. Nat Biotechnol 7:273-278.

Hsu, P.D., Scott, D.A., Weinstein, J.A., Ran, F.A., Konermann, S., Agarwala, V., Li, Y., Fine, E.J., Wu, X., Shalem, O., Cradick, T.J., Marraffini, L.A., Bao, G., and Zhang, F. 2013. DNA targeting specificity of RNA-guided Cas9 nucleases. Nat Biotechnol 31:827-832.

Jo, K.R., Kim, C.J., Kim, S.J., Kim, T.Y., Bergervoet, M., Jongsma, M.A., Visser, R.G., Jacobsen, E., and Vossen, J.H. 2014. Development of late blight resistant potatoes by cisgene stacking. BMC Biotechnol 14:50.

Jones, J.D., and Dangl, J.L. 2006. The plant immune system. Nature 444:323-329.

Mali, P., Yang, L., Esvelt, K.M., Aach, J., Guell, M., DiCarlo, J.E., Norville, J.E., and Church, G.M. 2013. RNA-guided human genome engineering via Cas9. Science 339:823-826.

Murashige, T., and Skoog, F. 1962. A revised medium for rapid growth and bio assays with tobacco tissue cultures. Physiol Plant 15:473-497.

Nekrasov, V., Staskawicz, B., Weigel, D., Jones, J.D., and Kamoun, S. 2013. Targeted mutagenesis in the model plant Nicotiana benthamiana using Cas9 RNA-guided endonuclease. Nat Biotechnol 31:691-693.

PGSC. 2011. Genome sequence and analysis of the tuber crop potato. Nature 475:189-195.

Raffaele, S., Farrer, R.A., Cano, L.M., Studholme, D.J., MacLean, D., Thines, M., Jiang, R.H., Zody, M.C., Kunjeti, S.G., Donofrio, N.M., Meyers, B.C., Nusbaum, C., and Kamoun, S. 2010. Genome evolution following host jumps in the Irish potato famine pathogen lineage. Science 330:1540-1543.

Rakosy-Tican L, A.A., Aurori CM, Ispas G. 2004. Transformation of wild Solanum species resistant to late blight by using reporter gene GFP and MSH2 genes. Plant Breeding and Seed Science 50:119128.

Torto, T.A., Li, S., Styer, A., Huitema, E., Testa, A., Gow, N.A., van West, P., and Kamoun, S. 2003. EST mining and functional expression assays identify extracellular effector proteins from the plant pathogen Phytophthora. Genome Res 13:1675-1685.

Uitdewilligen, J.G., Wolters, A.M., D'Hoop B, B., Borm, T.J., Visser, R.G., and van Eck, H.J. 2013. A next-generation sequencing method for genotyping-by-sequencing of highly heterozygous autotetraploid potato. PLoS One 8:e62355.

Vleeshouwers, V.G.A.A., Driesprong, J.D., Kamphuis, L.G., Torto-Alalibo, T., van't Slot, K.A., Govers, F., Visser, R.G., Jacobsen, E., and Kamoun, S. 2006. Agroinfection-based high-throughput screening reveals specific recognition of INF elicitins in Solanum. Mol Plant Pathol 7:499-510.

Vleeshouwers, V.G.A.A., Raffaele, S., Vossen, J.H., Champouret, N., Oliva, R., Segretin, M.E., Rietman, H., Cano, L.M., Lokossou, A., Kessel, G., Pel, M.A., and Kamoun, S. 2011a. Understanding and exploiting late blight resistance in the age of effectors. Annu Rev Phytopathol 49:507-531.

Vleeshouwers, V.G.A.A., Finkers, R., Budding, D., Visser, M., Jacobs, M.M., van Berloo, R., Pel, M., Champouret, N., Bakker, E., Krenek, P., Rietman, H., Huigen, D., Hoekstra, R., Goverse, A., Vosman, B., Jacobsen, E., and Visser, R.G. 2011b. SolRgene: an online database to explore disease resistance genes in tuber-bearing Solanum species. BMC Plant Biol 11:116.

Wang, S., Zhang, S., Wang, W., Xiong, X., Meng, F., and Cui, X. 2015. Efficient targeted mutagenesis in potato by the CRISPR/Cas9 system. Plant Cell Rep 34:1473-1476.

Wang, Y., Cheng, X., Shan, Q., Zhang, Y., Liu, J., Gao, C., and Qiu, J.L. 2014. Simultaneous editing of three homoeoalleles in hexaploid bread wheat confers heritable resistance to powdery mildew. Nat Biotechnol 32:947-951.

Weber, E., Engler, C., Gruetzner, R., Werner, S., and Marillonnet, S. 2011. A modular cloning system for standardized assembly of multigene constructs. PLoS One 6:e16765.

Zischewski, J., Fischer, R., and Bortesi, L. 2017. Detection of on-target and off-target mutations generated by CRISPR/Cas9 and other sequence-specific nucleases. Biotechnol Adv 35:95-104. 


\title{
Chapter 6
}

\author{
General discussion
}


The potato crop suffers from many pests and pathogens, among which the late blight pathogen Phytophthora infestans is the most devastating (Haverkort et al., 2009). Breeding for resistance is of major importance for the global food security, yet, to achieve resistance, basic studies on the molecular interaction between plant and pathogen are essential. Plants are able to sense invading microbes and subsequently trigger immune responses by surface-localized pattern recognition receptors (PRRs) or nucleotide-binding leucine-rich repeat (NLR) cytoplasmic receptors. NLR-triggered immunity against $P$. infestans has been well studied in potato. Several NLRs have been cloned and bred into potato cultivars with proven effectivity. However, the lifespan of any introduced NLR has been relatively short due to the rapidly evolving nature of the pathogen (Haas et al., 2009; Haverkort et al., 2016). Contrary to the wealth of information on NLR-triggered resistance, cell surface-triggered immunity mediated by PRRs against oomycetes, and particularly Phytophthora has been understudied.

PRRs have been reported as the first line of defense that is mediated by apoplastic self- or microbe-derived molecules, which trigger a defense response that in many cases results in quantitative resistance against pathogens (Jones and Dangl, 2006). Phytophthora (and Pythium) pathogens are known to secrete elicitins, conserved apoplastic effectors that function in sterol nutrient uptake from the host (Stong et al., 2013; Derevnina et al., 2016). Since $P$. infestans cannot synthesize sterols, elicitins are indispensable proteins for its survival. Therefore, targeting plant receptors of elicitins was proposed as a promising approach to obtain a more durable resistance against this devastating pathogen (Du et al., 2015). Despite the fact that Nicotiana benthamiana and N. tabacum have been the model plants for elicitin perception since decades (Ricci et al., 1989; Kamoun et al., 1993; Panabieres et al., 1995), the first putative PRR responding to elicitins -ELR- was cloned from a wild potato species, Solanum microdontum.

At the start of this project it was known that ELR is able to respond to various elicitins by triggering cell death. This was shown by both transient co-expression in the genetic background of a non-responding Solanum genotype and with stable overexpression in Solanum tuberosum cv. Désireé (Du et al., 2015). However, it was not known whether ELR actually binds elicitins or is just part of a recognition complex. In addition, there was a need for producing recombinant apoplastic effectors for biochemical studies or for improving effectoromics screens in wild Solanum spp. to complement Agrobacterium-based screening assays. Therefore, our research questions were: is ELR a true PRR that binds elicitins? What are the first molecular players downstream of ELR? What would be the outcome of knocking out ELR in its native genetic background, and would these plants be less responsive to elicitins? And finally, can we optimize a heterologous system for efficient recombinant apoplastic effector production? 
All these questions come together in the research objectives of my work, i.e. 1 ) biochemical characterization of elicitin-perception by $E L R, 2$ ) investigation of modern genome editing techniques for use in reverse genetic studies in wild potato, and 3) optimization of producing recombinant effectors for biochemical studies and effector screens.

With the work presented here I have unraveled the mechanism underlying elicitin perception by the ELR receptor in potato. I have shown that ELR is a true PRR that binds elicitins and that it associates with co-receptors in order to trigger cell death. With these studies, I am revealing the first players in the elicitin perception pathway. In addition, I explored the possibilities of using CRISPR/Cas9-mediated genome editing for mutating ELR in wild Solanum. I have also optimized the heterologous apoplastic effector protein production in yeast for, among others, functional screens by infiltration in wild potatoes. This work is complementing the routine Agrobacterium-based screens and enables screening of Agrobacterium or PVX-recalcitrant species. Overall, my work has significantly expanded our knowledge on how PRRs function against oomycetes in a crop plant; potato. In addition, it highlights similarities to the perception of fungi and bacteria, while revealing aspects of this complex immune system.

\section{Recognition of the elicitin domain in Solanum is mediated by elicitin binding to ELR}

ELR, the first PRR that specifically responds to MAMPs of Phytophthora has been cloned from a wild potato species, Solanum microdontum (Du et al., 2015). ELR is a RLP lacking a cytoplasmic kinase domain that recognizes several elicitins ranging from 45-65\% amino acid similarity (Du et al., 2015). This spectrum includes Phytophthora elicitins belonging to class ELI-1 (e.g. INF1, RAMA1, ParA1, CRY2, $\beta$-CRY), ELI-2 (e.g. INF2A) and ELI-4 elicitins (e.g. INF5, INF6) (Jiang et al., 2006; Du et al., 2015)(Chapter 4). In this work we have shown that ELR physically binds INF1. This was evident from various experiments, including in planta and in vitro biochemical assays as well as binding studies with an INF1 cysteine mutant. Moreover, we have shown that ELR binds ParA1 and $\beta$-CRY elicitins (Chapter 4). The ELR-elicitin interaction is likely happening in the plant apoplast, since in all cases, the interaction was found to occur with the processed forms of elicitins (Chapter 4). We consider these findings as a milestone, as binding of MAMPs/ effectors to their PRRs has only been reported for very few PRR-MAMP pairs, even after many years since the identification of some of these (see Fig. 2, Chapter 1). 
We noted that elicitins that are recognized by ELR do not seem to share a conserved stretch of amino acids, as it is found in bacterial flagellin, EF-Tu or NLPs (Felix et al., 1999; Kunze et al., 2004; Bohm et al., 2014). Rather, the structure of elicitins is conserved and is likely recognized by ELR (Derevnina et al., 2016). Some elicitins form homo-oligomers, leaving their $\omega$-loop region exposed, yet they are able to bind ELR. Therefore, we can hypothesize that this region might be important for their recognition by the receptor (Chapter 4).

Searching of ELR homologs in other species of Solanaceae using BLASTp revealed some potential homologs in potato, tomato and pepper (e.g. $\approx 80 \%$ similar amino acid sequences found in S. tuberosum, S. pennellii and S. lycopersicum, and $\approx 70 \%$ in Capsicum annuum), in N. tabacum ( $\approx 70 \%$ similar amino acid sequence found), while no close homologs exist in $N$. benthamiana. It is known that the sequenced potato DM1-3 516 R44 as well as most S. tuberosum cultivars tested so far are not able to respond to elicitins (Du et al., 2015). The specificity of the elicitin response seemed to be linked to the absence of some LRRs (LRR3-6) in the sequence of those ELR homologs (Du, 2014). For the rest of the Solanaceae, in particular Nicotiana, future studies will reveal whether the response to elicitins is always due to ELR homologs or whether completely different PRRs recognize elicitins as well. However, based on our findings that the co-receptor SOBIR1 is required (Chapter 3), we expect that those receptors should be RLPs (Liebrand et al., 2014).

ELR is the first oomycete-specific RLP ever cloned with a known ligand (Chapter 4). The only other known PRRs that can recognize oomycetes are RLP23 from Arabidopsis and the very recently-identified RXEG1 from N. benthamiana. For these PRRs, binding has been demonstrated with their respective MAMPs, i.e. the nlp20 and GH12 (Albert et al., 2015; Boutrot and Zipfel, 2017; Wang et al., 2018). $\mathrm{Nlp} 20$ can be found in P. infestans, however GH12 can only be found in the related oomycetes $P$. sojae and $P$. parasitica and $P$. capsici. Just like ELR, these RLPs were shown to increase resistance to pathogens producing those MAMPs.

Other studies on elicitin perception by $N$. benthamiana, N. glutinosa, and C. annuum have revealed proteins with an unclear role. The B-type LecRKs NbLRK1 and NgRLK1 have been reported to interact with INF1 and a homolog of Phytophthora cactorum (PcINF1) in vitro (Kanzaki et al., 2008; Kim et al., 2010). For NbLRK1, interaction with INF1 occurred through its cytoplasmic kinase domain, which was unexpected, since ELI-1 elicitins are proteins secreted in the apoplast (Kanzaki et al., 2008). PcINF1 was also found to interact with the C2 domain of the calcium-binding protein SRC2-1 both in planta and in vitro (Liu et al., 2015). SRC2-1 is required for pepper responses to host and non-host pathogens and is also required for PcINF1-triggered cell death (Kim et al., 2008). Except for SRC2-1, 
evidence of in planta interaction between NbLRK1/NgRLK1 and INF1/PCINF1 are missing and currently it is not apparent how these studies link to the perception of elicitins by ELR. It is important to mention that our results on ELR are in line with other studies on elicitin/PRR signaling and fit our general model of surface receptor function (Boutrot and Zipfel, 2017).

\section{SOBIR 1 and SERK3 are both required for ELR function}

As a RLP, ELR is lacking a cytoplasmic kinase domain and is thus incapable of downstream signaling. RLPs are known to associate with co-regulatory LRRRLKs that are signaling competent (Chinchilla et al., 2009; Gust and Felix, 2014; Liebrand et al., 2014; Bi et al., 2016). SERK3 has previously been linked to cell death response caused by INF1 recognition in N. benthamiana (Chaparro-Garcia et al., 2011). Based on our studies, SOBIR1 was found to be required for INF1triggered cell death and for basal resistance to $P$. infestans, similar to SERK3 and to what has been reported for other pathogens (Chaparro-Garcia et al., 2011; Liebrand et al., 2014; Peng et al., 2015; Domazakis et al., 2018).

We have shown that ELR constitutively associates with SOBIR1 in a ligandindependent manner, and associates with SOMATIC EMBRYOGENESIS RECEPTOR KINASE 3 (SERK3) upon induction with INF1 (Gust and Felix, 2014; Liebrand et al., 2014; Bi et al., 2016; Postma et al., 2016; Domazakis et al., 2018). In other words, ELR is found in a preformed complex with SOBIR1 which recruits SERK3 upon ligand perception (Fig. 1).

From our experiments it was also evident that both SERK3 and SOBIR1 coreceptors are timely required for a robust response to elicitins. Artificial elicitins INF1-3HA, which likely forms homohexamers, and $\beta$-CRY chemically crosslinked dimer $\beta$-CRYDIM (which is also found in planta) are binding to ELR (indirect proof for $\beta$-CRY; only the monomer was shown to bind) but were found to not allow co-receptors to form a complex with the RLP, probably due to steric hindrance (Chapter 4) (Fig. 1). With INF1-3HA, both SOBIR1 and SERK3 are inhibited for associating with ELR, while $\beta$-CRYDIM affects association only with SOBIR 1 . In either case, elicitin-triggered cell death did not occur, but with $\beta$-CRYDIM PR gene expression was found, likely due to SERK3 still being in the complex (Chapter 4). To our knowledge, this is the first report of co-receptor inhibition by a ligand and we propose that such a setup could find application in RLP signaling studies. 


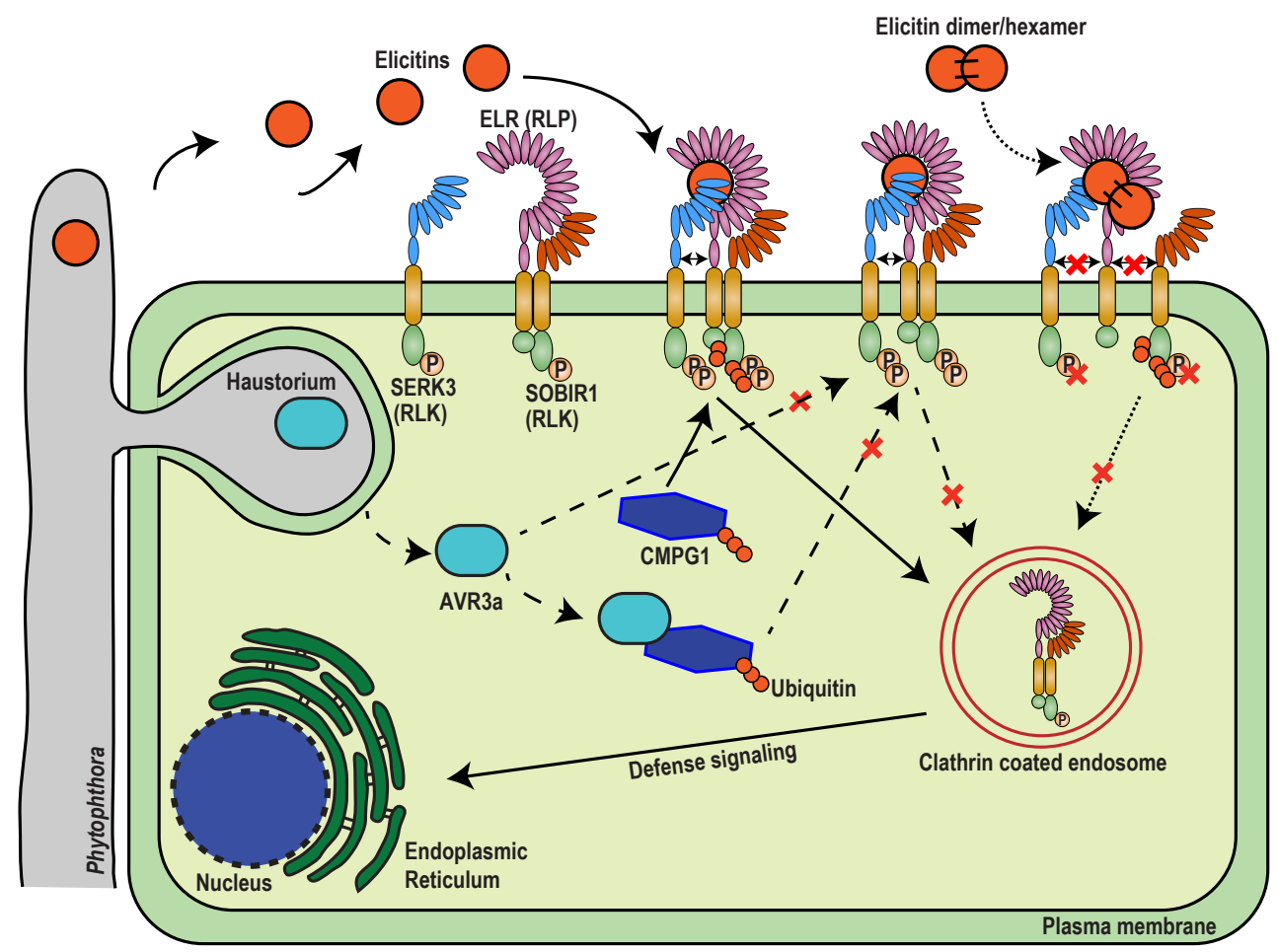

FIGURE 1 | A schematic overview of the first players in elicitin perception by ELR in Solanum sp. and different aspects affecting downstream responses. ELR is localized at the plasma membrane, where it is found in a preformed complex with the co-regulatory RLK SOBIR1 (Domazakis et al., 2018). Upon elicitin perception by ELR, the co-regulatory RLK SERK3 is recruited to the complex (dual arrow). After a series of phosphorylation $(\mathrm{P})$ and ubiquitination reactions, the complex seems to undergo endocytosis and triggers downstream signaling (normal arrows). We propose that only ELR and SOBIR1 are endocytosed and SERK3 is released from the complex shortly after elicitin binding by ELR (Chapter 4). AVR3a is secreted from Phytophthora infestans and suppresses responses to INF1 (dashed arrows). This is done by stabilizing CMPG1 and inhibiting it from ubiquitinating the ELR-SOBIR1 complex, or by AVR3a acting as a general ubiquitination inhibitor (Chapter 4). In either case, the receptor complex fails to be internalized and as a consequence, the downstream responses are blocked. In this thesis, we have also discovered another way of blocking elicitin signaling (Chapter 4). Two structurally altered elicitins, i.e. an affinity-tagged INF1 or an in planta dimerized $\beta$-CRY are both binding to ELR, however these elicitins fail to trigger a robust cell death response. We have shown that this is because of inhibition of the ELR-SOBIR1-SERK3 complex formation (Chapter 4).

But what is the function of SOBIR1 in the complex? We found that the kinase of SOBIR1 is required for elicitin-triggered cell death and is continuously phosphorylated, similar to SERK3 (Chapter 4). Preliminary experiments have shown that a short elicitation with purified INF1 protein leads to massive changes in ELR-SOBIR1 complex accumulation (Chapter 4). Without INF1 elicitation, SOBIR1 has a stabilizing effect on ELR, but as soon as INF1 is introduced, the amounts of detected ELR and SOBIR1 are severely reduced (Chapters 3,4 ). This 
was not the case for SERK3, indicating that it may not stay in the complex after signal transduction occurs (Fig. 1). We hypothesize that this rapid decrease in ELR/ SOBIR1 accumulation may happen due to the formation of insoluble endocytic vesicles rather than actual degradation of the proteins (Fig. 1). In line with this hypothesis, the elicitin ParA1 from $P$. parasitica was shown to induce SOBIR1 endocytosis (Peng et al., 2015). Moreover, the elicitin $\beta$-CRY from P. cryptogea has been shown to induce clathrin-mediated endocytosis in BY2 tobacco cells, which could be initiated by the tobacco elicitin receptor (Leborgne-Castel et al., 2008). For RLKs such as FLS2, PEPR1/2 and EFR it has been demonstrated that ligandactivated receptor complexes are internalized into clathrin-coated endosomes in a BRI1-ASSOCIATED KINASE 1 (BAK1)/SERK3-dependent manner (Mbengue et al., 2016). In a more related receptor to ELR, the RLP Cf-4, it was found that Avr4 elicitation leads to Cf-4 endocytosis together with SOBIR1, which is dependent on SERK3 (Postma et al., 2016). We propose that the activated ELR-SOBIR1 complex undergoes similar SERK3-dependent endocytosis, however this awaits experimental validation. This could be done with microscopy experiments similar to what has been performed for Cf-4 and the aforementioned RLKs (Postma et al., 2016).

\section{Phytophthora infestans AVR3a could suppress INF1 recognition by being a potent ubiquitination inhibitor}

P. infestans is able to suppress INF1-triggered defenses in two ways; by employing cytoplasmic effectors or by downregulating INF1 expression (Kamoun et al., 1997; Derevnina et al., 2016). Known cytoplasmic effectors with such a function are PexRD8 and PexRD36 ${ }_{45-1}$, PexRD27 and AVR3a, with the latter being the most studied (Armstrong et al., 2005; Bos et al., 2006; Bos et al., 2009; Oh et al., 2009; Bos et al., 2010; Zheng et al., 2014). Besides INF1-triggered cell death, AVR3a has been also shown to suppress Cf-4-, Cf-9- and Pto-mediated cell death, indicating that it targets a shared signaling component of those PRRs (Gilroy et al., 2011). Moreover, AVR3a is able to inhibit the endocytosis of FLS2, a PRR not related with elicitin perception, but does not affect BRASSINOSTEROID INSENSITIVE 1 (BRI1) endocytosis (Chaparro-Garcia et al., 2015).

It has been reported that AVR3a is able to suppress MAMP-triggered responses in at least two ways, i.e. 1) by associating and inhibiting the E3 ubiquitin ligase CYS, MET, PRO, and GLY PROTEIN 1 (CMPG1) and 2) by blocking receptor endocytosis via association with DYNAMIN-RELATED PROTEIN 2 (DRP2), a protein involved in cellular trafficking (Bos et al., 2010; Chaparro-Garcia et al., 2015). CMPG1 and 
DRP2 are both linked to the ubiquitination pathway, which plays a major role in immune receptor endocytosis function and is a common target for many effectors (Duplan and Rivas, 2014; Li et al., 2014; Banfield, 2015). During ubiquitination, a various number of ubiquitin moieties are covalently attached to a given substrate. This is done in a three step process involving ubiquitin ligases E1, E2 and E3, with the latter providing the substrate specificity (Vierstra, 2009; Duplan and Rivas, 2014). It is evident that many ubiquitin ligases are phosphorylated by interacting with RLKs indicating that they are involved in processes related to signaling (Furlan et al., 2012).

Preliminary data with two untagged AVR3a variants (AVR3a ${ }^{\mathrm{Kl}}$ and AVR3a $\mathrm{a}^{\mathrm{EM}}$ ) have shown that their expression in planta has a broad effect on inhibiting ubiquitination of proteins (Chapter 4 ). This was shown by the reduction in proteins carrying linked ubiquitin after total protein extraction in N. benthamiana (Chapter 4). Interestingly, similar findings have been reported previously, where AVR3a ${ }^{\mathrm{KI}}$ was shown to decrease smearing in the observed bands of FLS2, EFR and BAK1 (Fig. A2.3, (Chaparro-Garcia, 2012)). We hypothesize that AVR3a may be a potent general ubiquitination inhibitor and it would be interesting to test what is its effect on SOBIR1, which seems to be heavily modified (Fig. 1, Chapter 3). This may explain why AVR3a is able to inhibit the endocytosis of a range of activated immune receptors, even unrelated to elicitin perception and interact with different proteins such as CMPG1 and DRP2. It is conceivable that such an effector feature will be very beneficial for parasitic microbes such as Phytophthora.

\section{Using purified effector proteins for effectoromics screens}

Effector-assisted breeding was shown to accelerate the identification and cloning of $\mathrm{R}$ genes, speed up functional characterization of breeding material, and effectors can also be exploited for predicting the durability of introduced NLR genes (Vleeshouwers et al., 2011a; Vleeshouwers and Oliver, 2014). The successful cloning of ELR, which was possible thanks to accurate phenotyping based on effector responses, indicated that this approach could be extended to cell surface PRRs. However there are some difficulties which are often associated with high throughput effector screens in such diverse material as wild tuber-bearing Solanum species. In some cases, PVX agroinfection screens may be hindered by extreme resistance (ER) which is occurring at the single cell level (de Ronde et al., 2014) and leads to the absence of macroscopic cell death symptoms which are required for scoring. In other cases, agroinfiltration is hindered by unspecific cell death responses to Agrobacterium itself (Du et al., 2014). 
In Chapter 2, we describe simplified protocols for effectoromics screens in wild potato for the identification of PRRs. In this chapter, we also describe the design and production of affinity-tagged recombinant $P$. infestans apoplastic effectors in the yeast Pichia pastoris. Previously, this system was used for the production of P. infestans elicitins (Ponchet et al., 1999; Vleeshouwers et al., 2006) and other fungal effector proteins (Kombrink, 2012; Sánchez-Vallet et al., 2013), however with our design we were focused on introducing affinity tags for proteomic assays (discussed below), accelerating the identification of high protein producing yeast clones and optimizing yield in small culture setups (without a fermenter).

With the protocols described in Chapter 2, we were able to produce six His-HA tagged effector proteins (INF1, SCR74-A10, SCR74-G1, SCR74-B3b, EPI1, EPIC2B) at reasonable yields and purity. The functionality of those effectors was confirmed as they gave expected responses when infiltrated in responding genotypes (Chapters 2,4). Moreover, we were able to perform binding assays with His-HA-INF1 and ELR and obtained expected interactions (Chapter 4). No unspecific responses were observed when any of those effectors were infiltrated at concentrations up to $10 \mu \mathrm{M}$ in non-responding wild potato (data not shown), indicating that potential contaminants from $P$. pastoris are unlikely to trigger macroscopic responses. For Solanum this is very important as proteins derived from Escherichia coli systems often cause unspecific cell death (data not shown).

We propose that His-HA effectors produced with the P. pastoris system are functional proteins that are suitable for effector screens and can be used to complement responses obtained by other methods (i.e. PVX agroinfection or agroinfiltration) or to enable screening of Solanum germplasm which less amenable to Agrobacterium assays. The protein infiltration assays can also be performed in greenhouse compartments without biological containment. Moreover, they can be used for biochemical assays to characterize receptor function, identify new PRRs or other in planta interactors (Chapter 4).

\section{Proteomics as a tool for PRR identification}

To identify plant PRRs, several strategies have been used with the most robust being forward and reverse genetics (Boutrot and Zipfel, 2017). Forward genetics takes advantage of the natural variation or uses mutagenized material in order to identify variation in resistance to pathogens, or in the response to a said MAMP/ effector (Chapter 2, (Boutrot and Zipfel, 2017)). Using specific MAMPs/effectors for screenings instead of disease assays or crude protein extracts leads to a better understanding of the exact function of the PRRs cloned (Chapter 2, (Boutrot and 
Zipfel, 2017)). Reverse genetic approaches often include mutant libraries of plants with mutations in genes that are expected to be involved in disease resistance (e.g. RLPs, RLKs). The increasing knowledge on PRR structure and sequence has significantly increased the speed and efficiency of such methods, however, these have so far been restricted to model plants such as Arabidopsis thaliana.

However, there are cases that data from forward genetics do align with expected Mendelian segregation or the obtained resistance proteins are not PRRs, but rather participate indirectly in the defense pathway. Biochemical approaches have shown potential in identifying PRRs, though their application is still not very wide because of technical difficulties (Boutrot and Zipfel, 2017). Several PRRs have been cloned with methods such as ligand affinity (OsCEBiP, LYM2, PEPR1) or coreceptor binding (NbCSPR) (Kaku et al., 2006; Yamaguchi et al., 2006; Petutschnig et al., 2010; Saur et al., 2016).

In this thesis we provide evidence that ELR can be isolated from diluted total protein extracts suspension by using beads with immobilized INF1 (Chapter 4). Similar findings were obtained by infiltrating INF1 into the plant apoplast in N. benthamiana leaves expressing ELR (data not shown). These data suggested that ELR could potentially be identified from its native background using a similar setup. Alternatively, since it was known that INF1 response requires SERK3, an approach could be to transform $S$. microdontum potato plants with an affinity-tagged version of SERK3, but since this is difficult with current Agrobacterium protocols (Chapter 5), different species that carry a functional ELR receptor could be used ( $D u, 2014)$. It is anticipated, that overexpression of SERK3 may cause aberrant phenotypes in Solanum due to its involvement in several signaling processes, but if this is the case, inducible promoters could be considered (Chinchilla et al., 2009; Liebrand et al., 2014). Alternatively, the experiment could be performed in N. benthamiana which also carries an INF1 receptor and is more easy to transiently transform (Saur et al., 2016). Then, after performing a short elicitation by infiltrating INF1 protein, immunoprecipitation of SERK3 should also immunoprecipitate ELR. Such an approach was described in Saur et al. (2016), which led to the identification of NbCSPR. In Fig. 2 we schematically describe a general model for PRR identification using proteomics. It is important to mention that the use of SERK3 as a bait for capturing a PRR requires the confirmation that response to a said MAMP/effector requires the specific co-receptor. RNAi or virus-induced gene silencing (VIGS) could be used for this purpose. Moreover, proteomic databases are required for analyzing the data.

With the increased basic knowledge on immune receptor properties, it is anticipated that proteomics will be increasingly employed in the future in order to understand plant immunity. Provided that these experiments are performed with 
the right negative controls, the information derived from such methods can be valuable not only for PRR identification, but also for the identification of proteins such as effector targets and downstream signaling interactors (Fig. 2). Effector targets hold great promise for modification as they are often found to function as susceptibility (S-) genes (van Schie and Takken, 2014).

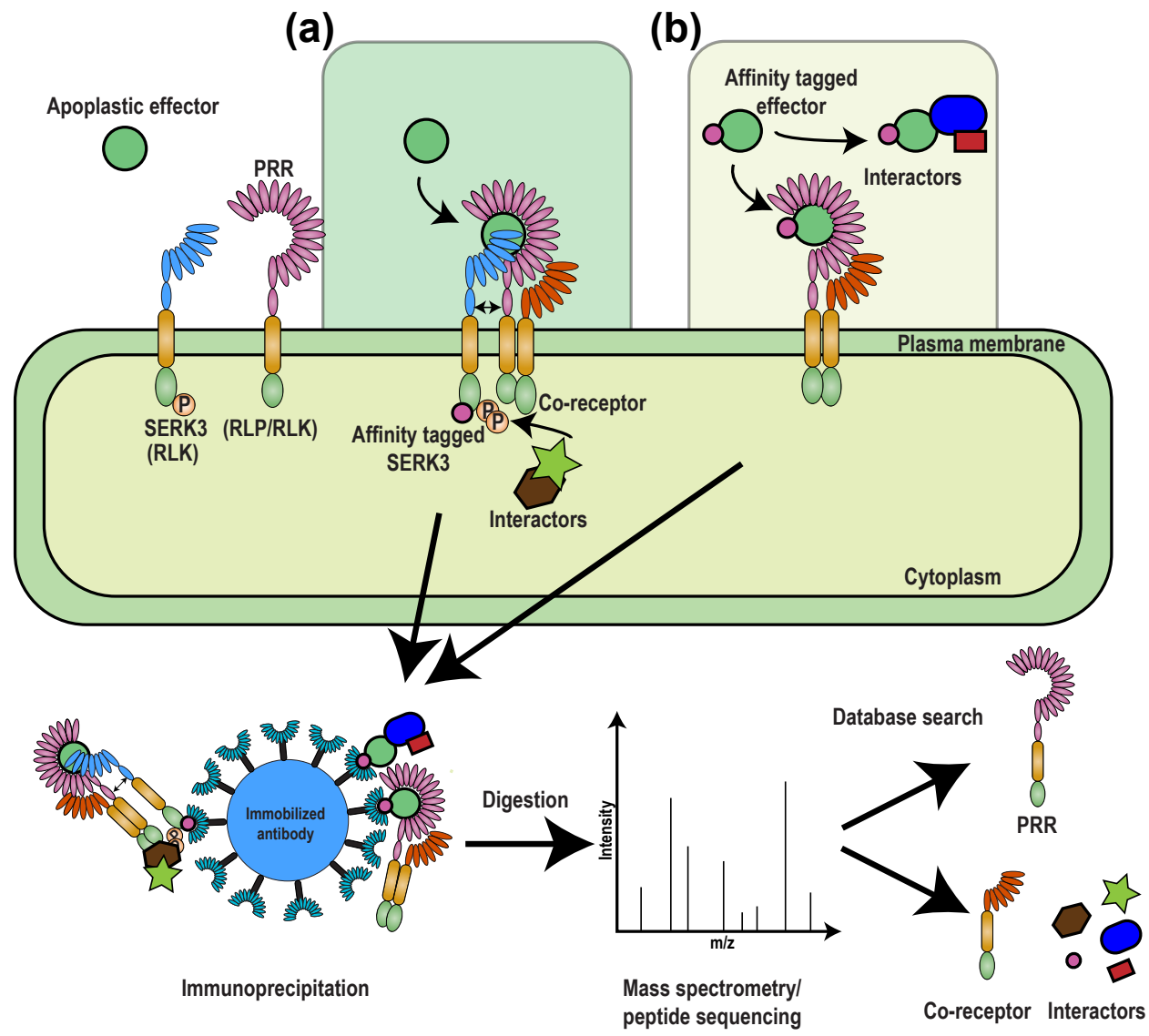

FIGURE 2 | Proposed proteomic approaches for accelerating the identification of PRRs, based on affinity-tagged co-receptors (a) or effectors (b). a) After confirming that a co-receptor (e.g. SERK3) is involved in a response to a said apoplastic effector, transgenic or transiently transformed plants expressing an affinity-tagged co-receptor can be generated. After a short elicitation with purified effector protein, the co-receptor will associate with the matching PRR. b) An alternative way is the use of affinity-tagged recombinant apoplastic effector. The protein is infiltrated into the plant apoplast where it will bind with PRRs or other interacting proteins (e.g. effector targets), or it may be first immobilized in a matrix and plant extract is applied (Chapter 4). In both cases ( $a$ and b), several negative controls must be included; e.g. for a); tagged control protein which localizes to plasma membrane, carrying the same tag as SERK3. Samples obtained from both elicited and non-elicited plants. For b); a different unrelated apoplastic effector carrying the same tag can be used. In both a) and b) cases, plant material, is collected for protein extraction and immunoprecipitation. Subsequently, samples are digested and peptides are sequenced using mass spectrometry. The identity of the PRRs and other proteins found in the mix is determined by database searches. 


\section{Genome editing for the functional characterization of PRRs in Solanum}

In recent years, genome editing has accelerated the targeted generation of desired mutations in model and crop plants (Belhaj et al., 2013; Bortesi and Fischer, 2015). The technology known as clustered regular interspaced short palindromic repeats (CRISPR)/CRISPR-associated protein 9 (Cas9) was relatively recently shown to function in plants and gained immediate attention from the research community. Since potato is not a model species, assays to assess gene function were difficult due to the high ploidy and self-incompatibility. Those problems have been largely overcome with the CRISPR/Cas9, and several reports emerged with the application of the method to alter agronomically important genes, with the main limitation being the transformation efficiency (Wang et al., 2015; Andersson et al., 2017). For ELR, we hypothesized that its activity could be more effective in its own genetic background S. microdontum, compared to S. tuberosum cv. Désireé (Du et al., 2015).

To understand the contribution of ELR in resistance to $P$. infestans in its native background, we explored the use of CRISPR/Cas9 in wild Solanum for generating an ELR knock-out (Chapter 5). Two ELR-targeting single guide RNA sequences (sgRNAs) were designed for this purpose. Their efficiency was successfully determined with a transient assay that we developed in N. benthamiana. We found that mutation enrichment was necessary for identifying mutations (Nekrasov et al., 2013). The constructs were then used for transforming S. microdontum. However, we were unable to obtain transformants using our routine Agrobacteriummediated transformation protocols, similar to what has been reported for this wild species (Rakosy-Tican L, 2004). To overcome this, we initiated transformations in various other Solanum sp. (S. edinense, S. papita, S. phureja, S. microdontum subsp. gigantophyllum and $S$. chacoense), which are known to carry functional ELR homologs (Chapter 5). Positive transformants were found in S. edinense, S. papita, S. phureja and S. chacoense, which we then tested for altered responses to INF1. One transformant of S. edinense and one of S. phureja showed a decreased cell death frequency upon treatment with INF1, and those plants were studied further. Following a similar mutation enrichment strategy, we found evidence that some S. edinense and S. papita may contain heterozygous mutations. No full ELRknock-outs were obtained. The reasons for this could be that these species are polyploids $(4 n-5 n)$ that are more challenging for this approach, and we have used only one sgRNA sequence, which limits the targeting efficiency (Chapter 5). However increasing the sgRNA targets is known to increase mutation efficiency in polyploids and is something to be investigated (Wang et al., 2014). Interestingly, 
most mutations we have identified were not deletions. We hypothesize that this could be due to the high repeat content in $E L R$ itself as well as the genomic locus in general, which is full of ELR-like sequences. We propose that such sequences have potentially been used by the plant DNA repair machinery in order to repair the CRISPR-induced double strand breaks.

From our experiments it was evident that performing CRISPR/Cas9-mediated mutagenesis in wild potato is possible, provided that the genotype used is amenable to transformation. Moreover, for polyploid genotypes, it is preferable to use CRISPR/Cas9 designs with more sgRNAs, which is easy to do based on current cloning methods and available plasmids (Weber et al., 2011). We anticipate that CRISPR/Cas9 will be increasingly used for characterizing functionally characterizing genes such as PRRs. However developments in homologous directed repair could enable us to actually modify those receptors at will and e.g. enhance their recognition spectrum, though this is still not possible for plants (Belhaj et al., 2013).

\section{Final remarks}

Crop plants are continuously threatened by diseases that limit their yields. To feed the ever-increasing world population, such crop losses should be minimized. One way to do this is breeding for disease resistant cultivars. My work has contributed to understanding how cell surface-triggered immunity works in potato against the devastating pathogen P. infestans. I have shown that ELR is a true PRR and revealed the first interactors downstream of elicitin binding. I have also provided evidence that PRRs can potentially be identified using proteomics. Moreover, I explored the applicability of genome editing in wild Solanum for reverse genetic studies with the ultimate goal to enable characterization of PRR genes in their native background. My data show that immunity that is triggered by PRRs has potential for disease resistance against potato late blight (Chapter 3), however it is often suppressed by cytoplasmic effectors. In my opinion, no single strategy for obtaining durable disease resistance exists. However, by carefully selecting and combining several layers of defense, including PRRs, NLRs and S-genes in bred cultivars, and combining with pathogen monitoring can maximize our chances to outcompete rapidly evolving pathogens like $P$. infestans. 


\section{References}

Albert, I., Bohm, H., Albert, M., Feiler, C.E., Imkampe, J., Wallmeroth, N., Brancato, C., Raaymakers, T.M., Oome, S., Zhang, H., Krol, E., Grefen, C., Gust, A.A., Chai, J., Hedrich, R., van den Ackerveken, G., and Nurnberger, T. 2015. An RLP23-SOBIR1-BAK1 complex mediates NLP-triggered immunity. Nat Plants 1:15140.

Andersson, M., Turesson, H., Nicolia, A., Falt, A.S., Samuelsson, M., and Hofvander, P. 2017. Efficient targeted multiallelic mutagenesis in tetraploid potato (Solanum tuberosum) by transient CRISPRCas9 expression in protoplasts. Plant Cell Rep 36:117-128.

Armstrong, M.R., Whisson, S.C., Pritchard, L., Bos, J.I.B., Venter, E., Avrova, A.O., Rehmany, A.P., Bohme, U., Brooks, K., Cherevach, I., Hamlin, N., White, B., Frasers, A., Lord, A., Quail, M.A., Churcher, C., Hall, N., Berriman, M., Huang, S., Kamoun, S., Beynon, J.L., and Birch, P.R.J. 2005. An ancestral oomycete locus contains late blight avirulence gene Avr3a, encoding a protein that is recognized in the host cytoplasm. Proc Natl Acad Sci USA 102:7766-7771.

Banfield, M.J. 2015. Perturbation of host ubiquitin systems by plant pathogen/pest effector proteins. Cell Microbiol 17:18-25.

Belhaj, K., Chaparro-Garcia, A., Kamoun, S., and Nekrasov, V. 2013. Plant genome editing made easy: targeted mutagenesis in model and crop plants using the CRISPR/Cas system. Plant Methods 9:39.

Bi, G., Liebrand, T.W., Bye, R.R., Postma, J., van der Burgh, A.M., Robatzek, S., Xu, X., and Joosten, M.H. 2016. SOBIR1 requires the GxxxG dimerization motif in its transmembrane domain to form constitutive complexes with receptor-like proteins. Mol Plant Pathol 17:96-107.

Bohm, H., Albert, I., Oome, S., Raaymakers, T.M., van den Ackerveken, G., and Nurnberger, T. 2014. A conserved peptide pattern from a widespread microbial virulence factor triggers patterninduced immunity in Arabidopsis. PLoS Pathog 10:e1004491.

Bortesi, L., and Fischer, R. 2015. The CRISPR/Cas9 system for plant genome editing and beyond. Biotechnol Adv 33:41-52.

Bos, J.I., Chaparro-Garcia, A., Quesada-Ocampo, L.M., McSpadden Gardener, B.B., and Kamoun, S. 2009. Distinct amino acids of the Phytophthora infestans effector AVR3a condition activation of R3a hypersensitivity and suppression of cell death. Mol Plant Microbe Interact 22:269-281.

Bos, J.I., Kanneganti, T.D., Young, C., Cakir, C., Huitema, E., Win, J., Armstrong, M.R., Birch, P.R., and Kamoun, S. 2006. The C-terminal half of Phytophthora infestans RXLR effector AVR3a is sufficient to trigger R3a-mediated hypersensitivity and suppress INF1-induced cell death in Nicotiana benthamiana. Plant J 48:165-176.

Bos, J.I., Armstrong, M.R., Gilroy, E.M., Boevink, P.C., Hein, I., Taylor, R.M., Zhendong, T., Engelhardt, S., Vetukuri, R.R., Harrower, B., Dixelius, C., Bryan, G., Sadanandom, A., Whisson, S.C., Kamoun, S., and Birch, P.R. 2010. Phytophthora infestans effector AVR3a is essential for virulence and manipulates plant immunity by stabilizing host E3 ligase CMPG1. Proc Natl Acad Sci USA 107:9909-9914.

Boutrot, F., and Zipfel, C. 2017. Function, discovery, and exploitation of plant pattern recognition receptors for broad-spectrum disease resistance. Annu Rev Phytopathol 55:257-286.

Chaparro-Garcia, A. 2012. Molecular basis of plant cell death suppression by the Phytophthora infestans effector AVR3a (PhD dissertation), University of East Anglia.

Chaparro-Garcia, A., Wilkinson, R.C., Gimenez-lbanez, S., Findlay, K., Coffey, M.D., Zipfel, C., Rathjen, J.P., Kamoun, S., and Schornack, S. 2011. The receptor-like kinase SERK3/BAK1 is required for basal resistance against the late blight pathogen Phytophthora infestans in Nicotiana benthamiana. PLoS One 6:e16608.

Chaparro-Garcia, A., Schwizer, S., Sklenar, J., Yoshida, K., Petre, B., Bos, J.I., Schornack, S., Jones, A.M., Bozkurt, T.O., and Kamoun, S. 2015. Phytophthora infestans RXLR-WY effector AVR3a associates with dynamin-related protein 2 required for endocytosis of the plant pattern recognition receptor FLS2. PLoS One 10:e0137071.

Chinchilla, D., Shan, L., He, P., de Vries, S., and Kemmerling, B. 2009. One for all: the receptor-associated kinase BAK1. Trends Plant Sci 14:535-541.

de Ronde, D., Butterbach, P., and Kormelink, R. 2014. Dominant resistance against plant viruses. Front Plant Sci 5:307. 
Derevnina, L., Dagdas, Y.F., De la Concepcion, J.C., Bialas, A., Kellner, R., Petre, B., Domazakis, E., Du, J., Wu, C.H., Lin, X., Aguilera-Galvez, C., Cruz-Mireles, N., Vleeshouwers, V.G.A.A., and Kamoun, S. 2016. Nine things to know about elicitins. New Phytol 212:888-895.

Domazakis, E., Wouters, D., Visser, R.G.F., Kamoun, S., Joosten, M.H.A.J., and Vleeshouwers, V.G.A.A. 2018. The ELR-SOBIR1 complex functions as a two-component RLK to mount defense against Phytophthora infestans Mol Plant Microbe Interact (Accepted).

Du, J., Rietman, H., and Vleeshouwers, V.G.A.A. 2014. Agroinfiltration and PVX agroinfection in potato and Nicotiana benthamiana. J Vis Exp:e50971.

Du, J., Verzaux, E., Chaparro-Garcia, A., Bijsterbosch, G., Keizer, L.C., Zhou, J., Liebrand, T.W., Xie, C., Govers, F., Robatzek, S., van der Vossen, E.A., Jacobsen, E., Visser, R.G., Kamoun, S., and Vleeshouwers, V.G.A.A. 2015. Elicitin recognition confers enhanced resistance to Phytophthora infestans in potato. Nat Plants 1:15034.

Duplan, V., and Rivas, S. 2014. E3 ubiquitin-ligases and their target proteins during the regulation of plant innate immunity. Front Plant Sci 5:42.

Felix, G., Duran, J.D., Volko, S., and Boller, T. 1999. Plants have a sensitive perception system for the most conserved domain of bacterial flagellin. Plant J 18:265-276.

Furlan, G., Klinkenberg, J., and Trujillo, M. 2012. Regulation of plant immune receptors by ubiquitination. Front Plant Sci 3:238.

Gilroy, E.M., Taylor, R.M., Hein, I., Boevink, P., Sadanandom, A., and Birch, P.R. 2011. CMPG1-dependent cell death follows perception of diverse pathogen elicitors at the host plasma membrane and is suppressed by Phytophthora infestans RXLR effector AVR3a. New Phytol 190:653-666.

Gust, A.A., and Felix, G. 2014. Receptor like proteins associate with SOBIR1-type of adaptors to form bimolecular receptor kinases. Curr Opin Plant Biol 21:104-111.

Haas, B.J., Kamoun, S., Zody, M.C., Jiang, R.H., Handsaker, R.E., Cano, L.M., Grabherr, M., Kodira, C.D., Raffaele, S., Torto-Alalibo, T., Bozkurt, T.O., Ah-Fong, A.M., Alvarado, L., Anderson, V.L., Armstrong, M.R., Avrova, A., Baxter, L., Beynon, J., Boevink, P.C., Bollmann, S.R., Bos, J.I., Bulone, V., Cai, G., Cakir, C., Carrington, J.C., Chawner, M., Conti, L., Costanzo, S., Ewan, R., Fahlgren, N., Fischbach, M.A., Fugelstad, J., Gilroy, E.M., Gnerre, S., Green, P.J., Grenville-Briggs, L.J., Griffith, J., Grunwald, N.J., Horn, K., Horner, N.R., Hu, C.H., Huitema, E., Jeong, D.H., Jones, A.M., Jones, J.D., Jones, R.W., Karlsson, E.K., Kunjeti, S.G., Lamour, K., Liu, Z., Ma, L., Maclean, D., Chibucos, M.C., McDonald, H., McWalters, J., Meijer, H.J., Morgan, W., Morris, P.F., Munro, C.A., O'Neill, K., Ospina-Giraldo, M., Pinzon, A., Pritchard, L., Ramsahoye, B., Ren, Q., Restrepo, S., Roy, S., Sadanandom, A., Savidor, A., Schornack, S., Schwartz, D.C., Schumann, U.D., Schwessinger, B., Seyer, L., Sharpe, T., Silvar, C., Song, J., Studholme, D.J., Sykes, S., Thines, M., van de Vondervoort, P.J., Phuntumart, V., Wawra, S., Weide, R., Win, J., Young, C., Zhou, S., Fry, W., Meyers, B.C., van West, P., Ristaino, J., Govers, F., Birch, P.R., Whisson, S.C., Judelson, H.S., and Nusbaum, C. 2009. Genome sequence and analysis of the Irish potato famine pathogen Phytophthora infestans. Nature 461:393-398.

Haverkort, A.J., Struik, P.C., Visser, R.G.F., and Jacobsen, E. 2009. Applied biotechnology to combat the late blight in potato caused by Phytophthora infestans. Potato Research 52:249-264.

Haverkort, A.J., Boonekamp, P.M., Hutten, R., Jacobsen, E., Lotz, L.A.P., Kessel, G.J.T., Vossen, J.H., and Visser, R.G.F. 2016. Durable late blight resistance in potato through dynamic varieties obtained by cisgenesis: scientific and societal advances in the DuRPh Project. Potato Research 59:35-66.

Jiang, R.H., Tyler, B.M., Whisson, S.C., Hardham, A.R., and Govers, F. 2006. Ancient origin of elicitin gene clusters in Phytophthora genomes. Mol Biol Evol 23:338-351.

Jones, J.D., and Dangl, J.L. 2006. The plant immune system. Nature 444:323-329.

Kaku, H., Nishizawa, Y., Ishii-Minami, N., Akimoto-Tomiyama, C., Dohmae, N., Takio, K., Minami, E., and Shibuya, N. 2006. Plant cells recognize chitin fragments for defense signaling through a plasma membrane receptor. Proc Natl Acad Sci USA 103:11086-11091.

Kamoun, S., Klucher, K.M., Coffey, M.D., and Tyler, B.M. 1993. A gene encoding a host-specific elicitor protein of Phytophthora parasitica. Mol Plant Microbe Interact 6:573-581.

Kamoun, S., van West, P., de Jong, A.J., de Groot, K.E., Vleeshouwers, V.G.A.A., and Govers, F. 1997. A gene encoding a protein elicitor of Phytophthora infestans is down-regulated during infection of potato. Mol Plant Microbe Interact 10:13-20.

Kanzaki, H., Saitoh, H., Takahashi, Y., Berberich, T., Ito, A., Kamoun, S., and Terauchi, R. 2008. NbLRK1, a lectin-like receptor kinase protein of Nicotiana benthamiana, interacts with Phytophthora infestans INF1 elicitin and mediates INF1-induced cell death. Planta 228:977-987. 
Kim, Y.C., Kim, S.Y., Choi, D., Ryu, C.M., and Park, J.M. 2008. Molecular characterization of a pepper C2 domain-containing SRC2 protein implicated in resistance against host and non-host pathogens and abiotic stresses. Planta 227:1169-1179.

Kim, Y.T., Oh, J., Kim, K.H., Uhm, J.Y., and Lee, B.M. 2010. Isolation and characterization of NgRLK1, a receptor-like kinase of Nicotiana glutinosa that interacts with the elicitin of Phytophthora capsici. Mol Biol Rep 37:717-727.

Kombrink, A. 2012. Heterologous production of fungal effectors in Pichia pastoris. Pages 209-217 in: Plant Fungal Pathogens: Methods and Protocols, D.M. Bolton and P.H.J.B. Thomma, eds. Humana Press, Totowa, NJ.

Kunze, G., Zipfel, C., Robatzek, S., Niehaus, K., Boller, T., and Felix, G. 2004. The N terminus of bacterial elongation factor Tu elicits innate immunity in Arabidopsis plants. Plant Cell 16:3496-3507.

Leborgne-Castel, N., Lherminier, J., Der, C., Fromentin, J., Houot, V., and Simon-Plas, F. 2008. The plant defense elicitor cryptogein stimulates clathrin-mediated endocytosis correlated with reactive oxygen species production in bright yellow-2 tobacco cells. Plant Physiol 146:1255-1266.

Li, B., Lu, D., and Shan, L. 2014. Ubiquitination of pattern recognition receptors in plant innate immunity. Mol Plant Pathol 15:737-746.

Liebrand, T.W., van den Burg, H.A., and Joosten, M.H. 2014. Two for all: receptor-associated kinases SOBIR1 and BAK1. Trends Plant Sci 19:123-132.

Liu, Z.Q., Qiu, A.L., Shi, L.P., Cai, J.S., Huang, X.Y., Yang, S., Wang, B., Shen, L., Huang, M.K., Mou, S.L., Ma, X.L., Liu, Y.Y., Lin, L., Wen, J.Y., Tang, Q., Shi, W., Guan, D.Y., Lai, Y., and He, S.L. 2015. SRC2-1 is required in PCINF1-induced pepper immunity by acting as an interacting partner of PCINF1. J Exp Bot 66:3683-3698.

Mbengue, M., Bourdais, G., Gervasi, F., Beck, M., Zhou, J., Spallek, T., Bartels, S., Boller, T., Ueda, T., Kuhn, H., and Robatzek, S. 2016. Clathrin-dependent endocytosis is required for immunity mediated by pattern recognition receptor kinases. Proc Natl Acad Sci USA 113:11034-11039.

Nekrasov, V., Staskawicz, B., Weigel, D., Jones, J.D., and Kamoun, S. 2013. Targeted mutagenesis in the model plant Nicotiana benthamiana using Cas9 RNA-guided endonuclease. Nat Biotechnol 31:691-693.

Oh, S.K., Young, C., Lee, M., Oliva, R., Bozkurt, T.O., Cano, L.M., Win, J., Bos, J.I., Liu, H.Y., van Damme, M., Morgan, W., Choi, D., van der Vossen, E.A., Vleeshouwers, V.G.A.A., and Kamoun, S. 2009. In planta expression screens of Phytophthora infestans RXLR effectors reveal diverse phenotypes, including activation of the Solanum bulbocastanum disease resistance protein Rpi-blb2. Plant Cell 21:2928-2947.

Panabieres, F., Marais, A., Le Berre, J.Y., Penot, I., Fournier, D., and Ricci, P. 1995. Characterization of a gene cluster of Phytophthora cryptogea which codes for elicitins, proteins inducing a hypersensitive-like response in tobacco. Mol Plant Microbe Interact 8:996-1003.

Peng, K.C., Wang, C.W., Wu, C.H., Huang, C.T., and Liou, R.F. 2015. Tomato SOBIR1/EVR homologs are involved in elicitin perception and plant defense against the oomycete pathogen Phytophthora parasitica. Mol Plant Microbe Interact 28:913-926.

Petutschnig, E.K., Jones, A.M., Serazetdinova, L., Lipka, U., and Lipka, V. 2010. The lysin motif receptorlike kinase (LysM-RLK) CERK1 is a major chitin-binding protein in Arabidopsis thaliana and subject to chitin-induced phosphorylation. J Biol Chem 285:28902-28911.

Ponchet, M., Panabieres, F., Milat, M.L., Mikes, V., Montillet, J.L., Suty, L., Triantaphylides, C., Tirilly, Y., and Blein, J.P. 1999. Are elicitins cryptograms in plant-oomycete communications? Cell Mol Life Sci 56:1020-1047.

Postma, J., Liebrand, T.W., Bi, G., Evrard, A., Bye, R.R., Mbengue, M., Kuhn, H., Joosten, M.H., and Robatzek, S. 2016. Avr4 promotes Cf-4 receptor-like protein association with the BAK1/SERK3 receptor-like kinase to initiate receptor endocytosis and plant immunity. New Phytol 210:627642.

Rakosy-Tican L, A.A., Aurori CM, Ispas G. 2004. Transformation of wild Solanum species resistant to late blight by using reporter gene GFP and MSH2 genes. Plant Breeding and Seed Science 50:119128.

Ricci, P., Bonnet, P., Huet, J.C., Sallantin, M., Beauvais-Cante, F., Bruneteau, M., Billard, V., Michel, G., and Pernollet, J.C. 1989. Structure and activity of proteins from pathogenic fungi Phytophthora eliciting necrosis and acquired resistance in tobacco. Eur J Biochem 183:555-563. 
Sanchez-Vallet, A., Saleem-Batcha, R., Kombrink, A., Hansen, G., Valkenburg, D.J., Thomma, B.P., and Mesters, J.R. 2013. Fungal effector Ecp6 outcompetes host immune receptor for chitin binding through intrachain LysM dimerization. eLife 2:e00790.

Saur, I.M., Kadota, Y., Sklenar, J., Holton, N.J., Smakowska, E., Belkhadir, Y., Zipfel, C., and Rathjen, J.P. 2016. NbCSPR underlies age-dependent immune responses to bacterial cold shock protein in Nicotiana benthamiana. Proc Natl Acad Sci USA 113:3389-3394.

Stong, R.A., Kolodny, E., Kelsey, R.G., Gonzalez-Hernandez, M.P., Vivanco, J.M., and Manter, D.K. 2013. Effect of plant sterols and tannins on Phytophthora ramorum growth and sporulation. J Chem Ecol 39:733-743.

van Schie, C.C., and Takken, F.L. 2014. Susceptibility genes 101: how to be a good host. Annu Rev Phytopathol 52:551-581.

Vierstra, R.D. 2009. The ubiquitin-26S proteasome system at the nexus of plant biology. Nat Rev Mol Cell Biol 10:385-397.

Vleeshouwers, V.G.A.A., and Oliver, R.P. 2014. Effectors as tools in disease resistance breeding against biotrophic, hemibiotrophic, and necrotrophic plant pathogens. Mol Plant Microbe Interact 27:196-206.

Vleeshouwers, V.G.A.A., Driesprong, J.D., Kamphuis, L.G., Torto-Alalibo, T., van't Slot, K.A., Govers, F., Visser, R.G., Jacobsen, E., and Kamoun, S. 2006. Agroinfection-based high-throughput screening reveals specific recognition of INF elicitins in Solanum. Mol Plant Pathol 7:499-510.

Vleeshouwers, V.G.A.A., Raffaele, S., Vossen, J.H., Champouret, N., Oliva, R., Segretin, M.E., Rietman, H., Cano, L.M., Lokossou, A., Kessel, G., Pel, M.A., and Kamoun, S. 2011. Understanding and exploiting late blight resistance in the age of effectors. Annu Rev Phytopathol 49:507-531.

Wang, S., Zhang, S., Wang, W., Xiong, X., Meng, F., and Cui, X. 2015. Efficient targeted mutagenesis in potato by the CRISPR/Cas9 system. Plant Cell Rep 34:1473-1476.

Wang, Y., Cheng, X., Shan, Q., Zhang, Y., Liu, J., Gao, C., and Qiu, J.L. 2014. Simultaneous editing of three homoeoalleles in hexaploid bread wheat confers heritable resistance to powdery mildew. Nat Biotechnol 32:947-951.

Wang, Y., Xu, Y., Sun, Y., Wang, H., Qi, J., Wan, B., Ye, W., Lin, Y., Shao, Y., Dong, S., Tyler, B.M., and Wang, Y. 2018. Leucine-rich repeat receptor-like gene screen reveals that Nicotiana RXEG1 regulates glycoside hydrolase 12 MAMP detection. Nat Commun 9:594.

Weber, E., Engler, C., Gruetzner, R., Werner, S., and Marillonnet, S. 2011. A modular cloning system for standardized assembly of multigene constructs. PLoS One 6:e16765.

Yamaguchi, Y., Pearce, G., and Ryan, C.A. 2006. The cell surface leucine-rich repeat receptor for AtPep1, an endogenous peptide elicitor in Arabidopsis, is functional in transgenic tobacco cells. Proc Natl Acad Sci USA 103:10104-10109.

Zheng, X., McLellan, H., Fraiture, M., Liu, X., Boevink, P.C., Gilroy, E.M., Chen, Y., Kandel, K., Sessa, G., Birch, P.R.J., and Brunner, F. 2014. Functionally redundant RXLR Effectors from Phytophthora infestans act at different steps to suppress early flg22-triggered immunity. PLoS Pathog 10:e1004057. 

Summary

Samenvatting

Acknowledgements

About the author

List of publications

Education statement 



\section{Summary}

Potato (Solanum tuberosum) is the most important non-cereal crop for human consumption and its starch and fibers are also used to produce several industrial products. Potato suffers from many pests and diseases. The most threatening and re-emerging disease of potato worldwide is late blight, which is caused by the notorious oomycete Phytophthora infestans (Chapter 1). This pathogen is a hemibiotrophic organism that secretes a huge arsenal of apoplastic and host-translocated cytoplasmic effectors in order to colonize the host. Interestingly, wild potato plants have evolved receptors that recognize some of those effectors and trigger defense responses. These wild plants are a major source of resistance genes that can be transferred to the cultivated potato. Resistant cultivars obtained by breeding are highly desirable because the costs for chemical control of the disease are very high and there is also a need to reduce their use in order to preserve the environment. Moreover, the pathogen has developed resistance to some of those chemicals.

Receptors that recognize cytoplasmic effectors often belong to the nucleotidebinding leucine-rich repeat (NLR) family of resistance genes, ( $R$ genes), and they have been used for several years in resistance breeding. Despite the effectivity of NLRs in providing resistance, so far, most single NLR genes introduced into cultivated potato have been defeated by $P$. infestans rather quickly. To effectively control the pathogen in the long term, resistance gene stacking approaches in combination with new layers of defense have to be considered.

Like NLRs, cell surface-residing receptors, or pattern recognition receptors (PRRs) trigger defense responses and contribute to basal or non-host resistance against pathogens. They do so by recognizing apoplastic effectors or microbe-associated molecular patterns (MAMPs). Usually PRR-triggered resistance is quantitative and not as robust as NLR-based resistance, however it is believed to be more durable. In potato, PRR-based immunity that is triggered by the recognition of MAMPs/ effectors has remained unexplored. The first receptor against oomycetes was recently identified from a wild potato species, S. microdontum. The receptor, named ELICITIN RESPONSE (ELR), was found to recognize elicitins, a family of conserved apoplastic effectors with MAMP features, found specifically in Phytophthora and Pythium (Chapter 1). The research described in this thesis focused on studying PRRtriggered immunity in potato against the devastating pathogen $P$. infestans, by using ELR as a model (Chapter 1).

Effector-assisted breeding has proven to be a great tool for identifying resistances against pathogens and was pioneered from research on potato late blight. In a process also known as effector genomics (effectoromics), candidate effectors are predicted from the genome of pathogens such as $P$. infestans. Candidate effectors 
are cloned in plant expression vectors and are screened in a wild resistant germplasm for occurrence of specific responses. In Chapter $\mathbf{2}$ we show how effectoromics can be used to identify PRRs in Solanum spp. Simplified protocols are described for performing the effector screens, selecting plants for crosses and genetically mapping the responses. For performing effector screens, besides the routinely used potato virus $X(P V X)$ agroinfection and agroinfiltration, we describe the use of recombinant apoplastic effector proteins. This strategy can complement the results obtained by the other routinely applied Agrobacterium-based methods or enable screening of Agrobacterium- or PVX-recalcitrant plants. We provide protocols for heterologous apoplastic effector expression in the yeast Pichia pastoris. This includes recombinant effector design, cloning, high throughput $P$. pastoris clone selection and small scale protein production. We also provide an example with the production of six different $P$. infestans effectors using this system.

ELR is a receptor-like protein (RLP) and as such, it lacks a cytoplasmic signaling domain that is required for triggering defense responses. It was known that SOMATIC EMBRYOGENESIS RECEPTOR KINASE 3 (SERK3) is a receptor-like kinase (RLK) required for cell death triggered by the elicitin INF1 and that it also biochemically associates with ELR. In Chapter $\mathbf{3}$ we investigated the association of ELR with another interactor, which has been proposed to be specific for RLPs; the RLK SUPPRESSOR OF BIR1-1 (SOBIR1). Virus-induced gene silencing (VIGS) assays showed that SOBIR1 is required for cell death response triggered by INF1 and for basal resistance to $P$. infestans in Nicotiana benthamiana. Genetic complementation assays demonstrated that the kinase of SOBIR1 is required for INF1-triggered cell death. Protein co-immunoprecipitation studies showed that ELR is associating with S. microdontum SOBIR1 and its close homolog SOBIR1-like. From our findings it seems that ELR is found in a constitutive complex with SOBIR1, which recruits SERK3 upon INF1 elicitation.

True PRRs are known to physically interact with their ligands, however, this was not explored yet since the identification of ELR. In Chapter $\mathbf{4}$ we studied whether ELR is able to interact with various elicitins by using in planta and in vitro coimmunoprecipitation assays. We showed that ELR is able to physically bind INF1 in both setups, indicating that the interaction is very specific. Moreover, we found that ELR binds with the elicitins ParA1 (P. parasitica) and $\beta$-CRY (P. cryptogea). We also found that ELR is able to trigger cell death with additional elicitins, but likely binds them with lower affinity that remained under the detection limit. Interestingly, we observed that one C-terminally tagged version of INF1 was binding to ELR but failed to trigger cell death, in contrast to $N$-terminally tagged INF1. Similarly, a $\beta$-CRY dimer failed to trigger cell death when infiltrated in leaves expressing ELR. We hypothesized that the cause of these phenotypes could be due to altered interaction 
of ELR with the RLKs SOBIR1 or SERK3. Indeed, with the C-terminally tagged INF1, we found that both SOBIR1 and SERK3 were not in complex with ELR, while the $\beta$-CRY dimer was not allowing SOBIR1 to associate. To our knowledge, this is the first time that such a co-receptor inhibition is reported. Our data, therefore, highlight the necessity of performing functional control experiments for tagged proteins and further strengthen our earlier finding that both SOBIR1 and SERK3 are required for INF1-triggered cell death by ELR. These discoveries could prove useful for enabling detailed studies on RLP signaling.

When transformed into cultivated potato, ELR was known to enhance resistance against $P$. infestans, however, it remained unknown what the resistance contribution of this PRR in its native genetic background (i.e. S. microdontum) is. We hypothesized that recent developments of genome editing technologies can be used to perform such studies in non-model plants like (wild) potato. In Chapter 5, we used clustered regularly interspaced short palindromic repeat (CRISPR)/CRISPR-associated protein 9 (Cas9)-mediated genome editing to target ELR in wild Solanum. We generated a CRISPR/Cas9 construct that was found to be effective in inducing targeted mutations in ELR when tested in a transient setup in planta. Since it was impossible to transform the wild S. microdontum with the construct, we attempted the transformation of five different species that were known to carry ELR homologs. We obtained transformants from S. edinense, S. papita, S. phureja and S. chacoense, which were then screened for altered responses to INF1. Promising transformants with altered responses to INF1 were obtained in the pentaploid S. edinense and tetraploid S. papita. These transformants were subsequently searched for mutations using a mutation enrichment approach, followed by PCR and sequencing. No full ELR knock-outs were obtained, however, partly mutated and partly wildtype alleles could be found in these transformants. Altogether, these findings show that CRISPR/ Cas9 approaches are effective for functional characterization of genes in wild Solanum spp. However, they are limited by the transformation efficiency and ploidy level of a said genotype.

Finally, in Chapter 6, the findings of this thesis are discussed and placed in a broader perspective. A schematic overview of the perception of elicitins by ELR in wild potato is provided including all of our findings on elicitin binding, interaction with co-receptors SERK3 and SOBIR1, as well as some preliminary findings on AVR3a, an effector that suppresses INF1-triggered cell death as well as receptor endocytosis. In addition we propose two proteomic approaches for PRR identification, taking advantage of the obtained knowledge on effector/PRR or PRR/co-receptor interactions. Overall my research has contributed to the characterization of the first line of induced defense against Phytophthora in potato and could be instrumental for achieving durable resistance against late blight. 



\section{Samenvatting}

Aardappel (Solanum tuberosum) is een belangrijk gewas voor de wereldvoedselvoorziening, en voor de zetmeel- en vezelindustrie. De aardappelplant is echter vatbaar voor een groot aantal ziekten. De belangrijkste, de zogenaamde 'aardappelziekte' wordt veroorzaakt door de oomyceet Phytophthora infestans (Chapter 1). Deze hemi-biotrofe ziekteverwekker scheidt een arsenaal aan apoplastische (buiten de cel) en cytoplasmatische (in de cel) effectoren uit, om de plant te kunnen koloniseren. In wilde aardappelplanten zijn tijdens de evolutie receptoren ontstaan die sommige effectoren kunnen herkennen, en dit kan vervolgens leiden tot een afweerreactie van de plant. De wilde aardappelsoorten vormen een belangrijke bron van resistentiegenen, die gebruikt kunnen worden voor de veredeling van rassen. Rassen die resistent zijn tegen Phytophthora zijn zeer gewild aangezien de kosten voor chemische bestrijding hoog zijn, en bovendien een bedreiging voor het milieu. Helaas heeft Phytophthora resistentie ontwikkeld tegen een aantal bestrijdingsmiddelen.

Receptoren die de effectoren ín de cel herkennen behoren over het algemeen tot de familie van de nucleotide-binding leucine-rich repeat (NLR) resistentiegenen ( $R$ genen). Deze $R$ genen worden al jarenlang gebruikt in de resistentieveredeling. Ondanks dat ze in eerste instantie een goede resistentie geven, worden de individueel ingebrachte NLR tot dusver snel doorbroken door P. infestans. Voor een effectievere ziektebeheersing op de langere termijn, moeten we overwegen of we NLR kunnen combineren met nieuwe vormen van afweer.

Receptoren aan het celoppervlak, oftewel de 'pattern recognition receptors' (PRRs) kunnen ook afweerreacties aanschakelen, net als NLR. Deze PRR dragen bij aan de basale resistentie, en de niet-waardresistentie tegen ziekteverwekkers. Dit doen ze door middel van de herkenning in de plant van apoplastische effectoren of 'microbe-associated molecular patterns' (MAMPs). De PRR-gebaseerde resistentie is over het algemeen kwantitatief van aard en minder robuust dan NLRgebaseerde resistentie, maar wordt wel gezien als potentieel meer duurzaam. PRR-gebaseerde resistentie is in aardappel tot dusver nog niet bestudeerd. Een aantal jaren geleden is in een wilde aardappelsoort, Solanum microdontum, de eerste PRR receptor tegen oomyceten geïdentificeerd. Deze receptor, genaamd ELICITIN RESPONSE (ELR), herkent elicitinen, een familie van geconserveerde apoplastische effectoren / MAMP van Phytophthora en Pythium soorten (Chapter 1). Het onderzoek dat is beschreven in dit proefschrift is gericht op het bestuderen van PRR-gebaseerde resistentie tegen Phytophthora infestans in aardappel, door gebruik te maken van ELR als modelsysteem (Chapter $\mathbf{1}$ ). 
Effector-gestuurde veredeling is een moderne, beproefde manier om nieuwe ziekteresistenties te identificeren. Pionierend onderzoek naar Phytophthora resistentie in aardappel heeft geleid tot de ontwikkeling van 'Effectoromics'. Uit de genoom sequentie van Phytophthora worden kandidaatgenen van effectoren voorspeld, die in expressievectoren worden gekloneerd en gescreend op het aanschakelen van specifieke afweerreacties in resistente wilde Solanum soorten. Optreden van een reactie wijst op de potentiële aanwezigheid van $R$ genen. In Chapter 2 laten we zien dat effectoromics ook kan worden toegepast om PRRs te identificeren in de wilde Solanum soorten. Vereenvoudigde protocollen zijn omschreven voor effectortoetsen, kruisingen, en voor genetische kartering van onderliggende genen. Naast de routinematige experimenten die gebaseerd zijn op het gebruik van Agrobacterium tumefaciens (agro-infiltratie), en/of aardappel virus $X(P V X)$ (agroinfectie) beschrijven we het gebruik van recombinante apoplastische effectoren op eiwit niveau. De eiwitinfiltratie screening is een uitbreiding van de beschikbare functionele effectorscreening voor aardappel, en o.a. goed bruikbaar voor planten die niet geschikt zijn voor Agrobacterium- en/ of PVX-gebaseerde experimenten. We ontwikkelden protocollen voor heterologe expressie van apoplastische effectoren in de gistsoort Pichia pastoris. Dit omvat het ontwerp van de recombinante effector, klonering, P. pastoris kloon selectie met een geïnserteerde effector en eiwit productie op kleine schaal. Ook laten we een voorbeeld zien van de productie van zes verschillende apoplastische effectoren van P. infestans, gebruikmakend van dit systeem.

ELR is een 'receptor-like' proteïne (RLP) en als zodanig mist het een cytoplasmatisch signaleringsdomein dat nodig is om afweerreacties aan te schakelen. Het is bekend dat het 'receptor-like kinase' (RLK) SOMATIC EMBRYOGENESIS RECEPTOR KINASE 3 (SERK3) nodig is om de celdoodreactie tegen INF1 elicitine aan te schakelen, en dat SERK3 associeert met ELR. In Chapter $\mathbf{3}$ onderzoeken we de associatie van ELR en een andere component die gedacht wordt specifiek te zijn voor RLPS, namelijk de RLK SUPPRESSOR OF BIR1-1 (SOBIR1). 'Virus-induced gene silencing' (VIGS) experimenten lieten zien dat SOBIR1 nodig is voor de INF1-geinitieerde celdood reactie en voor basale resistentie tegen $P$. infestans in Nicotiana benthamiana. Tevens bleek het kinase domein van SOBIR1 nodig voor de celdoodreactie tegen INF1. Eiwit co-immunoprecipitatie (CoIP) studies tonen aan dat ELR is geassocieerd met SOBIR1 (en SOBIR1-like) van S. microdontum. Uit onze resultaten blijkt dat ELR constitutief een complex vormt met SOBIR1, waar SERK3 zich bij aansluit na elicitatie met INF1.

Authentieke PRRs kunnen fysiek binden met hun ligand, echter, dit was nog niet onderzocht voor ELR. In Chapter 4 bestuderen we of ELR kan binden met verschillende elicitinen, door middel van in planta en in vitro ColP experimenten. 
We laten op beide manieren zien dat de interactie zeer specifiek is en dat ELR fysiek bindt met INF1. We vonden tevens dat ELR ook kan binden met de elicitinen ParA1 ( $P$. parasitica) en $\beta$-CRY (P. cryptogea). Daarnaast bleek dat ELR celdood induceert met een aantal andere elicitinen, maar deze blijkbaar met een latere affiniteit bindt, die onder de detectiegrens van de gebruikte methoden blijft. We zagen dat C-terminaal gelabelde INF1 wel ELR kon binden maar geen celdood kon induceren, terwijl N-terminaal gelabeld INF1 dit wel kon. Ook een $\beta$-CRY elicitine dimeer kon geen celdood induceren na infiltratie in bladeren die ELR tot expressie brengen. We stelden dat deze fenotypen veroorzaakt kunnen worden door een veranderde interactie van ELR met SOBIR1 of SERK3. Inderdaad, met C-terminaal gelabeld INF1 vonden we zowel SOBIR1 als SERK3 niet terug in het complex met ELR, en dat het $\beta$-CRY dimeer de associatie met SOBIR1 verhinderde. Zover we weten is dit de eerste keer dat zo'n remming door een co-receptor wordt gerapporteerd. Onze resultaten geven daarmee het belang aan van functionele controle experimenten met gelabelde eiwitten, en versterken verder onze eerdere vinding dat zowel SOBIR1 als SERK3 nodig zijn voor de INF1geinitieerde celdoodreactie met ELR. Deze ontdekkingen kunnen bruikbaar zijn voor meer gedetailleerde studies aan RLP signalering.

Stabiele transformatie van ELR naar aardappelplanten leidt tot een verhoogde resistentie tegen $P$. infestans. Echter, het was nog niet bekend wat de precieze resistentiebijdrage van dit specifieke PRR is in zijn oorspronkelijke achtergrond (S. microdontum). We stelden vast dat we de recente ontwikkelingen in 'genome editing' technologieën ook kunnen gebruiken in niet-modelsystemen als wilde aardappel. In Chapter 5, gebruiken we 'clustered regularly interspaced short palindromic repeat' (CRISPR)/CRISPR-associated protein 9 (Cas9)-mediated genome editing' om ELR uit te schakelen in wilde Solanum soorten. We hebben een CRISPR/Cas9 construct gemaakt dat gerichte mutaties kon aanbrengen in $E L R$, in een proef met transiënte expressie. Aangezien het niet mogelijk bleek om de wilde S. microdontum stabiel te transformeren, hebben we geprobeerd om het construct te transformeren naar verschillende wilde Solanum soorten waarvan bekend was dat ze ELR homologen bevatten. We verkregen transformanten van S. edinense, S. papita, S. phureja en S. chacoense. Deze hebben we getest op de INF1 reactie. Veelbelovende transformanten die een veranderde reactie op INF1 lieten zien, werden verkregen van de pentaploïde S. edinense en de tetraploïde S. papita. Deze transformanten hebben we vervolgens onderzocht op mutaties door middel van een mutatieverrijkingsbenadering, gevolgd door PCR en sequencing. Volledige ELR knock-outs met alleen gemuteerde allelen werden niet verkregen, echter, planten met gedeeltelijk wildtype en gedeeltelijk gemuteerde allelen wel. Onze resultaten geven aan dat de CRISPR/Cas9 methode effectief is voor 
functionele karakterisering van genen in wilde Solanum soorten, maar er zijn grenzen aan de transformatie efficiëntie van de soort en aan het ploïdie niveau van gegeven genotypen.

Uiteindelijk, in Chapter 6, worden de resultaten van die proefschrift bediscussieerd en in een breder perspectief geplaatst. Een schematisch overzicht van de herkenning van elicitinen door ELR in wilde aardappel geeft een samenvatting van onze resultaten over de binding van ELR met elictinen, de interactie met de co-receptoren SERK3 en SOBIR1, evenals voorlopige bevindingen met AVR3a, een effector die INF1-geinitieerde celdood en receptorendocytose onderdrukt. Daarnaast stellen we twee nieuwe proteomics benaderingen voor om PRRs te identificeren, waarbij we gebruik maken van de verkregen kennis rond effector/PRR en PRR/co-receptor interacties. Over het geheel genomen heeft mijn onderzoek bijgedragen aan de karakterisering van een vroege kwantitatieve afweerreactie tegen Phytophthora in aardappel die van nut kan zijn voor het verkrijgen van een meer duurzame resistentie. 


\section{Acknowledgements}

Coming to study in Wageningen was a defining moment in my life, both as a scientist and as a person. I met people from different cultures, professors that are open to discussions and felt as I was in the heart of high impact scientific research. It was an amazing journey that led me into pursuing a PhD. During my PhD, I was given the chance to develop my research skills and explore my ideas as well as to meet nice people and join great group activities. I am most grateful for that! However, like most nice things in life, the $\mathrm{PhD}$ time is both fun and limited.

A lot of people were directly or indirectly involved during my $\mathrm{PhD}$ research which I would like to thank individually. First and foremost, I would like to thank my supervisor Vivianne Vleeshouwers. I am so grateful that you chose me for this exciting PhD project and that you have been so kind and open to my ideas. I felt that you were more my friend than my supervisor. I am also grateful about your advice; always critical and to the point for keeping me on track. I believe we had the smoothest of collaborations. One thing I noticed is that you are good into collecting nice people in your research group somehow. I wish you all the best for the future and I hope we will stay in touch! Also special thanks to Richard Visser. Thank you for accepting me as a PhD candidate in Plant Breeding! I still remember that I could not believe it when you told me that I got the PhD position. Your critical overview of my progress was instrumental for the completion of this thesis. Big thanks to Evert Jacobsen; from the beginning you were very interested in my project till the end, where we were discussing my future plans. You were also keen on talking in Dutch with me, so thank you for helping me practice the language! I would like to extend my gratitude to my VIDI project committee members. Your feedback was very valuable for the success of the project! I would also like to thank my external supervisor, Suzan who was always there for me! Thank you for the support!

Thanks to my collaborators! First and foremost, Matthieu, you triggered my interest on co-receptors and you were always keeping the excitement high about my project! Thomas thanks for your introduction to co-immunoprecipitations! Sophien, I would like to thank you for your interest in my work and for the invitation to visit your lab! Your critical eye on my experiments and the feedback from your team were of outmost importance. Jan thanks for your contribution to my project! I am sure that something nice will come out from this, looking forward!

Gerard and Doret, thank you for being there for me. Gerard you are a very smart person with very broad knowledge! I was always happy to work in the lab with you and discuss about things outside the University! Doret, thank you for your great 
planning skills and for helping me with my experiments! My appreciation extends to the rest of Vivianne's lab; Juan, Jaap, Carolina and Xiao. I loved our BBQs, our discussions and our (beer) journal clubs! To the new lab members, Xinfang, Aviv and Yerisf, I hope you will continue the nice atmosphere in the group! I would also like to thank my MSc students Dorien, Kiros, Alemnew, Hagos and Fokion, for helping me in exploring several ideas. I hope you have learned some things by working with me! I wish you a successful future!

Big thanks to my officemates! First of all, Abe, you were the protein guy in the lab and the most experienced post-doc. We spent countless hours critically discussing our results and experimental setups. You were always very friendly and helpful for everyone. I also enjoyed the history lessons you gave me! Thank you Carolina for tolerating me as your quiet neighbor during the end of my PhD. Also thanks to Michiel and Dennis, you were subtle and hard-working during your time in your (shared) office. Your company and discussions was a nice distraction from my PhD stuff! Thanks to Eliana, I was happy to see more Greeks in the lab and find out that there are actual programmers working in Plant Breeding! I would also like to thank you Christos Kissoudis for your interest in my project and the fun times I had while I was trying to impersonate you in your graduation video! Big thanks to my fellow PhDs at Plant Breeding; Anne, Atiyeh, Behzad, Cynara, Ernest, Geert, Izan, Jarst, Jasper, Johan, Jordi, Kaile, Kim, Mathilde, Mengjing, Michela, Myluska, Pauline, Peter Dinh, Raana, Rafael, Valentina, Viviana, Xuan, Yan, Yajun and Peter Bourke! You made our lab a nice place to work! A great appreciation goes to my close research fellows and paranymphs, Xiao and Carolina. You were always very supporting and helpful. I am happy I met you and I wish you all the best!

Thanks to the Phyto's Aranka, Elysa, Hanna, Jordi, Kiki, Mireille and members of the EPS PhD council for the nice dinners and discussions! To my colleagues and friends at Enza Zaden, thank you for all the understanding, the support and the friendly atmosphere at work!

Also thanks to my Greek friends! Christos Kavvouris, you helped me a lot in establishing at Wageningen and on finding a part time job to support my studies. I will be forever grateful for that. Fotis, my friend and коuнпápoc, since the University in Greece we followed a similar path. You are always there for me and I wish you all the best! Thanks Margarita for our fun times we have when going out. You are great in creating a nice and relaxing atmosphere! We have lots of trips to plan together. Many thanks to lliana for helping with making my thesis look pretty, and for the nice discussions we had with you and Jordi! Thanks to Christos Kolymbiris (the professor), Dimitris (goal machine), Ilias, Filippos and Andreas for the nice times we had together playing football or doing BBO! My big thanks extend to 
the rest of the international futsal team that kept me busy on Sunday afternoons. Playing football helped me relax and start strong on Mondays.

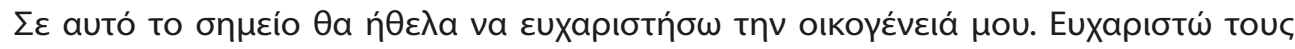

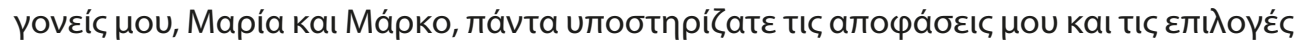

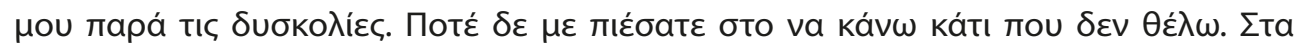

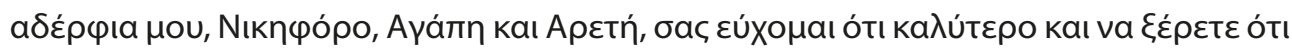

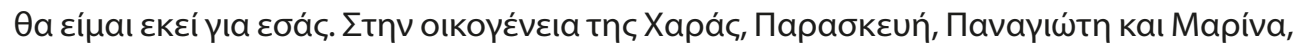

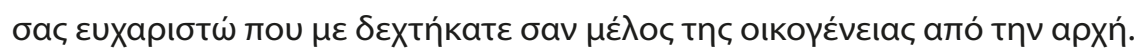

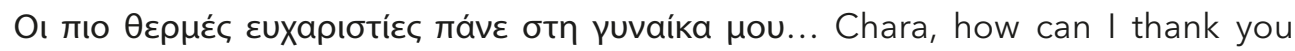
enough? You are the love of my life, my partner, and my support for all these $(13,5)$ years. I still do not understand how you tolerate me but it seems we function quite complementary. You triggered my interest in phytopathology and always helped me disconnect from talking about experiments. We went through all of our studies together, up to the day of our PhD defense! This is quite an achievement and I am very proud of you! We have had great times together and I am sure we will

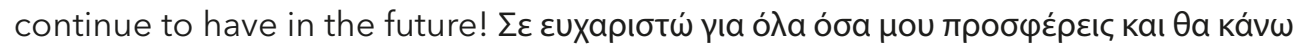

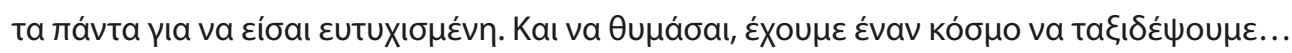

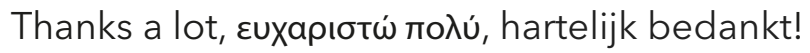




\section{About the author}

Emmanouil (Manos) Domazakis was born on the $10^{\text {th }}$ of January, 1987 in Rethymno, Crete, Greece. He grew up at a (very) small village called Melissourgaki. After finishing his primary and secondary education, in 2004, he moved to Athens for a 5-year BSc program in Plant Sciences at the Agricultural University of Athens. At the mid of his BSc studies, he became fascinated by the field

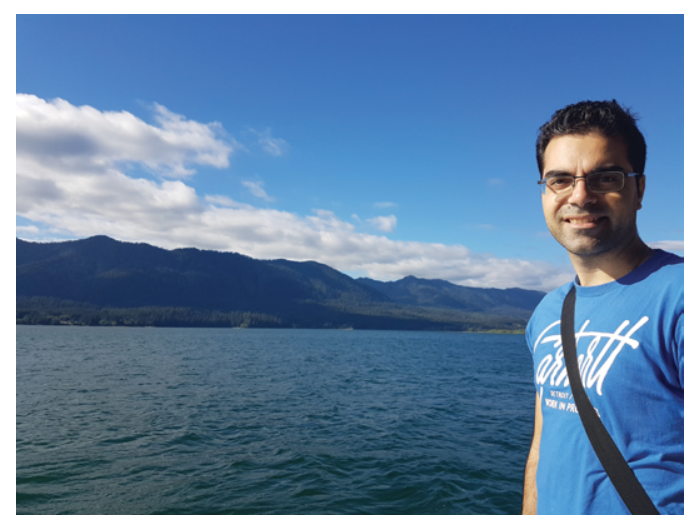
of Phytopathology and graduated with the specialization plant protection and environment. His BSc thesis was about biocontrol of Fusarium vascular wilt in melon, while both his BSc internships (Benaki Phytopahological Institute, Laboratory of Phytopathology) were at phytopathology-related subjects including diagnostics and disease trials. In 2010, for his MSc studies, he came to the Netherlands, at Wageningen University \& Research. There, he gained more knowledge on molecular plant-microbe interactions. He did his MSc thesis on Verticillium vascular wilt and Cladosporium leaf mold of tomato at the Laboratory of Phytopathology and his internship on disease quantification at Monsanto Vegetable Seeds. For his $\mathrm{PhD}$, he moved to Plant breeding at Wageningen University \& Research where he worked with the major pathogen affecting potato production, Phytophthora infestans, under the supervision of Dr Vivianne G. A. A. Vleeshouwers and Prof. Dr Richard G. F. Visser. The outcome of this research is described in this thesis. Soon after finalizing his experimental work, in November 2017, he was employed as molecular phytopathologist at Enza Zaden B.V. 


\section{List of publications}

Domazakis, E., Wouters, D., Visser, R.G.F., Kamoun, S., Joosten, M.H.A.J., and Vleeshouwers, V.G.A.A. 2018. The ELR-SOBIR1 complex functions as a twocomponent RLK to mount defense against Phytophthora infestans Mol Plant Microbe Interact (Accepted).

Domazakis, E., Lin, X., Aguilera-Galvez, C., Wouters, D., Bijsterbosch, G., Wolters, P.J., and Vleeshouwers, V.G.A.A. 2017. Effectoromics-based identification of cell surface receptors in potato. Pages 337-353 in: Plant Pattern Recognition Receptors: Methods and Protocols, L. Shan and P. He, eds. Springer, New York.

Kombrink, A., Rovenich, H., Shi-Kunne, X., Rojas-Padilla, E., van den Berg, G.C., Domazakis, E., de Jonge, R., Valkenburg, D., Sánchez-Vallet, A., Seidl, M.F. and Thomma, B.P. 2017. Verticillium dahliae LysM effectors differentially contribute to virulence on plant hosts. Mol Plant Pathol 18: 596-608

Derevnina, L., Dagdas, Y.F., De la Concepcion, J.C., Bialas, A., Kellner, R., Petre, B., Domazakis, E., Du, J., Wu, C.H., Lin, X., Aguilera-Galvez, C., Cruz-Mireles, N., Vleeshouwers, V.G.A.A., and Kamoun, S. 2016. Nine things to know about elicitins. New Phytol 212:888-895.

Tzima, A.K., Paplomatas, E.J., Schoina, C., Domazakis, E., Kang, S., and Goodwin, P.H. 2014. Successful Agrobacterium mediated transformation of Thielaviopsis basicola by optimizing multiple conditions. Fungal Biology 118:675-682.

Charalambous, A., Tjamos, S.E., Domazakis, E., and Paplomatas, E.J. 2013. Incorporation into the transplant soil plug of the plant protective agent Paenibacillus alvei strain K165 confers protection to melon against Fusarium wilt. BioControl 58:685-692. 



\section{Education Statement of the Graduate School Experimental Plant Sciences}

Issued to: Emmanouil Domazakis

Date: 1 June 2018

Group: Plant Breeding

University: Wageningen University \& Research

\section{1) Start-up phase}

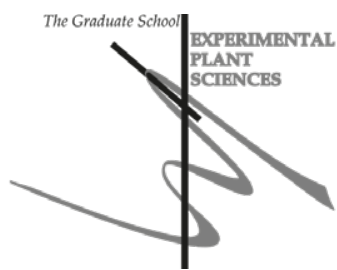

- First presentation of your project

Title: Apoplastic immunity against Phytophthora infestans in potato

26 Nov 2013

- Writing or rewriting a project proposal

Title: Identification and characterization of novel cell surface immune receptors against potato late blight

- Writing a review or book chapter

Effectoromics-based identification of cell surface receptors in potato, IN: Plant Pattern Recognition receptors: Methods and Protocols, Methods in Molecular Biology, Vol.1578, DOI 10.1007/978-1-4939-6859-6_29, Springer (2017)

- MSc courses

Laboratory use of isotopes

Subtotal Start-up Phase 13.5 credits*

\section{2) Scientific Exposure}

date

- EPS PhD student days

EPS PhD student day, Leiden, NL

29 Nov 2013

EPS PhD student day 'Get2Gether', Soest, NL

29-30 Jan 2015

EPS PhD student day 'Get2Gether', Soest, NL

28-29 Jan 2016

\section{EPS theme symposia}

EPS theme 2 symposium 'Interactions between Plants and Biotic Agents', together with Willie Commelin Scholten Day, Amsterdam, NL

EPS theme 2 symposium 'Interactions between Plants and Biotic Agents', together with Willie Commelin Scholten Day, Utrecht, NL

EPS theme 2 symposium 'Interactions between Plants and Biotic Agents', together with Willie Commelin Scholten Day, Leiden, NL

- National meetings (e.g. Lunteren days) and other National Platforms

Annual meeting 'Experimental Plant Sciences', Lunteren, NL

Annual meeting 'Experimental Plant Sciences', Lunteren, NL

14-15 Apr 2014

Annual meeting 'Experimental Plant Sciences', Lunteren, NL

13-14 Apr 2015

Annual meeting 'Experimental Plant Sciences', Lunteren, NL

11-12 Apr 2016

Annual meeting 'Experimental Plant Sciences', Lunteren, NL

10-11 Apr 2017 


\section{- Seminars (series), workshops and symposia}

Mini-symposium: How to write a world-class paper

17 Oct 2013

Crop Pathology and Plant-Microbes Interaction symposium

08 May 2015

EPS flying seminar Plant intracellular immunity: evolutionary and molecular underpinnings

21 Jan 2016

EPS flying seminar How do plants read their own shape

16 Mar 2016

Invited seminar 'Rewriting our genes', Jennifer Doudna and Edze Westra

30 Sep 2016

EPS flying seminar dr. Rossana Henriques: Circadian regulation of long non-

coding RNAs

16 Nov 2015

Invited seminar 'Reprogramming cells for defense in plant innate immunity', Jane Parker

09 Apr 2014

Invited seminar: 'Dissecting the interactions between Phytophthora sojae and soy bean: making sense of signaling and effectors', Yuanchao Wang

$16 \mathrm{Jul} 2014$

EPS Symposium 'Omics Advances for Academia and Industry - Towards True Molecular Plant Breeding', Wageningen, NL

11 Dec 2014

\section{- Seminar plus}

- International symposia and congresses

2014 XVI International Congress on Molecular Plant-Microbe Interactions (MPMI), Rhode Island, Greece

06-10 Jul 2014

2016 XVII International Congress on Molecular Plant-Microbe Interactions

(MPMI), Portland, Oregon, USA

17-21 Jul 2016

- Presentations

Talk: COST SUSTAIN 2nd Annual Conference, Poland

$14-15$ Oct 2014

Poster: MPMI (Greece)

09 Jul 2016

Poster: MPMI (USA)

19-20 Jul 2016

Talk: IACGS (International Academic Conference for Graduate Students), China

$16-19$ Oct 2016

Talk: Understanding how the ELicitin Response receptor (ELR) functions against

Phytophthora infestans, Lunteren, NL

11 Apr 2017

\section{- IAB interview}

\section{- Excursions}

Excursion to Rijk Zwaan, De Lier, NL

27 Sep 2013

Subtotal Scientific Exposure 14.9 credits $^{\star}$

\section{3) In-Depth Studies}

date

\section{- EPS courses or other PhD courses}

Advanced course: 'Bioinformatics: A user's approach'

26-30 Aug 2013

Advanced course: 'The power of RNA-seq'

16-18 Dec 2013

- Journal club

Member of literature dicussion at Plant Breeding

$2015-2017$

- Individual research training

TALEN \& CRISPR training school (COST Action), Halle-Wittenberg, Germnay

24-28 Mar 2014 


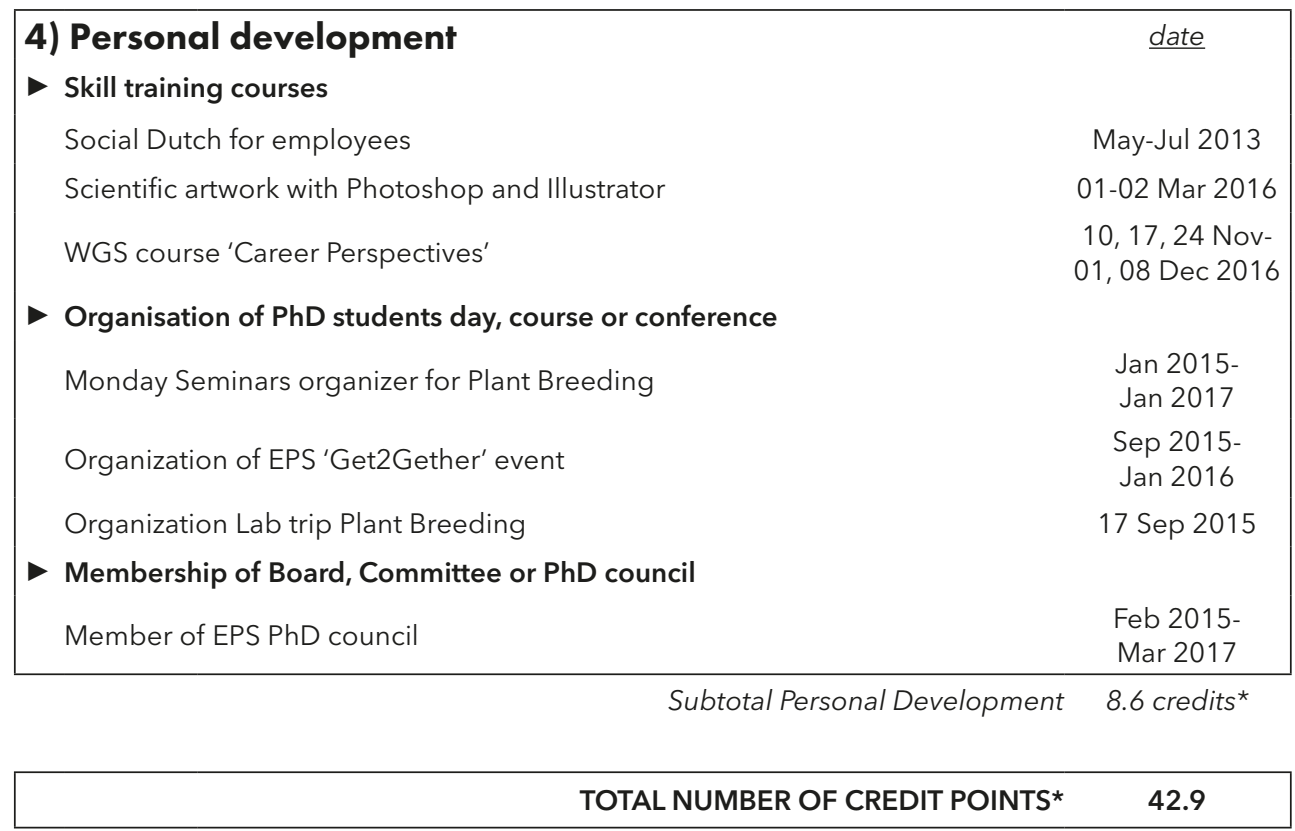

Herewith the Graduate School declares that the PhD candidate has complied with the educational requirements set by the Educational Committee of EPS which comprises of a minimum total of 30 ECTS credits

* A credit represents a normative study load of 28 hours of study. 
This work was supported by a VIDI grant (no. 12378), awarded to Dr Vivianne G. A. A. Vleeshouwers from the Netherlands Organization for Scientific Research (NWO). The work was performed at Plant Breeding, Wageningen University \& Research.

Cover \& layout design: Iliana Boshoven-Gkini | AgileColor.com Printed by:Ridderprint B.V.| Ridderkerk 
